\title{
Service quality and customer loyalty in professional business service relationships : an empirical investigation into the customer-based service quality concept in the Dutch advertising industry
}

Citation for published version (APA):

Venetis, K. A. (1997). Service quality and customer loyalty in professional business service relationships : an empirical investigation into the customer-based service quality concept in the Dutch advertising industry. [Doctoral Thesis, Maastricht University]. Universiteit Maastricht.

https://doi.org/10.26481/dis.19970919kv

Document status and date:

Published: 01/01/1997

DOI:

$10.26481 /$ dis. $19970919 \mathrm{kv}$

Document Version:

Publisher's PDF, also known as Version of record

Please check the document version of this publication:

- A submitted manuscript is the version of the article upon submission and before peer-review. There can be important differences between the submitted version and the official published version of record. People interested in the research are advised to contact the author for the final version of the publication, or visit the DOI to the publisher's website.

- The final author version and the galley proof are versions of the publication after peer review.

- The final published version features the final layout of the paper including the volume, issue and page numbers.

Link to publication

\footnotetext{
General rights rights.

- You may freely distribute the URL identifying the publication in the public portal. please follow below link for the End User Agreement:

www.umlib.nl/taverne-license

Take down policy

If you believe that this document breaches copyright please contact us at:

repository@maastrichtuniversity.nl

providing details and we will investigate your claim.
}

Copyright and moral rights for the publications made accessible in the public portal are retained by the authors and/or other copyright owners and it is a condition of accessing publications that users recognise and abide by the legal requirements associated with these

- Users may download and print one copy of any publication from the public portal for the purpose of private study or research.

- You may not further distribute the material or use it for any profit-making activity or commercial gain

If the publication is distributed under the terms of Article 25fa of the Dutch Copyright Act, indicated by the "Taverne" license above,

Download date: 26 Apr. 2023 


\section{SERVICE QUALITY AND CUSTOMER LOYALTY IN PROFESSIONAL BUSINESS SERVICE RELATIONSHIPS}

An empirical investigation into the customer-based service quality concept in the Dutch adwertising industry

\section{PROEFSCHRIFT}

ter verkrijging van de graad van doctor aan de Universiteit Maastricht, op gezag van de Rector Magnificus, Prof, mr. M.J. Cohen, volgens het besluit van het College van Decanen, in het openbaar te verdedigen op

vrijdag 19 september 1997 ,om 14.00 uur.

door

Karin Ariadne Venetis 


\section{Promotores:}

Prof. dr. J.D.P. Kasper

Prof. dr. P.N. Ghauri (Rijksuniversiteit Groningen)

Beoordelingscommissie:

Prof. dr. S.J.M. Maijoor (voorzitter)

Dr. J.G.A.M. Lemmink

Prof. dr. M. Wedel (Rijksuniversiteit Groningen) 
To my father,

whose work has been done,

and whose heritage is safely passed on. And to little Leon, whose life has just begun... 
Financial and/or material support was provided by:

BOVIL Reclame \& Marketing Adviesbureau

BVA, association of Dutch advertisers Art de Triomphe 


\section{Acknowledgements}

The tangibility and compactness of this book conceal much of the process that preceded its conception. It can be compared to the tangible result of advertising services, which are investigated in this dissertation. Writing a Ph.D. shares other typical characteristics with these services: the expertise of the researcher is at the core of the project, the production process takes a very (1) long time to be completed, it has a tangible immediate outcome, and yet, the final outcome of this dissertation still remains to be seen... Working for so long on one project is like establishing a relationship with it and I found it to my cost that commitment is an absolute necessity for maintaining and enhancing this relationship. A sizeable amount of affective commitment with the subject made me start this project, but, if it wasn't for the commitment of others it would never have been completed this successfully. I was very fortunate to have many people behind me who supported me and my project substantially. This space is never enough to thank them all, but I will give it a shot.

First, I want to thank my supervisors Hans Kasper and Pervez Ghauri, who never lost faith in me and always remained calm and patient whenever I rushed in with a panic-attack. And Steven Maijoar, Michel Wedel and Jos Lemmink for evaluating the final version. I can never thank Diamantis Diamantopoulos, Peter Leeflang, Piet Eichholtz, and Anja de Boer enough for their invaluable help at crucial moments during the project.

Second, many people in the advertising industry assisted in acquiring the valuable empirical data, without which this dissertation would be non-existent. I am much indebted to the persons who participated in the exploratory research and offered their valuable time and knowledge to my project. I want to thank Theo Poiesz and Giep Franzen for their academic view on the research and questionnaire, Hein Becht \& Bart Brüggenwirth of SCAN, and, Paul Boreel, Ronald Groen \& Pieter van den Busken of PRAGMA, for their lively description of the ins and outs of the advertising market, Rob Benjamens, Jaap de Kreek, Peter Joziasse, Henk de Cleen and Petros Venetis for sharing their agency point-of-view, and, Eugene Springer, les Hoogland, Peter Verveen, Ruud de Jong, Yvonne Medenbach and mr. Bojans for sharing their client experiences and the questionnaire pre-test.

The field study would have been impossible without the extensive co-operation of Han Nieman from the VEA, and Greetje Kamminga of the BVA, who actively and personally assisted in promoting this project towards their members, and the co-operation of the 33 agencies that were so generous to let me approach their clients. Among these agencies are Frappant bv, Ton Sandig reklame \& marketing, Mundocom.AAC, Schoep \& van der Toorn, Busken Advertising bv, Lowe Kuiper \& Schouten, D\&M Cujik bv, Brinkerink \& Partners, Bates Nederland, Promotional Campaigns bv, Grey Amsterdam, and, HLPB. I am very grateful to them and the other 21 agencies who wished to remain anonymous. The 241 clients who took the trouble to answer and return the extensive questionnaire provided the most valuable contribution to this research. Thank you.

I would especially like to thank BOVIL Reclame \& Marketing Adviesbureau for their continuous support in various ways in the project. The never ceasing energy of Ed Rohof was very inspiring and resulted in valuable contributions to the research. 
Furthermore, I would like to thank Leo Paas and Michel Wedel for their advice on Lisrelanalysis. And Williane Bovens, Hendrik Schwartz and Katja van Schie for their assistance in the execution of the research, and my colleagues who were willing to discuss and comment on parts of my research. Kanin Smits of Art de Triomphe was so kind to share her artistic ideas and invaluable energy for the cover of this book.

And last, but never least, I do not know how to thank my family and friends who stood by me throughout this ordeal, during which many other stiming events happened. First of all, my mom, who kept encouraging me despite her own difficulties and is the living proof of how drawbacks can be overcome by a positive attitude and a believe in own strength. Much of my work has been conceived far away from home, in many places ranging from Ameland to Dubai. I am grateful to everybody who gave me the opportunity to combine complete concentration with fun and relaxation. In particular I want to thank Erik-Jan, Renée and my godchildren M\&M Bink, as well as Kris and Karin Venetis, for putting up with me for so long and for offering me their stimulating environment and wam support at very crucial moments. I want to thank Piet and Margo Eichholtz, Charles Pahud, Marjolijn de Bont, Stuart Dixon, Marion Seuren, Mijjam Spaans, Anja de Boer, Frank and Maus Meier-Ganweg and Father Crutzen for showing me what good friends are and that there is more to life than writing a Ph.D.!

Karin Venetis

July 1997, Maastricht. 


\section{Contents}

Acknowledgements

List of tables

List of figures

VI

VIII

Chapter 1: Introduction

1.1 Background

1.2 Research aims

1.3 Research approach

1.4 Chapter outline

Chapter 2: Service Quality

2.1 Introduction

2.2 Defining service quality

2.3 Importance of service quality

2.4 General service quality models

2.4.1 Two dimensional service quality model

2.4.2 Three dimensional service quality model

2.4.3 Ten dimensional service quality model

2.4.4 Six dimensional service quality model

2.4.5 Discussion of the service quality madels

2.5 Professional business services

2.6 Service quality of professional business services $\quad 20$

2.6.1 Three dimensional quality model for professional services $\quad 21$

2.6.2 Three dimensional quality model for professional business services $\quad 22$

2.6.3 Outcome dimensions of professional business services $\quad 23$

2.6.4 Synthesis: integrated service quality model for professional business services 24
2.6.5 Empirical evidence

2.6.6 Comparison to the proposed quality model 30

2.7 Summary \& Conclusions $\quad 35$

Chapter 3: Relationship Maintenance $\quad 37$

3.1 Introduction

3.2 Long-term relationships $\quad 38$

3.3 Relationship Models $\quad 39$

3.3.1 Generic relationship stage models $\quad 40$

3.3.2 Stage models of professional business service relationships 41

3.3.3 Synthesis relationship stage models $\quad 42$

3.3.4 Relationship process models 44

3.4 Relationship commitment and maintenance $\quad 46$

3.5 Antecedents to relationship commitment 49

3.5.1 Antecedents to relationship commitment: business relationships 51

3.5.2 Empirical evidence $\quad 53$

3.5.3 Antecedents to relationship commitment: business service relationships 55

3.5.4 Empirical evidence $\quad 56$

$\begin{array}{ll}3.6 \text { Summary and conclusions } & 58\end{array}$ 
Chapter 4: Research Design and Exploratory Study 60

4.1 Introduction

4.2 Research objectives \& propositions 60

4.2.1 Research model $\quad 62$

4.2.2 Empirical setting $\quad 64$

4.3 Research design $\quad 64$

4.4 Design exploratory research $\quad 66$

4.4.1 Literature advertising market 66

4.4.2 Key-infomant interviews. $\quad 66$

4.4 .3 In-depth interviews with selected cases 68

4.5 Results exploratory research $\quad 69$

4.5.1 Advertising agencies \& services $\quad 69$

4.5.2 Agency-client relationships $\quad 70$

4.5.3 The agency-client relationship process $\quad 72$

4.5.4 Service quality of advertising services $\quad 74$

4.5.5 Relationship commitment in agency-client relationships $\quad 77$

4.5.6 Antecedents to relationship commitment in agency-client relationships 78

4.6 Concllusion exploratory research: evidence for research model 81

Chapter 5: The Measurement Instrument : $\quad 83$

$\begin{array}{lc}5.1 \text { Introduction } & 83\end{array}$

5.2 Developing the measurement instrument: methodology 83

5.3 Developing the rough measures 90

5.3.1 Measuring service quality 90

5.3.2 Measuring relationship commitment and its consequences 93

5.3 .3 Measuring relational bonds $\quad 99$

5.3.4 Measuring trust $\quad 100$

5.4 Pre-testing \& purification of measures $\quad 101$

5.4.1 Outcomes regarding conceptualisation 101

5.42 Outcomes on item-level $\quad 102$

5.5 Summary \& conclusions measurement instrument 104

Chapter 6: The Field Study 106

$\begin{array}{lr}6.1 \text { Introduction } & 106\end{array}$

$\begin{array}{lr}\text { 6.2 Research design } & 106\end{array}$

6.2.1 Research goals $\quad 106$

6.2.2 Questionnaire $\quad 106$

6.2.3 Population and sample frame $\quad 109$

6.3 Survey Response $\quad 113$

6.3.1 Sample representativeness

6.3.2 Sample descriptives $\quad 117$

6.4 Final measures and descriptives $\quad 119$

6.4.1 Service quality measures $\quad 119$

6.4.2 Commitment and behavioural intentions $\quad 121$

6.4.3 Relational bonds and trust $\quad 123$

6.4.5 Conclusion research concepts: adjusted model $\quad 125$

6.5 Data analysis: methodology $\quad 126$

6.5.1 Using structural equation modelling $\quad 129$ 
7.1 Introduction

7.2 Customer-based service quality for advertising services

7.2.1 Analysis of quality determinant measures

7.2.2 Analysis of quality items

7.2.3 Synthesis structure of customers' quality perception

7.3 Relative importance quality determinants

7.3.1 Evidence from the initial five quality determinant measures

7.3.2 Evidence from the adjusted quality dimensions

7.4 Conclusions clients' service quality perception $\quad 150$

Chapter 8: Service Quality and Relationships

8.1 Introduction

8.2 Structure of relationship maintenance

8.2.1 Structure of commitment dimensions

8.2.2 Commitment and behavioural intentions

8.2.3 The time dimension

8.2.4 Summary commitment structure

8.3 Antecedents to relationship maintenance

8.3.1 Correlation analysis

8.3.2 Structural equations analysis

8.3.3 Relative importance of antecedents for relationship maintenance 167

8.3.4 Summary antecedents to relationship maintenance 168

8.4 Service quality determinants and relationship maintenance

$\begin{array}{ll}\text { 8.5 Summary \& Conclusions } & 173\end{array}$

Chapter 9: Conclusions and Discussion $\quad 176$

9.1 Introduction $\quad 176$

9.2 Findings and discussion $\quad 177$

9.2.1 Service quality perception of professional business services 177

9.2.2 Service quality perception and long-term relationship maintenance 181

$\begin{array}{lr}9.3 \text { Conclusion } & 184\end{array}$

9.4 Managerial implications $\quad 186$

9.5 Limitations $\quad 188$

$\begin{array}{lr}9.6 \text { Further research } & 189\end{array}$

Appendix 1: The Questionnaire 191

Appendix 2: Measure Validation and Purification 197

\begin{tabular}{lr} 
References & 208 \\
\hline
\end{tabular}

Samenvatting $\quad 218$

\begin{tabular}{lr} 
Curriculum Vitae & 223 \\
\hline
\end{tabular} 


\section{List of tables}

Table 2.1: Categorisation of different quality models into three quality dimensions

Table 22: Classifications of SERVQUAL dimensions

Table 2.3. Classification of empirical findings into the proposed quality model.

Table 2.4: Qualitative studies of professional business service quality

Table 2.5. Quartitative studies service quality of professional busir ess services.

Table3.1a: Generic stage models of business relationships

Table $3,1 \mathrm{~b}$. Stage models of business service relationships

Table 4.1: Steps in empinical research

Table 4.2 : Classification of interviewed advertising agencies.

Table 4.3: Classification of interviewed clients

Table 4.4: Quality evaluation criteria mentioned by the clients

Table 4.5: Reasons of clients to keep relationship, classiffed into bond types

Table 5.1: Summary evaluation criteria of measurement models

Table 5.2: Steps in measurement development and chapter reference of their resuits.

Table 5.3: Overview of quality elements to be covered by each quality determinant

Table 5.4: Empirical studies regarding clients' evaluation of advertising senices

Table 5.5: Advertising service evaluation iterns classified into service quality determinants.

Table 5.6: First draft of items generated per quality determinant: pre-test questionnaire

Table 5.7a: Items used for affective commitment, based on existing scales

Table $5.7 \mathrm{~b}$ : Items used for calculative commitment, based on existing scales

Table 5.8: Items for measuring behavioural intentions

Table 5.9: Pre-test items generated for the operationalisation of relational bonds

Table 5.10: Measurement items for trust

Table 6.1: Measures for service quality concepts in questionnaire $\quad 107$

Table 6.2: Measures for relationship variables in questionnaire

Table 6.3: Co-operating agencies and selected sample frame through these agencies

Table 6.4: Sample frame through BVA

Table 6.5: Total sample frame created through both channels

Table 6.6: Response rates per channel

Table 6.7: Background items asked from agencies and respondents

Table 6.8a: Agency-clients versus agency-respondents: Industry and budget

Table 6.8b: Agency-clients versus agency-respondents: other items

Table 6.9a: BVA-respondents versus agency-respondents: industry and budgets

Table 6.9b: BVA-respondents versus agency-respondents: other items

Table 6.10: Amount of agency-relationships with different agencies in sample

Table 6.12: Bases of agency-relationships

Table 6.13: Purification and properties service quality scales

Table 6.14: Descriptives service quality variables

Table 6.15: Purfication and properties of relationship commitment and intention scales 122

Table 6.16: Descriptives relationship commitment and stay intentions 122

Table 6.17: Purification and properties of relational bond and trust scales $\quad 124$

Table 6.18: Descriptives relational bonds and trust 124

Table 7.1: Confirmatory analysis uni-dimensionality of five quality determinants 133

Table 7.2: Confirmatory factor analysis four quality determinants 134

Table 7.3: Descriptives final six quality dimensions 
Table 7.4. Results hierarchical factor analysis six quality dimensions 140

Table 7.5: LISREL estimates of altemative quality model 141

Table 7.6: Direct importance scores five original quality determinants 146

Table 7.7: Regression of proposed quality determinants on overall service quality $\quad 147$

Table 7.8: Regression of adjusted quality dimensions on owerall service quality 148

Table 8.1: Fit-statistics \& comelations of commitment dimensions and intentions 156

Table 8.2: Correlation between relationship variables andrelationship length 157

Table 8.3: Correlations between antecedents and commitment dimensions 158

Table 8.4: Fit-statistics of saturated(sub-)model 160

Table 8.5: Estimated parameters and fit-statistics of proposed(sub-)model 161

Table 8.6: Fit-statistics and difference test of proposed and saturated(sub-)model 162

Table 8.7: Fit-statistics and difference tests of nested altemative (sub-)models 164

Table 8.8: Estimated parameters and fit-statistics of final sub-model 165

Table 8.9: Correlations of social and investment bonds with all other variables 166

Table 8.10: Total effects of antecedents on affective commitment and stay intentions $\quad 167$

Table 8.11: Fit-statistics and difference tests of nested alternative models. 170

Table 8.12: Estimated parameters and fit-statistics of final model 170

Table 8.13: Total effects of quality determinants on relationship variables $\quad 172$

Table A.1: Confirmatory analysis overall service quality items

Table A.2 Scale analysis service quality items $\quad 199$

Table A.3: Confirmatory factor analysis service quality deteminants 199

Table A.4: Scale analysis commitment scales $\quad 200$

Table A.5: Confirmatory factor analysis two commitment dimensions 201

Table A.6: Scale analysis of relationship intention scales $\quad 202$

Table A.7: Confirmatory factor analysis initial and adjusted "stay intentions" 203

Table A.8: Analysis of bonds scalles $\quad 204$

Table A.9: Confirmatory factor analysis initial and adjusted bond scales $\quad 205$

Table A. 10: Item analysis of trust scale $\quad 206$

Table A.11: Confirmatory factor analysis trust items $\quad 207$ 


\section{List of figures}

Figure 1.1: Relation between service quality and profftability

Figure 1.2. Issues addressed in this study for professional business services

Figure 1.3: Issue 1: customer-based quality concept for professional business services

Figure 1.4: Issue 2 contribution of service quality to long-term relationship maintenance

Figure 1.5: Outine of the study

Figure 1.6: Chapter outine

Figure 2.1: Three-dimensional quality model for professional services

Figure 2.2. Quality model of professional business services

Figure 2.3: A quality model of professional business services

Figure 2.4: Synthesis of the quality models for professional business services

Figure 3.1: Process model of relationship development

Figure 3.2: Proposed structure of relationship maintenance

Figure 4.1: Proposed structure of professional business service quality

Figure 4.2: Proposed structure of relationship maintenance

Figure 4.3: Proposed antecedents to relationship commitment

Figure 4.4: Proposed research model

Figure 4.5: Adjusted research model for the advertising market

Figure 5.1: Research modell adjusted to conceptualisation of concepts

Figure 6.1: Overview of channels used to create sample frame of clients

Figure 6.2: Industry descriptives

Figure 6.3: Client size descriptives: Tumover

Figure 6.4: Respondent function

Figure 6.5: Final Research Model

Figure 7.1: Part of research model analysed in this chapter

Figure 7.2: Proposed determinants of professional business service quality 132

Figure 7.3: Correlation two scales of overall service quality

Figure 7.4: Proposed structure in quality items

Figure 7.5: Proposed versus found structure in service quality items

Figure 7.6: Hierarchical confirmatory factor analysis of quality items: LISREL notation 139

Figure 7.7: Altemative quality model: LISREL notation $\quad 142$

Figure 7.8: Correlation between two measures of perceived service quality $\quad 1.43$

Figure 7.9: Comparison of proposed and modified quality structure $\quad 1.45$

Figure 7.10: Regression of quality dimensions on overall service quality 148

Figure 7.11: Quality determinants of advertising services 150

Figure 7.12: Adjusted research model 153

Figure 8.1: Parts of research model analysed in this chapter $\quad 154$

Figure 8.2: Regression (t-values) of commitment on stay-intentions 156

Figure 8.3: Proposed structural (sub-)model 161

Figure 8.4: Alternative sub-model; two paths added 163

Figure 8.5: Final sub-model with parameters $\quad 164$

Figure 8.6: Final research model $\quad 171$

Figure 9.1: Structure of clients' quality perception of advertising services 178 


\title{
Chapter 1: Introduction
}

In this study the influence of customers' perceived quality of professional business services on the maintenance of long-term relationships will be analysed. This research is inspired by the researcher's own interest in the complexity of professional business services, and the currently overwhelming interest in service quality and relationship management within marketing science and practise.

\subsection{Background}

\author{
When I make a feast. \\ I would like my guests to praise it, \\ not the cooks"
}

J. Harington, Epigrams, 1610

As early as 1610 , centuries before marketing was introduced to our vocabulary, J. Harington recognised that even the best creations can be worthless if the users do not appreciate it. Although the quotation may sound trivial now, a highly topical discussion on the concept of quality is expressed by it. For what constitutes an excellent feast? is a feast good if the best cooks prepare the feast to the best of their ability, or is it good when the guests perceive it as such? Ingredients can be combined in several ways. A good recipe can be one that follows the guidellines of the "haute cuisine', or one that satisfies the taste of the customer.

In some sense services are like food, the proof of which is in the eating. Services are experience goods, that have to be experienced first before its quality can be assessed. It is difficult to assess the quality of a hairdresser, bank, or restaurant unless we have actually experienced a hair-cuit, a money transfer, or tasted its food. Customers can thus only judge a service once they have experienced it. What then constitutes an excellent service: something the provider thinks is good, or what the customer experiences as good?

In the services marketing literature this question is traditionally resolved by defining service quality as what the customers perceive as quality. Since the 1980 's, the quality concept has become paramount in services marketing and is approached from a customer-based perspective. The quality that the customer perceives, is the quality that has been actually delivered. In this view, the quality of a service is thus determined by the quality criteria customers use to evaluate the service. Service providers will have to live up to, or preferably exceed, customers" service expectations. Customers' evaluation criteria thus play a central role for the quality standards service providers use to produce and control the quality of their services. Since services are deeds, processes and performances (Zeithaml \& Bitner 1996) in which the customer usually participates, there are very few standard ingredients that customers can evaluate other than the experience itself. Customers will not only evaluate the final taste but the whole process and environment in which it is conceived and consumed. Therefore, this quality concept encompasses customers' evaluation of the entire service experience. 
Despite the overwheiming interest in this customer-based approach to service quality in the services marketing literature, the professional (business) services sector used a different approach to the quality of their services. In this sector, the opinion of the cooks has long determined the quality of the feast. Professional (business) services are generally complex and rely heavily on the expentise of the professional. Therefore, the quality of these services is traditionally approached from professional and industry-based standards. It is the doctor, lawyer, or business consultant who knows what is best for the client Isn't that exactly what they are hired for? The specific market structure of these services reinforced the use of this quality concept. Most professional (business) service industries have long been guarded and protected by official institutions and associations that laild down requirements of competence and enforced a code of ethics. This raised entry barriers, and competition was kept at arms-length. As long as the professionals fulfilled the professional standards and kept to the rules and regulations, $a$ minimum degree of quality was secured. Since every accredited provider had to live up to the same (professional-based) standards, customers had little incentives and possibilities to compare and switch providers.

However, the professional service markets are now changing drastically: deregulation, increasing (international) competition, and increasing sophistication and education of the customers are making the markets more competitive. The traditionally long customer relationships are not sustained by inertia anymore (Yorke 1990). Professional business service providers are now realising -reluctantly- that the marketing concept has to enter their business as well, in order to remain competitive. The delivery of outstanding services is now becoming a high priority (Patterson 1995). This has implications for how the quality concept should be approached. For an impeccable service from a professional point of view, can only be outstanding if the customer recognises it as such. Now that the expertise of the customers is increasing as well as the amount of alternatives they can choose from, it is the customers' quality perception that determines the quality that has been delivered. The service quality concept for these services should thus shift from their traditionall focus on professional standards to the customer-based perspective that is used in the more traditional (consumer) services.

The customer-based service quality concept has grown to become the 'single most researched area in services marketing to date" (Fisk et al. 1995). It is regarded as a more effective competitive tool for service companies than other marketing instruments (Neijzen \& Trompetter 1989). After an extensive body of research on the conceptualisation of this quality concept research has shifted towards its consequences for service companies. The most concrete consequence that has been established is the profit impact of service quality. Research is accumulating that shows a positive link between service quality and profitability (cf. Anderson \&. Fornell 1992, Rusit et al. 1995). This link is explained by two underlying causes (Zahorik \& Rust 1992):

- firstly, service quality is related to the attraction of new customers by the competitive advantage it creates for the service company. Furthermore, providing good service quality to existing customers will encourage their word-of-mouth advertising, which is one of the few effective ways for service companies to gain new customers. New customers, in turn "contribute to the profitability of the service company; and,

- secondly, service quality is also related to the loyalty of existing customers. Delivering excellent service quality to existing customers, increases the chance that they will come back. This creates more service transactions for the service provider, which in itself contributes to the profitability. However, there is more to the effects of loyal customers. It has recently been acknowledged that keeping existing customers is ultimately much more profitable than the 
conquering of new customers, especially in highly competitive markets. Research has shown that the retention of $5 \%$ of the existing customer base can have a profit impact up to as much as $125 \%$ (Reichheld \& Sasser 1990, Buchanan 1990). This profit impact is explained by several factors. First of all; it is more costefficient to service existing customers than new ones: Secondly, the cost-efficiency increases over time, and customers who stay in the long run are more likely to buy more and different services, and are less price-sensitive than new customers. Therefore, additional benefits can be gained when long-term customer relationships are created. Establishing long term relationships with customers has become the new marketing paradigm in the 1990 's. Marketing has been redefined as:

"..to establish, maintain and enhance relationships with customers and other partners,

at a profit, so that the objectives of the parties involved are mef: (Grönroos 1990).

Authors now argue that service quality will also contribute to the development and strengthening of long-term customer relationships (Rust \& Zahorik 1993, Anderson \& Fornell 1994, Strandvik 1994).

These two effects of service quality are portrayed in figure 1.1.

Figure 1.1: Relation between service quality and profitability

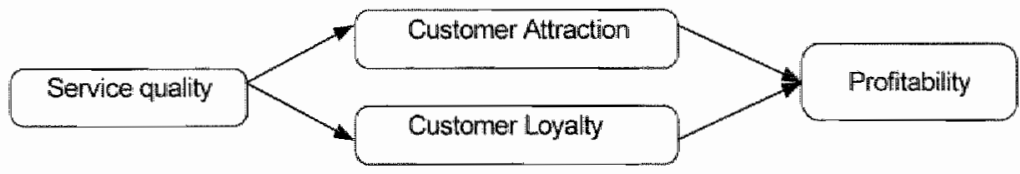

The customer-based service quality concept can thus be regarded as an important success factor for service companies in several ways. Also for professional business services, the importance of a customer-based service quality concept is now recognised. Authors declare it crucial to remain competitive, to attract new customers and to establish long-term relationships with existing customers (Day et al. 1988, Morgan 1991, Bojanic 1991 "Patterson 1995). However, the industry and researchers alike, have only recently become interested in this customerbased service quality concept for professional business services. Despite the enormous interest in this quality concept in the service marketing literature, the professional business services sector has received very little research attention so far (LaPierre \& Filiatrault 1995, Dassen 1995). Moreover, the relationship paradigm has only recently entered the service marketing literature (Grönroos 1993) and very little empirical evidence is provided for the generally assumed positive relation between service quality and the establishment of long-term customer relationships. 


\subsection{Research aims}

To rediress some of the omissions in the service quality research area, this study aims to contribute to an understanding of the customer-based quality concept for professional business services and its importance for the long-tem retention of customers. This aim encompasses two research issues: the customer-based quality concept itself " and its importance for the longtem retention of customers, as portrayed in figure 1.2. These research issues and the specific research aims will be described below.

Figure 1.2. Issues addressed in this study for professional business senvices

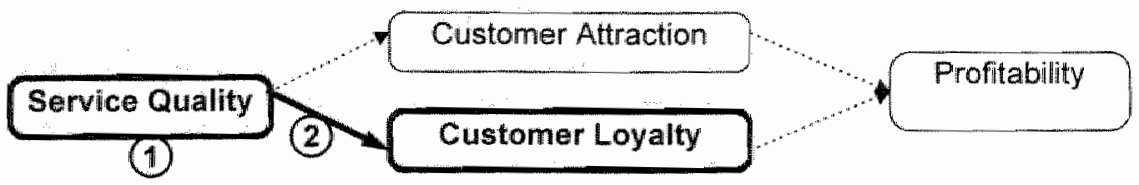

\section{Issue 1: Quality of professional business services}

Despite the extensive research on the service quality concept, strikingly few studies addressed customers' quality perception of professional business services (LaPierre \& Filitreault 1995). Although much knowledge has been gained regarding customers' service quality perception of the more traditional (consumer) services, professional business services share specific characteristics that warrant special attention. They are probably the most 'pure' services that exist, that can not even be compared to the metaphorical food. They are not only experience 'goods", but also consist of many credence features, which means that even after 'eating' there is still no full proof of the pudding. For how good is a consultant's reorganisation advice, an accountants' assessment, or a sales training as such? These services generally contribute somehow to the well-being of a customer-company, the results of which can not be assessed till long after the service has been delivered, if at all. However, clients do evaluate the quality of professional business service providers, difficult as it may be. The question is how they evaluate it.

A few authors investigated the service elements customers incorporate in their quality assessment of professional business services. Quantitative studies used existing quality models to measure customers' quality perception of professional business services (Bojanic 1991, Mlorgan 1991, Freeman \& Dart 1993, Tzokas et al. 1994, Dassen 1995, Moore 1994) and almost all found that these models do not sufficiently capture the specifics of professional business services. In-depth investigations of customers" quality perception of particular professional business services provided insights into the specific service elements customers use in their quality assessments (Teas 1988, Day \& Barksdale 1992, Halinen 1994, LaPierre \& Filiatrault 1995). However, no general quality model has been developed that identifies the key-quality determinants that customers use in their quality assessment of professional business services. Therefore, we will attempt to answer the following question in our study: 


\section{Research question 1}

How do customers assess the quality of professional business services? What are the key quality determinants in their quality assessment?

With this question we aim to:

1) identify the key quality determinants of customers' quality perception of professional business services; and to,

2) analyse the relative importance of each of these determinants for customers overall quality perception of professional business services.

These aims are graphically presented in figure 1.3.

Figune 1.3: Issue 1: customer-based quality concept for professional business services

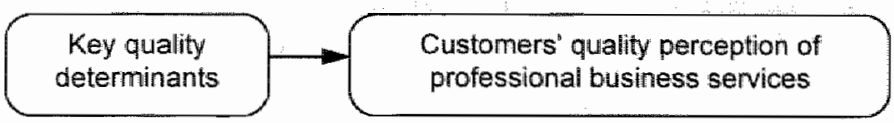

\section{Issue 2: The influence of service quality on customer loyalty}

As indicated above, one of the assumed consequences of service quality is its contribution to the development and strengthening of long-term customer relationships also for professional business services. Empirical support for this proposed consequence of service quality is used from studies addressing the effect of service quality on customers' repurchase intentions. It has consistently been found that service quality is positively related to customers' repurchase intentions (for an overview see Zeithaml et al. 1996). However, what does this mean for the loyalty of customers? Will they be retained for a next service transaction: probably yes; for subsequent transactions: maybe; for long term relationships: we don't know. Traditional service quality research is conducted mainly from a transactional perspective, i.e., the effects of service quality and other marketing tools are studied for subsequent transactions. The new relationship paradigm, however, advocates to go beyond the transaction level and to study customer loyalty from a relationship perspective. The findings so far indicate that service quality can retain a customer at least on a short-term basis, and could therefore contribute to the start of a potential long-term relationship. However, once a relationship has started, will service quality then indeed contribute to its strengthening and enhancement, as is generally assumed, or will other factors become more important to maintain a once started relationship on the long-term?

Research in this area is still scarce in the service marketing liferature. A few authors argue that customers" repurchase intentions indeed do not suffice to determine whether a long-term relationship is or can be established. The attitudes or motivations that underlie these intentions are a better indicator for customers' true loyalty (Strandvik 1994). This view is derived from the business marketing literature, in which long-term (customer) relationships have been a topic of research interest for a longer time than in services marketing. Research is now accumulating regarding the dynamics of business relationships and the factors that contribute to the development of long-term business relationships. Long-term customer relationships with professional business service providers are also studied in this literature. However, service quality is usually not addressed in this 
research domain. Therefore, we will integrate the business marketing literature with the service marketing literature to address the following question:

\section{Research question 2}

Does service quality contribute to the maintenance of long-term customer relationships? What is its importance next to other factors that enhance long-term customer relationships?

Integrating notions from the business relationship literature into service quality research is relatively new. One group of service researchers used insights from the business relationship literature to model the role of service quality in long-term consumer service relationships (Storbacka \& Strandvik 1994, Liljander \& Strandvik 1995, Strandvik 1994). Their conceptual models are dynamic (longitudinal) in nature, and have not been explored empirically (yet). A few authors in the business marketing literature also started to explore the role of customers' service evaluations in the development of business service relationships (Young \& Denize 1994, Halinen 1994, LaBahn \& Kohli 1995), although the service quality concept as such is not addressed. Only Halinen (1994) directly used notions from the service quality literature and studied its role in the development and maintenance of long-term professional business service relationships, by an in-depth longitudinal case study.

With this second research question we aim to:

1) identify the key-concepts of relationship maintenance and its antecedents for professional business service relationships from the business marketing literature; and to

2) analyse the contribution of customers' service quality perception to the long-term maintenance of these relationships, relative to the other identified antecedents.

These aims are graphically presented in figure 1.4 .

Figure 1.4: Issue 2: contribution of service quality to long-term relationship maintenance

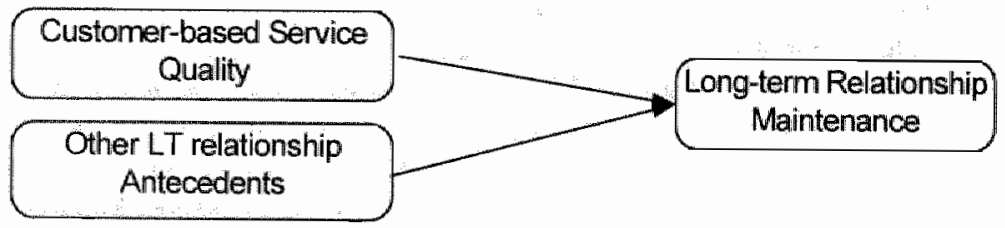




\subsection{Research Approach}

In sum, in this study the following two research questions will be addressed:

How do customers assess the quality of professional business senvices? Does this customerbased quality concept contribute to the long term maintenance of customer nelationships? These questions will be investigated by the following four research objectives:

1. to identify the key quality deteminants of customers' quality perception of professional business services;

2. to analyse the relative importance of each of these deteminants for customers' overall quality perception of professional business services;

3 . to identify the key-concepts of relationship maintenance and its antecedents for professional business service relationships, and $_{\text {. }}$

4. to analyse the contribution of service quality perception to the long-term maintenance of these relationships, relative to the other identified antecedents.

These objectives will be pursued by integrating notions from the business relationship literature with the service quality literature into one research model. This research model will then be explored empirically by a qualitative in-depth study, and a quantitative field study in one professional business service market: the advertising market. This is graphilcally expressed in figure 1.5, which integrates figures 1.3 and 1.4 :

\section{Figure 1.5: Outline of the study}

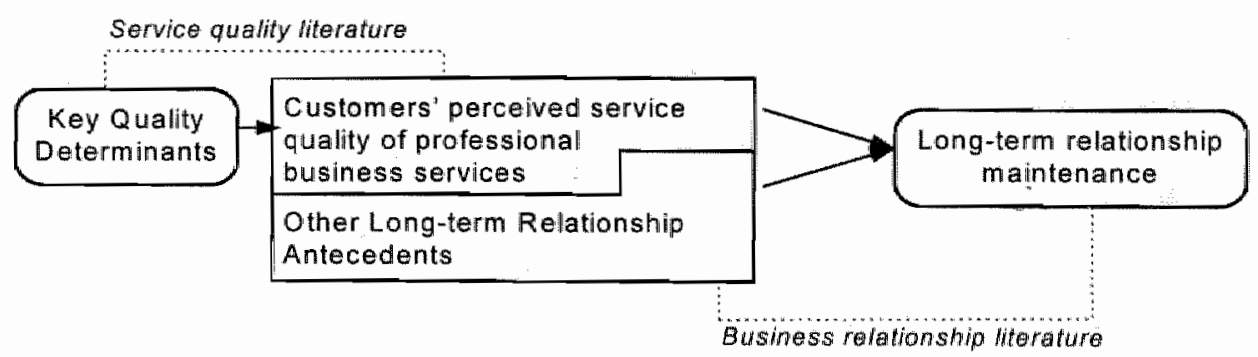

These objectives will be first addressed theoretically by a thorough literature review. As indicated in figure 1.5, the service quality literature will be used to address the objectives 1 and 2 . For the third objective, the business relationship literature will be used to conceptualise the maintenance of long-term business relationships, and to identify its most cited antecedents. This knowledge will then be translated into a professional business service context and integrated with the service quality literature to address the fourth objective. This will result in a tentative theoretical model, which will then be explored empirically by studying the contribution of the customer based service quality concept to the maintenance of long term customer relationships in the advertising market.

The research modell will thus be tentative in nature. By conducting an in-depth exploratory study and a subsequent large-scale field study we aim to contribute to an understanding of the role of the customer-based service quality concept in the maintenance of long-term customer relationships, rather than to find conclusive answers to all the objectives. 


\subsection{Chapter Outline}

In chapter 2 the first research question will be addressed theoretically, by analysing the customer-based service quality concept for professional business services. A general overview will be given of the service quality concept and the quality models that are well-accepted in the service marketing literature. Then the specific characteristics of professional business services will be addressed and an overview will be given of the few quality models proposed for these services. Based on the literature review, an integrated

\section{Figure 1.6. Chapter outine}

Chapter 2: Served atally

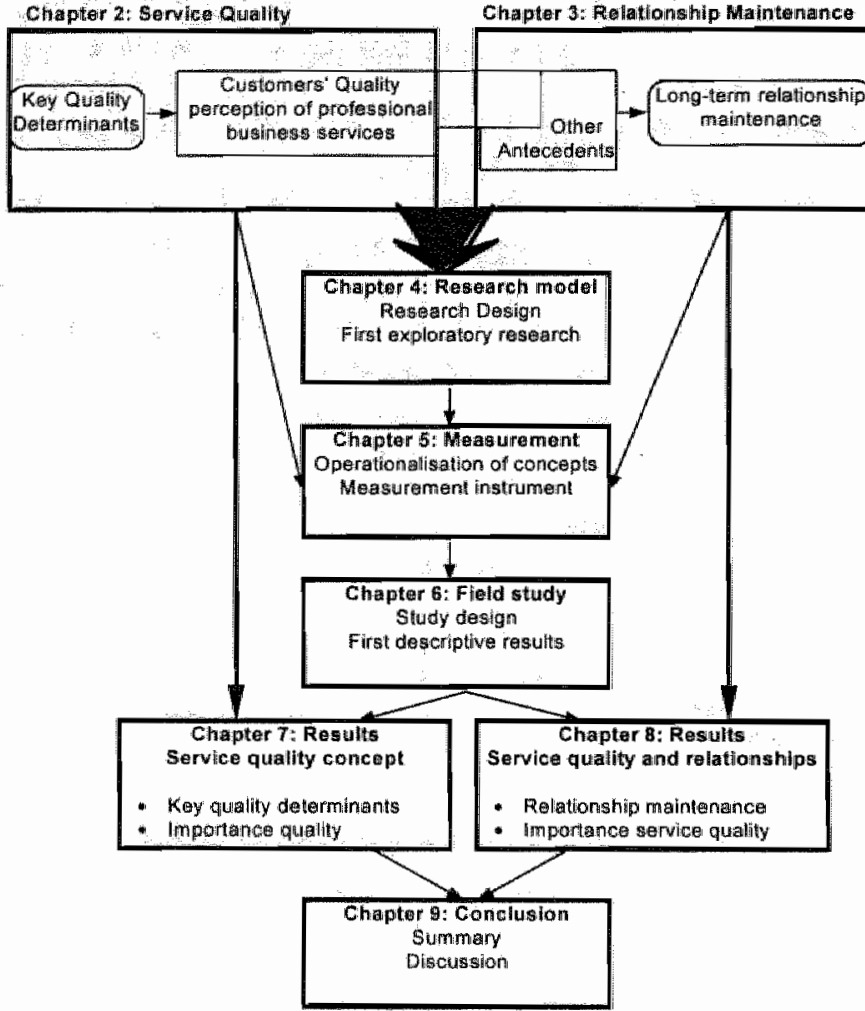
quality model for professional business services will be developed. This model will then be compared to the empirical evidence found from studies that studied customers' quallity perception of professional business services. This analysis will result in a quality model, in which the key-quality determinants of customers' quality perception of professional business services will be proposed.

In chapter 3 the second research question will be addressed, by a literature review on the development and maintenance of long-term business relationships. The concept of long-term relationship maintenance and the factors that have been identified to contribute to it will be discussed from the business marketing literature. These concepts will be translated into a professional business service context, and propositions will be formulated regarding the long-term maintenance and the antecedents to professional business service relationships.

Chapter 4 concludes and integrates the theoretical discussions of service quality and relationship maintenance. The research model will be presented in which the propositions from the literature reviews are integrated. Then the research design will be described that will be used to explore this research modell empirically in the advertising market. The chapter will conclude with the findings from the first step of the research design: the in-depth exploratory research in the advertising industry. 
In chapter 5 the development of the measurement instrument will be described; which will be used in the quantitative field study. The concepts of the research model are analysed indepth and will be operationalised for the advertising industry.

In chapter 6 the research design of the quantitative field study will be presented and explained. Then the first descriptive results of the field study will be presented and the concepts of the research model will be validated and purified.

In chapter 7 the empirical data will be analysed regarding the first research question. The proposed quality model for professional business services will be analysed, and conclusions will be drawn regarding the key-quality determinants for advertising services.

In chapter 8 the second research question will be addressed by an analysis of the empirical data. The propositions regarding the maintenance of professional service relationships and its antecedents will be analysed first, after which the relative importance of service quality will be explored. Based on the findings, the research model will be adjusted and conclusions will be drawn regarding the relative importance of service quality and its determinants for the maintenance of long-term relationships in the advertising market.

In chapter 9 the findings from both empirical studies will be discussed, and their theoretical and managerial implications will be addressed. The chapter will conclude with avenues for future research. 


\section{Chapter 2: Service Quality}

"But even though Quality cannot be defined, you know what Quality is.",

Pirsig 1984

\subsection{Introduction}

The senvice quality concept lies at the heart of this research project. In this chapter the first research question will be addressed: how do customers assess the quality of professional business services? What are the key-determinants in their quality assessment? The aim of this chapter is to identify the key-determinants of customers' quality perception of professional business services by a literature review regarding the customer-based service quality concept and the specifics of professional business services.

The chapter will start with a definition of the customer-based service quality concept (section 2.2) and its importance for service companies (section 2.3). In section 2.4 several service quality models will be reviewed that have been developed in the mainstream service quality research. After this general description, in section 2.5 the professional business services will be addressed and their differences with the more traditional (consumer) services. In section 2.6 the few service quality models that have been proposed specifically for professional business will be reviewed and synthesised into a new service quality model for professional business services. Five generic senvice quality determinants will be proposed in this model, which will be compared to the findings from recent empirical studies regarding service quality perception of professional business services.

\subsection{Defining service quality}

Service quality is a fuzzy entity, difficult to define (Zeithaml 1988, Gummesson 1991). Also for the manufacturing industry, where interest in quality and quality control already started in the 1920's, different conceptualisations and approaches have been used regarding the quality concept. According to the classification by Garvin $(1984,1988)$ there are as much as eight different definitions of quality, of which two are of particular interest to the quality of services. The manufacturing-based approach defines quality as 'conformance to requirements' (Crosby 1979,1984 ). In this view, the company specifies requirements and rules according to which the various functions of the firm must comply. Quality is achieved when the performance matches the pre-specified standards. According to this view quality management means 'doing things right' (Gummesson 1991). Customers' perceptions do not play a role in this definition.

The second approach is user-based, and defines quality as 'fitness for use' (Juran et al. 1974, Juran 1982). This approach is customer ariented and implies that a company should produce that which provides utility and satisfaction for the customer. Specifications are thus not set by the company, but by the needs and wants of the customer. In this view quality is achieved when customers perceive it as such, which is based on their 
subjective judgement regardless of the technical specifications. Quality management would thus become 'doing the right things' (Gummesson 1991).

In the services marketing literature interest in quality started in the 1980 's. From the early beginning, the concept of service quality was approached from the latter customer-based approach because of the specific characteristics of services. Services were recognised as being customer experiences rather than tangible objects with identifiable attributes. Services are highly intangible and usually require customers' participation in their production, which make it almost impossible to define general objective quality standards to which a provider should comply. Due to the absence of objectively identifiable quality standards, service quality lies essentially in the eyes of the beholder. Service quality depends thus on the standards that customers use to evaluate the quality upon, which are by definition more subjective than company or industry-based standards.

One of the first service quality models is the Perceived Service Quality Model by Grönroos (1982) who regards service quality as the outcome of an evaluation process by the customer, in which customers' pre-purchase expectations play a central role. Service quality is defined as the degree to which the delivered service meets or exceeds customers' pre-purchase expectations. Although some authors tried to transfer other ideas from manufacturing literature to services (see e.g. Gummesson \& Grönroos 1987, Shostack $1984,1987)$ the main-stream research on service quality is based on this initial customeroriented view and the (dis)confirmation of customers' expectations. The current dominating conceptualisation of service quality defines it as an evaluative judgement by the customer, which is a function of the discrepancy or 'gap' between what customers expect of a service and what they experience from the service encounter (Parasuraman et al. 1985, Zeithaml et al. 1990). To emphasise the subjective nature of the concept it is usually referred to as perceived service quality.

Perceived service quality is regarded as the customers' overall assessment of the excellence or superiority of a service provider. This means that it is based on an accumulated perception of all previous experiences with the service provider, resembling an attitude that is relatively stable over time (Zeithaml 1988, Zeithaml et al. 1988 , Bolton \& Drew 1994). The overall quality assessment is thus based on the quality evaluations of all service transactions, which will be assimilated over time (Poiesz \& Bloemer 1991, Strandvik 1994). Even though it is now assumed that customers can also evaluate service quality on a transaction level, these transaction evaluations will be assimilated into their overall perceived quality (Anderson \& Fornell 1994, Parasuraman et al. 1994, Rust \& Oliver 1994). So although different levels of customers' service quality perception can be identified, we will approach service quality from the (traditional) overall level.

Defined as such, service quality is not just one of the attributes of a service. It is seen as a higher-order concept resembling an attitude, encompassing all elements of customers' service experiences (Zeithaml 1988). These services experiences are multidimensional in nature (Bolton \& Drew 1994, Rust \& Oliver 1994), and will all be somehow included into customers' overall quality perception. Understanding which service elements customers use in their service quality assessment is thus paramount for the management and control of service quality. In section 2.4 the different quality models that identify these elements will be reviewed. 


\subsection{Importance of service quality}

Services are '... deeds, processes and performances' (Zeithaml \& Bitner 1996, p.5) rather than concrete objects, and they are produced in the customers' presence. This makes them interactive, experiential in nature, heterogeneous, and consequently difficuit to control for the service provider. The customer-based service quality concept, and the resulting understanding of customers' quality perception provides the necessary guidelines and standards by which service providers can manage and control their service performances.

Service quality has also been identified as one of the few means for competitive differentiation of service companies (Parasuraman et al. 1985, Grönroos 1987). The generally low entry barriers in service industries, the rapid diffusion of innovations, and the few possibilities for price competition in these industries, makes competition on quality more effective than the use of other marketing instruments (Neijzen en Trompetter 1989) to attract new customers.

The extensive body of research on service quality indicates that it is not only important for the attraction of new customers, but also crucial for the retention of existing customers. its close, conceptual as well as empirical, link to customer satisfaction turned it into the core marketing instrument of service companies, which made service quality as the 'single most researched area in senvices marketing to date' (Fisk et al, 1995). Delivery of service quality is now related to customer retention, market share and profitability (Rust et al. 1995).

Research is accumulating that shows a positive link between service quality and profitability (Buzzel \& Gale 1987, Capon et al. 1990. Fornell 1991,1992, Anderson 1992, Anderson \& Fornell 1992). This link is not straightforward (Zahorik \& Rust, 1992) but is explained by the effects of service quality on:

1. The attraction of new customers. As indicated above, competing on quality is the most effective way for differentiation and will attract new customers. New customers will also be attracted by favourable word-of-mouth advertising by the existing customers. The experiential nature of services makes it difficult for customers to compare service providers when buying a new service, word-of-mouth from people who already have experience is therefore a crucial source of information for potential customers to make a buying decision. High perceived service quality will stimulate customers to tell others about their satisfying experiences (Parasuraman et al. 1985, Swartz \& Brown 1989, Anderson et al. 1994, Rust et al. 1995).

2. Retention of existing customers (Anderson \& Fornell 1994, Anderson et al. 1994, Rust et al. 1995): If good service quality is delivered to existing customers, these customers will have no reason to switch to another provider. As long as customers are satisfied with this service provider, the chances increase that they will come back. The retention of existing customers not only secures a steady stream of income, but also contributes to the profitability of service companies in other ways:

- existing customers purchase more than new customers (Rose 1990). Over time, customers will also buy other services from the company;

- greater efficiencies can be established in dealing with existing customers;

- as a rule of thumb it is assumed that keeping existing customers is about five times cheaper than attracting new ones (Peters 1988, Fornell 1992); and, 
- existing customers were found to have a reduced price elasticity (Garvin 1988) and are more willing to accept a price increase.

Service quality is thus not only important for service differentiation, but also for the build up and enhancement of customer relationships (Anderson \& Fornell 1994). Empirically this relation has been addressed by studying the effects of service quality on customers" repurchase intentions. Different studies found that perceived service quality is indeed strongly related to customers' repurchase intentions either directly (Kasper 1988, Bitner 1990, Bolton \& Drew 1991, Anderson \& Sullivan 1993, Boulding et al. 1993, Cronin \& Taylor 1994, Liljander \& Strandvik 1994), or indirectly through its influence on satisfaction (Crosby 1991, Cronin \& Taylor 1992, Rust \& Zahorik 1993, Strandvik \& Liljander 1994). The positive relation between service quality and customer retention was also confirmed in the integrated study by Zeithaml et al. (1996), who found that customers' perceived service quality is positively rellated to customers' repurchase intentions and has a positive effect on customers" loyalty, switch intentions, and intentions to pay more, in four different service industries.

\subsection{General service quality models}

Service quality is thus a powerful marketing tool for service companies by which new customers are attracted, existing customers will be retained and consequently, the profitability is improved. As described in section 2.2, service quality is defined from a customer-based perspective. It is defined as the customer's overall judgement of the whole service experience, which is multidimensional in nature. For the management and control of service quality it is thus imperative to understand which service elements customers use to assess the service quality. Several models have been developed that try to identify the service dimensions on which customers' quality perception is based. In this section several service quality models will be reviewed and discussed.

\subsubsection{Two dimensional service quality model}

In one of the first models of service quality perception, Grönroos (1982) identifies two service quality dimensions on which customers base their quality evaluations: the technical quality and the functional quality.

- The fechnical quality refers to an evaluation of what the customer received from the interactions with the service provider. This is the technical outcome of the (service) production process, which can be evaluated on relatively objective criteria.

- The functional quality refers to how the technical outcome is performed. Because customers interact with the service provider during the service production process, they not only perceive the outcome, but also the process by which it is produced. The service accessibility, the customer contacts, and the behaviour and attitudes of the service provider towards the customer during the process will also influence the quality evaluation by the customer. This is the functional quality and is more subjectively evaluated than the technical quality.

The perceived service is regarded as a bundle of service dimensions, some of which are technical and others functional in nature. This dichotomy in service quality dimensions is well accepted in service quality literature. The technical and functional dimension have been referred to by others as 'core service' versus 'peripheral service' (laccobucci et all. 1994), 'physical quality' versus 'interactive quality' (Swartz \& Brown 1989) and 'output' 
versus 'process' quality (Lehtinen \& Lehtinen 1991). Also the three most influential authors in this area called a similar distinction 'outcome quality' versus 'process quality' emphasising that:

"Quality evaluations are not made solely on the outcome of a service; they also involve evaluations of the process of service delivery" (Parasuraman et al. 1985, p.42).

We prefer this latter terminology, for the words 'process' versus 'outcome' quality reflect the actual service performances better than the 'functional' versus 'technical' quality. The 'process' dimension not only refers to the functional transfer of the outcome, but also to the production process by which the outcome is produced. The distinction into process and outcome reflects the time-dimension that is inherent to service production: customers first experience and participate in the production process before they can perceive its outcome.

\subsubsection{Three dimensional service quality model}

Lehtinen \& Lehtinen (1991) developed a three dimensional service quality model, consisting of the Physical Quality, Interactive Quality and Corporate Quality. These three together form the basic dimensions of the service performance and service organisation, i.e. the natural productive elements that customers use to evaluate the service performance on.

- Physical Quality refers to the evaluation of all the physical products/elements that are part of the service (e.g. the meal in a restaurant, the room of a hotel), and of the physical support used during service delivery (e.g. the environment or the instruments used in the delivery of the service).

- Interactive Quality refers to customers' evaluation of all the interactions with the service provider, whether with its contact personnel or with equipment used in the service delivery process (e.g. automatic teller machines).

- Corporate Quality refers to the evaluation of the corporate entity, image or profile of the service provider as a whole. This evaluation will be more stable than the other two, because the image of a company will not change easily. It is, however, an important aspect that influences the overall service quality evaluation by the customer. Especially because it is one of the few aspects that a customer can perceive before the service production process.

\subsubsection{Ten dimensional service quality model}

Parasuraman et al. (1985) developed a service quality model, which was initially based on an extensive exploratory study in different service industries, including banks, credit card companies, stock brokers and household repair service companies. In their 'Gap Model' service quality is defined from a customer perspective. Perceived service quality is defined as a function of the gap between customers' service expectations, and their service performance perceptions on a number of service elements. From their research they identified ten service dimensions that customers use to assess service quality: 
1. Rellability: refers to the evaluation of the providers' consistency of service performance and its dependability in performing what they promised.

2. Competence: refers to an evaluation of the availability of the required skills and knowledge at the provider.

3. Responsiveness: refers to an evaluation of the willingness and readiness of the service provider to provide the service.

4. Courtesy: refers to an evaluation of the politeness, respect, consideration and friendliness of the contact personnel.

5. Security: refers to an evaluation of the risk, danger or doubt for customers in dealing with the provider.

6. Accessibility: refers to an evaluation of the approachability and ease of contact with the service provider.

7. Communication: refers to an evaluation of how well the service provider keeps the customer informed in a language that is understandabie and his willingness to listen to the customer.

8. Understanding the customer: an evaluation of the degree to which the provider makes an effort to understand customer needs.

9. Credibility: an evaluation of the trustworthiness, believability and honesty of the service provider, whether it serves the customer's best interests.

10. Tangibles: an evaluation of the physical evidence of the delivered service.

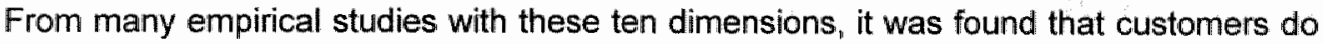
mot distinguish between all ten dimensions separately in their quality assessments, and that some of the dimensions are overlapping. Customers' evaluations of the competence, courtesy, credibility and security were hardly differentiated and were therefore merged into one quality dimension "Assurance". Also customers' evaluations of the accessibility, communication, and understanding the customer dimensions showed considerable overlap, and could be merged into one service quality dimension 'Empathy'. These adjustment resulted in a new service quality model with five independent service quality dimensions: Reliability, Responsiveness, Assurance, Empathy and Tangibles (Zeithaml et al. 1988). These five dimensions are operationalised in the well-known and widely used measurement scale of customers' perceived service quality: the SERVQUAL-Scale (Zeithaml et al. 1988, Parasuraman et al. 1993).

This empirical study supports the notion that customers not only evaluate the outcome of a service but also the process by which the service is produced. From a closer look at the dimensions one can see that four of the five dimensions relate to customers' assessment of the service production process and the interactions with the service provider during this process. Only the reliability dimension (doing what was promised) refers to the outcome of the service. In the empirical studies conducted with these five dimensions, using the SERVQUAL-scale, it was found that the reliability of the service provider is the most important service quality dimension , and the tangibles the least important quality dimension for customers' overall quality perception (Parasuraman 1995). The service outcome is thus very important, although the service process is evaluated on much more different aspects. 


\subsubsection{Six dimensional service quality model}

Grönroos (1988) integrated findings from different empirical studies on service quality (Gronnroos 1984, Parasuraman et al. 1985, Garvin 1987) and concluded that the following six criteria are crucial for customers' perceived service quality:

1. Professionalism and Skills: the presence of the required skills and knowledge at the service provider, regarding its employees, operational systems, and physicall resources to solve customers' problems in a professional way.

2. Attitudes and Behaviour: the capability of the contact persons to show concern and genuine interest in solving customers' problems in a friendly and spontaneous way.

3. Accessibility and Flexibility; the degree to which the service provider, its location, operating hours, employees and operational systems are designed and operate such that the service is easy accessible and that the provider is flexible to adapt to the demands and wishes of the customer.

4. Reliability and Trustworthiness: the assurance that the service provider, its employees and systems keep their promises and perform with the best interest of the customer at heart.

5. Recovery: the degree to which the service provider takes prompt corrective actions whenever something goes wrong or something unexpectedly happens.

6. Reputation and Credibility: the customer's belief that the operations of the service provider can be trusted, and that the philosophy and values of the provider are shared by the customer.

\subsubsection{Discussion of the service quality models}

The reviewed quality models thus identify many different service dimensions on which customers base their quality assessment of the service provider. The models by Grönroos (1982) and Lehtinen \& Lehtinen (1991) identify general service quality dimensions, which each encompass several service elements. The other two models by Parasuraman et al. (1985) and Grönroos (1988) try to identify the actual service elements that are included into customers' service quality evaluation. Although the authors use different terminology, the models can be related to each other. The elements identified in the latter two models are specifications of the more general dimensions identified in the first two models.

As indicated earlier, the technical and functional quality dimensions of Grönroos' (1982) model, can be rephrased into the service process versus service outcome quality dimensions. We already described how the five dimensions by Parasuraman et al. (1985) can be classified into these two quality dimensions (Zeithaml et al. 1988). The tangibles, responsiveness, assurance and empathy dimensions can be classified as service process dimensions, whereas the reliability dimension reflects the service outcome. The three dimensions of Lehtinen \& Lehtinen (1991) also partly reflect the two-dimensional structure. Their Interactive Quality clearly refers to the interactions during the service process, and could be classified as a process quality dimension. Their Physical Quality dimension reflects both quality dimensions, it partly refers to the physical elements that are present during the service production process (equipment used and environment), and also to the physical elements of the service outcome (tangible evidence of the delivered service). Their Corporate Quality, however, is an addition to the service process and service outcome dimensions, for it is not comprised in either one of them. Also Grönroos dis- 
cussed in his original model (1982) the importance of company image for customers? quality perception. In his opinion, it acts as a kind of filter for the other two dimensions on customers' overall perceived quallity, because it is a more stable factor of the service provider, as also Lehtinen \& Lehtinen (1991) argued. The service process and outcome quality dimensions could thus be complemented with a third quality dimension: the corporate quality. The more specific quality elements that Gronroos (1988) integrated from different studies can be classified into these three general quality dimensions. The Reputation and Credibility dimension clearly refers to the Corporate quality. The Reliability and Trustworthiness, Recovery, Accessibility and Flexibility, and Attitude and Behaviours are categorised as Service Process dimensions, while the Professionalism \& Skills are categorised as a Service Outcome dimension. There are thus three super-ordinate service quality dimensions, in which the empirically found service quality dimensions can be comprised:

Table 2. 1: Categorisation of different quality models into three quality dimensions

\begin{tabular}{|c|c|c|c|c|}
\hline $\begin{array}{l}\text { Quality } \\
\text { dimensions }\end{array}$ & Grönroos(1982) & $\begin{array}{l}\text { Lehtinen \& } \\
\text { Lehtinen } 1991\end{array}$ & $\begin{array}{l}\text { Zeithaml et al. } \\
\text { (1988) }\end{array}$ & Grönroos 1988 \\
\hline Corporate quality & (Image) & Corporate Quality & - & Reputation and credibility \\
\hline $\begin{array}{l}\text { Service } \\
\text { Process quality }\end{array}$ & Functional quality & $\begin{array}{l}\text { Physical Quality } \\
\text { Interactive Quality }\end{array}$ & $\begin{array}{l}\text { Tangibles } \\
\text { Responsiveness } \\
\text { Assurance } \\
\text { Empathy }\end{array}$ & $\begin{array}{l}\text { Attitudes and behaviour } \\
\text { Accessibility and Flexibility } \\
\text { Rellability and trustworthiness } \\
\text { Recovery }\end{array}$ \\
\hline $\begin{array}{l}\text { Service } \\
\text { Outcame quality }\end{array}$ & Technical quality & Physical Quality & Rellability & Professionalism \& Skills \\
\hline
\end{tabular}

The significance of the specific quality elements can vary considerably between types of services and types of buyers (Edvardsson et al. 1994). Also the structure of the elements can vary. Many empirical studies performed with the SERVQUAL-scale did not fully confirm the existence of the five or ten separate dimensions (Carman 1990. Finn and Lamb 1991, Babakus \& Boller 1992, Babakus \& Mangold 1992). The structure and individual attributes of customers' quality perception seem to be service and industry specific. On a more general level, however, customers evaluate three general service dimensions ${ }^{2}$ that can be operationalised by different service elements, depending on the kind of industry.

- the outcome of the service (or technical quality);

- the process of the service delivery (or functional quality); and,

- and some stable characteristics of the service provider (image or corporate quality).

\footnotetext{
1 Further research with the five dimensions of SERWQUAL have showin that a three dimensional model is also feasible: 1) the reliablity, and 2) the tangibles as two separate dimensions, and 3) the responsiveness, assurance and empathy merging into one dimension (Parasuraman 1995). Although the tangib|les dimensions does not entively reflect the "corporate quality", thist three-dimensionall model resembles the three dimensions portrayed there very much.

2 Interestingly, also the service providers seern to be convinced of the importance of these three dimentions. In a study in The Netherlands service providers indicated that the three most important key-success factors for service firms are the 1) product/service quality, 2) close links with the cusstomers, and 3) company/brand reputation (Kasper at all. 1997).
} 


\subsection{Professional business services}

Although no exclusive and generally accepted definition exists so far, professional business services can be described as services that are advisory in nature and focus on problem solving The services are provided by independent qualified professionals, whose expertise and skills are at the core of the service performance (Gummesson 1978, Yorke 1990). The services are rendered to organisational customers and contribute to the well-being of the organisation and it: stake holders. Some illustrating examples of professional business services are financial serv ices, business consultancy services, advertising and other agency services, engineering anc architectural services, or legal services. The service is rendered by professionals who use thei expertise to solve client-specific problems. These problems can be very complex and the services will be generally customised requiring customers' active participation during the servica production process. The service production processes (i.e. development of the solution) ofter covers a long time span.

In terms of the general service characteristics, professional (business) services are the mos 'pure' senvices that exist, regarding their degree of intangibility, customisation and custome participation during their production. Therefore, it is often difficult for clients to objectively evalu ate the service even after purchase and consumption (Patterson 1995). The outcome of thi service production process is usually a solution to a client-specific problem. The actual merits $\mathrm{c}$ a produced solution can often not be perceived by clients until long after they have been im plemented and put into practise. And even then it is difficult to determine the actual merits because in many cases the assignments produce indirect, though positive, effects, which an but one of several factors that influence the situation of the client (Gummesson 1983). Thi effects of a consultant's reorganisation advice, for instance, are hard to measure and even business results are changing, it is hard to determine which part of it could be ascribed to th reorganisation and which to other factors (like market changes). Likewise, the effects of a advertising campaign take a long time to be conceived and even then it is not always obviou which sales effects are directly attributable to the campaign and which to other factors, lik competitors' actions. But even if the results could be evaluated, customers rarely know whethe another professional would have done a better job (Gummesson 1979) because the service have to be customised to their specific problems. These services thus possess many credeno qualities, l.e. qualities that cannot be detected even after purchase or consumption but muc later (Nilessen 1993 "Zeithaml 1988), and are associated with high perceived risk by the cus tomers.

\section{Market situation}

To protect customers from abuse and some of the risks, government and trade association introduced rules and regulations that not only attempted to secure a minimum level of servic quality, but as a by-product also protected many professional service markets. These regule tions raised entry barriers that shielded professional service providers from fierce competitior Once a professional service provider was accepted to enter the market, it was almost automal cally assured of a secure clientele. Clients had few alternatives available and confidence wa instilled by the official recognition of the accepted companies, which made the accepted provic ers homogeneous in the customers' eyes. This, together with the high uncertainty attached 1 these services, induced clients' loyalty to familiar service providers. Professional busines service companies thus faced a luxurious market situation; once they could enter the marke they were assured of a clientele that stayed loyal to them. These customer relationships, hov 
ever, were guided more by inertia from the customer than satisfaction or superior quality (Yorke 1990).

However, lately almost all professional service industries are being deregulated ${ }^{3}$ and (international) competition ${ }^{4}$ is rapidly increasing. Higher education levels (in the western world) increase customers' own expertise and make them more critical towards professional business senvice providers. Customer-relationships are not sustained by inertia anymore (Yorke 1990) and customers have many more alternatives available to choose from or switch to. These changes in the market force professional service firms to become more competitive and call for a different, more customer-oriented approach for professional service firms as well.

"While traditionally the professions avoided even using the word marketing, they are now seeking better ways to understand and segment their customers, to ensure the delivery of quality services, and to strengthen their positions amidst a growing number of competitors' (Zeithaml and Bitner, 1996, p.11)

\section{implications for service quality}

In the old market situation, service quality and service performance of professional (business) services were traditionally controlled by regulations and professional standards (Morgan 1991). As long as the professionals possessed the required qualifications and the professional service companies fulfilled the criteria set by government or industry, quality was secured. Because of their expertise, the professionals decided what was best for the client, applying their professional standards to the delivery of quality. The service quality concept of profiessional business services was thus based on industry and professional standards, like the manufacturing-based approach in product quality as described in section 2.2.: Quality as conformance to requirements. With the requirements based on professional standards.

The market changes have implications for the quality concept used in these industries. Quality based on professional standards will not suffice to provide a competitive differential, nor does it take customers' needs into account. A customer-based approach to service quality, as is used in the more traditional (consumer) service industries, is now called for. It has become a high priority for professional business services to deliver outstanding service and to ensure customer satisfaction, in order to remain competitive and to maximise their chances of gaining repeat business and developing longer term relationships with clients (Patterson 1995).

A customer-based service quality concept is gaining more and more in importance for the professional business senvices as well. Authors see it crucial for customers' recommendation efforts, providing the word-of-mouth communication that is so important for these services (Woodside et al. 1992), and also for customer satisfaction (Day et al. 1988, Morgan 1991), and

\footnotetext{
3 In The Nethenlands the Law for Economïc Competition (Wet Economische Mededinging) was broadened in Sept. 1995 to include the free-professions. This law already deregulated the actvertising industry in 1989 when the "rules" set by the ROTA were found to be in defiance of anti-trust legislation. The rules were weakened and more agencies were allowed to enter the masket. Furthermore, in why 1995 the Dutch cabinet accepted the operation Market forces, Deregulation and Legislation quality" in which the deregulation of lawyers, insurance brokers, hospitals and educational services are among the spear heads (press release of Ministry of Economic Affairs 11/07/1995 and 31/08/1995).

4 The business senvices are among the fastest growing industries. In the US all business service segments exceeded GDF growth in 1982-1992 (Wilson \& Smith 1996). Professional business service industries are also expanding intemationally (cf. Elfing et al 1993). For instance, EC-directives in 1993 (no. 8 and the acknowledgement of educational diplomas) made it easier for foreign accountants to become registered accountants in The Netherlands.
} 
for customers' repurchase intentions and loyalty to the professional business service provider (Bojanic 1991, Morgan 1991).

This means that the conceptualisation of service quality for professional business services should thus shift from the traditional focus on industry and professional standards to a customer-based approach. Atthough this service quality concept is well accepted in the more traditional (consumer) service industries and has been studied since the early 1980's, surprisingly little studies addressed service quality of professional business services (LaPierre \& Filiatrault 1995). In the next section the few customer-based service quality models that have been developed for professional business services will be reviewed and the empirical studies regarding customers' quality perceptions of professional business services will be discussed.

\subsection{Service quality of professional business services}

Customer-based service quality was described as the customers' overall judgement of the whole service experience, which is multidimensional in nature. In section 2.4 several quality models were reviewed that identify the service dimensions on which customers' service quality assessment is based. The SERVQUAL-model is the most accepted and widely used one of these models, which identifies five (or ten) service quality dimensions on which customers base their quality perception.

Recently a few empirical studies have been conducted with the SERVQUAL-model that investigate customers' quality perception of professional business services, like, legal services, CPA services, and business communication services (Bojanic 1991, Morgan 1991, Freeman \& Dart 1993, Tzokas et al. 1994, Dassen 1995). As described in section 2.4.3, this five (or ten) dimensional quality model is derived from empirical studies conducted mainly in traditional (consumer) service industries. However, as described in the previous section, professional business services share some distinct characteristics that differentiate them from the more traditional services. It is therefore questionable whether customers use the same service dimensions to assess the quality of professional business services. Some authors call for an adjustment of these quality models for professional business services (Szmigin 1993, LaPierre \& Filiatrault 1995).

In the next paragraphs the customer-based quality models that have been developed especially for professional business services will be reviewed. The adjustments proposed in these models will be synthesised into an integrated framework of the key determinants ${ }^{5}$ of customers' quality perception particularly for professional business services. Since professional services share many distinctive characteristics, whether they are performed to organisations or individuals, the first model reviewed will be one developed for professional services in general. After this model the quality adjustments proposed for professional business services in particular will be described.

5 To distinguish the quality dimensions in our final integrated quality model from the existing temninollogy. we will call the dimensions "quality determinants'. 


\subsubsection{Three dimensional quality model for professional services}

Health care researchers developed a model for customers' quality evaluation of professional services (Donabedian 1980). This model consists of three interrelated quality components: the input or structure of the service provider, the service process, and the service outcome. Although it was developed for use in health care, it is proposed to be appropriate for all professional services (Stiff \& Gleason 1981). These three components are believed to have an impact on customers' service quality perception, and are described below.

- The process quality reflects the way in which the service is produced and delivered;

- The outcome quality reflects the results of the delivered service; and,

- The input or structure refers to all the input components of the service provider. needed to perform the service.

The service process and service outcome components are very similar to the process and outcome quality dimensions used in the traditional quality models. These authors also argue that customers' quality assessment is not only based on the outcome of the service, but also on the process by which it was produced. The 'input or structure' component is comparable to the 'corporate quality' used in some of the traditional models. In German literature this quality component has been rephrased as 'potential quality' (Meyer \& Mattmüller 1987, Corsten 1990, Haller 1995), indicating that the input or structure refers to the available potential at the service provider to perform its services. It consists of the professional staff, available facilities and equipment, and the management structure in which they are utilised. It thus refers to all human, material and financial potential of the professional service provider.

Many of these structural characteristics of the service provider can be perceived by clients even without experience with the provider. The available potential can thus be used by clients to compare service providers in their selection decision. It signals the potential quality a provider will be able to deliver (Haller 1995), which is an important part of the image of the provider. However, this component will also influence the quality perception of customers who dó have experience with the service provider. The process and outcome of the service may be impeccable; if the client is, however, convinced that the provider has not enough potential to meet his (future) needs, this will affect his quality perception. So customers' assessment of the potential quality is not only determined by the provider's reputation, but also by the visible tangibles, physical support, and the available expertise.

Figure 2.1: Three-dimensional quality model for professional services

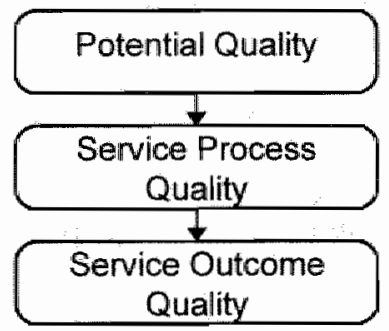

Based on: Donabedian 1980 
This modell is thus very similar to the general service quality dimensions that were identified in the traditional service quality models. The definition of these three professional service quality components indicates that they should be regarded as super-ardinate quality dimensions. The perceived service is regarded as a bundle of service dimensions which can be either potential, process or outcome related.

\subsubsection{Three dimensional quality model for professional business services}

Szmigin (1993) developed a model of service quality dimensions specifically for the professional business services. She identified three overall service quality dimensions of professional business services, based on Grönroas' (1982) basic distinction into the technical and functional quality. The quality dimensions are the "hard quality", the "soft quality", and the 'outcome quality'.

- The 'hard quality', refers to what is being performed during the service process, the technical quality of the way in which the service production process is carried out.

- The "soft quality' refers to how the service is performed during the service process, the functional quality during the service production process.

- The 'outcome quality' refers to the ultimate achievement of the desired goal or service outcome by the delivered service.

The first two quality components thus refer to two dimensions within the service process. She argues that clients' evaluation of the service production process is based on an assessment of the technical and functional quality within the service process, that she calls 'hard' and 'soft' quality. Although Szmigin does not define the hard and soft quality, in some of the examples given she ascribes to the hard quality the promptness and accuracy of the service production and to the soft quality the attitudes of the service personnel, the accessibility, appearance and service-mindedness of the personnel, which refers to the interactions during the process that are not necessarily core-servilce related.

The outcome quality refers clearly to an evaluation of the service outcome. However, this outcome dimension is particularly matched to the characteristics of professional business services. She argues that customers' perception of the outcome dimension is differentiated from the other two quality dimensions mainly because it cannot always be controlled by the service company. A service provider may perform superbly on the soft and hard elements, but may still not reach the ultimate goal. A lawyer may present a perfect case, but the court can still rule against his client, or an advertising agency can make an advertising campaign that meets the brief in all particulars, but may still not result in the clients' sales or mage objectives. This outcome quality is thus susceptible to outside influences and conditions, but will still be part of customers 'overall quality assessment.

In this model an additional distinction within the service process is thus proposed. Customers not only evaluate the functional quality during the service production process (as is assumed in the traditional quality models), but also the technical quality of the process itself. The outcome of professional business services has a separate position and Szmigin defines it as the ultimate result or effects of the delivered service. In the next paragraph customers' service outcome assessment will be addressed further. 
Figure 2.2. Quality model of protessional business senvices

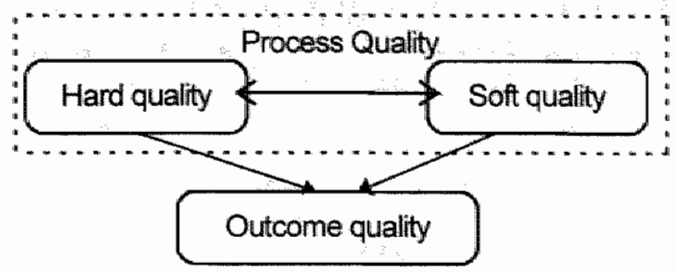

Source: Szmigin 1993

\subsubsection{Outcome dimensions of professional business services}

The outcome of professional business services is one of the specific characteristics that differentiates these services from the more traditional (consumer) services. The service outcome manifests itself -if at all- belated and is susceptible to outside influences (Gummesson 1983, Szmigin 1993). Therefore, some authors proposed an additional distinction into several service outcome dimensions for professional (business) services. They argue that the service outcome can be distinguished into an immediate service outcome and an ultimate service outcome for professionall services (Meyer \& Mattmüller 1987, Halinen 1994):

- the immediate senvice outcome refers to the solution that is offered to the client-specific problem, it is the direct result of the service production process;

- the ultimate service outcome refers to the effects or results of this offered solution, after it has been implemented and its effects can be perceived.

In many professional business services customers can make a clear distinction between the two service outcomes. The design an architect has developed for a building (immediate outcome) can be evaluated differently from final building when the client has moved in (final outcome). A consultant's reorganisation plan can be perfectly matched to the clients" organisational structure and problems (immediate outcome), but the expected efficiency gains (final outcome) can only be evaluated after the plan has been implemented. Between the two concepts lies an inherent time-dimension and customers will be able to assess them separately.

Halinen (1994) proposes three service dimensions that clients use to evaluate professional business services: the process outcome, the service outcome, and the ultimate service outcome.

- The process outcome is defined as the level of satisfaction the parties perceive with respect to the interactive service process, i.e., all the interaction episodes between the parties during an assignment process' (p.258). It refers to the way in which the service is rendered, the way in which the client participates in the service production process, and the interactions between the interacting individuals, combining the functional quality, process quality and interactive quality as defined by Grönroos (1982) and Lehtinen \& Lehtinen (1991).

- The service outcome is defined as 'the level of satisfaction the parties perceive with respect to the immediate result of the service production process (p.261), which she compares again to the outcome quality as defined by Grönroos and Lehtinen \& Lehtinen . 
- The ultimate service outcome is defined as the level of satisfaction the parties perceive with respect to the final and indirect results of an assignment process on each company's business' (p.264). Halinen regards this outcome as particular for professional business services.

In her model she stresses the importance of the time-dimension that lies within the assignment processes, from which customers can perceive the different service dimensions. Graphically her model can be presented as:

Figure 23: A quality model of professional business services

Source: Halinen 1994

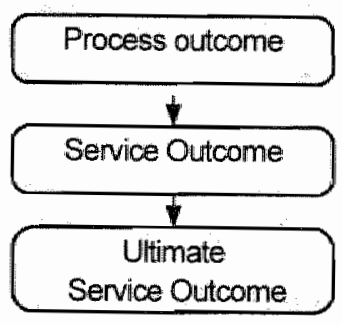

\subsubsection{Synthesis: integrated service quality model for professional business services}

In the quality models reviewed in the previous paragraphs some adjustments are suggested for customers" quality perception of professional business services. However, all the models start from the same basic service dimensions that were proposed in the traditional service quality models: customers' quality perception is not only based on the service outcome but also on the service (production) process. The model of professional service quality "based on Donabedian (1980), adds a third quality component to these basic two. It is argued that customers also include the potential of the service provider into their quality perception. In the traditional service quality models it is also suggested that customers' perception of more stable characteristics of the service provider contribute to their overall quality perception, mainly described as the provider's reputation or image. Although more elements are comprised into the perceived potential quality, the concepts are comparable and we can conclude from this that the general distinction into three crucial service quality elements; provider characteristics, service process and service outcome, is applicable to professional business services as well.

Starting from this basic three-dimensional service quality model, two important adjustments were suggested by quality models for professional business services.

First, within the service process two separate service dimensions can be distinguished that contribute to customers" quality perception of professional business services: the hard quality and the soft quality of the process as identified by Szmigin (1993). The hard quality refers to the technical way in which the service is produced, and the soft quality refers to the interactions and dealings with the customer during the production process. This distinction is highly relevant for professional business services, because the production process usually covers a long time span in which the customer is not only present. but actively participates. Many exchange episodes are needed before a service outcome is achieved, which form different stages in the service production process (Gummesson 1991). Customers are involved in many or all the stages by which the service is produced. This means that they do not only experience the way in which the provider inter- 
acts with the client (soft or functional quality), but they experience step by step the strategy by which the service is technically produced (hard or technical quality). The evaluation of the two process dimensions are not inextricably linked: Customers can perceive very satisfying interactions with the service provider, but the service can be performed technically in an unprofessional way or vice versa. Therefore, we argue that this distinction into two separate process dimensions is highly relevant for professional business services.

Second, several authors suggested an adjustment within the service outcome for professional business services. Also for this dimension a further distinction into two separate quality components is suggested: the immediate outcome quality and the ultimate outcome quality. The immediate outcome refers to customers" evaluation of the direct outcome of the service production process, whereas the ultimate outcome refers to the effects of this outcome for the client's business. Again, this distinction is highly relevant for professional business services, because their final outcomes cannot be evaluated until some time has passed after the completion of the assignment process (Meyer \& Mattmüller 1987). This differentiates the evaluation of the two outcome dimensions according to their time of perception. Both service outcomes are also conceptually different. The immediate outcome is usually intangible and consists of many credence elements, whereas the final outcomes can be evaluated on relatively hard criteria. As indicated earlier, a customer can perceive a very good legal defence from his lawyer "but the judge can still rule against the client. A client can perceive a good investment advice from his broker, but the gains can be disappointing. Although the final outcomes are not entirely controlled by the service provider, and are susceptible to outside influences, it will be part of customers' overall quality perception (Szmigin 1993). It is the main reason why the service provider was hired in the first place.

Integrating the adjustments suggested in these models we propose that customers' quality perception of professional business services is based on their evaluation of five key-quality determinants. These determinants are summarised below.

1. Potential Quality: the customers' evaluation of the available human, material and financial potential at the service provider to perform its services.

2. Soft Process Quality: the customers' evaluation of the interactions with and treatment of the customer during the service production pracess.

3. Hard Process Quality: the customers' evaluation of the (technical) way in which the coreservice is produced by the service provider.

4. Immediate Outcome Quality: the customers' evaluation of the direct outcome of the service production process.

5. Final Outcome Quality: the customers' evaluation of the finai results or consequences of the (implemented) senvice outcome.

These five determinants are the key service dimensions on which customers' service quality perception of professional business services is based. All five determinants are part of customers' quality perception of professional business services. We prefer to call them determinants to reflect the 'super-ordinate' nature of these quality dimensions. As can be seen from the descriptions above, the determinants reflect overall dimensions, that each encompass several service elements or lower-level service dimensions as used in other quality models (like, e.g., the 10 dimensions of the SERVQUAL model). In figure 2.4 the integration of the reviewed models into our proposed service quality model is graphically presented. 


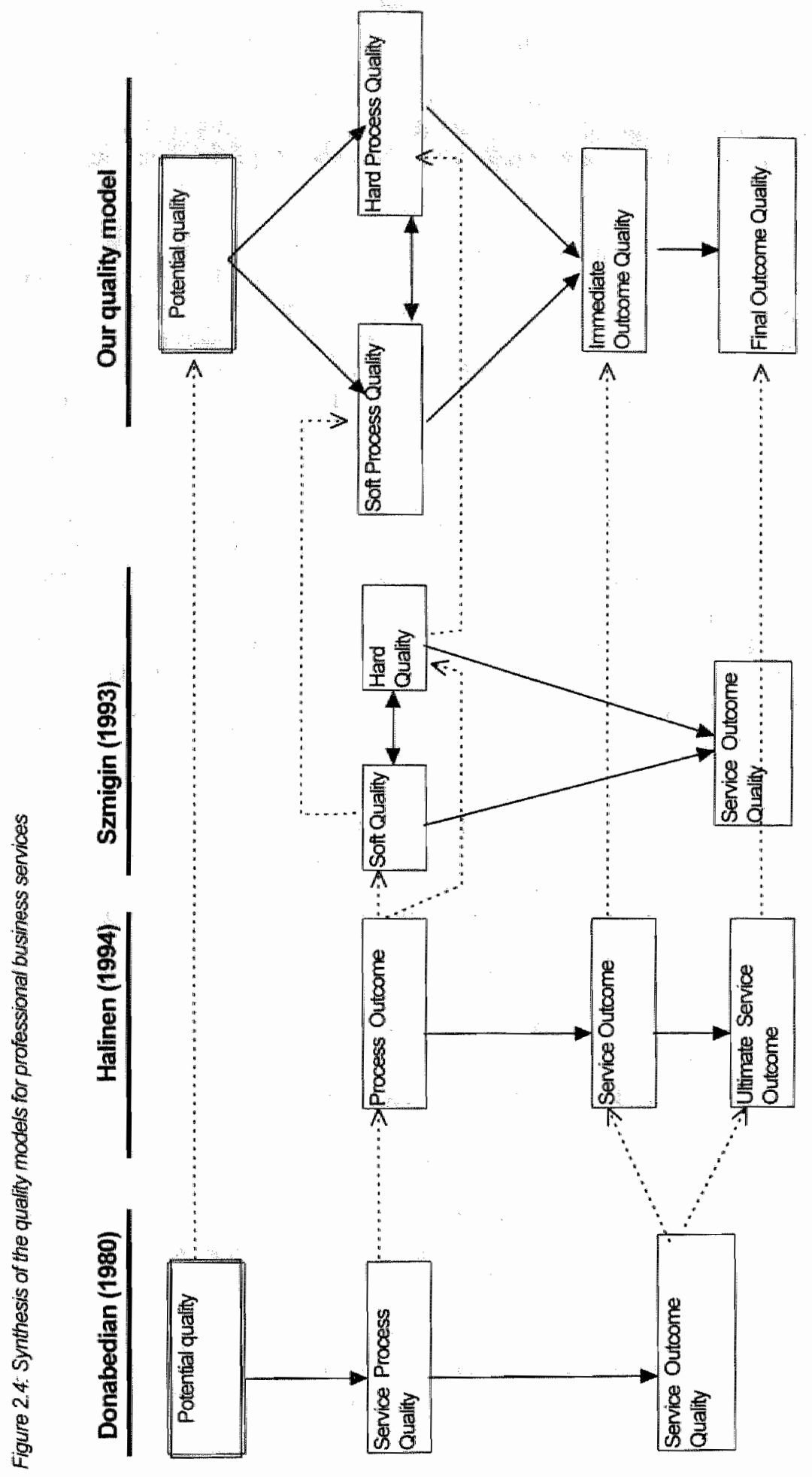




\subsubsection{Empirical evidence}

A few empirical studies have been conducted that investigate service quality perception of professional business services from a customer's perspective. Some studies were qualitative and exploratory in nature and tried to identify the service aspects customers use in their quality assessment of professional business services. The few quantitative studies used the ten or five SERVQUAL dimensions of Parasuraman et al. (1985) and adapted them to the industry studied to measure professional business service quality. In tables 2.4 and 2.5 these qualitative and quantitative studies are summarised.

Because the studies were conducted in different professional business service industries, authors use different terminology for their findings about customers' service quality perception. This makes it difficult to compare the findings of the studies directly. The quantitative studies all used the SERVQUAL scale (either the five or ten dimensions). Therefore, the empirical studies will be discussed in SERVQUAL-terminology. The findings of these studies will then be used to explore the feasibility and interpretation of the theoretically derived five quality determinants of professional business services proposed in the previous section.

As described earlier, Parasuraman et al. (1985) found ten dimensions of service quality that customers use in their quality assessment of services. These ten dimensions were found from interviews in different service industries and it is assumed that these dimensions are generally applicable for different service industries. From the quantitative studies with these ten dimensions, conducted mainly in consumer service industries, they found that some of these dimensions are overlapping and they reduced the ten dimensions to five quality dimensions (Zeithaml et al. 1988). In terms of the super-ordinate service process versus service outcome quality dimensions, they classified four of the dimensions as belonging to customers' evaluation of the service process, and only one as belonging to their evaluation of the service outcome(see table 2.2). We will use this SERVQUAL terminology to discuss the findings from the empirical studies in the professional business senvice industries.

Table 2.2: Classifications of SERVQUAL dimensions

\begin{tabular}{|c|c|c|}
\hline 10 original dimensions & Raduced to 5 dimensions & Categorised into 2 overall dimensions \\
\hline 1. Tangibles & 1. Tangibles & \\
\hline 2. Responsiveness & 2. Responsiveness & \\
\hline $\begin{array}{l}\text { 3. Competence } \\
\text { 4. Courtesy } \\
\text { 5. Credibility } \\
\text { 6. Security }\end{array}$ & 3. Assurance & 1. Service Process Quality \\
\hline $\begin{array}{l}\text { 7. Accessibility } \\
\text { 8. Communication } \\
\text { 9. Understanding customer }\end{array}$ & 4. Empathy & \\
\hline 10. Reliability & 5. Reliability & 2. Service Outcome Quality \\
\hline
\end{tabular}

* Categorisation made by the authors (Zeithaml et al. 1988) 
Because the five quality dimensions of the SERVQUAL model are frequently used in the quantitative studies, we will structure the discussion of their findings around these five SERVQUAL dimensions, and categorise the findings from other studies into these five. Then the additional findings that can not be categorised in these five dimensions will be discussed.

\section{SERVQUAL dimensions}

- Tangibles : Physical facilities, equipment, and appearance of personnel.

- In the qualitative studies, summarised in table 24 , no findings were reported on customers mentioning tangibles as an important aspect in their quality perception of professional business services. The quantitative studies in the professional business service industries, in table 2.5 , show that the tangibles dimension was found as a separate quality dimension, but in most studies it was not considered an important quality determinant. The study by Tzokas et all. (1994), however, reported that the availability of up-to-dlate equipment was important to customers of business communication services.

- Responsiveness: Willingness to help customers and to provide prompt service.

- The qualitative studies report findings that resemble the responsiveness dimension as defined by Parasuraman et al. (1985) Clients indicated that for their quality perception the responsiveness and accessibility of the provider (Teas 1988), the active style of the employees, and the extra time and effort they devote to the customer (Halinen 1994) are important. The quantitative studies found the responsiveness dimension as a separate quality dimension, which was found to be an important quality dimension in most of the studies (Bojanic 1991, Freeman \& Dart 1993, Moore 1994).

- Assurance: knowledge and courtesy of employees and their ability to inspire confidence.

Of the original sub-dimensions reflecting this quality dimension (competence, credibility, courtesy, security) especially competence and credibility were mentioned by clients as important quality aspects in the qualitative studies (Day \& Barksdale, 1992, LaPierre et al. 1994, 1995). In the quantitative studies the security (Moore 1994), knowledge at service provider (Bojanic 1991), the assurance, the professionalism (Freeman \& Dart 1993) and ability (Dassen 1995) were found as separate quality dimensions, reflecting mainly the competence of the service provider. These were found to be important quality determinants.

- Empathy" the caring and individualised attention the firm provides to its customers.

All three sub-dimensions reflecting this quality dimension (accessibility, communication, understanding customer) were mentioned by the clients as important quality aspects in all the qualitative studies (see table 2.4). Also in the quantitative studies this dimension was found as a separate quality dimension, which was an important determinant of customers' quality perception (see table 2.5).

- Reliability: ability to perform the promised service dependably and accurately.

From their qualitative interviews in two different countries, LaPierre et al. (1994,1995) found that the reliability dimension consisted of two different quality elements that clients included in their quality assessment: the functional reliability and the technical reliability. Clients were not only concerned that the service provider ultimately delivered what was promised (technical reliability) but also that he is reliable during the service production process in keeping to time-schedules and budgets (functional reliability). Also in the other qualitative studies customers explicitly mentioned the contraclual conformance (Day \& Barksdale 1992), and meeting time-tables and 
budgets (Halinen 1994) as service quality determinants. The technical reliability dimension was also found to be part of their quality judgement by evaluating the performance as such (Day \& Barksdale 1992) or the service outcome (Halinen 1994). Halinen (1994) also found a further distinction within this technical reliability for advertising services as explained in section 2.6 .3 . Customers not only evaluate the immediate service outcome (the campaign) but also the final service outcome (the effects of the campaign). The quantitative studies did not find the reliability as a separate quality dimension in their data. Only the studies by Freeman \& Dart (1993), and Dassen (1995), who added 'technical quality' as a separate dimension to the SERVQUAL scale, found it as a separate and important quality deteminant for CPA services. In the study by Freeman \& Dart it formed a quality dimension together with the responsiveness items. They called this dimension 'Timeliness', which refers more to the functional reliability as defined by LaPierre et al. (1994, 1995).

\section{Additional findings}

Apart from these SERVQUAL dimensions, some additional quality elements were found in the empirical studies in professional business services.

- The reputation/image of the service provider was found to be an important quality aspect for customers of professional business services in the qualitative study by LaPierre et al. (1994. 1995). Moore (1994) found the same from her quantitative study among customers of industrial transportation services.

- The adaptability and flexibility of the service provider were also found to contribute to customers' quality perception of professional business services in the qualitative study by Teas (1988) and the quantitative study by Moore (1994).

- Recovery was found as a quality element by LaPierre \& Filiatrault (1995) from their interviews with customers of engineering services. Recovery refers to way the service provider handles problems or corrects for errors that were made.

- Fees and Price of the service were found by Halinen (1994) and used by Freeman \& Dart (1993) as part of customers quality perception.

These empirical studies on the quality of professional business services thus in general confirm the existence of the five (and ten) quality dimensions by Parasuraman et al. (1985). Although the tangibles were not found to be very important, they were still confirmed as a separate quality dimension. Of the Assurance dimension, mainly the competence was found to be important for professional business service quality. Especially the Empathy dimension, but also the Responsiveness and Reliability dimensions were confirmed as important quality dimensions for professional business services as well.

However, some adjustments are suggested from these data. Especially the reliability dimension seems to capture customers' evaluation of professional business services insufficiently. Several studies suggest that clients of professional business services include the reliability of the service provider in sticking to time-tables and budgets during the service production process in their quality evaluations, which was called the functional reliability. This aspect is not covered by any of the SERVQUAL dimensions. It is separated from the technical reliability which refers to the providers' reliability in providing what was promised, or stated differently: the outcome of the service. Although this is what is meant by the reliability dimension of the SERVQUAL scale, other authors (Strandvik \& Liljander 1994) also argued that the SERVQUAL instrument falls. short of measuring the outcome quality of services. This probably explains why the quantitative studies in the professional business service industries that used the SERVQUAL scale, did not 
confirm the existence of this dimension, unless they had specifically added it to the instrument. From the qualitative studies it seems that customers do include the service outcome in their quality perceptions. Halinen (1994) even went one step further and found that customers also evaluate the final outcome of the service in their quality perception, although it was not the mast important quality determinant. The implications hereof will be discussed in the next paragraph.

\subsubsection{Comparison to the proposed quality model}

The SERVQUAL instrument thus captures important quality aspects also for professional business services, but the specific characteristics of these services call for an adjustment of the quality model. As a first test of the relevance of our proposed five key-quality determinants for professional business services in section 2.6 .4 , we will now analyse whether the empirical findings, described above, support the structure of this quality model. This will be done by integrating the SERVQUAL dimensions and the additional findings from the empirical studies into our proposed five quality determinants. We propose that customers' quality assessment of professional business services is based on their assessment of the providers" potential, the hard and soft process quality, and the immediate and final outcome quality.

The tangibles, responsiveness, assurance and empathy dimensions of the SERVQUAL model were all categorised as service process dimensions by Zeithaml et al. (1988). If we take a look at the tangibles, i.e., the available equipment and facilities, we can see that it refers to stable characteristics of the service provider. It is not likely that the available equipment and facilities change for each service process, only the use of them will differ. Therefore, we argue that it is an element that reflects the providers ${ }^{\prime}$ potential quality, rather than the quality of the process. The available equipment and facilities signal to the client what the provider is potentially capable of doing for the client.

The responsiveness, willingness to help and provide prompt service, is something that clients can indeed only assess during the service production process. It refers to the way in which the provider produces the core service, which in our definition is part of the hard process quality.

The assurance dimension consists of many different elements: competence, courtesy, credibility, security. From the empiricall studies it seemed that especially competence is an important quality determinant for professional business services. The actual competence of the service providers is exthibited during the senvice process, by the way in which the service is produced. Because the clients participate during the service production process, they can perceive the competency and professionalism in executing the assignment. The competence thus refers to the way in which the core service is produced, which is part of the hard process quality. However, clients can also perceive the competence that is potentially available at the service provider. The qualifications of the personnel inspire confidence and credibility of the service provider, even when clients do not have experienced the available expertise during the production process. This dimension thus also partly reflects the potential quality of the service provider.

The empathy dimension, the caring and individualised attention the firm provides its customers, was found to be an important quality aspect also for professional services. The empathy of the service provider can only be experienced by the customer during the service production process. It refers to the way in which the client is treated and interacted with during the service 
production process, rather than to the professionalism and the way in which the service is provided. This thus reflects the soft process quality.

The reliability dimension was categonised by Zeithaml et al.(1988) as the only dimension that reflects customers' evaluation of the outcome of the service. As discussed earlier, the empirical studies indicated that this dimension can be divided into two kinds of reliability: the technical reliability and the functional reliability, which are both important quality determinants for customers of professional business services. The technical reliability, whether the provider delivers what was promised, reflects the evaluation of the service outcome. More specifically, it refers to the evaluation of what the customer actually gets from the service production process, i.e. whether the produced service is in line with what the customer has asked for. This is the solution that is provided as a result of the service production process and can be classified as immediate outcome quality. However, the provider not only promises to produce a solution to the client-specific problem, this solution is also expected to actually solve the customer's problem. The technical reliability thus also refers to the degree to which the delivered solution indeed solved the customers' problem, which is the final outcome quality. The functional reliability, refers to the reliability in keeping promises that are made about the service production process itself, which was found to be an important additional quality aspect for customers of professional business services. Whether the service provider sticks to the deadlines, budgets and any other agreements that are made, can clearly only be experienced during the service production process. Since this is part of the way in which the service is actually produced it reflects part of the hard process quality, in the way we defined it.

The additional findings from the empirical studies were not yet classified into process or outcome dimensions. Therefore, we will now explore whether and how they fit into our proposed quality determinants.

The reputation/image of the service provider was found to be an additional quality aspect for customers of professional business services. The reputation of a compary is part of its structural characteristics. Although it does not add to the service providers' potential as such -the reputation will hardly contribute to the production of the service-, for customers it is an important signal of the providers' potential. Therefore we argue that the reputation will be part of customers' potential quality evaluation.

The adaptability and flexibility of the service provider also seemed an important aspect for customers' quality perception of professional business services. The degree to which the service provider can easily adapt to circumstances or clients' wishes can only be experienced during the service production process. Because it refers to the way in which the service is actually produced it is part of customers' hard process quality.

The 'recovery', that was mentioned as a quality aspect in the empirical studies, refers to the way in which the service provider recovers errors or incidents of bad service. This clearly is a service process element, which deals with the way the service is performed. Therefore is should be part of customers' hard process quality assessment. 
Some of the studies added price or fees as a quality aspect. There is much debate in literature whether this is indeed included in customers' quallity assessments. It is generally assumed that quality only refers to the 'get' elements (Zeithaml 1988, Liljander \& Strandivik 1994) of a service, regardless of what the customers had to 'give' to get it. Halinen (1994) categorised it as an immediate service outcome element; because the actual price is usually not known until after the process is completed. We, however, argue against including costs as part of service quality.

In the table below we summarise the discussion above, and present how the SERVQUAL dimensions and additional findings from the empirical studies can be categorised into the five quality determinants we proposed for professional business services.

Table 2.3: Classification of empirical findings into the proposed quality model.

\begin{tabular}{|c|c|c|}
\hline $\begin{array}{l}\text { Proposed quality } \\
\text { deteminants }\end{array}$ & 10 dimensions PZB (SERVQUAL) & $\begin{array}{l}\text { Additional findings empirical } \\
\text { studies (see tables } 2.4 \text { and } 2.5 \text { ) }\end{array}$ \\
\hline Potential Quality & $\begin{array}{l}\text { Competence } \\
\text { Tangibles } \\
\text { Credibility }\end{array}$ & Reputation/image \\
\hline Soft Process Quality & $\begin{array}{l}\text { Empatty (Courtesy, Accessibility, Credibility, } \\
\text { Communication, Understanding customer) }\end{array}$ & \\
\hline Hard Process Quality & $\begin{array}{l}\text { Reliability (functional) } \\
\text { Responsiveness } \\
\text { Competence }\end{array}$ & $\begin{array}{l}\text { Functionall reliability } \\
\text { Adaptation and Flexibility } \\
\text { Recovery }\end{array}$ \\
\hline Immediate Outcome Quality & Reliability (technical) & $\begin{array}{l}\text { Technical reliability } \\
\text { Performance/outcome }\end{array}$ \\
\hline Final Outcome Quality & Reliability (technical) & ultimate outcame \\
\hline
\end{tabular}

The findings of the empirical studies mentioned above can thus all be categorised into the proposed five quality determinants, including the additional quality elements that were not captured by the SERVQUAL scale. This indicates that these five determinants are indeed related to customers' quality perception, as we proposed. 
Table 2.4: Qualtative studies of professional business service quality

\begin{tabular}{|c|c|c|c|}
\hline Author & $\begin{array}{l}\text { Studied } \\
\text { industry }\end{array}$ & Research method & Service quality findings \\
\hline Teas 1988 & $\begin{array}{l}\text { Financial } \\
\text { Business } \\
\text { Services }\end{array}$ & $\begin{array}{l}\text { Open ended interviews with } \\
\text { clients about service quality }\end{array}$ & $\begin{array}{l}\text { Product and price related items not important } \\
\text { Functional issues are important: } \\
\text { - Responsiveness \& accessibility } \\
\text { - Familiarity \& sensitivity } \\
\text { - Flexibility } \\
\text { - Infornation source } \\
\text { - Stable linkage } \\
\text { - Evidence that bank values customer }\end{array}$ \\
\hline $\begin{array}{l}\text { Day \& } \\
\text { Barksdale } \\
1992\end{array}$ & $\begin{array}{l}\text { Architectural and } \\
\text { Engineering } \\
\text { services }\end{array}$ & $\begin{array}{l}\text { Client interviews: Open } \\
\text { ended questions regarding } \\
\text { performance evaluation cri- } \\
\text { teria and service satisfaction. }\end{array}$ & $\begin{array}{l}\text { Performance quality evaluation consists of: } \\
\text { Expertise, competence } \\
\text { Undlerstanding clients needs } \\
\text { Interactions with client } \\
\text { - Contractual conformance } \\
\text { Performance }\end{array}$ \\
\hline $\begin{array}{l}\text { LaPierre et al. } \\
1984_{1} 1995\end{array}$ & $\begin{array}{l}\text { Industrial } \\
\text { engineering } \\
\text { services in } \\
\text { France \& } \\
\text { Canada }\end{array}$ & $\begin{array}{l}\text { Client interviews with apen } \\
\text { ended questions regarding } \\
\text { their quality perception }\end{array}$ & $\begin{array}{l}\text { Most important quality aspects: } \\
\text { - Technical quality (= technical reliability) } \\
\text { Respect of schedule (= functional reliability) } \\
\text { - Respect of budget (= functional reliability) } \\
\text { - Communications } \\
\text { Reputation } \\
\text { - Confidence \& Credibility } \\
\text { Recovery }\end{array}$ \\
\hline Halinen 1994 & $\begin{array}{l}\text { Advertising } \\
\text { services }\end{array}$ & $\begin{array}{l}\text { Longitudinal study, in depth } \\
\text { interviews with clients } \\
\text { regarding service evaluations }\end{array}$ & $\begin{array}{l}\text { Service performance is evaluated on: } \\
\text { Process outcome - } \rightarrow \text { important } \\
\text { (Open communication, Active style, Agreement } \\
\text { goals, Clear responsibilities, Meeting time-tables, } \\
\text { Meeting budgets, Extra time \& effort) } \\
\text { Senice outcome (Creative output, Reception in refe- } \\
\text { rence groups, Final price) } \\
\text { Ultimate outcome least important }\end{array}$ \\
\hline
\end{tabular}


Table 25: Quantitative studies service qualty of professional business services.

\begin{tabular}{|c|c|c|c|}
\hline Author & $\begin{array}{l}\text { Studied } \\
\text { industary }\end{array}$ & $\begin{array}{l}\text { Service Quality } \\
\text { measurement method }\end{array}$ & Service quality findings \\
\hline $\begin{array}{l}\text { Moore } \\
1994\end{array}$ & $\begin{array}{l}\text { lindustrial } \\
\text { transpontation } \\
\text { services }\end{array}$ & 10 dimensions of SERVQUAL & $\begin{array}{l}\text { Factor anallysis } 4 \text { factors } \\
\text { Customer Response } \\
\text { Adaptability } \\
\text { - Inage } \\
\text { Security }\end{array}$ \\
\hline $\begin{array}{l}\text { Morgan } \\
1991\end{array}$ & $\begin{array}{l}\text { Legal } \\
\text { Services }\end{array}$ & 9 self constructed items, $\alpha=84$ & $\begin{array}{l}\text { Confidence \& trust and personal attention } \\
\text { influence quality perception }\end{array}$ \\
\hline $\begin{array}{l}\text { Bojanic } \\
1991\end{array}$ & $\begin{array}{l}\text { CPA } \\
\text { services }\end{array}$ & $\begin{array}{l}5 \text { SERVQUAL dimensions, } 12 \\
\text { items }\end{array}$ & $\begin{array}{l}\text { Most important quality dimensions: } \\
\text { Responsiveness } \\
\text { Employee knowledge (assurance) } \\
\text { Partner knowtedge (assurance) } \\
\text { Personal attention (empattry) } \\
\text { Tangibles not important }\end{array}$ \\
\hline $\begin{array}{l}\text { Freeman \& } \\
\text { Dart } 1993\end{array}$ & $\begin{array}{l}\text { CPA } \\
\text { services } \\
\vdots\end{array}$ & $\begin{array}{l}5 \text { SERVQUAL dimensions }+2 \\
\text { added dimensions: } \\
\text { Value of service } \\
\text { Approach by accountant to } \\
\text { perform job } \\
13 \text { items added }\end{array}$ & $\begin{array}{l}\text { Factor analysis: } 7 \text { quality factors } \\
\text { Timeliness (Responsiveness\&Reliability) } \rightarrow \\
\text { Assurance ->important } \\
\text { Exceptions } \rightarrow \text { important } \\
\text { Fees related } \\
\text { Professionalism } \\
\text { Empathy } \\
\text { Tangibles ->not important }\end{array}$ \\
\hline $\begin{array}{l}\text { Dassen } \\
1095\end{array}$ & CPA services & $\begin{array}{l}5 \text { SERVQUAL dimensions } \\
+ \text { an additional 'techinical quality' } \\
\text { dimension }\end{array}$ & $\begin{array}{l}\text { Factor analysis } 8 \text { quality faciors: } \\
\text {. Empathy } \rightarrow \text { important } \\
\text { Detection Ability } \rightarrow \text { important } \\
\text { Partner in Business (assurance) } \rightarrow \text { important } \\
\text { Communication (empathy) - > important } \\
\text { Straightfonwardness (responsiveness) } \\
\text { Whistle Blowing (extra services) } \\
\text { Appearance (tangibles) } \\
\text { Quasi-Professional (tangibles) }\end{array}$ \\
\hline $\begin{array}{l}\text { Tzokas et } \\
\text { al. } 1994\end{array}$ & $\begin{array}{l}\text { Business } \\
\text { communil- } \\
\text { cation } \\
\text { services }\end{array}$ & 5 SERVQUAL dimensions & $\begin{array}{l}\text { Servqual dimensions not supported. Important quality } \\
\text { items: } \\
\text { Up-to-date equipment } \\
\text { Telling when service will be performed } \\
\text {. Customers best interest at heart }\end{array}$ \\
\hline
\end{tabular}




\subsection{Summary \& Conclusions}

In this chapter the customer-based quality conception of service quality is discussed, which is traditionally used in the service marketing literature. Service quality is delivered only when the customer perceives it as such. Customer-based quality standards are thus central to the quality delivery. This service quality concept, is defined as the customers' overall assessment of the excellence or superiority of a service provider, based on an accumulated perception of all previous experiences with the service provider. The extensive body of research in this area shows that this quality concept is strongly related to the attraction of new customers as well as the retention and loyalty of existing customers, the effects of which contribute to the profitability of service companies.

Although research interest in this area started from the early 1980 's, so far surprisingly little research has been conducted on service quality perception in the professional business service industries. This is probably due to the fact that in these industries the quality concept is traditionally approached from industry norms and professional standards, due to the market situation and the specific service characteristics. However, now that the market situation is changing dramatically, a more customer-oriented approach is called for, and the industry is becoming increasingly interested in a customer-based service quality concept. The academic interest followed this development, and lately studies have been conducted regarding this concept in professional business service industries. It is assumed that performing services that meet and preferably exceed customers' expectations will have the same positive consequences for professional business service providers as have been found for the more traditional (consumer) services, i.e. generation of word-of-mouth advertising and the enhancement of the loyalty and profitability of existing customers.

Therefore, it is important to understand how customers assess the quality of professional business services, and on which service elements this assessment is based. Some of the conceptual quality models were reviewed that identify key service dimensions in customers" quality assessment of traditional (consumer) services. These models are used in the few empirical studies regarding customers' quality perception of professional business services. However, because professional business services share some distinct characteristics that differentiate them from the more traditional (consumer) services, it is highly likely that the traditional service quality models should be adjusted to the specifics of these services. Therefore we integrated the few quality models that address the specifics of professional (business) services into one integrated quality model of customers" quality perception of professional business services. This model is very similar to the basic ideas proposed in the traditional quality models with two adjustments for customers' quality assessment of professional business services.

As was found in the more traditional (consumer) service industries, we propose that customers' quality perception of professional business is based on an evaluation of the service (production) process, the service outcome and on stable characteristics of the service provider. Adjustments to this basic model regard the specifics of the service production process of professional business services, and the specifics of the service outcome of professional business services. Regarding the service process, we propose that customers make an additional distinction within their evaluation of the technical process by which the service is produced, and their evaluation of the soft process (i.e. interpersonal interactions) during the service production. Regarding the 
service outcome, we propose that customers perceive and evaluate the immediate outcome of the service production process differently from the final results of this outcome. Empirical evidence from studies conducted in different professional service industries, largely supported these proposed adjustments to the traditional quality models, and the quality model seems to capture the quality elements customers used in the reviewed studies rather well.

We thus propose that customers' quality perception of professional business services is based on five key quality determinants, which can be summarised as follows:

1. Potential Quality: the customers" evaluation of the available human, material and financial potential at the service provider to perform its services;

2. Soft Process Quality: the customers' evaluation of the interactions with and treatment of the customer during the service production process;

3. Hard Process Quality: the customer's evaluation of the (technical) way in which the coreservice is produced by the service provider;

4. Immediate Outcome Quality: the customers' evaluation of the direct outcome of the service production process; and,

5. Final Outcome Quality: the customers' evaluation of the final results or consequences of the (implemented) service outcome

Customers overall service quality perception of professional business services is based on their evaluation of these five quality determinants. The quality determinants should be regarded as five overall dimensions of professional business services, which each encompass several service elements (see table 2.3).

In the empirical study we will investigate this proposed structure of customers" quality perception within one professional business service industry and explore whether this quality model is supported. However, the lack of research on a customer-based quality concept for professional business services not only left a gap in understanding the structure of customers' quality assessment, but also regarding the importance of this quality concept for professional business service companies. One of the alleged effects of using a customer-based quality concept is its contribution to customer loyalty. In our study we will therefore not only address the structure of customers' quality assessment but also explore whether and how it is related to the long-term retention of existing customers. In the next chapter this loyalty concept will be elaborated upon for (professional) business (service) relationships. 


\section{Chapter 3: Relationship Maintenance}

"Do not aduttery conminit, advantage rarely comes of it"

A.H. Clough, "The latest decalogue'

\subsection{Introduction}

In this chapter the second research question will be addressed: does customers' quality perception contribute to the maintenance of long-term customer relationships? What is its importance next to other antecedents for relationship maintenance?

This question was raised because in the services marketing literature it is now assumed that service quality enhances the building and strengthening of long-term customer relationships. Authors argued that also for professional business services the customer-based service quality concept will have a positive influence on the maintenance of long-term customer relationships (Bojanic 1991, Patterson 1995). The relationship paradigm has, however, only recently entered the services marketing literature (Grönroos 1993). The assumption that service quality leads to customer loyalty, has so far been supported by the many studies that found a positive effect of customers' service quality perception on their repurchase intentions (for an overview see Zeithaml et al. 1996). Repurchase intentions reflect customers' intentions for a subsequent service transaction(s). Relationships between business partners, however, are more complex than just buying and selling transactions (Wilson et al. 1995). From a relationship perspective, we are interested in the contribution of service quality to long-term customer relationships. The business marketing literature has become interested in longterm relationships since the early 1980 's. Therefore, this literature will be used to describe what long-term (business) relationships are and to understand the dynamics of long-term business relationships and the factors that contribute to its development and maintenance.

In section 3.2 a general description of long-term relationships will be given and their importance for the marketing of business firms. In section 3.3 the development of long-term relationships will be described from a dynamic perspective. Literature will be reviewed that describes the development process of long-term relationships. In section 3.4 the concept of relationship maintenance will be scrutinised and the variables that define this concept the best. In section 3.5 literature will be reviewed that identifies the antecedents to relationship maintenance. This review will be done first for business relationships in general. Then long-term relationships in professional business service markets will be discussed and the antecedents found for the maintenance of long-term relationships in these industries. These findings will be compared and integrated into propositions regarding the antecedents that are important for the maintenance of professional business service relationships. 


\subsection{Long-term relationships}

Keeping existing customers and establishing long-term customer relationships has now become the new marketing paradigm and its importance is stressed for almost any industry. Emphasis has shifted from offensive marketing (conquering new customers) to defensive marketing (protecting the existing customers), not so much out of defeat, but because it is realised that maintaining existing customers will ultimately be more profitable than constant 'combat'. Research showed that for some industries an increased customer retention rate of $5 \%$ can have a profit impact of 20 to $125 \%$ (see e.g. Reichheld \& Sasser 1990, and Buchanan 1990).

In their comprehensive overview of the shift in marketing paradigm from transactional marketing to relationship marketing, Sheth and Parvatiyar (1995) conclude that "the purpose of relationship marketing is, therefore, to enhance marketing productivity by achieving efficiency and effectiveness" (p.400). The retention of existing customers and the sharing of resources with them will reduce operating costs of the marketer, and thus increase efficiency. Effectiveness will be improved by the involvement of customers in the development of marketing programs, which facilitates the future marketing efforts of the company. Furthermore, by customisation the needs of each customer can be addressed better, increasing the effectiveness of the marketing actions. It is argued that with long-term customer relationships higher quality can be delivered at lower transaction costs (Heide \& John 1992). Both parties thus benefit from a relationship.

For service relationships it is also argued that both parties will benefit from long-term customer relationships. The interactive nature of services provides unique opportunities to create customer relationships (Berry 1983). For customers, relationships can reduce the uncertainty and perceived risk incurred by the purchase of the intangible and expenience-based services. Especially when services are complex, periodically delivered, vary in quality, and require customer involvement, customers desire continuity and customised service delivery. Professional business services have these characteristics, and relationships will make the provider more knowledgeable about the customers" needs, by which the service delivery can be customised more effectively. Also social benefits can be gained for the customers by the individualised treatment they can get in relationships (Berry 1995).

Service providers can also benefit from long-term customer relationships. Loyal service customers generate more revenue (Reichheld \& Sasser 1990) for a longer period of time, and the costs of maintaining existing customers are usually lower than of acquiring new customers (Berry 1995). Szmigin (1993) summarises the benefits particularly for professional business service providers. She argues that long-term customer relationships provide barriers against competition, decrease price competition, and create an unwillingness by the customer to switch suppliers due to the investments in the relationship. Furthermore, a continuous relationship provides a secured flow of future benefits and profits, in which more efficient use of assets can be made because of the familiarity with the client. The benefits of each customer relationship should, of course, exceed the costs invested in terms of time, money, effort and people.

Long-term relationships are thus potentially beneficial for both parties. Clients can get better service at lower transaction costs, due to more customised services and savings an search and negotiating costs with new providers. Providers can use their assets more efficiently and effectively in satisfying customer needs and simultaneously save on the costs of constant combat for new customers. 
However, even though relationships may be potentially beneficial, not all relationships are long: tem. In human relationships, people also generally recognise that long-tem relationships are in principle a better means to achieve the individual partners' goals in life, but not all human relationships are long-term. First of all, there is the group of convinced bachelors who do not want to attach themselves to one partner, even if they do recognise the potential benefits of a long-term relationship in principle. They want to get the best out of each temporary partner and then move on to the next. Secondly, even if both partners want to have a long-term relationship. this is no guarantee that they will stay together in the long-run. Relationships are not stationary, many processes occur within a relationship that will determine its long-tem maintenance.

Likewise in business markets, relationships can be described on a continulum from transactional relationships to co-operative relationships, also referred to as relational exchange relationships (Jackson 1985, Dmyer et al. 1987, Schijns 1993). In pure transactional relationships the buyer primarily buys on price, uses multiple sources of supply and tends to switch suppliers frequently over time. These are the convinced bachelors, who do not want to attach themselves to one party. Relational exchange relationships, on the other hand, emerge when the buyer and supplier develop a relationship with a more long-term orientation. Continuity is a key element of relational exchange, which does not necessarily mean that the exchange events are frequent or repeated. Transactions may occur rarely or irregularly, and the relationship might be domant for a period of time. As long as the parties have bilateral expectations of future exchange, the relationship should be considered as relationall (Halinen 1994). Business relationships are evolutionary in nature, and starting a relationship will not guarantee its maintenance. From a micro-perspective, relationships can be reglarded as a sequence of discrete interactions and transactions, or in services: a sequence of service encounters. As a whole these interactions are part of a relational process that evolves over time. From this relational perspective, a relationship starts to develop when the relation goes beyond discrete transactions "reflecting an ongoing process" (Dwyer et al. 1987).

\subsection{Relationship Models}

In this section the development process of business relationships will be described. The dynamic relationship process has been modelled in two ways. First, there are the relationships stage models, in which relationships are regarded as life-cycles, i.e. relationships develop progressively through different stages over time. Second, there are the relationship process models, in which the development of a relationship is described by the casual relations between relational variables. All models are necessarily simplifications of reality, and try to generalise the patterns of long-term relationships that are essentially unique processes. Basically every relationship can intensify, decline or remain stationary at any point in time (Anderson 1995). However, for parties to become truly loyal to each other, a general development pattern can be detected that is generalisable to different relationships. How fast this pattern is gone through and whether or not the relation actually becomes long-term, is relationship specific. Sections 3.3.1-3.3.3 give an overview of the stage models developed for business relationships and business service relationships. In section 3.3 .4 the dynamic relationship process will be described using one of the few relationship process models that identify the causal processes that underlie the development of a long-term business relationship. 


\subsubsection{Generic relationship stage models}

Several authors designed models that describe the process of business relationship development in stages (see table 3.1a). These models apply to the development of long-term cooperative relationships. The stages identified by different authors will be shortly described for business relationships in generall. The information from these models will be integrated in paragraph 3.3.3 with the information from the models defined for professional business sevices relationships.

Table 3 , 1a: Generic stage models of business relationships

\begin{tabular}{|c|c|c|c|c|}
\hline$\therefore$ & Fond 1980 & Dwyer et al. (1987) & Wilson 1995 & Ford \& Rosson 1982 \\
\hline $\begin{array}{l}\text { Find of model: } \\
\text { Stages }\end{array}$ & $\begin{array}{l}\text { Conceptual business } \\
\text { relations }\end{array}$ & $\begin{array}{l}\text { Conceplual business } \\
\text { relations }\end{array}$ & Cronceptual business relations & $\begin{array}{l}\text { Empirical business } \\
\text { relations }\end{array}$ \\
\hline 1. Selection & $\begin{array}{l}\text { 1. Premelationship } \\
\text { 2. Early stage }\end{array}$ & 1. Awareness & 1. Search \& Selection & 1. New \\
\hline 2. Development & 3. Development stage & 2. Exploration & $\begin{array}{l}\text { 2. Defining Purpose } \\
\text { 3. Boundary Definition } \\
\text { 4. Creating relationship value }\end{array}$ & $\begin{array}{l}\text { 2a. Growing } \\
\text { 2b. Troubled } \\
\text { 2c. Static }\end{array}$ \\
\hline $\begin{array}{l}\text { 3. Maintenance } \\
\text { 4. Temination }\end{array}$ & $\begin{array}{l}\text { 4. Long-tem stage } \\
\text { 5. Finall stage }\end{array}$ & $\begin{array}{l}\text { 4. Commitment } \\
\text { 5. Dissolultion/inertia }\end{array}$ & 5. Relationship Maintenance & 3. Inert \\
\hline
\end{tabular}

- Ford (1980) developed a conceptual stage model that describes the relationship process in five stages. Customer first go through the 'pre-relationship stage', where they recognise a need and develop criteria for a new provider. Then in the 'early stage' potential providers are selected and initial contacts are made, which results in the selection decision of the final provider. Then the relationship starts and the 'development stage' begins. The increasing experience with the provider decreases the uncertainty of what to expect, and the distance between the parties. During the development stage the parties will become closer and make adaptations, which will increase the commitment between the parties. At some point the relationship will reach the "long-term stage", where the parties are committed to each other, ultimately leading to the "final stage' in which the relationship has become institutionalised at both parties and the interactions are routinised.

- Dwyer et al. (1987) also describe the relationship process in five stages and start with a stage before the parties have decided to work together, the 'awareness stage', where the parties are aware of each other's existence. Then the 'exploration stage' begins in which the party is thoroughly explored on his merits. The chances of break-off of the relationship is the highest in this stage. If the party is evaluated as attractive, the relationship will be expanded in the 'expansion stage', and a power base and norms will be created. The interdependency between the parties will be increased during this stage and the relationship will develop into the 'commitment stage' in which the parties are truly committed to the relationship, which they define as the highest stage of relational bonding. After the commitment stage the relationship will either 'dissolve' or will continue out of 'inertia', after which it will dissolve at some point.

- Based on a literature review Wilson (1995) identifies also five stages in the relationship process. Unlike Ford, he identifies only one stage before the parties decide to work together, 
which he calls the 'search and selection' stage. After the selection decision, the parties will negotiate the relationship and 'define the purpose' of the relationship. Then the 'boundary definition' of the relationship begins after which the 'relationship value will be created. Only if this is achieved, the 'maintenance stage' is reached, which makes the relationship really longterm. Based on a literature review he identifies the crucial relationship variables that become salient in certain stages and become latent in subsequent stages of the relationship.

- Ford \& Rosson (1982) described stages based on empirical data in industrial relationships. They identify three basic stages, which can take different forms. They start from the point where the partner is selected, which marks the 'new' relationship stage. And they argue that every relationship ends in the 'inert' stage, where the parties stay together without questioning the relationship. Between the 'new' and 'inert' stages the relationship will either 'grow', become 'troubled' or be 'static' in nature. Any of these three relationship forms might occur, and the relationship can switch from one form to the other, ultimately ending in an inert stage. The forms are defined in terms of the intensity of business exchange and the stakes the parties have in the relationship.

\subsubsection{Stage models of professional business service relationships}

Also for the business services sector relationship stage models have been identified that describe the development of co-operative relationships between clients and business service providers (see table $3.1 \mathrm{~b}$ ).

Yorke (1990) and Sharma (1994) developed models for customer relationships of professional business service providers in general, based on qualitative interviews in different industries.

- Yorke identifies five relationship stages. Before the decision to work together, the parties will first be "ignorant" of the other's existence and will then become 'interested" in the other as a potential provider. After the selection decision, the relationship will be 'initiated' and the first service exchanges will take place. If these are considered satisfactory, the 'involvement' stage is reached. The parties will continuously adapt to changing needs, and trust will be developed. Yorke stresses that because of the continuously changing environment and needs and activities of the individual parties, relationships will not end in inertia anymore as some authors assume (see e.g. Ford \& Rosson 1982), a state in which the relationship is not questioned anymore or evaluated by its merits, but taken for granted. Instead, if the parties become involved enough, the relationship will ultimately reach the "integration' stage, in which the service provider is integrated into the company's business.

- Sharma describes four stages for long-term professional business service relationships. In the 'pre-relationship' stage the parties become aware of each other and the selection decision is made. Then the 'test stage' begins, in which clients will first start to negotiate and buy only pieces of a service from the new supplier, to test them before the client decides to continue the relationship. The provider will then be evaluated in the 'evaluation stage'. If the partner is evaluated as satisfactory the 'maturity stage' is reached. The main process of the relationship is described as the development of legitimacy and credibility of the service provider, closely related to increasing trust and dependability, and a decrease in distance. The buyer will show commitment in return.

Wackman et al. (1987) and Halinen (1994) proposed their models for advertising agency-client relationships.

- Wackman et al. (1987) describe four relationship stages through which the relationship is deepened and the amount of exchange increased. After a 'pre-relationship' stage in which the service provider is selected, the relationship will evolve in the "development stage'. After that, the 'maintenance stage' begins, in which the relationship will be maintained for the long-term. 
And then at some point the 'temination stage' begins, which is a process in itself, not a sudden decision.

- Halinen (1994) proposes five relationship stages based on a qualitative research in the advertising services industry. She also identifies a 'pre-relationship' stage in which a certain amount of attraction is established between the parties and the client makes the selection decision. Then the initial phase' begins in which the first exchanges are made and the actual attractiveness of the service provider can be evaluated. After this, the relationship can take either of three forms, it can 'grow', become "troubled" or 'constant'. There is no specific order and the relationship can go back and forth between these three, ultimately leading to a "decline" phase, after which the 'termination' follows.

Table 3: 1b: Stage models of business senvice relationships

\begin{tabular}{|c|c|c|c|c|}
\hline & Yorke 1990 & Sharma 1994 & Wackman et all. 1987 & Halinen 1994 \\
\hline $\begin{array}{l}\text { Kind of model: } \\
\text { Stages }\end{array}$ & $\begin{array}{l}\text { Business service } \\
\text { relations }\end{array}$ & $\begin{array}{l}\text { Business service } \\
\text { relations }\end{array}$ & $\begin{array}{l}\text { Advertising Agency - } \\
\text { client relations }\end{array}$ & $\begin{array}{l}\text { Advertising Agency - client } \\
\text { relations }\end{array}$ \\
\hline 1. Selection & $\begin{array}{l}\text { 1. Ignorance } \\
\text { 2. Interest }\end{array}$ & 1. Pre-purchase & 4. Pre-relationship & 1. Pre-relationship phase \\
\hline 2. Development & 3. Initiation & $\begin{array}{l}\text { 2. Test stage } \\
\text { 3. Evaluation }\end{array}$ & 2. Development & 2. Initial phase \\
\hline $\begin{array}{l}\text { 3. Maintenance } \\
\text { 4. Temination }\end{array}$ & $\begin{array}{l}\text { 4. Involvement } \\
\text { 5. Integration }\end{array}$ & 4. Maturity & 3. Maintenance & $\begin{array}{l}\text { 3a. Growth phase } \\
\text { 3b. Troubled phase } \\
\text { 3c. Constant phase } \\
\text { 4. Decline phase } \\
\text { 5. Termination Phase }\end{array}$ \\
\hline
\end{tabular}

\subsubsection{Synthesis relationship stage models}

Although not all models assume an equal amount of stages and each uses different names, some similarities can be detected in the different stage models. All authors identify one or more stages before the actual start of a relationship, a selection stage, and then all propose an initial stage in which the first exchanges occur and the party is rated on its merits, the development stage. Only after one or more of these initial stages, the relationship will be maintained for the long-term "which will be called the maintenance stage. And finally some authors describe the decline of the relationship, which will be called the termination stage. To describe the processes that will lead to the maintenance of a long-term relationship, the stages defined by the authors will be summarised into these four stages.

\section{1). Selection stage}

This stage represents the process of selecting a partner for a relationship. All the activities and interactions are included that are conducted before the actual relationship has started. Ford (1980) divides this process into two distinct stages. In the first stage the buyer recognises a need and develops criteria that might fulfil this need. In the second stage potential suppliers are selected for further evaluation and initial contacts are made. This division of the selection process in two stages is consistent with the ideas of Spekman (1988) and Möller (1986) who argue that industrial purchases are more and more merited on their long-term competitive gains and quality improvements they can potentially offer. This means that the supplier selection process will be more future oriented towards co-operative relationships, and will intensify into two stages: first the conventional selection process for potential partners, which will then be further exam- 
ined and selected for strategic, lie. long-tem, partnership. Commitment by the supplier, the understanding of buyers" problems and specific demands by the supplier will be important (extra) selection variables in this second stage. These selection stages are characterised by no or little experience between the partners, relatively high distance, and thus overall high uncertainty about future benefits and costs. The interactions in this stage will create expectations regarding future benefits and costs, although assessment of potential rewards is very difficult in the beginning. Reputation for performance and trustworthiness will be used as indicators if there is no experience with the partner (Wilson 1995). Especially for professional services the uncertainty will be very high due to the credence qualities of these services, as we have described earlier. This means that the selection decision will be very risky for a client. Attraction and general feeling of trust in the other partner should be established in this stage before a relationship will start (Halinen 1994).

\section{2). Development stage}

In this stage the selection decision has been made and the two parties start dating. Dwyer et al. (1987) stress the fact that because rewards and costs are so hard to judge before the selection decision, parties will first explore the partner thoroughly, before they expand the relationship. Sharma (1994) indicates that clients of professional services will first start to negotiate and buy only pieces of a service from the new supplier to test them. In this stage the chance of breaking the relationship is the greatest (Dwyer et al. 1987). Levinthal \& Fichman (1988) called this the thoneymoon ${ }^{21}$ period in professional service relationships and found that the chances of relationship dissolution reach a peak. After this stage the likelihood of staying together increases over time.

The interactions and exchanges in this stage increases the experience between the partners. A governance structure will be created between the partners, and they will be particularly focused on the performance outcomes provided by the partner (Wilson 1995). If the experience is satisfactory, more assignments will be given. The actual attractiveness of the partner can be assessed, and partners will communicate and bargain for future rewards and costs. These experiences will generate a level of trust in the other party based on their past and current behaviour (Dwyer et al. 1987, Halinen 1994, Wilson 1995). If rudiments of trust are established and the interactions also provide social satisfaction, the parties will adapt and invest in the relationship and will become more interdependent. These adaptations and investments in the relationship create structural bonds between the parties (Ford 1980, Wilson 1995). Valla (1986) found that in this stage the partners invest the most in the relationship, either with monetary or non-monetary resources (e.g. time, people or machinery). Business exchange will intensify and the interactions create a formal or informal infrastructure between the parties (Halinen 1994).

This stage can last for a very long time, sometimes years, in which parties get to know each other better and the relation evolves gradually over time. As Ford \& Rosson (1982) and Halinen (1994) indicate, the relationship does not necessarily have to grow. Events within this stage can make the relationship troubled or static for a while. Only if the interdependency increases and the partners still have expectations for future exchanges, the relationship will reach the next stage, which is the necessary stage for a long-term relationship.

1 Considering contemporary human relationships, the metaphor 'dating' is probably more appropriate than 'honeymoon'. 


\section{3). Maintenance stage}

The processes within the development stage will all affect the parties' commitment to the relationship (Ford 1980, Dwyer et al: 1987, Yorke 1990, Halinen 1994, Wison 1995). The maintenance stage occurs when true loyaly is achieved and parties are committed to one another. This stage has been described as the highest stage of relational bonding (Dwyer et al. 1987). Roles and norms are institutionalised and contact pattems routinised (Ford 1980 , Halinen 1994), which make the relationship more stabilised and less dynamic. Parties will not invest and adapt as heavily as before, and the interactions are integrated as if they are part of each others' organisation. Therefore, this stage is regarded as the most profitable one, in which maximum exchange efficiency is reached and little investments are needed (Wilson 1995).

However, the stabilisation and routinisation of the relationship entails the danger that parties perceive the other as less committed. Although inertia could previously sustain a relationship, this will not suffice anymore (Yorke 1990). It is important that the relation is still actively maintaimed, mainly by showing investment initiative (Halinen 1994) or using pledges (Anderson \& Weitz 1992), that demonstrate a willingness to sacrifice on behalf of the other party. Forces from outside will always threaten the relationship, but as long as the benefits from and the investments in the relationship exceed possible alternatives, the parties will remain together.

\section{4). Temination}

And then at some point the relationship will start declining. Some describe it as the mere conclusion of the rellationship maintenance stage (Anderson 1995); whereas others see it as a process in itself, not a sudden decision (Michell et al. 1992). Halinen (1994) describes the cycle of decline, in which the established relationship and the parties' satisfaction start to decline gradually over time, usually initiated by some critical incidents. The attraction, trust and commitment thus diminishes and the relationship will be slowly dissolved.

\subsubsection{Relationship process models}

Several processes thus lead to the maintenance (or decline) of a relationship. The dynamic nature of relationships makes it difficult to identify the causal relations between these processes, for basically everything is related to everything (Wilson et al. 1995). However, some authors have tried to model the sequence of important relational variables, at the expense of being complete. Wilson \& Mummalaneni (1988) tried to summarise this dynamic relationship process into a model, identifying the most important variables that influence the maintenance of interorganisational relationships.

Figure 3.1: Process model of relationship development

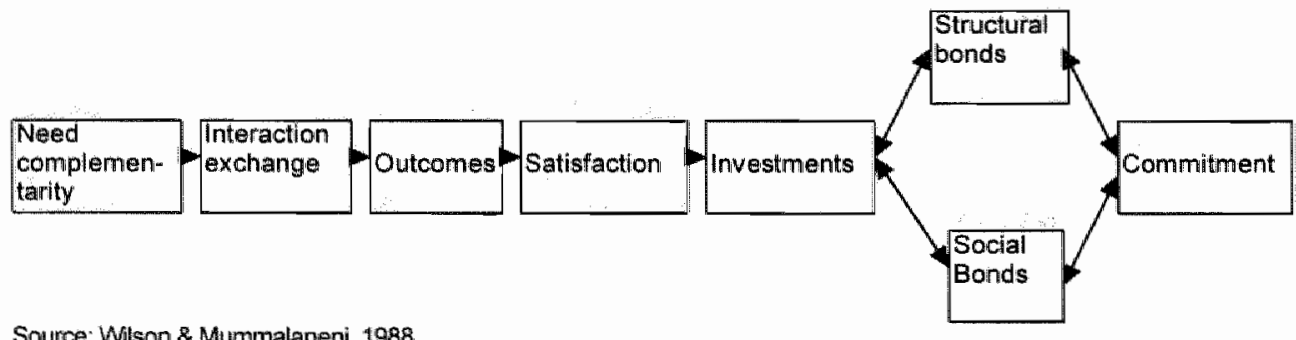


For inter-organisational relationships to start, the parties should have complementary needs and a common interest in developing a relationship. Based on this, the parties will start interactions and exchanges, which determine the process of the relation. The elements of exchange will be first informational and social and then tum into financial and product/service related exchanges (Crosby, 1991). After several exchanges the outcomes of the interactions can be assessed, and the costs and rewards will be evaluated. These outcomes will influence the parties' satisfaction with the relationship. If the outcomes are satisfactory the parties may decide to invest in the relationship.

Wilson \& Mummalaneni argue that relationiships develop through the incremental investments of resources. Investments will intensify the relationship because they demonstrate a party's interest in the relationship and their faith in the other to reciprocate. The investments can be either economic (investment in product or processes) or social (investment of time energy and friendship) in nature and they influence the creation of structural and social bonds between the parties. Structural bonds refer to the amount of irretrievable investments made to the relationship, the difficulty of its disengagement, social pressures within an organisation to keep a relationship, and to the availability of alternative providers. These are thus the structural ties that keep the parties together, which will become stronger the more a party invests in a relationship, but which themselves will also influence the amount of investments. If a party has few alternatives available or is for other reasons pressured to keep the relationship, they will be more willing to invest in making this relationship work. The social bonds refer to the social investments made, and the trust and attachment that is established between the parties. The authors give a special position to the trust variable. Trust develops from positive experiences with the interactions and the benefits gained from them. It is regarded as a precondition for the parties to irvest in the relationship. If a party can not be trusted, the other party will be very reluctant to invest in this party. Social bonds are thus not only influenced by the investments, but also influence the amount of investments.

The social and structural bonds will also influence the degree of commitment the parties have to the relationship, which they describe as the parties" true loyalty to the other party. The commitment, in turn, will increase the amount of investments, and will cause more interactions and exchange processes between the parties (Wilson \& Mummalaneni 1988). Commitment is an outcome variable that ensures the strength, stability and durability of a relationship.

Commitment thus seems to be a central outcome variable in the process of llong-term business relationships that ensures its long-tem maintenance. This central position of relationship commitment is also stressed by many other authors, who use it as a dependent variable in crosssectional studies on the success of inter-organisational relationships. Commitment is not only regarded as crucial for the continuation of the relation, it is also related to increasing relationship benefits, increasing competitive power, profitability and marketing success (Anderson \& Weitz 1992, Morgan \& Hunt 1994, Ganesan 1994). Morgan \& Hunt identified it as the key mediating variable for valuable relationship outcomes in channel relationships. Commitment ensures the strength, stability, durability and the profitability of a relationship (Dwyer et al. 1987, Wilson \& Mummalaneni 1990 * Han 1992).

The maintenance of long-term customer relationships is thus synonymous to the establishment and development of relationship commitment between the parties. As indicated by the dynamic models, relationship commitment is not built overnight and various processes precede its development. In the next section the concept of relationship commitment will be discussed. 


\subsection{Relationship commitment and maintenance}

Relationship commitment is a fairly new construct in the studies of inter-organisational relationships. lis conceptualisation in marketing is 'borrowed' from the social exchange literature (cif. Thibaut \& Kelly 1959, Blau 1964, Cook \& Emerson 1978), organisational behaviour literature (cif. Becker 1960, Porter et al. 1974, Meyer \& Allen 1984, Reichers 1985) and consumer buyer behaviour (cif. Day 1970, Assael 1987), where commitment has been a subject of research for a much longer time. The main ideas expressed in these disciplines regarding the commitment concept will be shortly reviewed here, which form the background for the different approaches used in the conceptualisation of commitment in business relationships.

In the social exchange literature, authors try to explain interpersonal loyalty in human relationships. Cook and Emerson (1978) posit that commitment is an interpersonal attachment that makes persons interact repeatedly with the same partner. They regard commitment as a variable that distinguishes social exchange from economic exchange. Only in social exchange will partners develop loyalty and longitudinal commitment towards each other.

In the literature on consumer buyer behaviour, authors study commitment to explain consumers' loyalty towards a brand. They identify a difference between mere brand repurchases by consumers ('spurious loyalty") and true or intentionall loyalty towards a brand. This difference is explained by the existence of brand commitment in the latter (Day 1969, Jacoby \& Chestnut 1978, Engel \& Blackwell 1982, Bloemer 1993). Commitment will arise from certain positive attitudes towards the brand, based on psychological processes. Spurious loyalty, on the ather hand, is explained by inertia: the consumer repurchases a brand, because of convenience, or indifference but not because of a desire to hold on to that particular brand, which would indicate true loyalty (Bloemer 1993).

In the organisational behaviour literature authors study the commitment of an employee towards the employing organisation. This 'organisational commitment' is one of the oldest and most studied concepts in the field (Reichers 1985). Many different conceptualisations of organisational commitment have been used (cf. Mowday et al. 1982, Reichers 1985), but roughly two views of commitment dominate the literature. The first sees commitment as affective or attitudinail. In this view the employee identifies with the organisation's goals and values, and desires to remain a member of the organisation (cf. Buchanan 1974, Mowday et al. 1982). Employees will stay with a firm because they like to and identify with it. It is a "partisan, affective attachment to the goals and values, and to the onganisation, for its own sake, apart from its purely instrumental worth' (Buchanan 1974). The second view evolved from the 'side-bet' theory by Becker (1960), who regarded commitment as behavioural rather than attitudinal. According to this view the individual is bound to the organisation by extraneous interests, rather than favourable affections towards the organisation. Commitment is viewed as a tendency to remain with an organisation based on the individual's recognition of the costs (or lost side-bets) associated with discontinuing the relationship. These 'side bets' refer to anything of value the individual has invested that would be lost or worthless to the individual if he would leave the organisation. The perceived cost of leaving will be enhanced by the perceived lack of altematives that may replace or makeup for the foregone investments (Meyer \& Allen 1984). Meyer \& Allen combined the two approaches to commitment and proposed two independent dimensions of organisational commitment, labelled as affective commitment and continuance commitment. The first expresses an employee's desire to remain with his company, whereas the latter refers to an employee's intention to stay with the company because of the costs of leaving. They developed measure- 
ment instruments to measure each form of commitment, which were later refined, tested and empirically confirmed (cf. McGee \& Ford 1987, Allen \& Meyer 1990).

From these approaches can be seen that commitment is described by different characteristics. It has behavioural components as well as attitudinal ones. Some describe it as social or affective in nature, and others describe it as more economicall and calculative. In the business relationship literature this diversity of the commitment concept is reflected in the different definitions used. Although most authors agree on the importance of relationship commitment in business relationships, there is less consensus about its conceptualisation. Different views have been used. According to the following definitions, commitment:

1. Has a behavioural dimension:

- 'An implicit or explicit pledge of relational continuity' (Dwyer et al. 1987).

- "intense long-tem loyalty and dedication, even with a single bad expenience" (Ulrich 1989)

- "inertial or binding force between exchange partners that can lead to the maintenance of an existing relationship to the exclusion of altematives" (Seabright et al. 1992)

- "a channel member's intention to continue the relationship" (Scheer \& Stern 1992, Geyskens \& Steenkamp 1994, Kumar et al. 1994).

2. Is proactive in nature:

- "An exchange partners' belief that an ongoing relationship with another is so important as to warrant maximum efforts at maintaining it. The committed party believes the relationship is worth working on to ensure that it endures indefinitely' (Morgan \& Hunt 1994).

3. Includes intentions and attitudes:

- 'Intentions to act and attitude towards interacting" (Liljander \& Strandvik 1994, Storbacka \& Strandvik 1994)

- "... a desire to develop a stable relationship, a willingness to make short-tem sacrifices to maintain the relationship, and a confidence in the stability of the relationship" (Anderson \& Weitz 1992)

4. Consists of an economic dimension:

- "perception of interdependence of outcomes, in which both a vendor's outcomes and joint outcomes are expected to benerit the retailer in the long nur" (Ganesan 1994)

5. and a psychological dimension:

- "that which binds one to another in situations where such constancy seems contrary to selfinterest" (Czepiel \& Gilmore 1987, Czepiel 1990)

- "The desire to continue the relationship and to work to ensure its continuance" (Wilson 1995)

- 'degree of loyalty, incoporating repeat interactions and attachment. There should' be a pledge of relational continuity. There is a need and some degree of desire to continue' (Sriram \& Mummalaneni 1990, Young \& Denize 1994)

All definitions of commitment refer to the likelihood of relationship continuance in the future. As can be seen from most definitions, commitment goes beyond mere repeat purchases (Dwyer et al. 1987, Wilson \& Mummalaneni 1988, Storbacka \& Strandvik 1994). It is the attitude and intentions of the partner on which their behaviour is based that distinguishes a committed relationship from mere inertia. Therefore, to distinguish relationship commitment from mere 
inertia or unintentional repurchase behaviour, we will define the general concept of relationship commitment as: A partners' intentional continuation of a business relationship.

The term 'intentional' not only expresses the intention to continue but also the deliberateness of these intentions. The intentions should thus stem from an explicit deliberation to continue and the parties should be motivated to do so. Relationship commitment thus reflects the underlying attitude on which the parties' intentions are based.

From the definitions can be seen that regarding this underlying attitude or motivation to continue, authors distinguish between a psychological and an economic dimension. The definitions by Anderson \& Weitz (1992), Morgan \& Hunt (1994) and Wilson (1995) clearly refer to the positive (affective) willingness and desire by a partner to maintain a relationship. Ganesan's definition (1994), on the other hand, refers to the economical dimension, in which parties intend to continue the relationship because of their inter-dependency of outcomes. The pledges of relational continuity", used by Dwyer et al. (1987) and Anderson \& Weitz (1992) refer to the idiosyncratic investments made by a partner in the relationship and are thus also economical motivations. These investments are called 'hostages' by Williamson (1985) "because they will keep a partner in a relationship because of the losses incurred if the partner switches to another relationship. The investments already done in the current relationship and the expected costs of switching to another partner will become strong motivations for a partner to stay in a relationship. The costs of ending the relationship may be so high that it is better to find a way to make the partnership work than try to end it (Möller \& Wilson 1995). From this view, the relationship will be maintained because of the perceived need to continue.

As in the organisational behaviour literature, some authors argue that also for inter-organisational relationships the psychological and economical aspects of commitment should be viewed as two dimensions of relationship commitment (Kumar et al. 1994, Geyskens \& Steenkamp 1995). Each dimension reflects a different motivation for continuing a business relationship, which are labelled as affective and calculative commitment.

- Affective commitment is defined as a party's desire to continue the relationship because "...they enjoy the relationship for its own sake, apart from the instrumental worth and because they experience a sense of loyalty and belongingness'. (Geyskens \& Steenkamp 1995).

- Calculative commitment refers to a more instrumental type of commitment, and is defined as 'the degree to which channel members experience the need to maintain a rellationship, given the significant perceived termination or switching costs associated with leaving. It is a cold calculation of costs \& benefits, including investments and available altematives to replace or make-up for foregone investment' (Geyskens \& Steenkamp 1995).

This two-dimensionality of commitment was empirically confirmed for channel relationships (Geyskens \& Steenkamp 1995, Kumar et al. 1994). Also in the accountancy market similar findings were found. Young \& Denize (1994) concluded from their study among clients of accountancy firms that different kinds of relationship commitment exist, depending on clients" motives for maintaining the relationship with their accountancy firm. Clients' commitment could be based on either the perceived need or desire to sustain the relation.

The desire and the need to continue are not inextricably linked (Young \& Denize 1994, Geyskens \& Steenkamp 1995). Clients can feel the need to continue a relationship and therefore deliberately choose to do so, even if they do not desire to continue this relationship. And vice versa, clients can feel the desire to continue a relationship, but do not necessarily perceive a need to. Young \& Denize (1994) argue that the parties should have a desire to continue in 
order to reach a real cohesive relationship. However, if parties have little to loose at a switch and they perceive no need to continue, they will be less motivated to maintain a relation and might switch more easily to attractive alternatives (Tumbull \& Wison 1989, Kumar et al. 1995). Relationships will thus be the strongest if both motives are present.

When taken separately however, the commitment dimensions have differentiating effects on customers' relationship intentions. Kumar et al. (1994) studied the effect of each dimension on different relationship intentions. They found that affective commitment is related stronger to a party's intention to stay, and their intention to make additional investments in the relationship. than calculative commitment. Calculative commitment was related stronger to a party's inclination to behave opportunistically and its intention to search for alternatives. So although both motivations will result in the strongest relationship, affective commitment has the strongest effects on the long-term maintenance of the relationship. Relationship intentions alone are thus not sufficient to maintain a relationship on the long-term. The attitude (or motivations) from which they stem are much better indicators, which is a party's relationship commitment. In figure 3.2 this conceptualisation of long-term relationship maintenance is presented.

Figure 3:2: Proposed structure of relationship maintenance

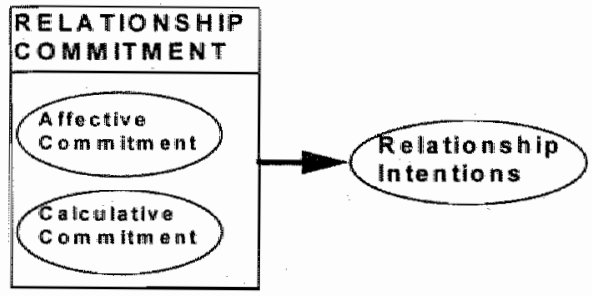

\subsection{Antecedents to relationship commitment}

Studies in the services marketing literature have demonstrated that customers' service quality perception is positively related to their repurchase intentions. Zeithaml, Berry \& Parasuraman (1996) tested and confimed this positive link between quality and customer retention in different (consumer) service industries. They used different kinds of behavioural intentions as indicators of retention. However, as. Wilson et al. (1995) formulated it : "Customer retention implies a longterm commitment of the part of the customer and the firm to maintaining the relationship. The development of the mutual commitment is the same process as creating a long-term buyerseller business relationship" (p.8).

As demonstrated in the previous section, the relationship commitment from which the behavioural intentions stem is the crucial variable that determines the long-term retention of the customer. Although service quality is generally assumed to be related to the retention of customers, little is known about its relation to customers' relationship commitment.

Commitment is something that is built gradually during the development of a relationship, and parties can be committed for different reasons. Therefore, authors argued that customers" 
satisfaction ${ }^{2}$ is an important but not a necessary condition for a party to be committed (Wilson \& Mummalaneni 1990). Parties can be committed even if they are dissatisfied with the relationship, because of the investments made in the relationship, or because there are no alternatives available. From a relationship perspective, the link between customer satisfaction and relationship commitment is not straightfonward because of the dynamics of the relationship (Wilson et al. 1995). Reichheld (1993) argues that satisfaction is not a surrogate for customer retention, and found that even satisfied customers can switch the relation. So satisfied customers do not necessarily stay in a relationship, and dissatisfied customers do not necessarily leave a relationship. Other factors are important as well for the development of customers' relationship commitment.

In the services marketing literature only a few authors recently acknowledged the complexity of the retention of existing customers. Storbacka \& Strandvik (1994) and Liljander \& Strandvik (1995) used the insights from the business marketing literature to model the relation between customers' service quality perception and customer retention for consumer services. Liljander \& Strandvik introduce the concept of relationship commitment as a crucial factor for the retention of service consumers. They propose that service quality is positively related to consumers" commitment together with different relational bonds that are created during the relation. Storbacka \& Strandvik tried to model the link between service quality and customer profitability from a rellationship perspective for the retail banking sector. They argue that the link between customers' satisfaction and 'relationship strength' is not straightforward but depends on the degree of commitment and the bonds that have been created during the relationship.

Also for professional business services the impact of service quality on customer retention is generally assumed (Day et al. 1988, Bojanic 1991, Morgan 1991) but has hardly been explicitly addressed. Young \& Denize (1994) studied the relationship between accountancy firms and their clients. They found that clients have several motivations to stay with their accountancy firm, which they identified as different kinds of commitment to the relationship. They argue that service quality and satisfaction will influence customers' desire to maintain a relationship, but that it is not a necessary condition for its maintenance because there can be other motives.

Thus also for service relationships some authors argue that commitment is a better indicator for the maintenance of long-term relationships than the mere repurchase intentions alone. And that service quality is an important, but not the only antecedent to customers' commitment. Storbacka \& Strandvik (1994) and Liljander \& Strandvik (1995) also include the bonds between the parties as important antecedents to the maintenance of long-term relationships.

To understand which variables contribute to the maintenance of long-term business service relationships, and the role that service quality plays in this process, the antecedents to relationship commitment will be reviewed. First, a review will be given of the antecedents proposed and found for business relationships in general in paragraphs 3.5.1 and 3.5.2. Then, in paragraphs 3.5 .3 and 3.5 .5 , the studies will be reviewed that address the antecedents of relationship commitment for business service relationships in particular.

\footnotetext{
2 The conceptualisation of satisfaction is very similar to the customerbased conceptualisation of service quality. Some authors use them as synonyms (Swartz 8 Brown 1989, laccobucci et all. 1994). For a detalled discussion on the conceptual differences see: Oliver 1993, Bloemer ef al. 1994. Because in the business marketing literature the concept of satisfaction is mostly used, we will use the assumptions and findings of satisfaction as an indication for the rolle of service quality in business relationships.
} 


\subsubsection{Antecedents to relationship commitment: business relationships}

As portrayed in the process model by Wilson and Mummalaneni (1988) in section 3.3, relationships grow through the incremental investments made in the relationship, nesulting in social and structural bonds that tie the parties together and enhance their commitment to the relationship. In general, the social bonds refer to interpersonal ties between the interacting parties that are created during the course of a relationship. The structural bonds refer to ties created on corporate level that endure beyond the individual relationships (Han et al. 1993). The terminology of "bonds' and especially the inclusion of social bonds is typical for the interaction and network perspective, developed by the Industrial Marketing and Purchasing (IMP) group. A part of this research group focuses on dyadic exchange relationships and the dynamics and processes that occur within business relationships (Håkansson 1982, Ford 1990, Möller \& Wilson 1995).

In this research group, structural bonds are regarded as an important antecedent to commitment. These structural bonds refer to the corporate ties created in a relationship that will incur considerable economical or financial costs for a party if severed. 'The creation of a structural bond happens when the two parties make investments that cannot be retrieved when the relationship ends, or when it is difficult to end the relationship due to the complexity and cost of changing sources' (Tumbull \& Wilson 1989, p. 233). As structural bonds in buyer-seller relationships Wilson \& Mummalaneni (1988) identified:

- the amount of irretrievable investments made to the relationship,

- the difficulty of disengagement,

- the social pressures within the organisation towards keeping a relationship, and

- the amount of available alternatives,

which will tie the parties together. The more investments are made in a relationship, and the more difficult its disengagement becomes, the more a party will be committed to continue the relationship. This also counts for the social pressures within an organisation and the amount of alternatives that are available to a party. In business relationships usually several people from different hierarchical levels are involved in the relationship from both sides. These people can put social pressures to keep a relationship. Also if a party has few alternatives available, the party will be more committed to keep this relationship.

Next to these structural bonds, social bonds will be created that can tie the parties together. Although the fundamental basis of a business relation is economic exchange, personal exchange will result as a by-product of it (Wilson 1990). The social bonds refer to the interpersonal relationships between buyer and seller (Tumbull \& Wilson 1989), which are the glue that holds individuals together (Wilson 1990). Parties not only make economic investments to the relation but also social investments in terms of time, energy and friendship. Personal contact enhances the inter-organisational communication and information exchange, knowledge gain and the establishment of credibility, which will enhance the development of the relation as a whole (Wilson \& Mummalaneni 1988). Social bonds can make the relationship a pleasant one for the individuals involved and will increase their commitment to the relationship. Wilson \& Mummalaneni ( 1986 ) found that buyers who have a strong personal relationship are more committed to maintaining the relationship than less socially bonded partners. Tumbull \& Wilson argue that the social bonds are easier to break than the structural bonds, because companies cannot justify an inferior decision based on friendship alone $(1989$, p. 233). Only when transactions are simple and if the competitors offer equal products relationships could be sustained by social bonds only (Wilson et al. 1995). Usually both structural and social bonds are to some degree present in a relationship. 
In the interaction and network theory approach, a framework of possible bonds has been developed. Different kinds of bonds have been identified according to the kind of adaptation and/or investment made in the relationship. These bonds can be economic, technical, time-

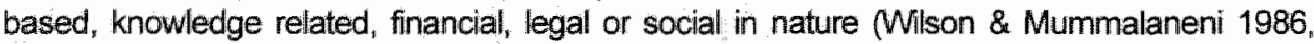
Paliwoda \& Thomson 1986, Tumbull \& Wison 1989, Halinen 1994). These bonds should be regarded as specifications of the above mentioned structural and social bonds.

- Economic bonds, are built by special credit agreements, intensity of money flow, economic risk taken on behalf of the partner and the switching costs created by the past investments and perceived risk of making a bad choice.

- Technical bonds are created by the investments on the technological level (R\&D, relationship specific machinery or systerns, technical assistance etc.).

- Time-based bonds, refer to the dependence on delivery times and other time-related issues.

- Knowledge bonds, are created by the body of knowledge that is built through which the partners have gained a thorough understanding of each other regarding their needs, wants and problems and by the exchange of confidential strategic information.

- Financial or legal bonds, consist of formal agreements and anrangements that have a lasting character.

- Social bonds, which can be on company or personal level, and are created by the build up of socilal relationships and familiar contact patterns.

Apart from the social bonds, these bonds are thus further specifications of the structural bonds and indicate what has been invested in and might be lost at a switch. These bonds create barriers to switch to another party. The more the variety and strength of the bonds the more the parties will be committed to the relationship. So even if a party is dissatisfied, these ties can be so strong that parties can still be committed to the relationship.

The literature on channel management studies the relationships between producers and their distributors from a different theoretical background than the IMP-group. Power dependence theories and transaction cost theory are central theories in their analyses of the development of channel relationships. From this view, the development of a relationship is described by the increasing interdependency between the parties, due to the incremental investments made in the relationship. A party's dependence on the other party is regarded as an important antecedent to their relationship commitment. Dependence (or its counterpart: power) has been defined in the marketing channell literature in different ways and covers at least the following aspects (Heide \& John 1988, Anderson \& Weitz 1992, Ganesan 1994, Geyskens \& Steenkamp 1995, Morgan \& Hunt 1994, Andaleeb 1996):

- The importance of the resources exchanged and the magnitude of exchange (cf. 'stakes') in the relationship;

- The idiosyncratic investments that will be lost if the relationship ends;

- The lack of available alternatives; and,

- The expected costs and risks associated with a switch to another supplier.

A party's dependence in a relationship is thus largely determined by the importance of the relationship and the replaceability of the partner. The more a party has to loose in ending a relationship, the more they are willing to sustain it (Kumar et al. 1995, Andaleeb 1996). This concept of interdependence between the parties can thus be compared to the structural bonds from the network and interaction theorists ${ }_{11}$ that tie the parties together. 
In the channel relationship literature and the power-dependence theories, the social bonds as such are not discussed as a separate force that keeps the parties together. However, special attention is paid to the role of trust in the relationship. Because bonds and investments in a relationship expose parties to dependence and make them vulnerable to the actions of the other party, trust is needed for a relationship to develop. Only if the partner is considered as trustworthy a party will be willing to invest and become committed to the relationship. The interaction and network theorists classify trust as a social bond between the parties (Turnbull \& Wilson 1989, Wilson \& Mummalaneni 1990). However, although trust is essentially a social construct, it has clear economic implications as well. Trust has been defined as: "the fim's belief that another company will perform actions that will result in positive outcomes for the firm, as well as not take unexpected actions that would result in negative outcomes" (Anderson \& Narus 1990) and it can be recognised as "a willingness to rely on an exchange partner in whom one has confidence" ( Moorman et al. 1993a, b) which refers to a behavioural dimension.

Trust is regarded as a valuable asset in a relationship that reduces perceived uncertainties and risk and is considered as a key variable for relationship success (Morgan \& Hunt 1994). Trust will develop slowly over time (Dwyer et al. 1987) and can become a relational bond in itself that will make the parties want to keep the relationship. Trust is regarded as an important antecedent to relationship commitment (Dwyer et al. 1987, Anderson \& Weitz 1992, Ganesan 1994, Halinen 1994, Morgan \& Hunt 1994, Geyskens \& Steenkamp 1995).

Summarising, through the incremental interactions and investments parties make during the course of a relationship, relational bonds are created that can be either social ( = interpersonal) or structural (= comporate) in nature. The structural bonds imply a degree of interdependency between the parties, which creates impediments to the termination of the relationship. These structural bonds can be brought about by different kinds of investments and adaptations (economic, technical, time-based, knowledge-related or legal). The stronger these bonds are, the more committed a party will become to the relationship. Next to the relational bonds the trust in the other party will also contribute to a party's commitment. Although interaction theorists classified it as a social bond, trust is not only an interpersonal variable and it also has economilcal implications which go beyond a mere social bonding. Finding a partner that can be trusted can be valuable enough for a party to be committed to the partner, even without having invested in the relation (yet).

\subsubsection{Empirical evidence}

The network and the interaction theorists in the IMP-group mainly conducted in-depth case studies in the field. Their goal is to describe and understand the complexity and dynamics of interaction phenomena ${ }_{1}$ in an international and European context (Möller \& Wilson 1995). Most of their ideas described above are based on these studies. In the marketing channels literature. authors studied the maintenance of long-term channell relationships and the antecedents to relationship commitment mainly by cross-sectional quantitative studlies. In these studies commitment or comparable concepts (like, e.g. long-term orientation) are explained by several antecedents simultaneously. These studies and their outcomes will be reviewed below.

- Different studies in the channel relationship literature assessed the role of trust and dependence on relationship commitment (Anderson \& Weitz 1992, Kumar et al. 1995, Geyskens and Steenkamp 1995, Andaleeb 1996) and on the "perceived continuity of the relationship' (Anderson \& Weitz 1989). Dependence was mainly operationalised by the 
idiosyncratic investments done in the relationship, the availability of alternatives and/or the perceived costs of switching. Both the trust and dependence variables were consistently found to contribute significantly to a party's relationship commitment:

Several studies also incorporated the role of performance satisfaction in their study of the explanation on a party's relationship commitment.

- Morgan \& Hunt (1994) developed a model in which they categonised trust and commitment as key variables that will result in valuable relationship outcomes in channel relationships. As antecedents to relationship commitment they included the "relationship benefits' (product profitability, customer satisfaction and product perfomance compared to competitors), 'the expected relationship temination costs' (i.e. the switch costs), the "trust' in the other party and the 'shared values' between the parties. The empiricall results of their study indicated that all variables contributed directly and significantly to the commitment except for the 'relationship benefits:.

- Ganesan (1994) also developed a model for channei relationships that explains a party's "Iong-term orientation' to the relationship, which is comparable to a party's commitment to the relationship. As antecedents they identified the party's 'satisfaction with the outcomes', their 'dependence' (importance of exchange, availability of alternatives, investments), the 'perceived dependence of the other party' (perceived investments by the other) and the 'trust' in the other party. All antecedents were found to contribute directly and significantly to a party's long-term orientation, including the satisfaction with the outcomes.

- Wilson et al. (1995) developed a model for business relationships in general and tested it for relationships between wheat farmers in Australia and the Australian Wheat Board, which markets the wheat. They found that farmers' "satisfaction', the 'structural bonds' (switch costs), the 'social bonds' and the 'trust' in the other party all had significant direct effects on the farmers' commitment to the Wheat Board.

Morgan \& Hunt's (1994) 'relationship termination costs' and the 'dependence' used in the channel relationship studies, are all part of the structurall bonds as previously defined. The studies thus all found that structural ties are indeed direct and significant antecedents to a party's relationship commitment. The social bonds were only included in the study by Wilson et al. (1995), and were found to contribute directly and significantly to a party's relationship commitment, next to the other antecedents. All studies included the trust variable and found consistently that it contributes directly and significantly to a party's relationship commitment. The satisfaction concept was only used in the latter three studies, and mixed results were found. Wilson and Ganesan found that satisfaction is directly and significantly related to a party's relationship commitment. Morgan and Hunt, however, found that it did not contribute significantly to a party's commitment next to the structural ties, trust and shared values.

As explained earlier (see footnote 2), the satisfaction concept comes closest to the service quality concept used in services marketing. It is exactly the contribution of this concept to the maintenance of long-term business relationship that is addressed in our research question. From the discussion above it may be concluded that relational bonds (structural as well as social), and trust are important antecedents to relationship commitment. Satisfaction seems to contribute as well to a party's relationship commitment, although its relative contribution next to the other antecedents remains unclear. 


\subsubsection{Antecedents to relationship commitment: business service relationships}

Berry (1995, see also Berry \& Parasuraman, 1991) describes in his article on the establishment and maintenance of long-term customer relationships in service markets in general, three different types of relational bonds that foster customer loyalty. Customer loyally can be achieved by financial bonds, socilal bonds or structural bonds, which are ordered in increasing strength of a service relationship. With financial bonds, customers become loyal only because of financial incentives from the service provider (e.g. frequent flyer programs). These customers are easily lost if competitors offer better financial incentives. Social bonding involves personalisation and customisation of the relationship. Like the social bonds described previously, these bonds are interpersonal. Although social bonding normally cannot overcome a non-competitive core service, it can drive customer loyalty when competitive differences are not strong. It is a stronger incentive to keep the relationship than only the price incentives, and Berry calls it a "level two' relationship. The third, and strongest, relationship level is formed by structural bonds. These are formed by structural solutions to customers" problems, which are difficult or expensive for customers to provide and which are not readily available elsewhere. These structural solutions are built within the service delivery system, and do not depend on the individual service providers (like the social bonds). Like the structural bonds described in the previous paragraph, these bonds are on company level. Examples of these bonds are customers' investment in computers of specific software by which the exchange with the service provider is enhanced, and which are worthless for dealing with other providers. These bonds create a strong foundation for maintaining and enhancing relationships. If these bonds exist together with social and financial bonds, the relation is not easilly broken.

Next to these bond types Berry identifies also trust as critical to the formation of service-based relationships because of the intangibility of services. Especially when services are personally important to customers, require considerable customer participation, and are heterogeneous or complex, customers are exposed to a high amount of uncertainty and risk in buying these services. Professional business services are characterised by all these elements. Trust in the service provider can reduce the vulnerability and uncertainty considerably, and will therefore increase customers' willingness to maintain the relation with the provider. Thus also for services in general ${ }_{\text {, }}$ the relational bonds and the trust in the other party are assumed to enhance the maintenance of long-term customer relationships.

Only a few authors addressed these variables for the maintenance of professional business service relationships. In developing a model for the development of advertising agency-client relationships, Halinen (1994) distinguishes between two types of relational bonds, that she calls 'relationall bonds' versus 'operational bonds'. Relational bonds are of a more abstract character than the operational bonds. As relational bonds she identifies the 'attraction', 'trust' and 'commitment' between the parties which are all gradually developed over time: parties will first become attracted to each other, then trust will be developed and ultimately commitment will be created. The 'operational bonds' refer to concrete ties that are created in day-to-day operations between the parties. She adapts the list of concrete bonds identified by the network and interaction theorists to advertising services, and proposes that clients and agencies can be tied by the social network and personal relationships, i.e. social bonds, by the intensity of money flow and switching costs, i.e. economic bonds, by the efficiency created in the interaction patterns, i.e. planning bonds, and finally, by the knowledge and (confidential) information that is exchanged, i.e. knowledge bonds. Especially these latter knowledge bonds have also been mentioned by other authors to be important relational bonds in professional business service 
relationships. The relationship-specific expertise is regarded as the most important relationship asset that is built within professional business service relationships, increasing customers' commitment to the relationship (Levinthal \& Fichman 1988, Woodside et al. 1992)

Trust has also been identified to be crucial in professional business services relationships. Trust is crucial in situations where uncertainty and vulnerability is high (Moorman et al. 1993a). Uncertainty is key in intangible, complex, unfamiliar and long-time horizon services (Crosby et al. 1990), which are all characteristics of professional services. Also because of the customised nature of these services, clients have to open up to the provider, which can only be done if the client trusts the provider (Czepiel 1990). Trust is thus a central element in professional service relationships that increases customers' willingness to maintain it (Crosby et al. 1990, Czepiel 1990, Grönroos 1990, Sharma 1994, Halinen 1994).

Thus, relational bonds (social and structural in nature) and trust are assumed to be crucial for the maintenance of long-term customer relationships also for professional business services. Social bonds and trust are regarded as particularly important for these service relationships, because of the intensive customer interactions and the high uncertainty attached to these services. Structural bonds are also identified for these service relationships, especially regarding the investments in knowledge.

\subsubsection{Empirical evidence}

A few empiricall studies have been conducted in the professional business services markets regarding the maintenance of long-term customer relationships. These are reviewed below.

- Seabright et al. (1992) studied the effects of individual attachments versus structural attachments on the chance for relationship dissolution in auditor-client relationships. They found that only the individual attachments had a predictive value for the chance of relationship dissolution. The structural attachment had no predictive value at all. From this they conclude that social bonds (i.e. individual attachments) are much more important for professional business services than the structural bonds (i.e. the experience gained and specific investments made during the course of a relationship).

- Moorman et al. $(1993 a, b)$ conducted an empirical cross-sectional study among clients of marketing research agencies. They found that the clients' trust in the agency, their perceived quality of interaction and their perception of the researcher involvement contributed significantly to the clients' relationship commitment.

- Halinen (1994) conducted a qualitative longitudinal analysis of advertising agency-client relationships. She followed a few customer relationships for a number of years and tried to describe and explain the long-term dynamics of these relationships. She found several antecedents to clients' commitment to their agency, that she called:

* Adaptation processes. She found that hardly any relationship specific investments on corporate level were made in the studied relationships. Adaptations were made more on an individual level, by the creation of personal relationships and increasing inter-firm knowledge in individuals;

* Inter-firm network of interpersonal relationships. Favourable personal relationships created commitment and secured the continuity of the relationship. Beside the individual relationships, the broader social structure also engenders commitment. Thus the stronger the relationships and the broader the network of interpersonal relationships the more committed the parties are; 
* Inter-firm knowledge. Inter-firm knowledge is closely related to the individual investments made in agency-client relationships by learning by doing. The acquired inter-firm knowledge exerts pressure to continue the relationship;

* The position of the partner. This refers to the importance of the partner in the party's net. If the agency was important to the client, they would be more dependent and therefore more committed to continue the relationship;

* Outcome satisfaction. Satisfaction with the services and the relationship were given as important reasons for commitment and contributed to long and stable exchange relationships; and,

* Trust. The more a party trusted the other, the more they were committed to that party.

- LaBahn \& Kohli (1995) conducted a cross-sectional study among clients of advertising agencies explaining clients' relationship commitment. They identified and empirically found that the 'trust', "productive interactions' and 'outcome satisfaction' were all significantly related to customers' commitment to their agency.

From the studies by Moorman et al., Halinen, and LaBahn \& Kohli, it is shown that trust is found to be an important antecedent to a party's relationship commitment also for professional business service relationships. The 'individual attachments' of Seabright et al., the 'quality of interactions', used by Moorman et al., and the 'interpersonal relations' by Halinen, all indicate that social bonds are also important for the maintenance of professional business service relationships. According to the study by Seabright et al., these social bonds are even more important than the structural ties. Halinen adds that not only the individual relationships are important but also the extensiveness of the interpersonal network. Regarding the structural bonds, Halinen found that corporate investments are a lot less for professional business service relationships than is generally proposed for business relationships. Hardly any tangible investments have to be made in the relationship. Structural ties are mainly created by the incremental knowledge that is developed during the relationship, which will be lost at a switch. The development of relationship expertise was also considered by Levinthal and Fichman (1988) to be the most important relationship specific asset that is created in auditor-client relationships. Halinen indicates that there can also be a degree of dependence on the partner by its importance for the party's business (i.e. the availability of alternatives). The service outcome satisfaction was only included by Halinen and LaBahn \& Kohli in their studies in the advertising industry. Both found it to be important antecedents to customers' relationship commitment. The quantitative study by LaBahn \& Kohli found that it contributed significantly to clients' relationship commitment next to their trust in the agency and the productivity of the interactions. However, they did not include the relational bonds as antecedents to relationship commitment in their study.

Trust and relational bond's are thus important antecedents to customers' relationship commitment, also in professional business service relationships. Social bonds are particularly mentioned for (professional) service relationships and structural bonds can also play a role, although they seem to be of a different nature than the ones identified for channel and industrial product relationships. Mainly the knowledge bonds seem to be important and some form of dependence. The assumed importance of service satisfaction, comparable to the service quality concept (see footnote 2), for relationship commitment seems to be confirmed in the few studies conducted, although its relative importance next to the trust and relational bond variables remains still unclear. This relationship will be explored in the empirical research. 


\subsection{Summary and conclusions}

Establishing long-term relationships with customers is recognised as a profitable strategy and has become the new paradigm within marketing. Service quality is regarded to be one of the few tools available for service providers to increase their profitability because of its assumed effect on the retention of existing customers. The relation between service quality and customer retention has, however; so far been approached from a transactional perspective. Research evidence has shown that service quality influences customers' repurchase intentions. From a relationship perspective however, we are interested in how service quality contributes to the development and maintenance of long-term customer relationships.

Therefore, in this chapter a review is given of theories and studies on the development and maintenance of business relationships from the business marketing literature. Academic interest in this topic is relatively new, and authors use many different theoretical frameworks, that are applied to different kinds of business relationships. However, comparable ideas are researched and similar results are found in studies from different frameworks. One thing all authors agree upon is that relationship commitment is crucial for the establishment and maintenance of true long-tem relationships.

Relationship commitment is defined as a party's intentional continuation of a business relationship. This definition reflects the deliberateness of a party's intentions, distinguishing it from mere inertia. In accordance with findings from the marketing channel literature and the accountancy industry, two main motivations were identified that underlie customers' intentions to maintain a relationship, which can be regarded as two dimensions of relationship commitment. We propose that customers' relationship commitment to professional business service providers is multi-dimensional in nature and consists of two dimensions:

1. Affective commitment, which reflects customers' affective motivations, and positive willingness to continue a relationship. It refers to the customers' desire to maintain the relation.

2. Calculative commitment, which reflects the calculative motivations, based on the incurred losses and costs of a switch to continue a relationship. It refers to the customers' perceived need to maintain the relation.

Each motivation will encourage a customer to put efforts in maintaining the relation and will therefore contribute to the strength, stability, durability and ultimately the profitability of a relationship. These motivations are not inextricably linked, and relationships will be the strongest if both motivations are present.

In order to study the importance of service quality for the maintenance of long-term customer relationships, its contribution to customers' relationship commitment will be investigated rather than to customers' relationship intentions alone. Commitment reflects the attitude (or motivations) that underlie customers" intentions, and can therefore distinguish between mere inertial relationships and true long-term ones. Also in the business marketing literature it is assumed that satisfaction (or service quality) will contribute to relationship commitment. However, because of the dynamic nature of relationships it has been argued that satisfaction (or service quality) may not be a necessary condition for customers to become committed to a relationship. Studies found mixed results about whether satisfaction still contributes significantly next to other antecedents to relationship commitment. Therefore, the importance of service quality will be studied next to the other identified antecedents. 
From the literature review three important antecedents to customers' relationship commitment were identified that are applicable to professional business service relationships as well. We therefore propose that:

1. customers' perceived service quality of professional business services will contribute positively to their relationship commitment;

2. the strength of relational bonds will contribute positively to customers' relationship commitment. These bonds can be either social (inter-personal) or structural (interorganisational) in nature; and,

3. the degree of trust in the professional business service provider will contribute positively to customers' relationship commitment.

These tentative propositions will be explored in the empirical study. The relative importance of service quality next to these other antecedents could not be inferred from the literature and will therefore be empirically explored in the empirical study. In the next chapter the research model and the research design will be presented and a first exploration of these propositions will be described. 


\section{Chapter 4: Research Design and Exploratory Study}

"One has to know much, to ask good questions about what one doesnt know".

Anonymous

\subsection{Introduction}

In the previous chapters the research objectives were addressed by a literature review. Propositions were made regarding customers' qually perception of professional business services and the variables that contribute to the long-term maintenance of business relationships. In this chapter, these propositions will be shortly reviewed in section 4.2 , and will then be summarised into one research model. This model will be the central research model that will be empirically explored in the rest of this thesis.

In section 4.3 the research design of the empirical study is described. This design consists of several empirical research steps. The first step is an exploratory research in the professional business service market in which the research model will be analysed: the advertising market. The design of this first exploratory study will be described in sections 4.4 and its outcomes in section 4.5 . In section 4.6 the initial research model will be adjusted to the findings from the advertising market. This adjusted research model will be analysed further in the next steps of our empirical research.

\subsection{Research objectives \& propositions}

In this section the literature review of chapters two and three will be summarised by reviewing the theoretical propositions for each of the research objectives defined in chapter 1 . These propositions will be integrated into one theoretical model that forms the basis for the empirical research.

\section{Objective 1: Key quality determinants of professional business senvices}

To understand customers' perception of the quality of professional business services, a literature review was conducted in chapter 2 . Based on service quality research in general and the studies on professional business service quality in particular, the following five key quality determinants were identified for customers" quality perception of professional business senvices:

1. Potential Quality: the customers' evaluation of the available human, material and financial potential at the service provider to perform its services;

2. Soft Process Quality: the customers' evaluation of the interactions with and treatment of the customer during the service production process;

3. Hard Process Quality: the customers' evaluation of the (technical) way in which the coreservice is produced by the service provider,

4. Immediate Outcome Quality: the customers' evaluation of the direct outcome of the service production process; and,

5. Final Outcome Quality: the customers' evaluation of the final results or consequences of the (implemented) service outcome. 
Customers' overall quality perception is proposed to be based on these determinants, and therefore the quality de teminants will all influence

Figure 4.1. Proposed structure of professional business service quality

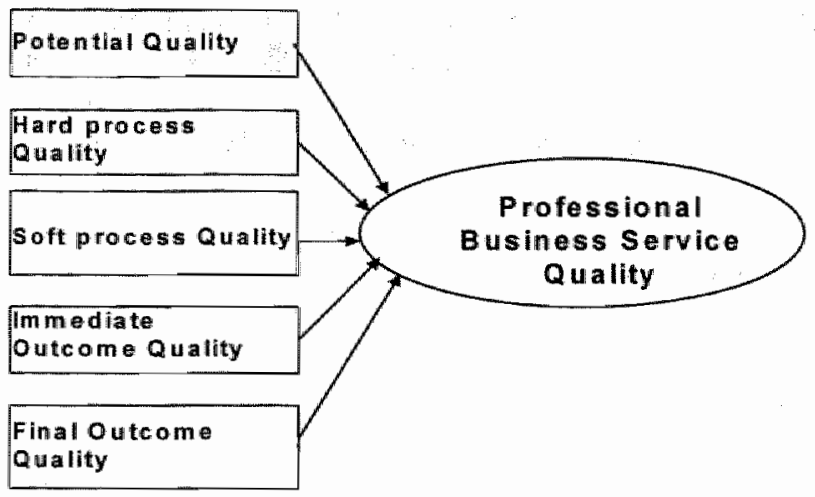
customers' quality perception. This proposition is graphically presented in figure 4.4 .

Objective 2: The relative importance of quality determinants

All five quality determinants are proposed to be incorporated into the overall service quality assessments by the clients. However, their relative importance to customers' overall service quality judgement could not be inferred from literature. This question will be addressed in the empirical research.

Objective 3: Relationship maintenance and its antecedents

From a review of business marketing literature it was found that relationship commitment is a crucial indicator for long-term relationship maintenance. Relationship commitment reflects the attitude or motivation on which customers' intentions are based. Two basic mótivations can underlie customers' (long tem) relationship intentions, which are defined as two dimensions of relationship commitment: affective commitment, reflecting the desire to continue the relationship, and, calculative commitment, reflecting the perceived need to continue a relationship. This proposed structure of long-term relationship maintenance is presented in 4.2 .

Figure 4.2: Proposed structure of relationship maintenance

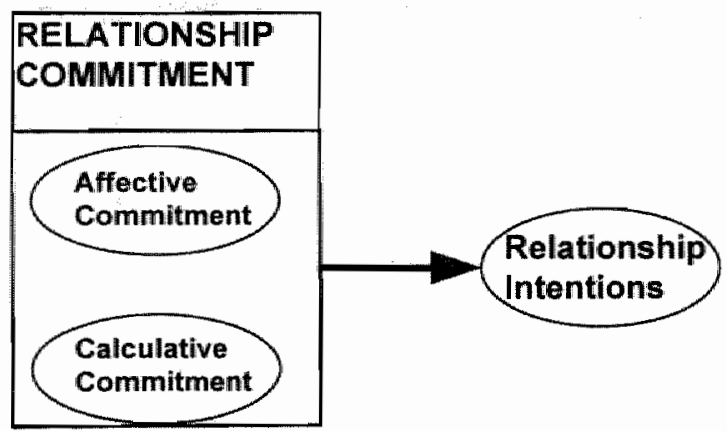


From the literature review on business relationships in general and professional business relationships in particular, three antecedents to relationship commitment were identified:

1. the established trust in the other party;

2. the established relational bonds, which can be social or structural in nature. Social bonds are the inter-personal ties created during the relation, whereas the structural bonds refer to the inter-organisational ties. Different kinds of structural bonds can be identified depending on the kind of relationship studied, and, finally,

3. the perceived service quality is proposed to contribute to customers' relationship commitment.

Figure 4.3: Proposed antecedents to relationship commitment

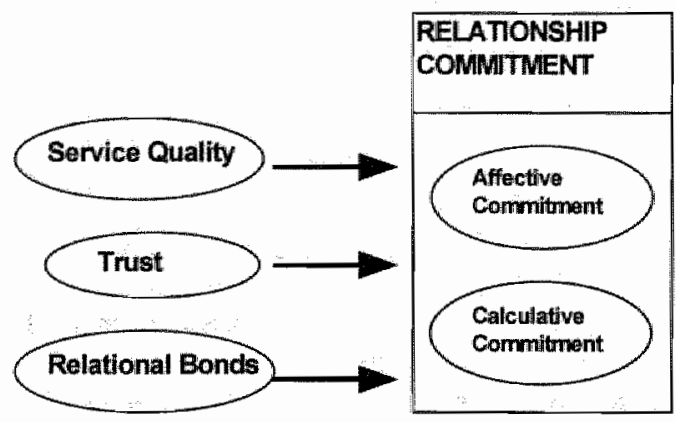

Objective 4: The impontance of senvice quality perception for relationship commitment Although perceived service quality (or the comparable concept of satisfaction in business marketing literature) was found to contribute positively to customers' relationship commitment, its contribution relative to the other antecedents is still unclear. One study found that despite its positive relation to relationship commitment, it did not contribute significantly next to the other antecedents. This is what will be explored in the empirical study.

\subsubsection{Research model}

These propositions form the building blocks of one theoretical model. This model is portrayed in figure 4.4. and constitutes the research model that will be explored in the empirical part of our study. In paragraph 4.2.2 the empirical setting is described in which this model will be explored. In the next section the empirical research design will be addressed. 


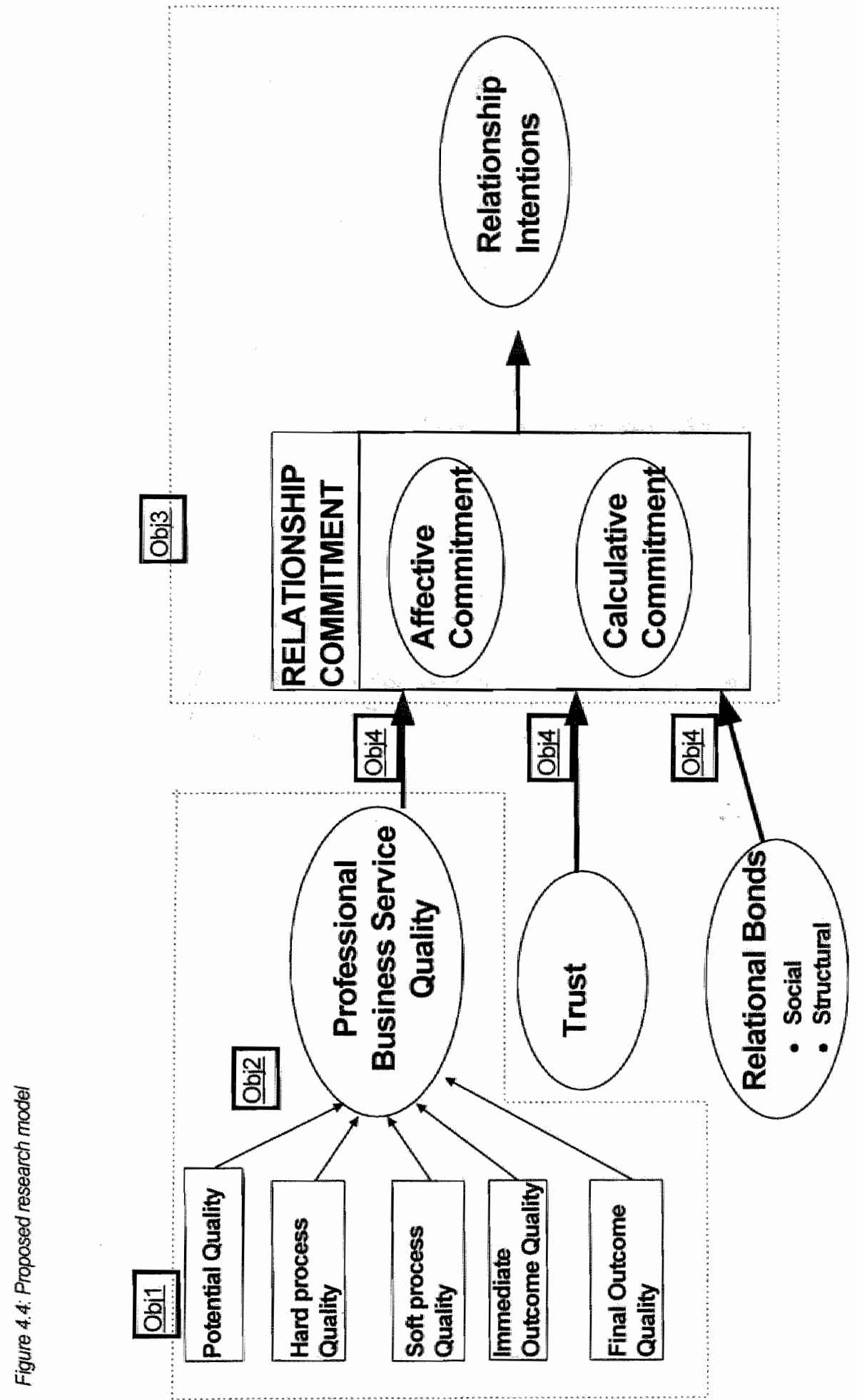




\subsubsection{Empirical setting}

This research model and the propositions will be investigated empirically within one professional business service market: the advertising market. Advertising services can be clearly categorised as professional business services (Gardner 1986, Halinen 1994). Long-term agency-client relationships are common within the advertising market Nerbeke 1988, Halinen 1994) which makes it an interesting and accessible market to investigate the causes for relationship maintenance. Furthermore, this market was chosen for practical reasons: personal interest by the researcher, and existing contacts with representatives of the advertising market made this market accessible.

Because the model is still tentative, the research objectives will be translated into empirical research aims particularly for the advertising market. The empirical research aims are:

1) to analyse whether the proposed five key quality determinants of professional business service quality are applicable to customers' quality perception of advertising services (cf. objective 1), and to analyse how these determinants are related to the overall perceived quality of advertising services (cf. objective 2);

2) to analyse whether the proposed conceptualisation of relationship commitment is applicable to advertising agency-client relationships, and the proposed relationship commitment antecedents are relevant for advertising-agency client relationships (cf. objective 3), and finally,

3) to explore whether and how perceived service quality contributes to customers' relationship commitment in advertising agency-client relationships, next to the other identified antecedents (cf. objective 4).

Although investigating one market puts limitations to the generalisability of the results, the advertising market will be used as an example of professional business services, and where possible, implications of the findings will be given for other professional business services.

Even though relationships are reciprocal phenomena, and relationship commitment is a mutual process (Anderson \& Weitz 1992), the research aims will be studied from the perspective of the customer. First of all, because our goal is to explore the customer-based concept of service quality, which by definition is based on customers' perceptions of quality, and secondly because most professional service markets have become buyers' markets (Crosby 1991), and customers usually influence the maintenance of the relationship the most, also in the advertising market (LaBahn \& Kohli 1995).

\subsection{Research design}

Although research designs differ depending on the specific purpose of the research, three main types can be distinguished: exploratory, descriptive, and causal (Aaker \& Day 1990, Churchill 1995). Exploratory designs are most appropriate when the purpose of the study is to gain new insights and understanding of a phenomenon. It helps to formulate a research problem more precisely or to develop hypotheses regarding the problem. Descriptive designs presuppose a broad knowledge of the problem and aim to describe the occurrence of certain phenomena or the association between pre-defined variables. It is usual, but not essential, that research hypotheses are defined and analysed in a descriptive study. Causal designs, however, require that hypotheses are precisely stated at the outset. The aim is to determine cause-and-effect relationships between variables. The exploratory, descriptive and causal designs are not just three different ways to set up a research, they can also be viewed as different stages in a re- 
search process, with each stage representing a more detailed examination of the research problem (Churchill 1995). In our research, two of these stages will be performed.

Because the research model and propositions are still tentative, an exploratory research in the advertising market is conducted first. The goal of this research is to become more famillar with the advertising market, to explore the feasibility of the propositions for this market, and to clarify the concepts of the research model. Based on this research the initial propositions may be modified or new ones developed.

These propositions will then be further explored in the second stage of our research: the descriptive research. A quantitative field study in the advertising market is conducted in which the research model and propositions will be further explored in a cross-sectional sample survey among advertising agency clients. Again, the tentativeness of our model does not allow for rigorous hypothesis testing, but the field study will be used to explore the propositions further in a qualitative setting. In terms of Kerlinger (1986) this field study should be regarded as exploratory in nature rather than hypothesis testing. Although the term "exploratory' may be confusing, it refers to field studies that aim to discover significant variables, analyse their inter-relationships, and to lay the groundwork for later, more rigorous and systematic testing of hypotheses (Kerlinger 1986). This more rigorous testing could then be done by a causal design, which is beyond the scope of the present research.

As stated above, descriptive designs pre-suppose a broad base of knowledge in order to quantitatively measure and describe the focal concepts and their inter-relations. Therefore we conducted after the initial exploratory research, an in-depth analysis of the research concepts and their measurement first, before the quantitative field study could be executed. The empirical research thus consists of three steps that will be described in the following chapters:

Table 4.1: Steps in empinical research

\begin{tabular}{llll} 
Research steps & Description & Goal & Described in: \\
\hline $\begin{array}{l}\text { 1. Exploratory } \\
\text { research }\end{array}$ & $\begin{array}{l}\text { First, qualitative exploration of } \\
\text { our model in the advertising } \\
\text { market }\end{array}$ & $\begin{array}{l}\text { Adjustment of propositions or } \\
\text { model to advertising market }\end{array}$ & Rest of Chapter 4 \\
$\begin{array}{llll}\text { 2. Development } \\
\text { of research in- } \\
\text { strument }\end{array}$ & $\begin{array}{l}\text { Second, in-depth analysis of } \\
\text { focal concepts }\end{array}$ & $\begin{array}{l}\text { Conceptualisation of concepts } \\
\text { and their measurement for ad- } \\
\text { vertising market }\end{array}$ & Chapter 5 \\
$\begin{array}{llll}\text { 3. Descriptive } \\
\text { research }\end{array}$ & $\begin{array}{l}\text { Large-scale quantitative ex- } \\
\text { ploration of (adjusted) model } \\
\text { and propositions in the ad- } \\
\text { vertising market }\end{array}$ & $\begin{array}{l}\text { Quantitative analysis of the con- } \\
\text { cepts and model defined is steps } \\
1 \text { and 2. }\end{array}$ & $\begin{array}{l}\text { Chapter 6: Design and de- } \\
\text { scriptive results }\end{array}$ \\
& & $\begin{array}{l}\text { Chapter 7 and 8: Analysis of } \\
\text { model and propositions }\end{array}$ \\
\hline
\end{tabular}

The remaining of this chapter will be devoted to the design and outcomes of the qualitative exploratory research (step 1). 


\subsection{Design exploratory research}

Different techniques can be used to conduct an exploratory research. Secondary data can be gathered by a literature search, and primary data can be gathered by experience or key- informant surveys, analysis of selected cases, and focus group discussions (Churchill 1995). In our study an industry-specific fiterature search, key infomant interviews, and in-depth interviews with selected cases were conducted in the advertising market to:

- abtain general information about the advertising market and advertising services;

- understand the establishment and development of agency-client relationships;

- explore whether our theoretical concepts and propositions are applicable to the advertising market; and to

- clarify the focal research concepts for the advertising market.

In this section the procedure used for each of these techniques is described. In the next section the information that was gathered by these techniques will be summarised.

\subsubsection{Literature advertising market}

The advertising market has often been object of research. The two Dutch trade magazines ('Adformatie' and 'Nieuwstribune') and the 'Journal of Advertising Research' report many empiricall studies regarding clients' evaluation of advertising services, and regarding agency-client relationships. Also academic studies have been conducted in the advertising market; of which the dissertation by Halinen (1994) deserves special attention. She conducted a longitudinal indepth study about a few agency-client relationships and described the agency-client relationship development process in great detail, including the role of customers' service evaluations.

From these studies information is glathered regarding the specifics of agency-client relationships, the applicability of our focal research concepts to the advertising market, and regarding the criteria clients use in evaluating advertising services. This information will be summarised in the appropriate paragraphs in the next section.

\subsubsection{Key-informant interviews}

Different key-informants were approached to provide background information about the advertising market and agency-client relationships. For general background information we approached representatives of the two trade associations of advertising agencies in The Netherlands. For information about agency-client relationships an advertising agency selection agency was approached that helps (potential) clients to select an agency and mediates between agencies and clients when problems arise in their relationship. For more specific information regarding advertising agency services, agency-client relationships, and clients perception of agency services (representatives of) six advertising agencies were interviewed.

With all these key-informants in-depth semi structured face-to-face interviews were conducted. The interview schedule consisted only of the main topics to be covered from the respective interviews. The respondents were asked to elaborate on the topics from their experience, with the interviewer only probing for more information. The interviews lasted 1 to 2 hours on average, and were conducted at the respondents' premises. The interviews were taped on taperecorder, the confidentiality of which was assured by the researcher. The specifics of each of these key-informant interviews will be described below. 


\section{Trade associations}

In August and September 1994 in-depth interviews with representatives of the two trade associations of advertising agencies in The Netherlands were conducted. The VEA represents the (115) bigger agencies in The Netherlands and PRAGMA is the association of (63) smaller agencies. Of the VEA the managing director was interviewed, who had previously worked for several advertising agencies in The Netherlands. At the PRAGMA the interview was conducted with the entire board, consisting of the secretary, the chaiman, and the vice chairman, who are both directors of their own advertising agency.

In these interviews information was gathered regarding the current state and developments in the advertising market, the rules and regulations that apply to this market, and the usual way of doing business. The respondents were confronted with our research plan and were asked to react on the relevance and applicability of this research for the advertising market. The information from these interviews will be reported in the appropriate paragraphs in the next section.

\section{Agency selection agency}

In September 1994 an in-depth interview with the managing director and a consultant of SCAN was conducted. SCAN assists advertisers in selecting a (new) advertising agency and mediates in problems between clients and their current agencies. Questions were asked about agency-client relationships, the most important problems in these relationships, and reasons for relationship continuation and/or termination. The respondents were confronted with the purpose of our research and were asked for their expert opinion. The information from this interview will be summarised in the appropriate paragraphs in the next section.

\section{Six advertising agencies}

Between July and October of 1994, representatives of six advertising agencies were interviewed. To get a broad idea about the different kinds of advertising services, different ways of doing business, and about different kinds of client relationships, different kinds of agencies were approached in terms of size, scope of operation, and service range (i.e. above-the-line advertising. e.g. mass media advertising, versus below-the-line advertising, e.g. direct marketing, sales promotions). Because of the in-depth information needed from the agencies, four agencies were selected by the accessibility criterion (Yin 1989), i.e. through existing connections. Because these four agencies were larger ones, also 'cold-calls' were conducted to smaller agencies registered in the 'Adformatie bureaubijlage' to co-operate in the research. Two agencies agreed to co-operate that fulfilled our criterion of small agency. The managing director or partner of the agencies were interviewed. A description of the agencies is depicted in table 4.2.

Table 4.2: Classification of interviewed advertising agencies.

\begin{tabular}{|c|c|c|c|}
\hline & Stze & Nationalintermational & Communication Services \\
\hline Agency 1 & Small & National & Below-the-line \\
\hline Agenoy 2 & Small & National & Above and below \\
\hline Agency 3 & Medium & National & Above and below \\
\hline Agency 4 & Medium & (Inter)national & Above and below \\
\hline Agency 5 & $\mathrm{Big}$ & International & Above and below \\
\hline Agency 6 & Big & Intemational & Above and below \\
\hline
\end{tabular}

\footnotetext{
1: Above-the-line advertising refers to all mass media (i.e. w/print/radjo) advertising. Below-the-line adwertising are all other forms of advertising like, sales promotions, direct marketing etc.
} 
From the agencies specific information was gathered regarding the services they provide, the way of doing business, the establishment and development of relationships with their clients, their opinion about customers quality assessment, and what constitutes and causes a committed relationship. At the end of the interview the respondents were confronted with our research proposal and asked for their expert opinion and suggestions. The information from these interviews will be reported in the appropriate paragraphs in the next section.

\subsubsection{In-depth interviews with selected cases}

Because the service quality perception and relationship commitment of clients is central to our research, several clients of advertising agencies, i.e. advertisers, were interviewed in the exploratory research. Different kinds of clients were selected, with different communication needs and agency relationships to get a broad view on the central research concepts.

Two managing directors of medium-sized companies operating in different industries were approached directly via existing connections. Two companies were selected for their international scale of operation in different industries, and the persons responsible for the communication and the agency-relationship were approached by connections. Two other companies were selected by a co-operating agency. One company was a highly satisfied client of the agency and one company had just broken the relationship with this agency. The representatives of these companies were directly approached by the researcher to ask for their co-operation. The information was guaranteed to be confidential and would not be reported back to the agency. The agency had agreed to this condition.

Six clients were thus selected. The clients represented advertisers from different industries and different sizes as presented in table 4.3. The selected clients all work with different agencies, except for the two selected by the agency (client no. 3 and 5 in table 4.3). The respondents all have direct contacts with their agency.

The following topics were covered in semi-structured in-depth interviews with the clients:

- general description of company, and their communication needs and practices ;

- assessment of the service quality of the current advertising agency and the criteria on which this assessment is based;

- description of the past and present relationship with their current agency;

- the respondent's commitment to the agency-relationship and the reasons why; and if applicable, reasons for breaking previous agency relationships.

Although the interviews were scheduled to last approximately one hour, the respondents were very open and the interviews lasted two to three hours. The interviewer made sure that the above-mentioned topics were covered during the interview, but within these topics the respondents were free to mention any of their experiences or opinions. At the end of the interview the respondents were confronted with our research ideas and propositions and asked to react to them from their own experiences. The information gathered from these interviews will be reported in the next section. 
Table 4.3: Classification of interviewed clients

\begin{tabular}{|c|c|c|c|c|}
\hline Client $t^{2}$ & Industry & Company & Responsible for: & Function \\
\hline Client 1 & $\begin{array}{l}\text { Consumer \& busi- } \\
\text { ness services }\end{array}$ & $\begin{array}{l}\text { Headquarters of Dutch } \\
\text { multinational }\end{array}$ & $\begin{array}{l}\text { Dutch \& global con- } \\
\text { sumer campaigns }\end{array}$ & Communication director \\
\hline Client 2 & $\begin{array}{l}\text { Business products } \\
\text { producer }\end{array}$ & $\begin{array}{l}\text { European headquarters of } \\
\text { foreign multinational }\end{array}$ & European campaigns & Communication director \\
\hline Client 3 & $\begin{array}{l}\text { Business \& con- } \\
\text { sumer products } \\
\text { producer }\end{array}$ & $\begin{array}{l}\text { National headquarters of } \\
\text { nationall company }\end{array}$ & National campaigns & Communication director \\
\hline Client 4 & $\begin{array}{l}\text { Retailer consumer } \\
\text { goods }\end{array}$ & $\begin{array}{l}\text { Independent national busi- } \\
\text { ness unit }\end{array}$ & National campaigns & Managing director \\
\hline Client 5 & $\begin{array}{l}\text { Consumer goods: } \\
\text { producer }\end{array}$ & $\begin{array}{l}\text { Dutch international com- } \\
\text { pany }\end{array}$ & $\begin{array}{l}\text { National consumer } \\
\text { campaigns }\end{array}$ & Marketing manager \\
\hline Client 6 & Non-profit services & $\begin{array}{l}\text { Regional subsidiary of na- } \\
\text { tional company }\end{array}$ & Regional campaigns & Managing director \\
\hline
\end{tabular}

\subsection{Results exploratory research}

As explained above, several information sources were used to get a deeper understanding of advertising services and agency-client relationships, and to explore the relevance and applicability of the research concepts and propositions for the advertising market. The information gathered from the literature search, key informant interviews and in-depth interviews with selected clients will be integrated in the paragraphs below. In paragraphs $4.5 .1-4.5 .3$ general background information regarding advertising services and agency-client relationships will be described. In paragraphs $4.5 .4-4.5 .6$ the specific information gathered regarding the research propositions will be integrated.

\subsubsection{Advertising agencies \& services}

An advertising agency is "an independent organisation of creative people and business people who specialise in the development and preparation of advertising plans, advertisements, and other promotional tools." (Bovee \& Arens 1992).

The core service they provide to the client is what one agency calls the 'Wisdom \& Magic', i.e. strategic advice and creative ideas regarding the clients' communication. Agencies analyse the marketing and communication strategy of the client and translate them into a creative concept, which is the central idea expressed in a communication campaign. Based on this creative concept the individual advertisements will be developed.

Apart from these core services many additional services can be performed by the agency: execution of the production work (printing, editing etc.), planning, buying and handling of the media, conducting market and advertising research, co-ordinate international campaigns, or provide services on other promotional tools, like sales promotion, direct marketing, sponsoring, PR activities and/or internal communication.

2 Because of the confidentiality of the infomation "the company names are not disclosed. 
'Full service agencies' can deliver the full range of services needed, either by using in-house expertise or through connections with other (specialised) agencies. The deregulation of the Dutch advertising market in the beginning of the 1990 ties resulted in a fragmented market with many specialised agencies that focus on one service aspect, like media agencies, direct marketing agencies, or creative teams. Clients can now hire different agencies and co-ordinate the activities themselves, or hire a 'main agency' that co-ordinates the activities from different agencies, the later of which is most common in The Netherlands.

The production of advertising services is a long process, which can be roughly divided into three stages: the strategic stage, in which the clients' marketing and communication strategies are translated into a concrete communication plan; the concept stage, in which the creative concept is developed by which the communication goals should be achieved. The communication mix and media plans will be developed; and finally, the production stage, in which the ideas will be produced and executed. The development of a campaign can take up to six months.

Advertising services can be classified as professional business services. The services are provided by independent qualified professionals, like the communication specialists and creative specialists (designers and copy writers), whose expertise and skills are at the core of the service performance. The services are rendered to organisational customers, contributing to the wellbeing of the client-organisation and its stakeholders. The services are customised to clientspecific problems and strategies. And clients participate during the whole service production process, by providing the necessary information and reaching agreement to every stage in the process. Unlike other professional business services, advertising services provide a tangible outcome of the service production process (the actual advertisements). However, the final results of these advertisements can not be perceived till long after the service delivery, if at all.

\subsubsection{Agency-client relationships}

Clients often have long relationships with their advertising agency. In a study in The Netherlands, the length of agency-client relationships varied between 0.5 and 28 years, with an average of 5.5 years (Verbeke 1988). The median was 4 years, which means that $50 \%$ of the sample had a relationship of 4 years or more. In a more recent study in The Netherlands $58 \%$ of the advertisers were certain that the relationship with their agency would still hold for the next 2 years (Hogerzeil-Hulsebos 1994). In a study in the UK it was found that $30 \%$ percent of agency-client relationships were still in tact after five years (Michell 1988b) and even 14\% of the relationships were still ongoing after 10 years (Michell 1988a).

Several potential benefits can be gained by clients from long tem relationships with an advertising agency. Relationships can reduce uncertainty, and can offer strategic efficiency and sociall benefits (Miettilä \& Möller 1990, Halinen 1994 ).

\section{Uncertainty reduction}

Ambiguity is an inherent part of advertising services that causes high uncertainty for clients. Clients face different kinds of ambiguities when they buy advertising services that Halinen (1994) classified as:

- need ambiguity: although clients can specify what they ultimately want to achieve with their advertising it is difficult to define what is exactly needed in order to reach this effect. It is difficult to set clear service specifications before the selection of an agency; 
- performance ambiguity: the intangibility and complexity of advertising services makes it difficult to assess how well an agency performs its work and how good this work really is:

- market ambiguity: because of the experiential and customised nature of advertising services the price and quality are difficult to compare between the agencies in the market. Furthermore, professionals often change agencies, which does not contribute to the stability and transparency of the industry; and finally,

- transaction ambiguity: because advertising services are customised processes, customers are uncertain about the delivery dates, quality specifications and invoicing procedures before each assignment has been negotiated with an agency.

These inherent ambiguities make customers highly uncertain about which agency to select and about what to expect from an agency once it is selected. Staying with a familiar agency can reduce this uncertainty considerably (Miettilä \& Möller 1990). The client will know what to expect and can influence the exchange processes with the agency.

\section{Strategic benefits}

Many clients have a need for consistency and continuity in their communications, especially when brand/company mames and images are important. Dealing with one agency can provide this consistency in communication. During a relationship the agency will learn to know the clientorganisation, its goals and target markets, as well as its way of thinking. This knowledge enables the agency to provide better service quality, by tailoring the service outcome as well as the service process better to the client's needs.

However, if agencies become too close to the client it is harder to attain the distance needed to create innovative ideas and new creative concepts. This tension between developing something new and original versus the need for consistency and continuity in the communication is very typical for agency-client relationships and will always be present throughout a relationship (Michell 1988).

\section{Efficiency benefits}

Apart from better service quality, the knowledge that an agency acquires during a relationship will also result in cost efficiencies for the client. Over time, clients have to invest less time and effort in providing the information that the agency has already acquired. Also exchange processes and procedures will be adapted to each other and will become institutionalised. This will increase the efficiency of the interactions.

\section{Social benefits}

Because of the intensive interactions needed between the client and agency representatives in every service production process, social benefits can be gained from long term relationships. Close interactions with the same people can become personal over time and very satisfying for the parties involved (Halinen 1994). 


\subsubsection{The agency-client relationship process}

Both parties could thus benefit from long-term relationships. However, not all relationships are long-term. The typical development process of agency-client relationships will be discussed now, and the reasons for terminating it.

\section{Selection stage}

The selection of an agency is the first step in the (poteritial) relationship process. As described earlier, clients are faced with high uncertainty in choosing an agency, which makes the selection decision an important but complex process. According to documentation from the advertising trade agencies, the "official" selection decision process of a new advertising agency consists of three steps:

- first, the client makes a long-list of potentially interesting agencies. Through desk research with publicly available information and requested agency documentation the agencies are examined, and a short-long list of interesting agencies is selected;

- these agencies are then contacted and invited to give a presentation about their agency. Based on the presentations, clients select a short-list of 3 to 4 potential agencies; and,

- these remaining agencies are then asked to conduct a competitive presentation or a pitch about an actual communication assignment for the client. In a pitch, agencies can be asked to perform the entire service process up to the development of concrete sample advertisements. These pitches can be very costly for the competing agencies, for which the (potential) client pays very little if anything. Winning a new client is rewarding enough for the agencies. The final decision will be based on this competitive assignment.

This 'official' selection process is complex and very time-consuming for the clients. In practice it seems that most clients skip the first two steps and only consider agencies from a short-list, which is created by referrals from friends and business associates, or by prior experience with (members of) an agency (Weilbacher 1983, Wills 1992, Clemens 1994, Halinen 1994). Research showed that agencies win new business mainly by positive recommendations from satisfied customers, and secondly, by new business presentations, like a pitch (Wills 1992). Our interviews with agency-clients are consistent with these findings. All six client-respondients created their short-list by referrals from friends and colleagues, or through previous contacts with members of an agency. In two cases the prior contacts with an agency resulted directly in the selection decision without a pitch or strategic presentation.

\section{Relationship devolopment/maintenance}

After the selection decision the relationship starts and the first campaigns will be developed. A campaign starts with a briefing from the client. Then a lot of energy is put into this assignment and many people from different levels are involved in both companies. The agency presents the strategic ideas, and then translates them into a creative concept. Budgets, appointments and plans will be made and approved. Clients may come by to look at the creative developments and will be present in the pre-test of the ideas and advertisements. Then, if the client has approved the ideas and the plans, the production will start. After the first advertisements of the campaign are executed, the interactions will slow down. Day-to-day operational issues will be dealt with and smaller assignments, based on the basic campaign, will be executed. These contacts are usually between lower hierarchical levels in both companies responsible for the execution. 
Each new assignment will vary in length, type, value, importance, degree of innovation and breadth. This means that clients' needs can change during the relation as well as the interaction intensity required to fulfil these needs. A relational infrastructure will be created during the assignment processes, in which the contact pattems become gradually routinised and the agency only needs half a word to know what it has to do. This infrastructure sets the framework for future interactions (Halinen 1994). How the relationships develop further is very relationshipspecific. Some relationships may be domant with an occasional assignment, whereas others are very dynamic with continuously different activities.

\section{Relationship termination}

At some point the temination of the relationship starts, which is usually a process, not a sudden decision (Michell et al. 1992). Many studies in the advertising market addressed the reasons for terminating an advertising agency relationship.

- Halinen (1994) described the cycle of decline, which usually starts with a few critical incidents from which the established relationship and satisfactions start declining.

- Several studies in different countries (Doyle et al. 1980, Wackman et al.1987, Michell 1987, Michell 1988a, Michell et al. 1992) indicated that the most important reasons for clients to switch advertising agencies was their dissatisfaction with the work performance, i.e. the standard of creative work, the sales and image results of the work, and the client service. Other reasons that were found to cause dissatisfaction in the relationship with an advertising agency (Nieuwstribune 1993, week 13) were failed planning, lack of initiative and too little knowledge about the market.

- Raphael (1981) and Heekin (1983) found that agency switches occur as often when clients' sales are up as when they are down. Therefore they argue that clients switch because of personal and people related reasons rather than because of the agency's performance. Heekin found that reasons like arrogance, inability to listen, preoccupation with acquiring new accounts, frequent personnel changes and the "chemistry" between the two parties are more important switch reasons. In a study in The U.K. (Adformatie 1994, nr. 40) the most frequently mentioned reason to switch was that the agency did not devote enough time and means to the client . Other reasons mentioned were: loss of enthusiasm on the account by the agency $(72 \%)$, conflicts with other accounts $(61 \%)$, 'incompatible characters' (44\%) and lack of knowledge about integrated marketing $(32 \%)$.

Other reasons to terminate the agency relationship are also important: the client can outgrow the agency (by internal growth or mergers) or change its marketing philosophy or strategy for which they want 'fresh ideas'. But also changes in the top-management of the client can be devastating for agency-client relationships. In our interviews the following anecdote in the advertising industry was mentioned: "a new product manager = a new product packaging, a new marketing manager = a new campaign, and, a new marketing director $=$ a new agency", regardless of its performance. But also changes within the agency, like personnel changes, mergers with other agencies, ${ }_{t i}$ or conflicting accounts ${ }^{3}$ can prematurely end an agency-client relationship.

After this general description of advertising services and the agency-client relationship "the findings regarding our research model and propositions will be summarised next.

\footnotetext{
3 A golden rute within the advertising market is that agencies can not work for wo competing companies in the same industry these are 'conficting accounts'.
} 


\subsubsection{Service quality of advertising services}

We proposed that customers' perceived quality of professional business services will be based on the following five key-determinants: The potential quality (i.e. the available potential of the agency), the hard process quality (i.e. the technical way in which the service is produced), the soft process quality (i.e. the interactions and treatment of the client during the production process), the immediate outcome quality (i.e. the direct results of the service production process), and finally, the final outcome quality (i.e. the results of this outcome). The findings from the literature search and the exploratory interviews regarding the service quality of advertising services, will be described and compared to our proposition.

\section{Studies in advertising market}

Although the concept of service quality perception has hardly been studied in the advertising industry, some studies imvestigated comparable concepts. Halinen (1994) proposed a model of how clients evaluate the service outcome of advertising services. Wackman et al. (1987) studled the structure of customers' satisfaction with advertising services. The theoretical assumptions and empirical findings of these studies for the advertising agency will be reported here.

Halinen (1994) argues that "When the temporal dimension of an assignment is taken into account, it seems necessary to distinguish between three elements in the perceived outcome of an assignment process: process outcome, service outcome and the ultimate service outcome" (p.257). The process outcome is defined as the evaluation of all the interaction episodes between the parties during an assignment process. It consists of the way a service is rendered, the way in which clients participate in the process and of the characteristics and styles of the interacting individuals. The service outcome, is defined as the evaluation of the immediate result of the service production process. This is the creative output, reception of creative output in relevant client nets and the final price of the service. The ultimate service outcome is defined as the evaluation of the final and indirect results of the developed campaigns to the clients' business.

Since her assumptions were partly used in the development of our service quality model for professional business services in general (see chapter 2), this distinction in evaluation factors is similar to our proposed service quality determinants. In her 'process outcome' dimension she does not make a separate distinction into the hard factors and the soft factors as is made in our quality model, but both aspects are specifically included in her definition of this 'process outcome". Halinen (1994) conducted a qualitative longitudinal study among several agency-client relationships, and found that clients indeed make a distinction between the evaluation of the service process and its outcome. She also found that clients of advertising agencies distinguish between the immediate and ultimate outcome of advertising services as we proposed in our quality model. However, she did not include the potential/organisational factor into clients' evaluation of advertising services.

Wackman et al. (1987) studied clients' satisfaction with the overall performance_and creative work of an advertising agency. They proposed and found four factors to be important determinants of clients' satisfaction. These are organisational factors, the work pattem of the agency, the relationship climate, and the work product factors. The organisational factors are operationalised as the structure and policy of the agency and the qualifications and experience of its personnel. The work pattem is described as the way in which the service is performed (the day-to- 
day activities, and co-ordination and communications about advertising development). The reJationship climate is described as the chemistry, trust, and rapport between the interacting parties. Finally, the work product is described as the primary work of the agency, ie. the produced advertisements and plans. They conducted a quantitative field studly among clients of advertising agencies and found that the four factors explained $55 \%$ of overall client satisfaction.

These four factors resemble the proposed five quality deteminants very much. Wackman et al.'s organisational factor resembles the 'potential quality' determinant and they found that this organisational factor influences clients' satisfaction with the work of the agency. Their distinction into the work pattem and relationship climate factors is comparable to the "hard process" and 'soft process' quality deteminants. They found that both aspects influence customers' satisfaction with the agencies' work. Their work product factor resembles the 'immediate outcome' quality, which was also significantly related to customers' satisfaction. They, however, did not make an extra distinction into the ultimate outcome as Halinen (1994) did.

Although these studies are not completely similar to our proposed quality model, the findings do provide a first support for the existence and relevance of the five proposed quality determinants for customers' assessment of advertising services.

\section{Inteniews with key-intormants and selected cases}

In the in-depth-interviews with agencies and clients, both groups of respondents were asked at the end of the interview to react to our proposed key quality determinants. The respondents all agreed that the five determinants would play an important role in the quality assessment of advertising services.

During the interview, the six clients were asked to rate the overall service quality of their current agency. After this general rating, they were asked to describe why they gave this rating. The clients mentioned many items and events on which their evaluation is based. To get a first indication whether the proposed quality determinants are relevant for respondents' evaluation of the service quality of their agency, we classified the mentioned items into the proposed quality determinants in table 4.4 . This classification is made post hoc by the researcher, not by the respondents.

From table 4.4 can be seen that items from each quality determinant category were mentioned by the respondents, although not every client mentioned items from each quality determinant. The fact that items from each quality deteminant were mentioned spontaneously as quality criteria indicates that these determinants are related to clients' service quality perception.

From table 4.4 we can see that items belonging to the service process and its immediate outcome are mentioned mast often by the clients. Keeping deadlines, the relationship with the contact people and the agency's creativity were mentioned most often. Few items were mentioned regarding the potential quality, and, only two of the six respondents mentioned the effectiveness of the agency"s work to motivate their quality rating. One client stated that they "get what they deserve", since they approved to execute the campaign and are therefore also responsible for its results. This was also found in the (qualitative) study by Halinen (1994), who concluded that clients pay relatively little attention to the ultimate service outcome in their evaluation of the agency. This was explained by the difficulty for clients to assess the effectiveness of advertising campaigns. A comparable finding was found in the study by Wackman et 
al.(1987). When they asked clients what would enhance the success of their agency relationship, clients mentioned most often work pattern factors (= hard process), relationship factors (= soft process), and the standard of the creative work (= immediate outcome). The sales and image results ( $=$ final outcome) of the work was only mentioned by a few clients. They also found that organisational factors hardly play a role on clients" satisfaction with the agency. As can be seen from table 4.4. our respondents also mentioned this aspect less than the items belonging to the process and immediate outcome quality determinants.

Table 4.4: Quality evaluation criteria mentioned by the clients

\begin{tabular}{l|l|l}
\hline Quality determinant & Mentioned items & Times mentioned (n=6) \\
\hline Potential quality & agency management & 1 \\
& equipment & 1 \\
& people & 1 \\
& tradiation' of agency & 3 \\
& the efficiency, budgets & 2 \\
& invoicing & 5 \\
& accuracy and keeping deadlines & 2 \\
& execution & 1 \\
& reachable & 3 \\
\hline Sord process quality & expertise & 2 \\
& nice people & 5 \\
& the relationship & 2 \\
& treat client as important & 3 \\
\hline Immediate outcome & take initiative & 2 \\
& creativity & 3 \\
& strategic analyses & 1 \\
\hline Final outcome & costs & 2 \\
\hline
\end{tabular}

Thus summarising; studies in the advertising market found comparable agency service evaluation criteria, as we proposed in the service quality model for professional business services. The key-informants and selected cases of the in-depth interviews all agreed to the relevance of the proposed quality determinants. And we found support that clients actually use criteria from these determinants in the service quality assessment of their advertising agency. Additionally, an indication is found for the relative importance of the quality determinants for clients' overall quality evaluation, which is the second research objective. The clients paid relatively little attention to the potential quality and final outcome quality of the agency's services in their explanation of their overall quality assessment. The two process quality determinants and the immediate outcome quality were mentioned most often. This finding is supported by the two studies in the advertising market reviewed above. These findings thus suggest propositions particularly for customers' quality perception of advertising services that should be explored in the field study. These propositions will be formulated in the next section. 


\subsubsection{Relationship commitment in agency-client relationships}

In this paragraph the findings of the exploratory research regarding clients' relationship commitment to their agency will be summarised. Two dimensions of relationship commitment were proposed: affective commitment and calculative commitment. In this paragraph the information sources will be used to explore whether and how these commitment dimensions are manifested in agency-client relationships.

\section{Studies in the advertising market}

The only studies known to us that studied commitment in advertising agency-client relationships are the studies by Halinen (1994) and LaBahn \& Kohli (1995). Both studies were used in the literature review in chapter three as empirical evidence for the research concepts in professional business service relationships. Our propositions are thus in principle supported for agency-client relationships. However, the studies will be used here to describe the concepts more extensively for the advertising market and to discuss the empirical findings. Our empirical findings from the interviews will be discussed after the review of the two studies.

Halinen (1994) defined commitment as 'an implicit or explicit pledge of relational continuity between the exchange parties'. She defined a priori that commitment consists of two dimensions: attitudinal and behavioural commitment. Attitudinal commitment is defined as the willingness of the parties to develop and maintain the relationship in the future, whereas the behavioural commitment is defined as the actions and choices taken over time through which the parties have become committed to each other. She found that the definitions and the distinction between the two commitment forms appeared to be highly relevant in the agency-client relationships that she studied. These two dimensions are very similar to the two dimensions we defined. The affective commitment, which we defined as a party's desire to continue a relationship, is comparable to the attitudinal commitment, and the calculative commitment, which we defined as a party's perceived need to continue a relationship, is comparable to the behavioural commitment concept. Even though the latter comparison is not straightfonward, we argue that the 'actions and choices taken over time' will at least partly refer to the investments made in the relationship, which contribute to a party's perceived need to continue a relationship.

LaBahn \& Kohli (1995) defined commitment as a clients' desire to remain in a focal relationship and its confidence in the relationships' continuation (p.3). This definition reflects mainly the affective commitment as we defined it. They specifically weakened their definition of commitment from more stronger ones, like the one by Morgan \& Hunt (1994) who define relationship commitment as 'an exchange partner's belief that an ongoing relationship with another is so important as to warrant maximum efforts at maintaining it. The committed party believes the relationship is worth working on to ensure that it endures indefinitely', because they state that agency-client relationships rarely reach this intensity. Also Halinen (1994) found that the interdependence between client and agency is not as strong, concrete and economically significant as in other industrial relationships, because the parties' adaptations and investments in the relationship are through individual and intangible resources rather than organisational and physical ones. 
Interviews with key-informants and selected cases

The six clients had relationships with their agency varying from 4 to 12 years. None of the respondents had the intention to break the relationship. However, when the clients were asked to indicate how committed they are to their agency, they all made a case of it to mention that they were not the ones who should be committed, but the agency. The term commiment seems to have specific connotations for the respondents. Some reacted to this question with: "we have no stakes in them" or "they should be there for us, we not for them". They were all very reluctant to admit to any degree of commitment from their side, the client should be "king". This seems to confirm the assumption by LaBahn \& Kohli (1995) that relationship commitment in agency-client relationships is not that strong. Indirect evidence, however, suggests that clients are more committed than they are willing to admit when asked directly. All clients indicated that they would accept failures or problems with their current agency to a certain extent, and that they are willing to put an effort in resolving them. They also indicated that they are prepared to invest in the maintenance of the relationship, without an immediate switch if problems occur.

The interviews with the agencies revealed that they also have emotionally committed clients, who are really proud of their agency and express it towards rellevant others. They described how some clients actively show their commitment to the agency by rewarding and stimulating them, hereby actively investing in the relationship itself, which is of course reciprocated by the agency's activities for them.

Summarising, the cited studies and our exploratory interviews indicate that clients of advertising agencies can be committed to their advertising agency. It is, however, suggested that the degree of commitment might be less than in other business relationships (e.g. channel relationships). The exploratory research did neither support nor reject the existence and relevance of our proposed two types of relationship commitment: affective commitment and calculative commitment, for the advertising market. The cited studies and the interviews with the agencies somehow supported the existence of affective commitment. The calculative commitment has not been addressed in previous studies in the advertising market, and will be explored further in the next stages of the empirical research.

\subsubsection{Antecedents to relationship commitment in agency-client relationships}

Three main antecedent variables to customers" relationship commitment are proposed for business service relationships in the research model: relational bonds, trust and service quality. In this paragraph these concepts will be described for advertising agency-client relationships and the evidence found from the exploratory research for the propositions.

\section{Relational bonds}

In chapter three the bonds were described that are created during a business relationship and tie the parties together. These bonds can be either social (inter-personal) or structural (interorganisational) in nature. The structural bonds refer to an interdependency between the parties, which can be brought about by different types of investments and activities in the relationship. It was argued that the structural bonds might be of a different nature in business service relationships, because parties' investments and adaptations are mainly through individual and intangible resources rather than organisational and physical resources (like equipment, personnel etc.). In this part we will try to identify the relational bonds applicable to agency-client relationships based on the exploratory research. 


\section{Studies in the advertising market}

Halinen (1994) defined in her study the following bonds for agency-client relationships:

- Knowledge bonds. During the service production processes, clients will have to disclose confidential strategic and sensitive market information to the agency. Furthermore, during the interactions, the parties get to know each other well, and clients know what to expect from their agency. This knowledge is a valuable asset in the relationship, which will be lost at a switch.

- Social bonds. Because of the peoples-based nature and intangibility of advertising services, many personal interactions are needed during the service processes, and personal relationships will emerge. Apart from the information exchanges, social exchanges will occur which can be very satisfying to the parties involved. Furthermore, usually several people from each company are involved in the interactions, and an inter-firm network is created which grows stronger over time. This network can tie the parties together, increasing the strength of the social bonds.

- Economic bonds. These can be created by special credit arrangements with the partner, by the intensity of money flows between the partners ('stakes'), and by the economic risk that is taken on behalf of the partner. These monetary and non-monetary investments (in time and effort) in the relationship will be lost at a switch and can tie the parties together. The more investments are made in the relationship the stronger this bond will become.

- Planning bonds. During the interactions, norms and unwritten rules will be created that routinise the interactions and make their co-ordination easier and more efficient. Matters will not have to be re-negotiated every time they occur, like the establishment of compensation systems, patterns of personal contacts, customs in division of work, formality of control, style of briefing (verbal/written), time perspectives for future planning and media campaigns etc.

From this it seems that there are four kinds of relational bonds that are applicable to agencyclient relationships.

\section{Interviews with selected cases}

The six clients were asked to explain why they want to continue the relationship with their current agency and what they would expect to loose from a switch. From these questions we tried to identify any aspect clients consider important for maintaining the relationship. Because of the exploratory nature of this part of the research, the questions were kept as open as possible to identify any aspect that might play a role in the maintenance of the relationship from their point of view. In table 4.5 the mentioned reasons to stay with the agency are classified into the bond types proposed by Halinen (1994). This classification is done post hoc by the researcher based on all the reasons mentioned (freely) by the respondents.

Table 4.5: Reasons of clients to keep relationship, classified into bond types

\begin{tabular}{lll}
\hline Relational Bonds & Mentioned reasons to stay & Times mentioned ( $\mathrm{n}=6$ ) \\
\hline knowledge & knowledge at agency & 2 \\
& they know what you want & 3 \\
\hline economic & costs in starting new relationship & 4 \\
& uncertainty what others can provide & 2 \\
& loss of investments at switch & 1 \\
social & know who you are & 2 \\
& good relationship & 4 \\
know who they are & 2 \\
\hline planning & efficiency & 2 \\
& tradition & 1 \\
& organisational culture \& politics & 1 \\
\hline
\end{tabular}


As reasons to stay in the relationship all respondents mentioned economic bonds: the costs and hassle of developing a new relationship was mentioned by all, but also the uncertainty of what other agencies would be able to offer, compared to what they already get from their current agency. Also knowledge bonds were mentioned by most clients. The acquired market knowledge as well as the knowledge about the client organisation were mentioned as reasons to stay. Social bonds were also mentioned: knowing whom to deal with and whom to trust. Two respondents even stated that all agency management is alike, except for their people. They considered the interpersonal relations as an important reason to stay. Planning bonds were mentioned by clients who stayed because of the efficiency created with this agency, and the tradition that had been established. Another respondent was actually stuck in the relationship, because of internal politics and organisational culture.

However, most were very critical towards their agency, and when asked directly, they stated that they would loose nothing from a switch, apart from the costs of building a new relationship. Especially the two smaller clients were concerned with the idea that agencies should not take them for granted and should be kept wide awake.

In addition to these reasons, clients also mentioned other reasons to stay in the relationship:

Trust

Four clients specifically mentioned that they trusted their agency, which was an important reason to maintain the relationship. One client expressed a great concern regarding this issue, and said that if the agency became too self-confident or would not have the clients best interest at heart anymore, they would leave immediately. One other client just had a trust-breaking incident with its agency: they found out that the agency had invoiced them too high on some parts of the work. They felt so betrayed that they invited three new agencies to present their ideas. Special arrangements with the current agency finally made them decide to maintain the relationship, but the incident resulted in a different attitude towards the agency. They now carefully watch the agency and almost wait for the next incident that will definitely break-up the relationship. Their commitment to the agency thus seems to be lower than before.

These examples illustrate that trust is an important factor in the maintenance of an agencyclient relationship. Both Halinen (1994) and LaBahn \& Kohli (1995) found in their empirical studies on agency-client relationships that trust is an important antecedent to clients' commitment to the relationship. Halinen (1994, p. 279)) defined trust as "One party's belief that its needs will be fuifilled in the future by actions undertaken by the other party". She found that trust was incurred by the agency's capabilities and expertise on the one hand and specific behaviours during the relationship on the other. LaBahn \& Kohli (1995, p.4) defined trust in the agency only in the behavioural way as :"the clients' willingness to rely on the agency's judgement, advice and behaviour" . They argue that a primary consideration in clients' commitment is the degree to which the agency has the clients' best interest in mind. If clients feel they can rely on their agency, there is little incentive to switch to another agency whose dependability is still unknown.

The examples from the interviews, however, also show that trust is not the only reason for relationship maintenance. Even after the trust-breaking incident described by one client, they eventually did return to this agency. Another reason to stay according to the clients was the satisfaction with the agency's work. 


\section{Service quality 4}

Our client-respondents mentioned the creative ideas, the delivered work and the quality of the agency also as important reasons to stay. These were mentioned by half of the respondents. An equal amount of respondents mentioned that the 'dry-up' of new creative ideas of their current agency would be a reason to terminate the relationship.

In the study by Wackman et al: (1987) it was found that the most important reason to switch agencies was dissatisfaction with the creative work and the effectiveness of this work. Halinen (1994) found in her qualitative longitudinal study that clients" satisfaction with the creative output, the price and the service process were given as reasons for a committed attitude of clients and for long and stable relationships. LaBahn \& Kohli (1995) found in their quantitative analysis that the 'creative and implementation quality' of the agency, and the 'productive interactions' with the agency contributes the strongest to clients' commitment, compared to the 'trust' in the agency and the 'conflicts' in the agency-client relationship. Unfortunately, they did not include relational bonds in their analysis of antecedents to clients' commitment in agency-client relationships.

One respondent mentioned that his organisation would stay with the agency even if the quality of the work would become less, because of the good relationship with the agency. Another respondent was dissatisfied with the work from the agency, but still maintained the relationship because of company-internal rules and policies. The dissatisfaction did, however influence the commitment to the agency. In fact, he used other agencies on the side to compensate for the deficiencies of this agency.

From this exploratory evidence it seems that service quality is indeed related to customers' relationship commitment. The information gathered supports this proposition. However, how service quality contributes relative to the other identified antecedents is hard to tell firom this evidence. There seems to be a kind of trade-off between the different antecedents.

\subsection{Conclusion exploratory research: evidence for research model}

The findings from the exploratory research will be summarised per research objective. They are graphically presented in the adjusted research model for advertising services in figure 4.5 .

1. Five key quality determinants for customers' assessment of advertising services.

Based on the studies in the advertising market and the client interviews, supporting evidence was found that all five quality determinants are incorporated into clients' quality assessments of the agency's services. The potential quality, the hard process and soft process quality, and the immediate and final outcome quality are all part of clients" overall perceived service quality.

\section{Relative importance of the quality determinants.}

Although all five determinants seem to be relevant for the quality perception of advertising senvices, the exploratory studiy indicates that not all determinants are equally important for clients overall perceived quality. Clients use primarily the service process (hard as well as soft), and its immediate outcome as indicators of quality. The potential quality and the final outcome of advertising services do not seem to be as important for clients' overall evaluation of the agency's services.

4 For a discussion on the concepts of service qualify and satisfaction see footnote 2 in chapter 3 . lt suffices herre to say that the concepts are strongly related, and that customers are accustomed more to speak in terms of satisfaction than service quality. 


\section{Relationship commitment in advertising agency-client relationships}

The distinction into affective and calculative commitment has not been used in studies in the advertising market, but a comparable distinction was found in one study on agency-client relationships (Halinen 1994). The interviews with the clients and agencies provided some support that the two kinds of commitment exist in agency-client relationships. When asked directly however, clients were very reluctant to admit that they are committed to their agency, apart from the expected costs of switching. Agencies, on the other hand, indicated that some of their clients are very committed to the relationship. The concept of affective commitment is researched most often in agency-client relationships, confirming its existence, although it is assumed to be less strong than in other business relationships. The existence and relevance of calculative commitment in agency-client relationships could not be assessed from the exploratory research. Even though clients do perceive switching costs, it remains unclear whether these are related to customers' perceived need to continue the relation.

\section{Antecedents to relationship commitment in agency-client relationships.}

The exploratory research indicates that our proposed antecedents, i.e. relational bonds, trust and service quality, are also relevant for agency-client relationships. Relational bonds were found to exist. Indications were found as to the kind of bonds that are created in agency-client relationships; these are knowledge bonds, planning bonds, social bonds and economic bonds. Trust is supported by different sources to be an important antecedent to relationship commitment also in agency-client relationships. Although senvice quality as we defined it, is not studied by others, customers service and quality evaluations were found to be positively related to the maintenance of the relationship and to clients" relationship commitment.

The information supported the proposition that service quality contributes positively to relationship commitment, however, its relative contribution could not be assessed. Although it was found to be the most important reason to terminate a relationship "this does not necessarily mean that it is also the strongest contributor to the motivations to stay. There seems to be a trade-off between the different antecedents, in which the relative importance of service quality is not yet clear. This has to be explored in the field study.

Figure 4.5: Adjusted research moctel for the advertising market ${ }^{\text {s }}$

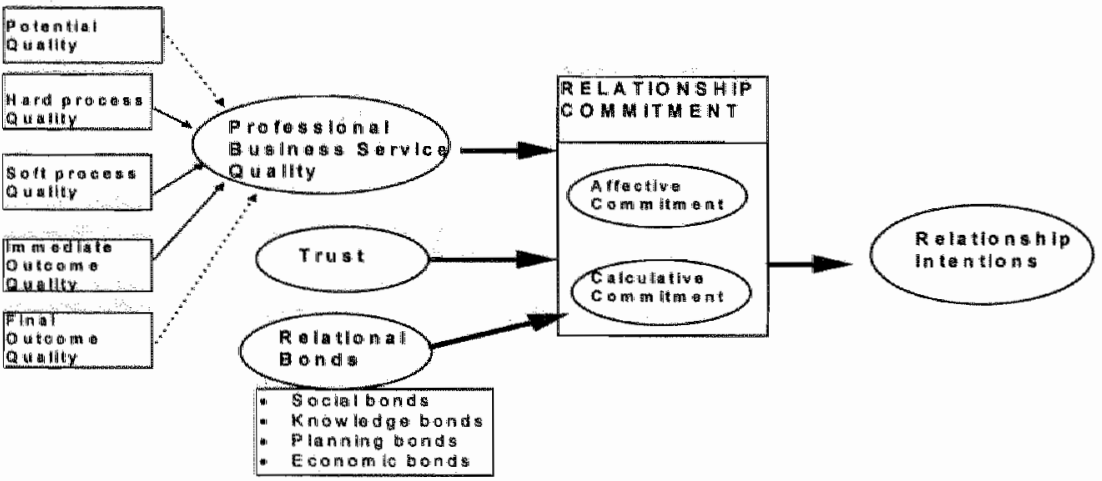

5 The broken lines indicate the proposed lesser importance of the qualily determinants. 


\section{Chapter 5: The Measurement Instrument}

"Scire est mensurare"

(knowing is measuring)

Rule of $J$ Kepler

\subsection{Introduction}

The exploratory research described in the previous chapter was the first step in the empirical research design (see table 4.1). In this chapter the second step is described before the quantitative field study can be carried out. Quantitative field studies put rigorous demands on the measurement instrument used. Drawing conclusions from a large group of respondents, implies that the information gathered should be comparable between respondents and thus be gathered in a standardised way. As stated in the research design in section 4.3 , descriptive research presupposes a broad base of knowledge of the concepts under study. The literature review and the exploratory research provided this knowledge, based on which the measurement instrument could be developed. In this chapter the development of this research instrument will be described. This instrument was pre-tested in a qualitative fashion, especially regarding the proposed conceptualisation of professional business service quality and the relational bonds in agency-client relationships. This pre-test and the resulting adjustments to the measurement instrument will be discussed, and the chapter will conclude with the final questionnaire used in the field study described in chapter 6.

In section 5.2 the entire procedure that is used to develop reliable and valid measures for the focal concepts in the research model will be described. In section 5.3 the first two steps of this procedure will be addressed by defining the focal research concepts and their operationalisation into the rough items developed from the literature review and the exploratory research. In section 5.4. the third and fourth step of the procedure will be addressed by the pre-test of the rough measures and the adjustments that resulted from this pre-test. These steps resulted in the final questionnaire, which is presented in appendix 1. In section 5.5. the (adjusted) conceptualisation of the focal concepts will be summarised in the research model.

\subsection{Developing the measurement instrument: methodology}

The research model consists of the proposed relations between five focal concepts: service quality, relationship commitment, relationship intentions, relational bonds and trust. In order to draw conclusions about these concepts and their interrelations, valid and reliable indicators of these concepts have to be developed, by which the concepts can be measured in a quantitative study. The validity of a measure is the degree to which it measures the concept it is designed to measure. This means that differences in the observed scores of the measure should reflect true differences in the characteristic one attempts to measure. The reliability of a measure is the degree to which the concept is measured in an error-free way. This means that independent but comparable measures of the same concept should agree with each other. Using multiple items to measure a construct enables the researcher to assess the reliability and provides indications for the validity of the measure. Therefore, the concepts and their underlying dimensions should be measured by multiple items. 
Churchill (1979) proposes eight steps for developing valid and reliable measures of complex constructs. This procedure was used to develop the measures for our focal concepts. In this section the purpose of each step will be shortly explained and the activities will be described that were conducted in each step for the development of our measures. In table 5.2. the activities are summarised for each step. In sections 5.3. and 5.4 the execution of the first four steps will be described.

\section{Specify the domain of the construct}

In this step the researcher must first define the construct to be measured and the boundaries of what is included and what is excluded from the definition. The research concepts and their boundaries were defined from the literature reviewed in chapters two and three.

\section{Generate samples of items}

The next step is to generate as many items that capture the domain specified in step 1. Literature search, interviews with experts and stimulating examples (cases) could all be used to generate items. A set of items should be developed that tap each of the dimensions of the construct at issue. The thus generated items should then be edited for clarity and wording.

In this step, items were generated for each of the concepts. Existing item-scales from other studies and the exploratory research provided useful information for the measurement of our research concepts. Based on this, existing items were reformulated or new items developed that capture the meaning of a construct and its sub-dimensions.

\section{3. \& 4. Data collection and measure purification}

In these two steps the generated items should be tested on a sample of respondents. Based on this pre-test, the measures can be purified by their metric properties and statistical relations. Because of the exploratory nature of our concepts, and the relative newness of measuring some of them in the advertising industry, we first tested the theoretical logic of the concept as a whole, and the practical relevance of our operationalisation of these constructs. Therefore, after the exploratory research, another in-depth analysis was conducted regarding the research concepts. Four activities were performed for this:

- interviews with two clients

Two clients were approached in July 1995 to discuss our theoretical ideas and operationalisations in face-to-face interviews. The respondents were agency clients that had already participated in the exploratory research and were located in Maastricht. Our goal was to find support for the conceptualisation of the constructs, to find support for the items generated in step 2, and eventually to explore whether important items/aspects were missing. Therefore, we first explained each concept and its conceptualisation (sub-dimensions) to the respondents and then asked their opinion about the logic and relevance of the conceptualisation, and whether aspects were missing. We then described each concept or sub-dimension separately (e.g. 'potential quality") and asked the respondents to name any aspect they thought belonged to that concept or sub-dimension. Finally, the respondents were asked to react to the items we had generated for each concept/sub-dimension. Based on these interviews, support was found for the practical relevance of our conceptualisations and new items were added or old ones adjusted. 


\section{- interviews with two academic advertising experts}

Two interviews were conducted face-to-face with two academic experts in the advertising field in September 1995. One respondent is a professor of economic psychology specialised in advertising research, and the other respondent is a professor of communication studies and exmanaging director of the largest advertising agency in The Netherlands. Our goal was to get their expert opinion about the proposed research model, our conceptualisation of the concepts, and the operationalisation of these concepts (= items). Because of their expertise, the respondents were asked to reflect on both the theoretical as well as practical relevance of the topics asked. The respondents received the following material before the interview: a summary of our theoretical ideas, the research model, a definition of each of the concepts and their subdimensions, and a list of the measurement items per concept and sub-dimension developed so far. In these interviews, our main ideas and concepts were supported by both respondents and they pointed us to possible pit-falls and difficulties in the measurement instrument, and the advertising terminology. This resulted in the adjustment of some items and the creation of the questionnaire that was used for the following pre-test step:

- survey among six advertising agencies

In Sept./October 1995 six advertising agencies that also participated in the exploratory research, were approached with a questionnaire. Three returned it by mail, and with one agency the questionnaire was discussed face-to-face. The questionnaire was rather complex and timeconsuming and despite their consent to participate, the remaining agencies did not return it before the deadline.

The goal was to get more concrete feedback on the operationalisation of the concepts.

1. Because the conceptualisation of senvice quality and the relational bonds are relatively new, respondents were specifically asked to give feedback on the conceptualisation of these two concepts. The definition of the service quality concept with its proposed five determinants, and of the relational bond concept with its proposed four sub-dimensions, were described and respondents were asked to rate the relevance of this conceptualisation for the advertising market on a four-point scale (not relevant-very relevant) and to indicate whether a crucial aspect was missing.

2. For feedback on the operationalisation of all the concepts, descriptions of each concept with their sub-dimensions were given, and the items developed for each concept by the previous steps and interviews. Respondents were asked to rate each item on: the relevance of the item for measuring the underlying construct/dimension in the advertising market, the clarity of the item for the advertising market, and to give an overall evaluation of each item. Respondents had to rate each of these aspects on a four-point scale', ranging from bad-very good. For the service quality items the respondents were also asked to choose the three items they thought were the best indicators of each quality determinant, and to indicate whether they thought an important aspect was left out. This was done to reduce the item-set developed for this concept. However, we made sure that not too many items would be deleted based on their judgement only, because in the final research the clients' judgement is central.

The respondents all agreed to the conceptualisation of the service quality concept, while the conceptualisation of the relational bonds was slightly adjusted. Regarding the operationalisation the concepts, some items were adjusted and some deleted from the questionnaire. The questions were then edited, and a lay-out of the questionnaire was chosen.

\footnotetext{
1 Because one of our goals was to select items we used an even numbered scale. These scales have no neutral mid-pioint, which forces a mespondent to rate each items either on the positive or negative side of the scalle.
} 
- pre-testing questionnaire with six clients and four colleagues

The resulting questionnaire from the previous step was then pre-tested on a small sample of advertisers (clients) who also participated in the exploratory research. The goal was to test the scaling of the items, to reduce items, to adapt the wording of items, and to test the lay-out and length of the questionnaire. The researcher visited three clients at their premises in October 1995 and asked them to complete the questionnaire in her presence, giving any comments they had while answering the questions. Specific questions were then asked regarding the layout and ease of answering. Three other clients received the questionnaire by mail, and were asked to complete the questions, and to write down any comments they had regarding the questions, layout and ease of answering. Their comments were retumed in October 1995.

Then; four colleagues from the marketing department, working in the field of service quality or business relationships, were asked to react to the questionnaire. The items were discussed in personal interviews based on the respondents' experience with survey research and their knowledge about other scales of service quality and relationship variables. The content, wording and scaling of the items were discussed. Based on these comments the items and lay-out were adapted.

As a final check for the clarity and wording of items, three persons who have nothing to do with academic research nor with the advertising industry were asked to read and comment on the questionnaire. These respondents were personal friends and a relative of the researcher. Their comments were used to refine the wording, clarity, and lay-out of the questions further. Based on these comments the final questionnaire was made.

\section{Data collection}

The next step in the procedure is then to test the (adjusted) measurement instrument on a large sample of respondents, based on which the final properties of the scales can be assessed. In our field study a large-scale sample of advertisers was approached with the refined questionnaire. The field study will thus be used to validate the concepts, and then to analyse their interrelations. We chose to do this for several reasons. First of all, we were confident about the measures used, because most are based on previous research and the concepts are pretested in-depth by the previous steps. Secondly, the field study is exploratory in nature, and the conceptualisation of the service quality concept is one of its research goals. And, finally, practical considerations underlie this decision. Time-constraints and the limited availability and accessibility of respondents made us decide against two separate field studies, in which the measures are analysed separately from their interrelations. Therefore, one large-scale field research will be conducted, in which the measures and their interrelations are simultaneously explored.

\section{6. - 8. Reliability, validity and noms.}

Based on the large-scale study, the reliability and validity of the items can be computed and the measures can be finally purified. The assessment of the reliability and validity of the measures will be carried out by confirmatory analyses that provide better indicators than the conventional methods suggested by Churchill (1979). The methods described by Gerbing \& Anderson (1988) and Steenkamp \& Van Trijp (1991) will be used, in which the assessment of the unidimensionality of a scale play a central role. Confirmatory factor analyses are needed for these methods, which will be conducted using the statistical package of LISREL8. The concepts in the research model are abstract social and behavioural concepts that are measured by multiple 
items. In LISREL teminology these concept are "latent constructs", and the items are the "indicators" of these constructs. If the construct is measured validly and reliably, the indicators should all share one underlying factor, reflected by an uni-dimensional scale that measures the latent construct. For multidimensional constructs (like our concept of senvice quality), each subdimension should be regarded as a latent construct that is measured by several items, which should form uni-dimensional scales to measure each sub-dimension validly and reliably. Because the dimensions are sub-dimensions of one concept, they should, in turn, also have one underlying factor in common, i.e. the main construct.

Gerbing \& Anderson (1988) and Steenkamp \& Van Trijp (1991) describe a procedure for assessing and enhancing the uni-dimensionality of measures. This procedure is used to develop reliable and valid scales for the research concepts and their proposed sub-dimensions. The procedure consists of three main steps:

1. Item-totall correlations.

A first indicator of uni-dimensionality is the item-total correlations of the items measuring one latent construct. This is a measure of the (cor)relation between one item and the rest of the items. Items with item-total correlations of 6 or above are supposed to be good indicators of the scale itt shares with the other items, i.e. one underlying construct. If a construct consists of more than one dimension, this analysis should be done for every sub-dimension separately. Items with low item-total correlations do not share enough variance with the other items, to justify the assumption that it measures the same construct as the other items. The scales can be purified by deleting these items.

\section{Exploratory factor analysis.}

The reduced set of items can the be explored further by explaratory factor analyses for each of the constructs or sub-dimensions. Items that are proposed to measure one construct should all load on only one factor. This way the dimensionality within each construct or sub-dimension can be examined. The analysis is thus confirmatory in the sense that it examines per construct whether the items are indeed unidimensional. The items can then be further reduced by selecting those items with the highest factor loading on their proposed construct.

\section{Confirmatory factor analysis.}

In this last step, the remaining items will be subjected to a confirmatory factor analysis, to confirm the dimensionality within the items. Using LISREL for this analysis provides an assessment of how well the observed interrelations between all the items fit to the proposed measurement model ${ }^{2}$. Next to this overall fit, it gives indications of the reliability and validity of each scale, and estimates the measurement error of each individual indicator (=item). Based on this analysis, indications are given about how the measurement model could be modified in order to give a better representation of the observed interrelations between the items. Unsuspected subdimensions can be detected and poor performing items identified. Adjustments should, how. ever, only be made if theoretically justified.

The measures and parameters that LISREL8 provides and the meaning they have for assessing the 'goodness' of a proposed measurement modell will be described below. These indices will be used to purify the measurement scalles and to assess their reliability and validity.

\footnotetext{
2 In the measurement model is specified which indicators belong to which latent construct. Severial concepits/sutb-dimensions can be speciffed within one measurement model.
} 
'Confirmatory' is the central word in a confimatory factor analysis for it can only confirm (or reject) a factor structure that is specified beforehand by the researcher. Therefore, a measurement model is specified beforehand, the 'goodness' of which will be assessed by the confirmatory factor analysis. Several authors suggested criteria for a good measurement model, which will be used in the assessment and improvement of the scales used for measuring the research concepts (Bagozzi \& Yi 1988, Steenkamp \& Van Trijp 1991, Jöreskog \& Sörbom 1993 "Hair et al. 1995). The criteria suggested to assess the overall model fit, and the criteria for the parameters estimates will be described separately and are summarised in table 5.1.

\section{- Criteria for overall model fit}

The first measure that LISREL provides is the 'gloodness' of the whole measurement model. It estimates how well the observed interrelations ${ }^{3}$ between the indicators fit to the proposed measurement model by several fit indices ${ }^{4}$. It thus tests whether indicators proposed to measure one construct are interrelated strong enough to measure one construct, and are related stronger with each other than with indicators proposed to measure another construct. The most important measure, on which all other are based, is the chi-squares goodness-of-ft test, which is actually a 'badness of fit' measure (Jöreskog \& Sörbom 1993). lt tests whether the implied(i.e. expected) interrelations from the model differ significantly from the observed interrelations between the variables. Therefore, the chi-square measure should be non-significant and its value should fall in between one and two times the degrees of freedom to indicate that the proposed measurement model fits well to the observed interrelations in the data. Because this absollute chi-square measure has some draw-backs ${ }^{6}$ other absolute fit measures are provided as well. The $\mathrm{GFI}^{7}$ (Goodness-of-Fit Index), and $\mathrm{AGFI}^{\mathrm{B}}$ (Adjusted Goodness of Fit Index), are both less dependent on the sample size than the chi-square measure and relatively robust against deviations from normality (Bagozzi \& $\bigvee_{1}$ 1988). Both indices assess how much better the proposed measurement model fits to the data as compared to no model at all, i.e. before any model has been fitted to the data (Jöreskog \& Sörbom 1993). Both indices should be close to 1 . preferably above 9 . to indicate that the proposed measurement model reflects an acceptable representation of the observed interrelations within the items.

Next to these absolute fit measures, also relative fit measures are provided that test how much better the proposed model fits to the data compared to a baseline model, usually the independence model. The CFI' (Comparative Fit Index) should be above. 90 to indicate that the proposed interrelations are better than no interrelations at all (i.e. when all variables are independent).

\footnotetext{
3 Correlations or covariancess.

4 LISREL estimates the (free) parameters in the proposed model $(0)$ ) such that the observed covaniances between the variables (S) are maximally reproduced by the estimated model. Based on the estimated and fixed parameters an implled covariance matrix between the wariables can be calculated: $\Sigma_{\theta}$. Different estimation procedures can be used to minimise the difference between the observed $S$ and the estimated $\Sigma_{0}$ using a fit function $F\left[S, \Sigma_{0}\right.$ ] that should be minimised. The overall model fit measures indicate how similar the implied covaniance matrix of the estimated model is to the observed covariance matrix (i.e. $H_{0}: S=\Sigma \theta$ ). The closer $\Sigma_{0}$ is to the observed covariances (S) the better the proposed model is.

5 Chil-squere is $N-1$ times the minimum value of the fit function, where $N$ is the sample size: $(N-1)^{*} F[S, \Sigma 0)$.

6 See e.g. Jöreskog \& Sörbom 1993, p.121-122, or Bollen 1989.

$7 \mathrm{GF}$ reflects the relative amount of (co)variances of $S$ that are predicted by $\Sigma_{0}$, and is deffned as: $1-\left(F\left[S, \Sigma_{0}\right) / F\left[S, \Sigma_{0}\right)\right.$, i.e. one minus the minimum of the fit function of the estimated model divided by the fit function before the parameters have been estimated(i e parameters $=0$ ).

8 The AGFI adjusts the GFI for model parsimony, l.e. the degrees of freedom melative to the amount of variables: $1-\mathrm{k}(\mathrm{k}+1)^{*}(1-\mathrm{GF})$, where $\mathrm{k}$ is the amount of variables and of the degrees of freedom.
}

प्रतli compt

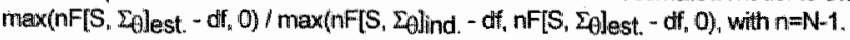


Another class of measures are non-centrality parameters that test for approximate fit of the model in the population instead of exact fit in the population as tested by the other measures. The RMSEA ${ }^{40}$ (Root Mean Square Error of Approximation) is a measure of the population discrepancy per degree of freedom. This measure should be as small as possible, with values preferably below .05 and maximally .08 .

\section{- Criteria for parameter estimates}

Besides the "goodness of fit" of the model as a whole, LISREL estimates parameters that give indications for the strength and significance of the association between each indicator and its proposed latent construct, based on the interrelations (i.e. covariances) between the indicators. E.g. if a construct is proposed to be measured by five items, LISREL assumes that the covariances between these five items is caused by the underlying construct they share. The observed variance in each indicator is divided by LISREL in an (estimated) variance that reflects the underlying construct, and in a remaining error variance. The error variance consists of the (random) measurement error in the indicator, and of the unique vaniance in the indicator that is not explained by the construct. Good indicators should be explained for a large part by the latent construct and should have relatively low error variance. For each indicator, LISREL estimates the standardised factor loading or standardised validity coefficient (called 'Lambda') and the multiple squared correlation, which both indicate the part of the indicator that is explained by the undertying construct. The standardised lambda of each indicator is recommended to exceed .60 , with a squared multiple correlation minimally around .50 , in order to be regarded as a reliable and valid indicator of the construct. The standardised lambdas of the indicators can also be used to calculate the (composite) reliability of the scale of indicators that measure one latent construct. This composite reliability is a better measure for scale reliability than the traditional Cronbach's Alpha measure, because it takes the measurement error of each indicator into account. Composite reliability ${ }^{41}$ is recommended to be above 70 . Furthermore, the percentage of variance extracted ${ }^{12}$ can be calculated, which represents the percentage of the variance in the indicators that is explained by the construct. This percentage is recommended to be minimally $50 \%$. These criteria are indicators of the reliability and the convergent validity of the constructs. The discriminant validity of a construct can be assessed if several constructs are included in the measurement model. If the analysis indicates a good overall model fit, it means that the constructs included in the measurement model can be clearly differentiated from each other.

Table 5. : Summary evaluation criteria of measurement modols

\begin{tabular}{lll}
\hline Kind of evaluation & Measure & Criterion \\
\hline \multirow{3}{*}{ Absolute model fit } & Chi-square & insignificant between $1-2$ fimes degrees of freedom \\
& GFI & $>=.90$ \\
Comparative model fit & CFI & $>=.90$ \\
Approximate model fit & RMSEA & $>=.90$ \\
Reliability of each indicatior & Lambda & $>=.05$, max. 08 \\
& Multiple $R^{2}$ & $>=.60$ \\
Reliability of indicator scales & Composite reliability & $>=.50$ \\
& Variance extracted & $>=50 \%$ \\
\hline
\end{tabular}

10 RMSEA is the population discrepancy per degree of freedom. The population discrepancy function is defined as: $\max \{F[S, \Sigma q]-(d f / N-1)$, of , where $F[S, \Sigma \theta]$ is the minimum value of the fit function.

11 Composite reliability $=(2 \lambda)^{2} /\left[(\Sigma \lambda)^{2}+\Sigma\left(1-\lambda^{2}\right)\right]$, cf. Hair et all. 1995

12 Explained variance $=\Sigma\left(\lambda^{2}\right) /\left[\left(\lambda^{2}\right)+\Sigma\left(1-\lambda^{2}\right)\right]_{1}$ of. Hair et al. 1995 
Because the data from our field study will be used to purify the scales and to assess the validity and reliability of the focal concepts, the results of this analysis will be described in chapter 6 after the design and execution of the field study is discussed. The purified reliable and valid scales for the concepts that result from this analysis (see chapter 6 ), will form the input for exploring the proposed interrelations between the concepts. The research modell and propositions will be analysed in chapters 7 and 8 . In the remainder of the current chapter the results of each of the first 4 steps of the development of our measurement instrument will be discussed: the focal research concepts will be defined, the rough items that were generated and the results of the qualitative pre-lest of these items will be presented. This chapter will conclude with the fina: measurement instrument used in the field study. This structure is presented in table 5.2.

Table 5.2 : Steps in measurement development and chapter reference of their results.

\begin{tabular}{|c|c|c|}
\hline Steps & What we did & Chapter reference \\
\hline $\begin{array}{l}\text { 1. Specify doman of construct } \\
\text { 2. Generate sample of items }\end{array}$ & $\begin{array}{l}\text { - Literature review } \\
\text { - Secondary data } \\
\text { - Exploratory research advertising market }\end{array}$ & Section 53 \\
\hline $\begin{array}{l}\text { 3. Collect data (pre-test) } \\
\text { 4. Purify measure }\end{array}$ & $\begin{array}{l}\text { - Pre-testing with in-depth interviews: } \\
\text { Selected cases: } 2 \text { clients } \\
\text { Fleld experts : } 2 \text { professors } \\
\text { Key infonmants: } 4 \text { agencies } \\
\text { - Pre-test questionnaire } \\
\text { Colleagues (4) } \\
\text { Clients face-to-face (3) } \\
\text { Clients by mail (3) } \\
\text { - Interpretation of qualitative data } \\
\text { - Final check unrelated persons (3) }\end{array}$ & Section 5.4 \\
\hline $\begin{array}{l}\text { 5. Collect datia } \\
\text { 6. Assess measure reliability } \\
\text { 7. Assess measure validity } \\
\text { B. Develop noms }\end{array}$ & $\begin{array}{l}\text { - Final research: mail sunvey } \\
\text { - Factor analysis } \\
\text { - Composite scale reliability } \\
\text { - Explained scalle variance } \\
\text { Construct validity } \\
\text { - Descriptive statistics }\end{array}$ & Chapter 6 \\
\hline
\end{tabular}

\subsection{Developing the rough measures}

In this section the conceptualisation and operationalisation of the focal research concepts are described. The domain of each concept will be defined and the measures that were generated to capture this domain. The measures are based on a literature review and the exploratory research in the advertising market.

\subsubsection{Measuring service quality}

In the proposed service quality model, customers' overall quality perception of professional business senices is based on five quality determinants. In measurement terminology, these determinants can be seen as sub-dimensions of the overall service quality construct. To explore the feasibility of this proposed structure in the field study, the service quality concept is operationalised on three levels: 1) customers' overall perceived service quality of their advertising agency; 2) customers' overall evaluation of each of the five service quality determinants, and 3) each service quality determinant is operationalised by multiple items that cover the domain of each determinant. Therefore, the domain of overall perceive service quality will be specified, 
and the domain of each service quality determinant separately, which should be reflected in the items that measure the construct as a whole and its proposed sub-dimensions. In chapter 2 the definition of perceived service quality and each quality determinant were discussed.

Overall perceived service quality is defined as 'the customers' overall assessment of the excellence of superiority of a service provider, based on an accumulated perception of all previous experiences with the service provider'. This concept should be captured in all its abstractness. Therefore, several items were developed that measure this broad overall evaluation of service quality. Many studies on service quality include one or more overall quality evaluation items, to which the more concrete dimensions or attributes can be related ( Cronin \& Taylor 1992, Liljander \& Strandvik 1994, Parasuraman et al. 1994). Three items are developed that measure this concept in different ways:

1. customers' rating of their agency's overall delivered service quality (anchors: very lowexcellent quality);

2. customers' rating of their agency's service quality compared to other agencies (anchors: much worse than other agencies - much better than other agencies); and,

3. customers' overall judgement of their agency on the Dutch school grading scale (1-10, with 10 meaning excellence).

The five service quality determinants were defined as:

1. Potential Quality: the customers' evaluation of the available human, material and financial potential of the service provider to perform its services;

2. Soft Process Quality: the customers' evaluation of the interactions with and treatment of the customer during the service production process;

3. Hard Process Quality: the customers' evaluation of the (technical) way in which the coreservice is produced by the service provider;

4. Immediate Outcome Quality: the customers' evaluation of the direct outcome of the service production process; and,

5. Final Outcome Quality: the customers' evaluation of the final results or consequences of the (implemented) service outcome.

In order to measure customers' overall evaluation of each of these quality determinants the definitions were translated into advertising terminology, resulting in the following five items:

- customers' overall rating of the available potential at their agency (available means, expertise, service range, personnel and management);

- customers' overall rating of the way the agency communicates with and treats them;

- customers' overall rating of the professionalism and way of working of their agency;

- customers' overall rating of the work made for the customer by the agency (concepts, campaigns and advertisements); and,

- customers' overall rating of the effectiveness of the work delivered by their agency.

The operationalisation of the five quality determinants should of course reflect the broad definitions given above. Since our goal is to explore the existence of these five determinants their operationalisation should be consistent with the existing operationalisations of customers' perceived service quality. As demonstrated in chapter 2 , table 2.3, the ten universal service quality dimensions found by Parasuraman et al. (1985) can be classified into our five quality determinants. Also the additional findings from the studies on professional business service quality were classified into our proposed five quality determinants. Integrating this existing knowledge into our five determinants gives a further specification of the domain to be covered 
by each deteminant, and provides guidelines for their measurement. The five deteminants should thus reflect the following service aspects (see section 2.6 .6 for an explanation of the tems):

Table 5.3: Ovenview of quality elements to be covered by each quality deteminant

\begin{tabular}{|c|c|c|}
\hline Five service quality determinants & $\begin{array}{l}10 \text { dimensions PZB } \\
\text { (SERVQUAL) }\end{array}$ & $\begin{array}{l}\text { Additional findings professional } \\
\text { business services }\end{array}$ \\
\hline Potential Quality & $\begin{array}{l}\text { Competence } \\
\text { Tangibles } \\
\text { Credibility }\end{array}$ & Reputation /inage \\
\hline Soft process Quality & $\begin{array}{l}\text { Courtesy } \\
\text { Accessibility } \\
\text { Credlibility } \\
\text { Communication } \\
\text { Understanding customer }\end{array}$ & \\
\hline Hard process Quality & $\begin{array}{l}\text { Relliabilly (functional) } \\
\text { Responsiveness } \\
\text { Competence }\end{array}$ & $\begin{array}{l}\text { Functional reliability } \\
\text { Adaptation and Flexibility } \\
\text { Recovery }\end{array}$ \\
\hline Immediate Outcome Quality & Reliability (technical) & $\begin{array}{l}\text { Technical reliability } \\
\text { Performance/outcome }\end{array}$ \\
\hline Final Outcome Quality & Reliability (technica) & Ultimate Outoome \\
\hline
\end{tabular}

To generate items that reflect these aspects and that are applicable to advertising services several studies were reviewed that measured clients' evaluation of advertising agencies and their services. The studies used are listed in table 5.4 .

Table 5.4: Empirical studies regarding clients' evaluation of advertising services

\begin{tabular}{|c|c|c|c|}
\hline Authoms & Collintry & Measurement of: & lltems \\
\hline Wackman et al. 1987 & USA & $\begin{array}{l}\text { Clients' perception of agency services regarding: work } \\
\text { product, work pattem, relationship and organisation }\end{array}$ & 18 \\
\hline Verbeke 1988 & The Netherlands & $\begin{array}{l}\text { Clients' satistaction rating of agency services (based on } \\
\text { Wackman study) }\end{array}$ & 20 \\
\hline Kaynak et al 1994 & Turkey & $\begin{array}{l}\text { Clients' satisfaction rating of agency services (based on } \\
\text { Wackman study) }\end{array}$ & 20 \\
\hline Bochowe 1994 & The Nethertands & Clients' importance and perception rating of agency services & 39 \\
\hline Halinen 1994 & Finland & $\begin{array}{l}\text { Open interviews on clients' evaluation of process outcome, } \\
\text { service outcome and ultimate service outoome. }\end{array}$ & 13 \\
\hline
\end{tabular}

The studies by Halinen (1994) and Wackman et al. (1987) used comparable service evaluation dimensions as the five quality deteminants (see chapter 4, section 4.5.4). Verbeke (1988) and Kaynak et al: (1994) replicated the study by Wackman et al. with slight adjustments in their items for their respective countries. The study by Bochove (1994) is a large scalle study of Dutch advertisers in which he used an exhaustive pool of items about the evaluation criteria clients use to assess advertising agencies. The items used in these studies are classified into each of the five quality determinants to which they are most suited (see table 5.5). The classifications were done independently by the researcher and two other judges, who had assisted in studies in the advertising market before and who are acquainted with service quality teminology and the five quality determinants. Items that were placed under different determinants were discussed, and based on consensus assigned to the determinant that was most applicable. In table 5.5 this categorisation is summarised. 
A second source for generating items that reflect the five quality determinants for advertising services is the exploratory research. The six clients that were interviewed, explained which aspects they used to base their quality assessment of their agency on. In table 4.4 the mentioned quality aspects were classified into the five quality determinants. Based on this, items were generated that reflect the quality aspects mentioned by the respondents that are not covered by the other studies mentioned above.

Finally, this list of generated items is compared against the service quality aspects that should be theoretically reflected in each quality determinant, as portrayed in table 5.3. New items were developed for the quality aspects that are not covered by the items from the studies in the advertising market, nor the exploratory research. And items were deleted that do not cover any of the quality aspects from the theoretical models ${ }^{13}$. Based on these methods items are generated for advertising services that cover each of the quality aspects in table 5.3. In table 5.6 these rough items for each of the five quality determinants, and the (sub-)quality aspects they cover are portrayed.

\subsubsection{Measuring relationship commitment and its consequences}

Relationship commitment was defined as 'a party's intentionality to continue a business relationship'. The intentionality reflects the deliberateness of the intentions to keep the relationship that can be brought about by two underiying motivations, the desire to continue or the perceived need to continue. These motivations were defined as two dimensions of relationship commitment. In the measurement instrument both commitment dimensions will be operationalised. Because these dimensions are a party's motivation to continue the relationship, also measures for clients' actual intentions to keep the relationship will be developed. These behavioural intentions can validate the proposed dimensions of relationship commitment in agency-client relationships.

The two dimensions of relationship commitment were defined in chapter 3 as:

- affective commitment, which refers to the affective motivations, i.e. the desire and positive willingness to continue a relationship; and,

- calculative commitment, which refers to the calculative motivations, i.e. the perceived need, based on the incurred losses and costs of a switch, to continue a relationship

The measurement instrument should reflect these definitions.

13. As can be seen in table 5.5 , wery detalled questions were used in the advertising studies regarding the organisation of the agency (potential) and the immediate outcome. Only those items were selected that are more general and that reflect the theoretical quality aspects from table 5.3 . 


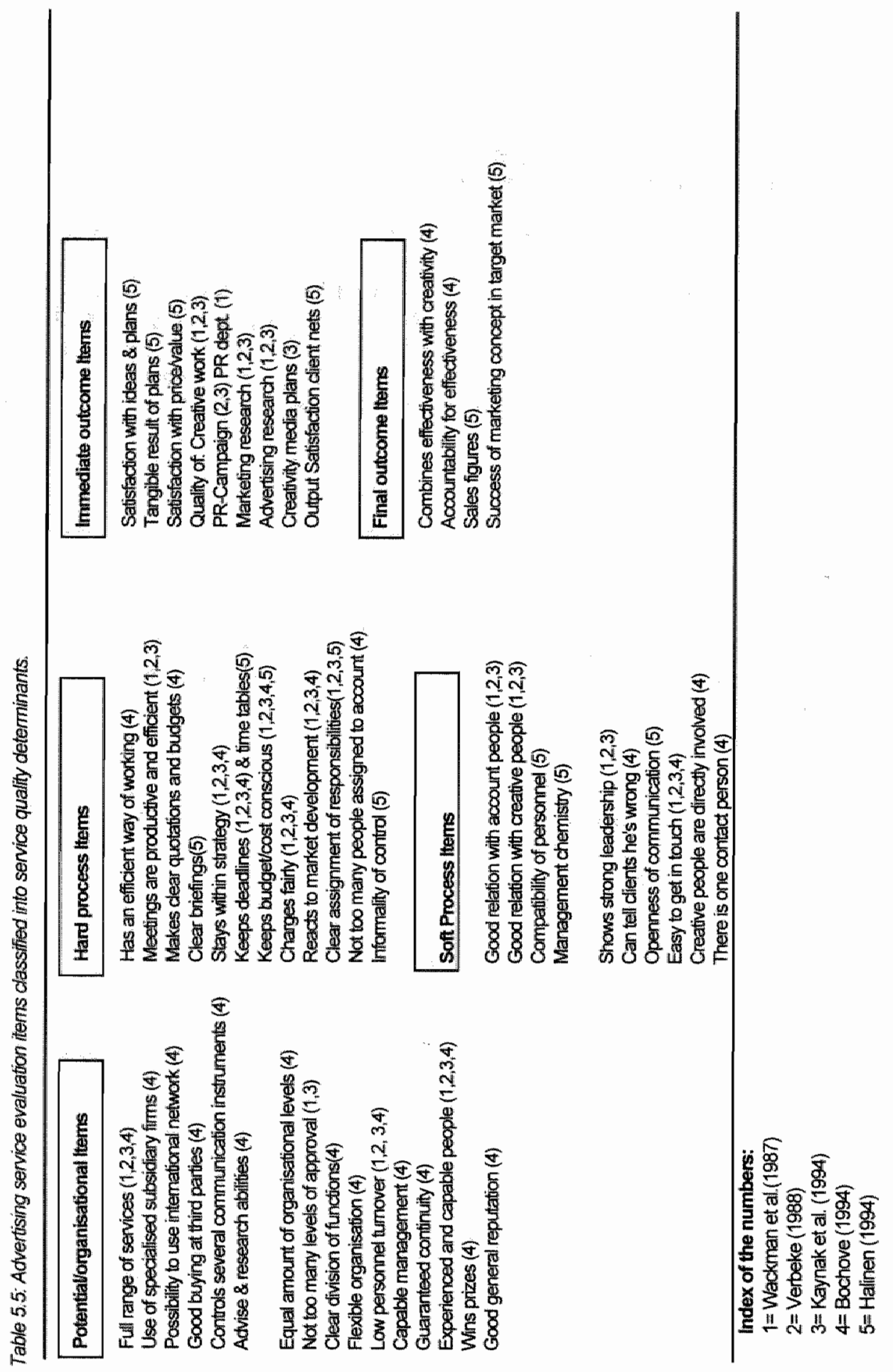




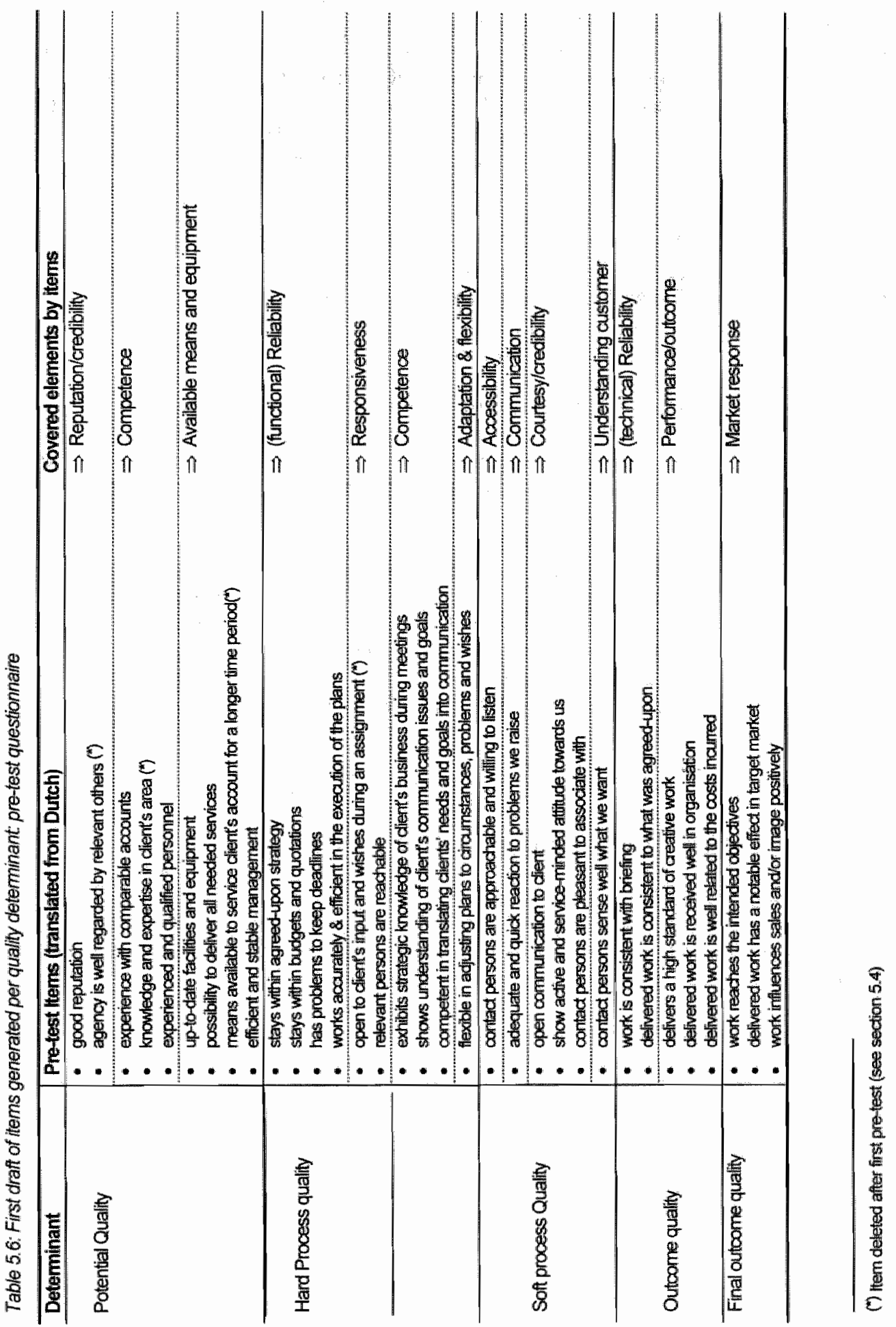


To generate items for each of the commitment dimensions studies were reviewed in which both dimensions of relationship commitment have been measured.

- Kumar et al. (1994) studied the nature of relationship commitment in marketing channels. One of their goals was to develop uni-dimensional, reliable and valid scales for measuring different types of commitment, in which affective and calculative commitment are included like we defined, in tables $5.7 \mathrm{a}$ and $\mathrm{b}$ these commitment scales are presented.

- Geyskens \& Steenkamp (1995) also used the distinction in calculative and affective commitment in marketing channel relationships. They cross-validated the measurement of both dimensions in two studies conducted in the Netherlands and in the USA. Because the measures are not given in their article, we contacted the authors. They gave us the items they used to measure affective and calculative commitment in both studies, and provided an additional item for measuring affective commitment they included in another (not yet published) study in Belgium. Furthermore, they suggested some additional items for both dimensions, that they had just developed and intended to use in a new study. All these items and their properties are presented in tables $5.67 \mathrm{a}$ and $5.7 \mathrm{~b}$.

- Also the Allen \& Meyer (1990) scales were checked that measure the dimensions of organisational commitment by employees, on which the scales by Kumar et al. (1994) and Geyskens \& Steenkamp (1995) are originally based. No additional items were found that were not already covered by the scales used in the channel studies. Therefore, these scales are not included in tables $5.7 a$ and $b$.

What was lacking in the commitment scales in these studies was a general sense of relationship commitment as is used by many authors studying business relationships. Many studies use an affective concept for commitment, which often includes an overall statement regarding a party's degree of sensed loyalty towards the other party (cf. Anderson \& Weitz 1992, Morgan \& Hunt 1994). Two of these overall items were added to our conceptualisation of affective commitment in the pre-test list of items. In tables $5.7 \mathrm{a}$ and $5.7 \mathrm{~b}$ the items generated for both commitment dimensions are summarised.

The behavioural intentions were conceptualised based on the article by Kumar et al. (1994), who found that the commitment dimensions are differentiated by their effects on different behavioural intentions. They identified three types of behavioural intentions:

- intentions to stay;

- intentions to invest in the relationship; and,

- intentions to search for altematives.

These intentions reflect the behavioural intentions clients have with the relationship, whereas the commitment dimensions reflect the motivations of why they stay.

The operationalisation of these three intentions is based on the validated scales used by Kumar et al. (1994). The items are adjusted to agency-client relationship terminology by the information from the exploratory research in the advertising market. Especially the investment intentions had to be adjusted for agency-client relationships compared to the dealer-manufacturer relationships studied by Kumar et al. The list of thus generated items is reflected in table 5.8. 


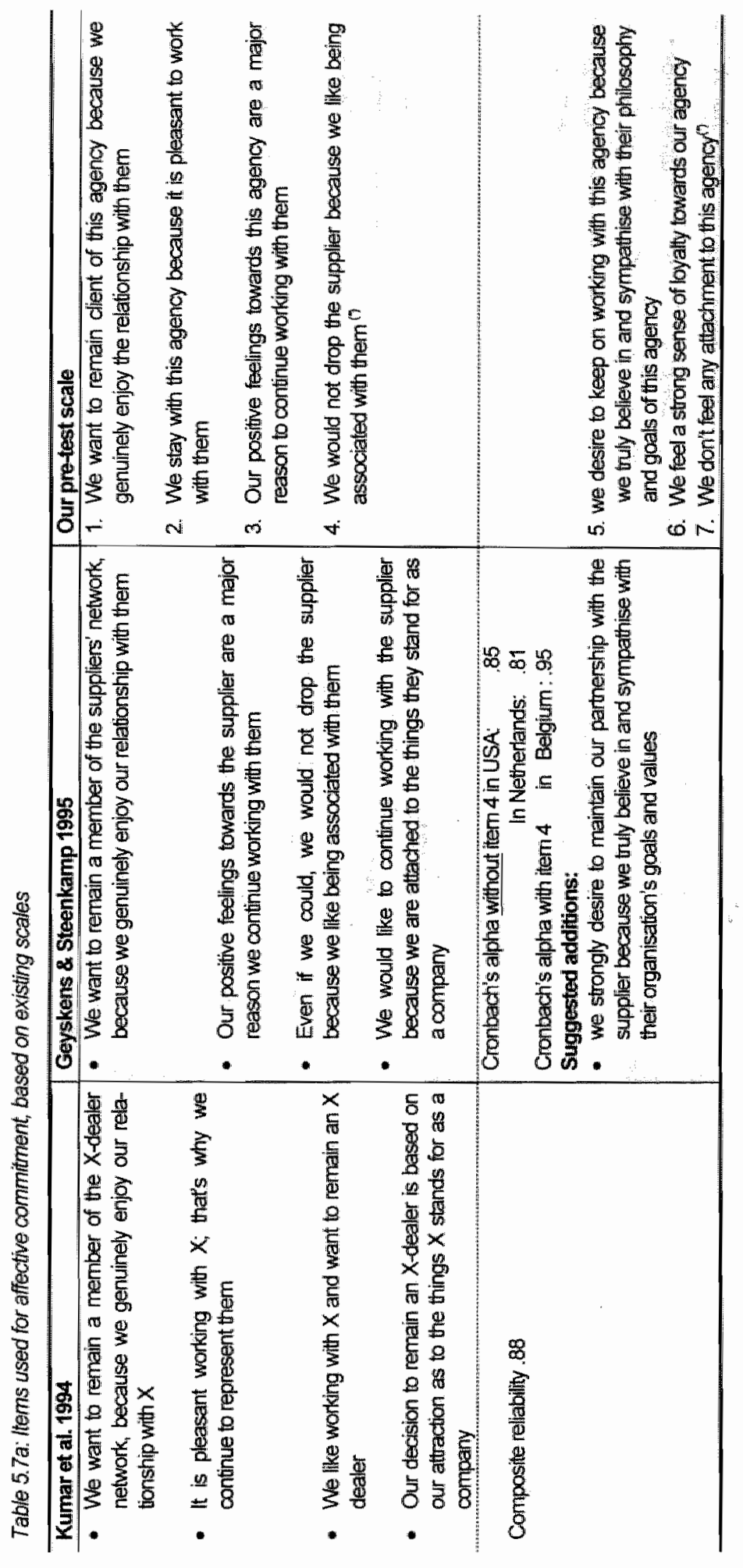



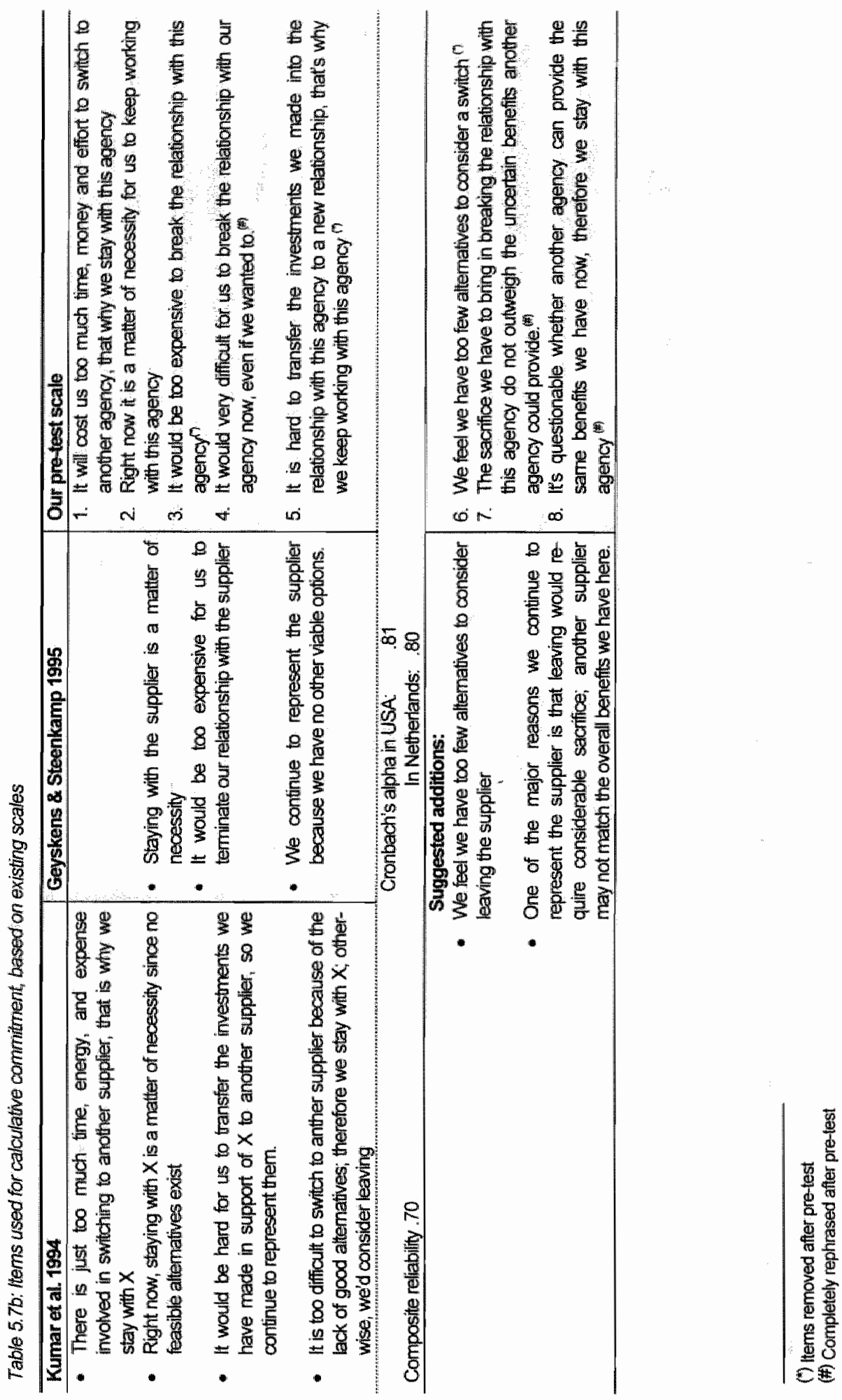
Table 5.8: ltems for measuning behavioural intentions

\begin{tabular}{|c|c|}
\hline Intentions & Items pre-test list \\
\hline Intentions to stay & $\begin{array}{l}\text { 1. The next communicalion assignment we have, we will give for sure to this agency } \\
\text { 2. The way things are now, we will surely keep this agency for a while } \\
3 \text {. It is highly unlikely that we will teminate the relationship within the next wo years n }\end{array}$ \\
\hline Intentions to invest & $\begin{array}{l}\text { 4. We want to involve our agency more in marketing and communication policy in the future } \\
\text { 5. We intend to assign more assignments, activities or product lines to this agency } \\
\text { 6. If necessary, we are willing to put effort in maintaining the relationship with this agency } \\
\text { 7. If this agency makes errors, we will immediately start to negotate with another agency }\end{array}$ \\
\hline $\begin{array}{l}\text { Intentions to search } \\
\text { alternatives }\end{array}$ & $\begin{array}{l}\text { 8. We are looking for alternatives, to reduce our dependency on this agency } \\
\text { 9. We intend to explore other agencies in the near future }\end{array}$ \\
\hline
\end{tabular}

\subsubsection{Measuring relational bonds}

Rellational bonds refer to all the ties that are built during a relationship that bind the parties together and will be lost if the relationship is terminated. As described in chapter 3 , these bonds can be defined in different ways. Based on the literature review of studies on relationships in professional business services, and the exploratory study in the advertising market four types of bonds were identified for agency-client relationships:

1. knowledge bonds: the relationship-specific knowledge that is created over the duration of a relationship. From a client perspective this means all the (confidential) knowledge that the agency has gained about the clients' business, goals and intemal policies. This knowledge will be lost if the client leaves the agency. The more knowledge that has been gained by the agency, the stronger this bond will be;

2. social bonds: the interpersonal ties and networks that are created during the course of a relationship. The interpersonal interactions form the glue that holds the organisations together. The broader these networks are, and the more intense and pleasant the interactions are between the interacting parties, the stronger this bond will be;

3. planning bonds: the inter-organisational agreements, routines and norms that have been established over the course of a relationship. These routines make the co-ordination of exchange easier and more efficient. The more institutionalised the exchange processes have become, the stronger this bond will be; and,

4. economic bonds: the monetary and non-monetary costs that are expected from switching agency. This includes all (non)monetary investments made into the current relationship that will be lost with a switch, as well as all the (non)monetary investments that are expected to be necessary for establishing a relationship with a new provider. The higher both investments are (cument and expected) the stronger this bond.

In the operationalisation the strength of these bonds in the current agency-client relationship should be captured. Items should thus capture those aspects that are related to the strength of these bonds.

For the operationalisation of each bond type items were generated from several sources:

- Halinen (1994) proposed items for measuring these bonds in the advertising industry. These items were used as a basis for all four bond types;

(4) Changed after pre-test

() Deleted after pre-test 
- also the exploratory interviews with clients suggested items for the measurement of each of the bonds (as was summarised in table 4.5);

- because the economic bonds resemble the structural and dependency bonds from other business relationship studies, the items should reflect concepts from those studies as well Milson 8 Mummalaneni 1988, Heide \& John 1988); and,

- For the measurement of sacial bonds also the items that Wilson (1990) proposed particularly for measuring social bonds were used.

The thus generated items are presented in table 5.9 .

\subsubsection{Measuring trust}

Trust was defined as the firm's belief that another company will perform actions that will result in positive outcomes for the firm, as well as not undertake actions that would result in negative outcomes'. Moorman et al. (1993) included a behavioural dimension in their definition: "a willingness to rely on an exchange partner in whom one has confidence". This behavioural aspect should also be reflected in the operationalisation of the trust concept.

Moorman et al. (1993) operationalised the trust concept for measuning clients' trust in their market research agencies, which are also professional business services. Furthermore, based on this scale, LaBahn \& Kohli (1995) constructed a measurement scale for clients' trust in advertising agencies, which they confirmed and validated in their study. Their scale consisted of four items, with a scale composite reliability of .83. These four items were used and two overall trust items were added based on the general notion of trust as Mooman et al. used, and on our definition of trust. These items are presented in table 5.10.

Table 5.9: Pretest items generated for the operationalisation of relational bonds

\begin{tabular}{|c|c|}
\hline Bond type & Pre-test items \\
\hline $\begin{array}{l}\text { Knowledge } \\
\text { bonds }\end{array}$ & $\begin{array}{l}\text { 1. The amount of specific knowledge gained at the agency regarding clients' business and market } \\
\text { 2. The amount of contidential (strategic) information provided to the agency } \\
\text { 3. The amount of understanding gained by the agency about client-intemal organisation culture }\end{array}$ \\
\hline Social bonds & $\begin{array}{l}\text { 4. Amount of people and hierarchical levels of the client in direct contact with the agency (2)" } \\
\text { 5. Frequency and intensity of contact with agency (2) } \\
\text { 6. Degree of personal friendship between parties } \\
\text { 7. Degree of "chemistry" with the contact persons. }\end{array}$ \\
\hline $\begin{array}{l}\text { Planning } \\
\text { bonds }\end{array}$ & $\begin{array}{l}\text { 8. Degree of efficiency of the procedures and contact pattems with agency } \\
\text { 9. Degree to which the agency is adapted to client } \\
\text { 10. Degree to which exchange procedures and routines are integrated in client's organisation } \\
\text { 11. Degree to which client is tied by contractual agreements (row) }\end{array}$ \\
\hline $\begin{array}{l}\text { Eoonomic } \\
\text { bonds }\end{array}$ & $\begin{array}{l}\text { 12. Amount of time, money or effort invested in the establishment of the relation with agency } \\
\text { 13. Amount of effort needed to find an agency comparable or better than cument agency } \\
\text { 14. Amount of time, money and effort needed to start a new relationship }\end{array}$ \\
\hline
\end{tabular}

(2) ittems split up into two separate items after pre-test.

(") item remowed affer pretest.

(it) re-phrased after pre-test.

(new) Reclassified into a new bond "being stuck" after pretest, to which a new item is added as well. 
Table 5.10: Measurement items for trust

\begin{tabular}{|c|c|}
\hline Source & Trust items \\
\hline LaBahn \& Kohli 1995 & $\begin{array}{l}\text { 1. We are willing to trust our agency to get the job done night even if we do not } \\
\text { review their work } \\
\text { 2. If we can not be reached, we are willing to let our agency make impontant } \\
\text { decisions without our inwolvement } \\
\text { 3. We are willing to acoeptour agency's advice without questioning their motives } \\
\text { 4. We awways have to check our agency's work to make sure that the work is being } \\
\text { done correctyy }\end{array}$ \\
\hline Mooman et al. $(1993 a, b)$ & 5. We generally tust our agency very much \\
\hline Own adidition & $\begin{array}{l}\text { 6. We trust that our agency has our best interest at heart and will not undertake } \\
\text { actians that will ham us }\end{array}$ \\
\hline
\end{tabular}

\subsection{Pre-testing \& purification of measures}

As stated in the methodology section these rough measures were pre-tested in two ways:

First, the theoretical assumptions of each concept as such were pre-tested by open-ended interviews with two clients, interviews with two professors in the fieid, and a survey arnong six advertising agencies. Especially our conceptualisation of service quality and the relational bonds were pre-tested thoroughly, for no accepted scales existed for these concepts.

Second, the individual items generated in the previous steps were pre-tested by the specia: questionnaire among the advertising agencies. The respondents were asked to rate each item on: 1) The relevance of the item for measuring the construct/dimension in the advertising industry, 2) the clarity of the item for the advertising market, and 3) overall evaluation of the item. Each of these aspects were rated on a 4-point scale, ranging from bad-very good. For the service quality items the respondents were also asked to choose the three items that they think represent each quality determinant the best to get indications of which items could be deleted. Care was taken not to delete items that the respondents rated as important. Also six clients four colleagues and three unrelated persons were asked to check the items for clarity, ease of answering and the lay-out of the questionnaire.

\subsubsection{Outcomes regarding conceptualisation}

In the interviews with the two academic advertising experts, both respondents supported our theoretical ideas for the advertising industry, and also our conceptualisation of the concepts. Indepth discussions helped us to sharpen the definition and the domain of each concept.

In the interviews with the two clients and the survey among the agencies, mainly the conceptualisation of service quality and the relational bonds were asked. The respondents all supported the relevance of the five quality determinants for clients' quality perception. Two respondents indicated that the potential quality would be less relevant than the other four determinants for customers' quality perception. All indicated that in their opinion no crucial quality determinant was left out.

All four bonds were classified as highly relevant for agency-client relationships by the agencies, and also the clients confirmed their relevance. When asked whether an important bonding element was left out one respondent suggested to include 'International Bonding", referring to the fact that some advertisers are tied to their agency because of decisions made at their 
(international) headquarters. This was also indicated by one of the clients in the exploratory study, who was tied to its agency because of international company policy and ties with the agency at intemational head-quarters.

As was portrayed in table 5.9, in the exploratory research we found a bonding ellement called 'contractual agreements', which was classified as a planning bond'. Elaboration on this bonding element and the suggested addition of international bonding reveals some similarities between the two. Contractual agreements as such are not something that are gradually built up during a relationship, and they do not necessarily increase the efficiency of the exchange processes as would be the case for a planning bond. They create (a legal) barrier to switching, but they are not something that would be lost at a switch or has to be created again after a switch. If the only tie a client has is a contractual one, then we might say that the client is 'stuck' to the agency. This is also the case for international bonds. If the only tie a client has to an agency are international rules or agreements, then this client is stuck to the agency. The intemational bonds are not necessarily contractual ones. In fact the respondent in the exploratory research stated that it was the organisational culture that dictated that a once chosen agency was not to be abandoned because the organisation would thereby admit failure in its choice. Therefore, we decided to add an extra bond: "Being stuck" which consists of contractual agreements as well as any internal agreement or policy within the client organisation that ties them to their agency for reasons beyond the level of the focal agency-client relationship (international agreements, financial ties like shares and ownership, or organisational culture). These bonds create barriers to switching, but not necessarily commitment to the relationship. In fact this bond could be related negatively to commitment, as our respondent indicated. The more one feels 'stuck' to a relationship the less motivation one has to continue it. Therefore we decided to add it as a separate bond which is related to relationship commitment as well.

\subsubsection{Outcomes on item-level}

The agencies were asked to rate each item on relevance for the concept measured, and we asked them and all other respondents to cormment on the clarity and formulation. The clients and colleagues were also asked to comment on the ease of answering each question (scales used) and the lay-out of the questionnaire. Based on this information, items were deleted and many items were rephrased according to the suggestions given by the respondents. In the tables 5.5 to 5.10 the adjusted items are marked. In this paragraph the main adjustments in the items and answering categories will be sumimarised per concept.

\section{Service Quallity items}

- The overall quality items remained unchanged

- The five quality determinant items were slightly reformulated

- Regarding the operationalisations of the five determinants three items were deleted belonging to the potential quallity, and one item belonging to the hard process quality (see table 5.6). Many items were rephrased for clarity reasons. Because one of our goals is to confirm the structure within these items we decided not to delete too many items. By the statistical analysis of the field study data the scales can be purified further.

One important observation during the face-to-face completion of the questionnaire was that negatively (reverse) worded items were not read well by the clients. Respondents searched for the key-words in the question and rated them like the preceding questions; as if they were positively stated. Based on this the questions were reformulated in a positive direction. 
Another finding was that some respondents thought that the soft process quality items were too softly stated. They argued that they did not want the agency always to agree with them and just to listen, but they shoulla also dare to argue with the client if they think the client is wrong. Based on this we added an item to the soft process quality items: "Our agency argues with us if they don't agree".

\section{Commitment items}

- Of the affective commitment items, two were deleted after the pre-test because they resembled other items too much, or because they were stated in negative wording (item 7). Again it tumed out that clients had difficulties in answering negatively stated items, next to positive ones (see table 5.7a).

- Of the calculative items three items were deleted, because they were too similar to other items, too vague, or not applicable to advertising relationships (item 5) according to the respondents. Three other items were completely reformulated because they were considered as too complex and unclear. Respondents did not suggest to add items (see table 5. 7b).

\section{Behavioural intentions}

- The behavioural intentions were partly reformulated. Especially the stay intentions. The first item for the intentions to stay: "hiring the agency for a new assignment' was split into two items as suggested by the respondents. Because some clients use their agency only on a project basis, we measured their intentions to hire the agency again for similar assignments separately from their intentions to hire the agency again for completely new assignments. The second and third item, however, were merged together, because item 3 was negatively stated and item 2 was to vague regarding 'a while', into." "It is highly likely that we will continue working with this agency for the next two years". The other intentions were only slightly reformulated.

\section{Relational Bonds}

- One item was deleted because it was considered as too vague (item 8 see table 5.9), two items were split into two separate items each, because they were double barrelled (items 4 and 5 in table 5.9 )

- Furthemore, the lay-out and scaling of the bond items were adjusted after the pre-test. Because the strength of existing bonds should be measured, it turned out that 7-point Likert scales measuring the degree of agreement to a statement, were not applicable to these iterns. We decided to use a semantic differentiall, in which the extremes of the scale are defined. Because the degrees between the extremes should be meaningful to respondents, 5 point scales were used instead of 7 point (e.g. measuring the amount of investments could range from nothing - very much, seven degrees in the amount of investments are hardly interpretable for respondents ).

\section{Trust}

- The pre-test with the experts as well as with the small sample of advertisers only suggested minor adjustments in the wording of the items. No items were deleted or added. 


\subsection{Summary \& conclusions measurement instrument}

For the survey research a questionnaire is developed, in which the focal constructs of the research model are measured by multiple ttems. The rough items were generated from existing scales, secondary data, and the exploratory research in the advertising market. These items were subsequently pre-tested by in-depth interviews and a small sample of clients and colleagues.

Because no scales existed for our conceptualisation of service quality and the relational bonds for professional business services, one of the pre-test goals was to find support for our conceptualisation from experts in the industry.

- Our conceptualisation of service quality for professional business services into five key determinants was supported by the experts. All determinants were rated as relevant for the quality of advertising services and no additional quality aspects were suggested.

- Our conceptualisation of the four relational bonds in agency-client relationships was also supported by the experts. All four bonds were rated as highly relevant. However, an important addition to these four bonds was suggested, which was also found in the exploratory research. We followed this suggestion and added an additionall bond to the four proposed: "Stuck bonds". This bond reflects the ties between two parties that are instilled by sources outside the activities within the focal relationship. This bond is proposed to be negatively related to the relationship commitment, unlike the other bonds.

For the measurement of commitment existing scales were used and adapted to agency-client relationships. No significant changes to this conceptualisation were suggested by the pre-test.

The relationship intentions of the clients are conceptualised by three behavioural intentions: the intentions to stay in the relationship, intentions to invest in the relationship, and intentions to search for alternatives. These intentions all reflect clients' actual intentions to continue the relationship, whereas commitment measures the motivation why a client continues a relationship. Existing scales were used to operationalise these intentions and they are adjusted to agency-client relationships.

The measurement of trust is based on existing scales that were developed for professional business service relationships.

The changes in the conceptualisation of the relational bonds and relationship intentions are portrayed in the adjusted research model in figure 5.1 .

As for the measurement of specific items the pre-test resulted in deleting irrelevant, superfluous and complex items. Furthermore, it resulted in reformulating many items into clear-cut and understandable items. Important changes were:

- respondents clearly had problems in answering reverse stated items. Therefore we reformulated almost all questions into the same direction; and,

- for reasons of clarity and ease of answering 5-point semantic differential scales will be used for measuring the strength of the relational bonds. All other concepts are measured on 7-point Likert scales (completely disagree - completely agree). 
Figure 51: Reseanch model adjusted to conceptualisation of concepts

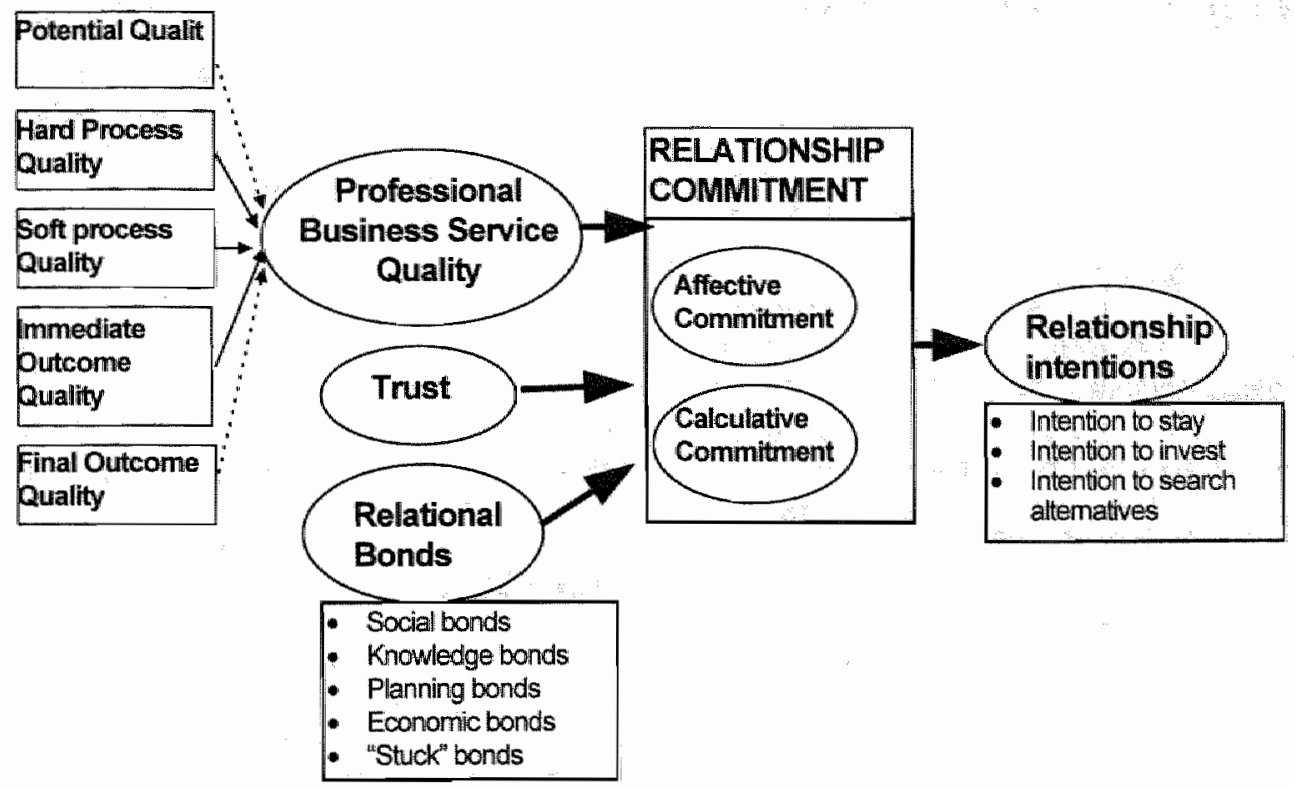




\section{Chapter 6: The Field Study}

"What is generally said by all,

can never be entirely untrue",

Thomas van Aquino

\subsection{Introduction}

After the exploratory research in the advertising market and the in-depth analysis of the focal research concepts, the third step in the empirical research will be addressed now: the field study. In this study the research model will be explored further among a large group of agencyclients. Because the literature review and the empirical studies in the advertising market, described in the previous chapters, did not provide enough information to formulate hard predictive hypotheses, the field study should be classified as a non-experimental exploratory field study (Kerlinger 1986). In this chapter the design of this study will be described, the measures will be purified and validated, and the first descriptive results will be presented. The analysis of the research model and its propositions will be discussed in chapters 7 and 8 .

In section 6.2 the research design of the field study will be described, including the research goals, the questionnaire, and the selection of the sample frame. In section 6.3 the response to the questionnaire, and the representativeness of this sample will be analysed. In section 6.4 the research concepts will be validated and purified using the procedure described in section 5.2 , and the descriptive results of the purified measures will be presented. Finally, in section 6.5 the method of data analysis will be described that will be used in the analyses in chapters 7 and 8 .

\subsection{Research design}

\subsubsection{Research goals}

The research goal with this field study is twofold: to explore the structure of customers' quality perception of advertising services; and, to explore its importance for customers' relationship commitment to their advertising agency, relative to the importance of relational bonds and trust. These goals and our propositions are depicted in the research model at the end of the previous chapter (see figure 5.1).

\subsubsection{Questionnaire}

A mail survey was chosen as research instrument, by which a broad cross-section of clients can be reached within reasonable time and costs. The measures that resulted from the procedure used in chapter 5 are used in the questionnaire. In appendix 1 the final questionnaire (translated into English) is given. The basic components and structure of the final questionnaire will be summarised here.

The final questionnaire consists of three parts. In part I general background questions about the client, its organisation, its communication needs and its dealings with their advertising agency were asked. Part II covers the questions regarding customers' service quality perception of their 
agency. Part III consists of questions regarding the relationship with the agency: customers trust in the agency, the established relational bonds, customers' affective and calculative commitment, and their relationship intentions.

\section{Part I Background items}

The items in this part were meant to describe the responding companies and to get an indication of their representativeness. In this part questions were added by which the respondent would select the agency-client relationship that fulfilled the criteria of this research. Respondents were asked to state the name of the agency with whom they work for at least a year and they are personally involved with, and to answer the questionnaire about this agency only.

\section{Part II Service quality}

In order to find support for the proposed five quality determinants of professional business services, service quality was measured on three levels (see table 6.1):

1. Customers' overall perceived service quality of the advertising agency.

Three measures of overall perceived service quality were used that capture different standards of customers' overall evaluation of the service quality of the agency: 1) customers' overall perceived service quality, 2) the perceived service quality relative to available alternatives, both on 7-point Likert scales, and, 3) a quality rating on the conventional Dutch school grading system, ranging from 1 (very bad) to 10 (excellent).

2. Customers' perception of the five service quality determinants.

Each quality determinant was described in advertising terminology, and customers had to rate their agency's performance on each quality determinant on a 7-point Likert scalle. Then they had to rate the relative importance of the quality determinants for their overall quality judgement by allocating 100 importance points among the five determinants.

\section{Customers' perception of 30 individual quality items.}

Each quality determinant was operationalised by several items (see chapter 5) and clients were asked to rate the agency's performance on each item on a 7-point Likert scale (see table 6.1).

In table 6.1 the service quality measures are summarised.

Table 6.1: Measures for service quality concepts in questionnaire

\begin{tabular}{|c|c|c|}
\hline Concepts & Conceptualisation & Measures: \\
\hline 1. Overall perceived senvice quality & Uni-dimensional & 3 Htems \\
\hline $\begin{array}{l}\text { 2. Penceived quality determinants } \\
\text { Relative importance determinants }\end{array}$ & - Five quality detenminants & $\begin{array}{l}5 \text { items } \\
1 \text { item }\end{array}$ \\
\hline 3. Perceived quality aspects & $\begin{array}{l}\text { - Potential quality } \\
\text { - Soft process quality } \\
\text { - Hard process quality } \\
\text { - Immediate oultcome quality } \\
\text { - Final outcome quality }\end{array}$ & $\begin{array}{l}6 \text { items } \\
7 \text { items } \\
9 \text { items } \\
5 \text { items } \\
3 \text { items }\end{array}$ \\
\hline
\end{tabular}

Service quality and its determinants were measured by perception scores only. Service quality is generally regarded as customers' (dis)confimation of expectations and is therefore often measured by differences scores: customers' perceptions minus their pre-purchase expectations (Parasuraman et al. 1985, 1990). We, however, chose to measure perceptions scores only 
because the respondents have previous experience with their agency, and therefore their 'prepurchase' expectations will be adjusted to what the agency has already performed. It has been argued that the more experience customers have with a service provider, the more their expectations will become equal to their perceptions over time (Bolton \& Drew 1991, Strandvik 1994). Furthermore, empirical studies showed consistently that perception scores alone are a better predictor of customers" service quality assessment than difference scores (Cronin \& Taylor 1992, Parasuraman et al. 1994)".

\section{Part III Relationship variables}

Four relationship variables are measured in this part of the questionnaire (see table 6.2):

1. Trust was measured by six items, based on previous research, by 7-point Likert scales;

2. Five types of relational bonds were measured, by several items for each bond (see chapter 5). Clients were asked to rate the strength of each bond item on a five-point semantic differential scale.

3. Customers' affective and calculative commitment were measured by multiple ittems based on existing scales (see chapter 5), on 7-point Likert scales.

4. Customers' intentions to stay, to invest in the relationship, and to search for alternatives, were measured by multiple items based on validated scales and the qualitative pre-test (see chapter 5). The items were all measured on 7-point Likert scale.

In table 6.2 the measures of the relationship variables are summarised.

Table 6.2: Measures for relationship variables in questionnaire

\begin{tabular}{l|l|c}
\hline Variable & Conceptualisation & Measures \\
\hline Trust & ane-dimensional & 6 items \\
Relational Bonds & - Social bonds & 6 items \\
& Knowledge bonds & 3 items \\
& - Plarning bonds & 2 items \\
& - Economic Bonds & 3 items \\
Relationship Commitment & - Affective Commitment & 2 items \\
& - Calculative Commitment & 6 items \\
Behavioural Intentions & - Intention to stay & 7 items \\
& - Intention to invest & 3 items \\
& - intention to search alternatives & 2 items \\
\hline
\end{tabular}

The three parts resulted in a questionnaire of nine pages (see appendix 1). The average time to fill-out the complete questionnaire was approximately 20 minutes. To encourage respondents' participation the questionnaires were personally addressed, and the relevance of the research and the respondents' participation was stressed in the cover letter. Respondents could indicate whether they wished to receive a free report of the main results. An official form signed by the researcher and the supervising professor was added, in which the anonymity of the information given by the respondent was guaranteed. Furthermore, one group of respondents received a recommendation letter by the 'BVA' (see sample selection below), of which this group is a member. After two weeks all non-respondents received a reminder fax.

1 For a comparison of different measurement methods of service quality and their properties see Parasuraman et al. 1994. 


\subsubsection{Population and sample frame}

The population to be reached with the questionnaire are clients from advertising agencies in the Netherlands. In principle any company is a potential advertiser that may use services from an advertising agency. The national bureau of statistics in The Netherlands has more than 9,000 companies registered as advertising agencies, many of which are small printing companies, or companies without personnel. It is therefore necessary to narrow down the definition of the clients needed in the study. First of all, the kind of agency used by the clients is important. Clients have to be selected that hire an agency for the core services of advertising agencies as defined in chapter 4 (i.e. the 'wisdom and magic'). Secondly, the maintenance of an agency relationship is crucial in our research and clients are needied that already have a relationship with their advertising agency. Therefore, two channels were used to create the sample frame for our study.

1. The first channel are the advertising agencies in the Netherlands that fulfil our definition of an advertising agency. Through this channel the client population can be identified that uses these advertising agencies. Furthermore, agencies possess information about the relationship length and the kind of services used, by which clients can be selected according to the second criterion. A third advantage of this channel is that agencies can identify the persons at a client who play an important role on the maintenance of the relationship. The disadvantage of this channel is the possible selection bias that can occur. Clients of only a few agencies will be selected this way. Therefore, a second channel is used independently from the agency used by the client.

2. The second channel is the BVA, the association of advertisers in The Netherlands, that protects the interests of large advertisers. The BVA members are an identifiable group of companies that advertise heavily, and are therefore potential clients of advertising agencies as we defined them. Also through this channel, the persons involved with the advertising of their company can be addressed personally. Furthemore, this channel makes the sample less dependent on the agencies that are willing to co-operate, and reduces the possible selection bias inherent to that channel. Below the procedure used to select clients through each channel and the resulting sample frame will be described.

\section{Advertising agencies.}

The title 'advertising agency' is not protected in The Netherlands. One criterion for defining an advertising agency is whether they are accredited by the ROTA, an organisation installed by the media that selects agencies entitled to get a $15 \%$ media reduction ${ }^{2}$. Around 260 agencies are accredited by this organisation, responsible for about $90 \%$ of the total agency income in The Netherlands. These agencies are organised in two trade association: the VEA and the PRAGMA. The VEA (Association of accredited advertising agencies) protects the interests of mostly larger agencies in The Netherlands. Currently 113 agencies are member, accounting for about $75 \%$ of total agency income in The Netherlands. The PRAGMA (Association of independent accredited advertising agencies) protects the interests of -mainly-smalier agencies that are ROTA-accredited and privately owned. 63 agencies are members of this association. The remaining ROTA -accredited agencies are not affiliated to either of the associations.

In order to reach the clients of the accredited agencies, the co-operation of these agencies was necessary. We approached the affiliated agencies through their trade association and the unat-

2 The ROTA selects agencies that are entitied to a media price-reduction of $15 \%$. Initially the association of accredited agencies (VEA) participated in the ROTA, and the accreditation critena were rather fierce. Due to anti-trust legislation in 1989 , the VEA has to step out, and the criteria were reduced to financial health and media sales volume of the agencies. 
filiated directly. In summer 1995 the VEA and PRAGMA were contacted and asked for their cooperation in our research. The PRAGMA gave us their list of members and contact persons, which were then contacted. The VEA agreed to support our study and they approached their members themselves with our request to co-operate, and added a recommendation letter. Another 30 independent accredited agencies were selected from the "Adformatie Bureaubijlage $1995^{\prime \prime}$ and asked for their co-operation in our research. The managing directors, as registered in the "Adformatie Bureaubijlage 1995", of these agencies were approached with our request.

The thus selected 206 agencies received a description of our research, and a request to cooperate by selecting clients that could be approached with our questionnaire. The agencies that agreed to co-operate were then asked to give the names, addresses and contact persons of all the clients that:

- use strategic and creative services from the agency;

0 are at least a year client of the agency; and that,

are personally involved in doing business with the agency and also possess decision power regarding agency decisions.

An official form signed by the researcher and the supervising professor was included, in which we guaranteed: 1) that the client-information would remain confidential and would not be used for any purpose other than for the execution of this research, that 2) clients as well as agencies would remain anonymous in any of the analyses and reports of the study, and 3) that no reports would be published in which agencies would be compared against each other in any way. The co-operating agencies were promised to get a report of the outcomes of this research. For a small contribution in the additional costs, agencies could also receive a report about the answers given about their agency by their own (anonymous) clients that had expressed their consent to this in the questionnaire.

The response of the agencies, the clients selected by them, and the contact persons provided are portrayed in table 6.3. Many agencies reacted positively to our initial request, but only 33 agencies actually co-operated and selected clients for us. The following reasons underlie this low response rate of $16 \%$ :

- our request was quite demanding, and agencies were reluctant to give away such sensitive information, despite the guarantees of confidentiality. The higher response rates from the VEA agencies indicate that the recommendation by the VEA increased their trust in the research(er);

- non-responding agencies were very hard to be reached by personal follow-up calls. Reaching decision makers of 206 agencies within a reasonable time-frame turned out to be impossible, which limited us to less personal communication by mail and fax;

- the time-schedule was rather tight, and some agencies could not get the data ready before the deadlines; and, finally,

- the independent agencies were selected from the "Adformatie Bureaubijlage 1995". It tumed out that the information was outdated: three agencies could not be traced and several contact persons had switched agency or function. This caused considerable delay in the negotiations, resulting in the previous problems with the deadlines.

The 33 agencies that participated, selected 438 client organisations with each 1 to 3 contact persons, resulting in a total of 611 respondents depicted in table 6.3 . 
Table 6.3: Co-operating agencies and selected sample frame through these agencies

\begin{tabular}{|c|c|c|c|c|c|}
\hline & $\begin{array}{l}\text { Agencies } \\
\text { approached }\end{array}$ & $\begin{array}{l}\text { Agency } \\
\text { response }\end{array}$ & $\begin{array}{l}\text { Agency } \\
\text { response } \%\end{array}$ & $\begin{array}{l}\text { Clients select } \\
\text { Companies }\end{array}$ & $\begin{array}{l}\text { by agencies: } \\
\text { Contact persons }\end{array}$ \\
\hline VEA-agencies & 113 & 24 & $21 \%$ & 308 & 454 \\
\hline PRAGMA-agencies & 63 & 6 & $10 \%$ & 100 & 119 \\
\hline Hndependent agencies & 30 & 3 & $\$ 0 \%$ & 24 & 38 \\
\hline Total & 206 & 33 & $16 \%$ & 438 & 611 \\
\hline
\end{tabular}

In November 1995, 611 questionnaires were sent to the 438 client companies. After approximately two weeks the non-respondents were approached with a reminder-fax.

\section{Association of advertisers (BVA)}

The second channel used to create the sample frame of agency clients was through the association of advertisers. 284 large advertisers are member of this association. In September 1995 we approached the BVA to co-operate in our research. They decided to support our study, under the condition that all the communications to their members would go through the BVA in order to protect their identity. Consequently, the BVA openly supported our study towards its members, increasing the response rate. However, the anonymity of the members made it impossible to select the advertisers on the sample criteria beforehand. Therefore ${ }_{\text {" }}$ the respondents were asked in the questionnaire to complete it only if they took strategic and/or creative services from their agency and if they dealt with the agency for minimally one year. This way the BVA-members had to select themselves for inclusion into the research. Each BVA member has several contact persons registered at the BVA. Of the 284 company-members, 501 contact persons are registered (see table 6.4).

\section{Table 6.4: Sample frame through BVA}

\begin{tabular}{l|l|l} 
& No. Companies approached & No. Contact persons approached \\
\hline Through BVA & 284 & 501
\end{tabular}

The BVA sent our questionnaire to all 501 contact persons in November 1995. The respondents were asked to retum the completed questionnaire directly to the researcher through a stamp-free return envelope that was included. The questionnaires were returned anonymously, but they were numbered to organise the follow-up of non-respondents. After two weeks the BVA received the numbers of the returned questionnaires, and they then sent a reminder letter to the non-respondents.

\section{Total sample frame}

The two sample frames have some overlap. Clients selected by the agencies can also be members of the BVA. Because of anonymity promises only the lists of advertiser companies was compared. We quickly verbally named the companies selected by the agencies, and the BVA counted the companies that are a member of the BVA. By this procedure it was found that 17 companies were on both lists. The identity of the contact persons were kept confidential, and so the individual respondents could not be compared. The representatives of the 17 overlapping companies do not necessarily have to work with the same agency. Large companies can work with several agencies for different business units or product lines. Therefore, all the contact persons from both channels were approached, at the risk of approaching persons from these 17 companies twice. In total 1,112 questionnaires were sent to representatives of 705 
different companies (see table 6.5). This sample frame includes an unknown amount of respondents that:

- do not fulfil our sample criteria. BVA members had to select themselves post hoc; and,

0 are counted double. Contact persons of 17 companies could be approached twice.

Table 6.5. Total sample frame created through bath channels

\begin{tabular}{|c|c|c|}
\hline & $\begin{array}{l}\text { Clients in sample frame: } \\
\text { Companies }\end{array}$ & Contact persons \\
\hline $\begin{array}{l}\text { Through agencies } \\
\text { Through } B V A\end{array}$ & 438 & $\begin{array}{l}611 \\
501 *\end{array}$ \\
\hline Doulble-counts & -17 & $-7 ?$ \\
\hline Total & 705 & 1,112 (incl double counts) \\
\hline
\end{tabular}

* Not selected on sample criteria

All 1,112 contact persons received a questionnaire, a postal paid retum-nvelope and a cover letter explaining the purpose of the research and a signed guarantee of the confidentiality of their personal data. Respondents were asked to complete the questionnaire about the main agency they are personally involved with, and with whom they have a relationship for at least a year. The entire sample selection process is portrayed in figure 6.1 .

Figure 6. 1: Oveniew of channels used to create sample frame of clients

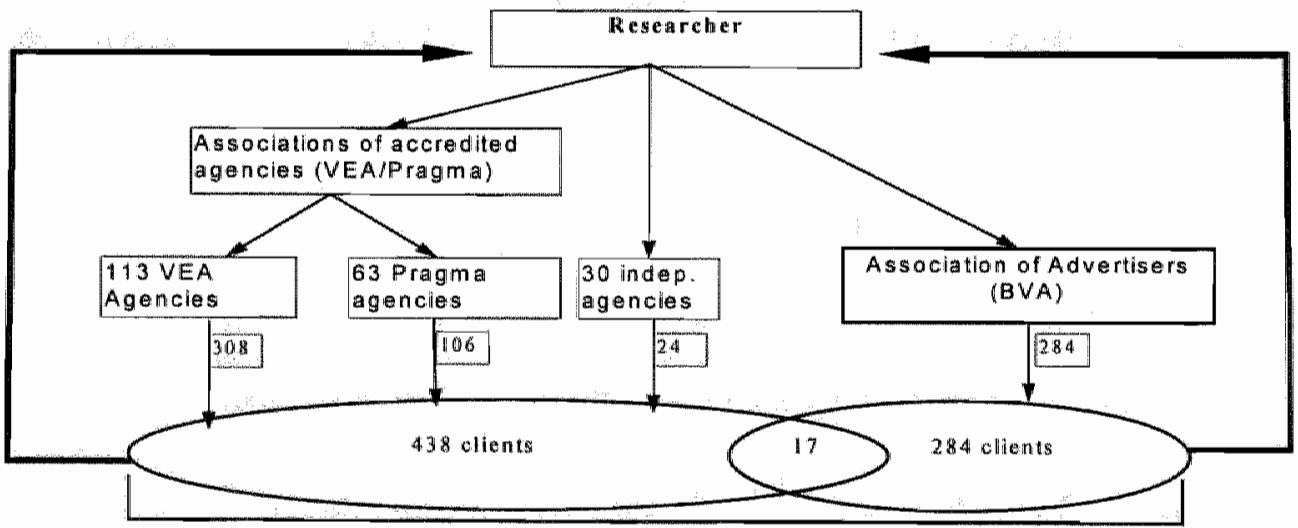

705 client companies 


\subsection{Survey Response}

In the beginning of 1996 a total of 241 questionnaires were returned, amounting to a response percentage of $22 \%$. This is $22 \%$ of the total amount of questionnaires that were sent, including double counts and persons not belonging to the sample criteria. These 241 respondents belong to 221 different companies, which is a response percentage of $31 \%$ in the amount of companies approached with our questionnaire (see table 6.6). This is a reasonable response rate, considering the length of our questionnaire and that $20 \%$ is a nomal response rate in The Netherlands (Verbeke 1988). Comparable studies among advertisers resulted in similar response rates of $26,5 \%$ in the US (LaBahn \& Kohli 1995), and $32,4 \%$ in Germany (Clemens 1994). Other studies also reported higher response rates, $48 \%$ in The Netherlands and Turkey (Verbeke 1988, Kaynak et al. 1994) and even 61\% in the US (Wackman et al. 1987), who had all added a one-dollar bill for the respondents ${ }^{3}$.

Table 6.6: Response rates per channel

\begin{tabular}{|c|c|c|c|c|c|c|}
\hline \multirow[b]{2}{*}{ Channel } & \multicolumn{3}{|c|}{ Total no. questionnailres } & \multicolumn{3}{|c|}{ no. client-companies } \\
\hline & Sent & Retumed & Response & Sent & Retumed & Response \\
\hline Through Agencies & 611 & 148 & $24 \%$ & 4.38 & $\sqrt{135}$ & $31 \%$ \\
\hline Through BVA & 501 & 93 & $19 \%$ & 284 & 86 & $30 \%$ \\
\hline Total & 1,112 & 241 & $22 \%$ & 705 & 221 & $31 \%$ \\
\hline
\end{tabular}

Of the returned questionnaires only 19 client-companies are represented by more than one respondent. In six of these cases the respondents used the same agency. Of the remaining 13 companies, the respondents completed the questions about different agencies, reflecting the fact that (larger) companies use different agencies. Therefore, all 241 responses will be used as assessments of separate agency relationships, even though in six cases the same relationship is evaluated by different persons.

\subsubsection{Sample representativeness}

To get an indication of the representativeness of the 241 respondents for the clients that were approached with our questionnaire, several comparisons are made. We will first assess the representativeness for each of the sample selection channels separately. First the data of the respondents selected through the agencies are compared to sample approached through this channel. The agencies filled out background questions about the clients they selected for our research (see table 6.7). This way, the client sample selected by the agencies is known and can serve as a comparison standard for the responding clients.

Unfortunately, no similar prior information is available from the BVA-members. However, the respondents had to fill out the same background items in the questionnaire (see table 6.7). To get an idea about the representativeness of the BVA- respondents, their background data are compared to the background data of the respondents selected through the agencies. To check for possible agency selection bias, the amount of respondents per agency will be compared. A last check for the representativeness of the sample is to compare the early respondents with the late respondents of the entire group of respondents. If there is no significant difference

3 Maybe a good recommendation for future studies. 
between respondents that retumed the questionnaire late or early, chances are smaller that non-respondents are different from the respondents. These analyses are presented below. In the next paragraph the descriptives of the entire sample are presented and discussed.

Table 6.7: Background items asked from agencies and respondents:

\begin{tabular}{|c|c|}
\hline Items & Answer categories \\
\hline 1: Client industry & $\begin{array}{l}\text { 5 categories: } \\
\text { - Consumer goods producer } \\
\text { - Industral goods producer } \\
\text { - Services (industrial + consumer) } \\
\text { - Nonhrofit } \\
\text { Other }\end{array}$ \\
\hline $\begin{array}{l}\text { 2. Average annual communication budget of elient } \\
\text { spent at agency }\end{array}$ & 4 categories (from <1 million to $>110$ million Dutch guilders) \\
\hline 3. Importance of client to the agency & 5-point rating scale (not at all important-very important) \\
\hline 4. Relationship strength with agency & 5-point rating scale (problematic-very strong relationship) \\
\hline 5. Relationship llength with agency. & Years: \\
\hline
\end{tabular}

1. Clients selected by the agencies versus 'agency-respondents'

The co-operating agencies filled out five background items of each client they selected for our study. These back ground items are presented in table 6.7. To get an indication of the representativeness of the respondents, the information given about the 438 selected clients will be compared with the background information about the 148 responding clients from this group. For ease of comparison, the information given by the agencies will be compared between the selected and responding group. In this way it can be seen whether the responding clients represent the same group as the agencies provided us. In tables $6.8 \mathrm{a}$ and $\mathrm{b}$ the background items given by the agencies will be compared between the two groups.

Table 6.8a: Agency-clients versus agency-respondents: Industry and budget

\begin{tabular}{|c|c|c|c|c|c|}
\hline Cllent Industry & $\begin{array}{l}\text { Total clients } \\
(n=438)\end{array}$ & $\begin{array}{l}\text { Respondents } \\
(n=148)\end{array}$ & Client Budget & $\begin{array}{l}\text { Total clients } \\
(n=438)\end{array}$ & $\begin{array}{l}\text { Respondents } \\
(n=448)\end{array}$ \\
\hline Non-profit & $10 \%$ & $8 \%$ & $=<1$ Million $\mathrm{Hffl}$. & $60 \%$ & $55 \%$ \\
\hline Industrial goods & $19 \%$ & $13 \%$ & 1 - 5 Million $\mathrm{HAl}$. & $27 \%$ & $24 \%$ \\
\hline Consumer goods & $40 \%$ & $39 \%$ & 5-10 Mallion Hif. & $7 \%$ & $6 \%$ \\
\hline Services & $28 \%$ & $29 \%$ & $>10$ million $\mathrm{HAl}$. & $6 \%$ & $6 \%$ \\
\hline Other & $3 \%$ & $11 \%$ & & & \\
\hline
\end{tabular}

Table 6.8a shows that agencies selected clients that operate mainly in consumer markets and in the service industry, with communication budgets around 1 million Dutch guilders. Table 6.8b shows that there is a high variance in importance of these clients to their agency, with a mean score just above the middle of the scale. Agencies selected clients with whom they have a rather strong relationship on average. To see if the respondents differ from the original selected group, t-tests and chi-square analyses were performed. The two groups do not differ significantly on any of these items $(\alpha=1 \%)$. The respondents are thus representative for the group approached regarding these items. As indicated, these respondents have rather close relationships with their agency. 
Table 6.8b: Agency-clients versus agency-respondents: other items

\begin{tabular}{l|l|l}
\hline Items (scale) & Means and (standand deviations) & Respondents (148) \\
\hline Importance of client (1-5) & $3.4(1.2)$ & $3.5(1.2)$ \\
relationship strength (1-5) & $4.0(.9)$ & $4.1(.8)$ \\
relationship length (years) & $5.3(4.6)$ & $5.8(4.8)$ \\
\hline
\end{tabular}

\section{BVA-respondents versus 'agency-respondents'}

The respondents answered the same background items as portrayed in table 6.7 in the questionnaire. To gett an indication about the kind of clients selected through the BVA, the BVA respondents will be compared to the respondents from the clients selected by the agencies. In tables $6.9 \mathrm{a}$ and $\mathrm{b}$ the answers given by each group of respondents ${ }^{4}$ are summarised. These tables show that both respondent groups represent the same industries, and have comparable relationship lengths and strengths with their agency. There are no significant differences in these items between the groups $(\alpha=1 \%)$.

Table 6.9a: BVA-respondents versus agency-respondents: industry and budgets

\begin{tabular}{|c|c|c|c|c|c|}
\hline Client Industry & $\begin{array}{l}\text { Respondents } \\
\text { BVA ( } 93 \text { ) }\end{array}$ & $\begin{array}{l}\text { Respondents } \\
\text { Agency (148) }\end{array}$ & Client Budget & $\begin{array}{l}\text { Respondents } \\
\text { BVA (93) }\end{array}$ & $\begin{array}{l}\text { Respondents } \\
\text { Agency(148) }\end{array}$ \\
\hline Non-profit & $4 \%$ & $9 \%$ & $=<1$ Million Hfl. & $27 \%$ & $68 \%$ \\
\hline Industrial goods & $14 \%$ & $16 \%$ & 1-5 Million Hifl." & $33 \%$ & $21 \%$ \\
\hline Consumer goods & $39 \%$ & $39 \%$ & 5-10 Million HAl. & $24 \%$ & $9 \%$ \\
\hline Services & $40 \%$ & $31 \%$ & $>10$ Million Hifl. & $16 \%$ & $3 \%$ \\
\hline Other & $3 \%$ & $5 \%$ & & & \\
\hline
\end{tabular}

Table 6.96: BVA-respondents versus agency-respondents; other items

\begin{tabular}{|c|c|c|c|}
\hline Items (scales) & $\begin{array}{l}\text { Means and (standard deviations) } \\
\text { BVA respondents ( } n=93 \text { ) }\end{array}$ & Agency re & lents $(n=148)$ \\
\hline $\begin{array}{l}\text { Importance of client }(1-5) \\
\text { relationship strength }(1-5) \\
\text { relationship length (vears }\end{array}$ & $\begin{array}{ll}4.0 & (.8) \\
3.6 & (1.1) \\
6.8 & (9.6)\end{array}$ & \begin{tabular}{|ll}
3.2 & $(1.1)$ \\
3.6 & $(1.0)$ \\
5.8 & $(4.7)$ \\
\end{tabular} & $\overline{3}$ \\
\hline
\end{tabular}

TSignificant group difference at $5 \%$ level

The respondent groups differ, however, regarding the size of their budgets and the importance they have for the agency. This is not surprising, since the BVA protects the interests of large advertisers, which have higher advertising budgets on average. The difference in perceived client-importance is most likely explained by this difference in budget size. The inclusion of the BVA-members thus increases the amount of larger clients in the sample. We have no reason to believe that this difference is due to (non)response bias.

\section{Agency bias}

Another point is raised by comparing the tables $6.9 \mathrm{a}, \mathrm{b}$ with $6.8 \mathrm{a}, \mathrm{b}$. The answers given by the agency-respondents themselves (tables $6.9 \mathrm{a}$ and $\mathrm{b}$ ) are slightly different from the data the agencies provided about these same clients (in tables $6.8 \mathrm{a}$ and $\mathrm{b}$ ). The budget spent at the agency is rated higher by the clients than by the agencies, and the relationship strength is rated lower by the clients. One explanation for this is that the perceptions between agency and client

4. The answers given by the agency-respondents themselves will be compared in these tables. Not the back-ground data prowled by the agencies as used in tables $6.8 a$ and $b$. 
differ. But there is also another explanation: not all respondents completed the questionnaire about the agency by which they were selected. This underscores the fact that (larger) clients use several different agencies. Some respondents thus completed the questionnaire about a different agency, which probably fulfilled the sample criteria better (i.e. personal involvement, min. 1 year relationship and use of core advertising services).

To get an indication of the spread of agencies evaluated by the respondents we will analyse the agencies evaluated by the agency-respondents and the BVA respondents. The agency-clients were selected by 33 co-operating agencies. The respondents of this client group $(n=148)$, however, reported relationships with 46 different agencies, of which 31 belong to the co-operating agencies. These respondents thus evaluated 15 additional agencies to the ones by which they were selected. The BVA-respondents $(n=93)$ evaluated 50 different agencies. Nine of these agencies are part of the 33 co-operating agencies and four agencies belong to the additional 15 agencies evaluated by the agency-respondents. The BVA respondents thus evaluated 37 additional agencies from the ones evaluated by the agency-respondents. In total, the respondents together $(n=241$ ) evaluated 83 different agencies (see table 6.10). A little more than half (47) of these 83 agencies are evaluated by only one respondent, whereas 20 agencies are represented by three or more clients (with a maximum of 15 clients for one agency).

Table 6. 10: Amount of agency-relationships with different agencies in sample

\begin{tabular}{|c|c|c|c|}
\hline \multirow[b]{2}{*}{ Used by: } & \multicolumn{3}{|c|}{ Amount of different agencies used by sample } \\
\hline & Participating Agencies ( $\mathrm{n}=33$ ) & Other agencies & $\|$ Total agencies \\
\hline Agency-respondents & 31 & 15 & 46 \\
\hline BVA-respondents & 9 & 41 & 50 \\
\hline Overlap & -9 & -4 & -13 \\
\hline Totall agencies & 31 & 52 & 83 \\
\hline \multicolumn{3}{|c|}{ Amount of clients per agency: } & \\
\hline & & 1 & 47 \\
\hline & & 2 & 16 \\
\hline & & 3 or more & 20 \\
\hline
\end{tabular}

There is thus a broad spread in the agencies used by the sample. This decreases the chance that the sample is biased by the restricted amount of agencies that participated in the study. From table $6.8 \mathrm{~b}$ it seemed that the co-operating agencies selected clients that have a rather close relationship with the agency. The likelihood of this selection bias is partly resolved because the respondents evaluated other agencies than the ones that selected them. Table $6.9 \mathrm{~b}$ shows that the agency-respondents themselves rate their agency relationship as less close than the agencies did. Furthermore, table $6.9 \mathrm{~b}$ shows that the BVA-respondents rated their agency-relationship equally close on average as the agency-respondents. Since the BVAclients were not selected by their agency, there is no indication that the agency selection resulted in a biased group of clients.

\section{Late versus early respondents}

Another way to get an indication of the representativeness of the sample is the comparison between early versus late responses. The entire group of respondents is divided into two groups: 1) respondents who responded within two weeks before the reminder was sent, and 2) respondents who responded after two weeks, following the reminder fax. Independent samples t-tests and chi-square difference tests were performed on the same background items as portrayed in table 6.7 to see whether the groups differ on any of these items. These test showed 
that the two groups do not differ on any of the variables (significance level:0.1). This finding decreases the likelihood that the client that did not respond at all will differ from the ones that did. It thus seems that the respondents are representative for the clients that were approached with the questionnaire.

Based on these four analyses it can be concluded that, regarding the items used, the respondents form a good representation of the population of clients that was approached with our questionnaire. No indications for non-response bias were found. The analyses also indicate that the likelihood of selection bias in the client group approached is small. The clients answered the questions about many different agencies, decreasing the chance of selection bias by the agencies that participated. The BVA-respondents represent mainly larger advertisers, which are complemented by the smaller clients selected by the agencies. There is no reason to believe that this will have a bearing on the analysis of our research questions.

The sample is thus representative for the group approached. How representative this group is for the Dutch advertiser in general is difficult to assess, for there are no comparison standards available. In the next paragraph the sample descriptives will be presented, and where possible compared to data available about the Dutch industry structure in 1995 and to findings from other studies. It should, however, be noted that the relevant population for our study consists of advertisers that use agency"s core advertising senvices for minimally one year, which restricts the population of Dutch advertisers considerably. The Dutch industry structure is thus not an ideal comparison standard. The channels used to create the sampling frame secured the group of advertisers that are relevant for the study.

\subsubsection{Sample descriptives}

The respondents represent different industries, with most respondents operating in consumer goods industries and service industries (business as well as consumer services), which together are re-

Figure 62: Industry descriptives

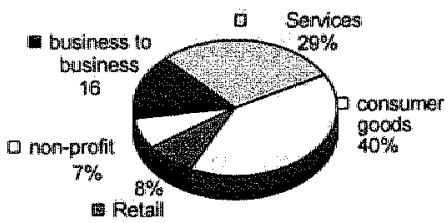
sponsible for $69 \%$ of our sample. These figures are comparable to the number of companies per industry in the Netherlands in 1995 (CBS statistics, 1996). Business companies are $14 \%$, consumer products $26 \%$, services $30 \%$ and non-profit $10 \%$ of the total amount of companies in the Netherlands 5 .

\footnotetext{
5 Taken from 'Bedrijven in Nederland 1995, CBS 1996 Voorburghteenten. These figures ane onhly indications. The CBS uses different categonies. Business (=Industry+constnuction), Consumer (=consumer, repair and retail), Serwices ( $=H$ Heca, Transpartation, communication, financial, business services, and cuttural services), Non-profit ( $=$ institutions, education and heallh senvices)
} 
The size of the clients is almost equally divided over small, medium and large companies, with more larger companies than small ones, in terms of their tumover and employees. Figure 6.3: Client size descriptives:

Tumover

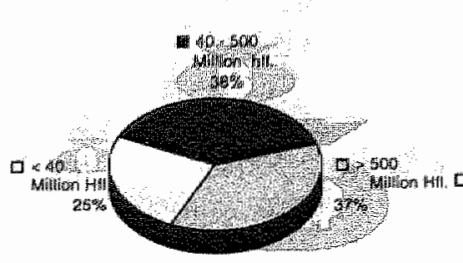

Employees:

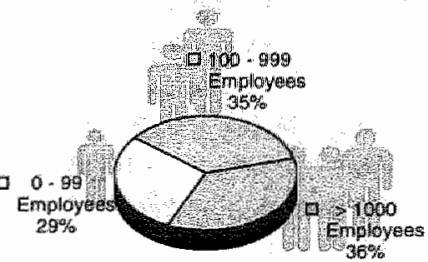
Compared to the industry structure in the Netherlands in 1995, this group represents mainly large companies, $89 \%$ of the Dutch companies are registered with less than 10 employees (CBS Statistics 1996). This large group of small com-

panies will, however, not all use advertising agencies in the way relevant for this study, whereas most large companies do. From figure 6.3 we can see that smaller clients are represented almost equally much as the medium and large-sized companies. Also the scope of operations is equally distributed within the sample; half of the companies are involved in intemational operations, whereas the other half only serves the national or regional markets in The Netherlands.

The respondents themselves represent mainly communication managers, followed by marketing managers and managing directors. Only $8 \%$ represent marketing or communication executives. The

Figure 6.4: Respondent function

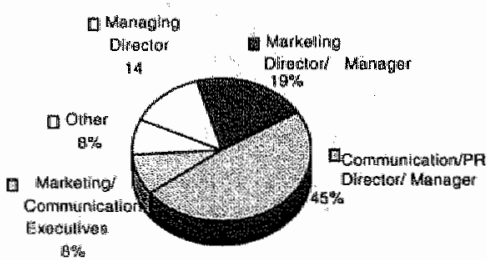

in the decision making. respondents all indicate that they thave an influence on decisions regarding the advertising agency (see question $\mathrm{nr} .16$ in appendix 1). The decision power is positively related to the hierarchical level of the respondent. The managing directors have final decision power, and the executives influence the decision. Most final decision makers (managing directors) are the least involved with the agency (see question $\mathrm{nr}$. 15). The marketing and communication managers are involved with the agency the most and are important influencers

Respondents hire their agency mainly for the development of the creative concept and for production services. Respondents seem to be reluctant to out-source the advertising research

Table 6.11:Agency services used

\begin{tabular}{ll}
\hline Agency Services & Used by: \\
\hline 1. Strategic sparring & $33 \%$ \\
2. Communication strategy & $64 \%$ \\
3. Creative concept & $90 \%$ \\
4. Production services & $82 \%$ \\
5. Media senvices & $61 \%$ \\
6. Pesearch & $29 \%$ \\
\hline
\end{tabular}
to the same agency that created the advertisements, as well as discussing their marketing strategy with them. Agencies are more involved with the clients' communication strategy than their marketing strategy. 


\section{Relationships}

The relationship between the respondents' organisation and agency ranges from 1 year to 75 years, with an average of 6,2 years and a median of 4 years. This is consistent with what Verbeke (1988) found on the Dutch advertising market and Buchanan \& Michell (1991) found in the British advertising market. The respondents themselves had shorter dealings with the agency ranging between 0,2 years to 35 years, with an average of 4,2 years and a median of 3 years. As indicated earlier, the respondents rated the strength of their agency relationship on the positive side: $13 \%$ rated their relationship as problematic, whereas $63 \%$ rated the relationship as rather to very close, the others were neutrall regarding the closeness of the relationship.

Two-thirds of the respondents hire their agency for the long-term satisfaction of their communication needs. A little bit more than a quarter hires the

Table 6.12: Bases of agency-relationships

\begin{tabular}{l|l|l}
\hline Agency used on: & by & Average relationship \\
\hline Ad-Hoc basis & $7 \%$ & 4.7 years \\
Project basis & $27 \%$ & 5.9 years \\
Long-term basis & $66 \%$ & 6.6 years \\
\hline
\end{tabular}

dents worked on this ad-hoc basis for more than 10 years. agency on a project-to-project basis. Only a few respondents hires the agency on an ad-hoc basis. This, however, does not seem to be detrimental for the development of long-term relationship: four respon-

\subsection{Final measures and descriptives}

The measures of the research concepts will be validlated and purified first with the survey data, before they will be used to analyse the research model. In chapter 5 (section 5.2) the procedure is described by which this will be done. This procedure is a confirmatory analysis of the itemscales used, consisting of three steps: 1) the item-total correlations among the scale items, 2) exploratory factor analyses per concept, and 3) a confirmatory factor analysis using LISREL8. In each step the 'goodness' of an item in measuring its proposed concept IS assessed, based on which poor performing items can be detected. If necessary, these items are deleted in order to create reliable and valid scales for each concept in the research model. The criteria used to do this are described in section 5.2. In appendix 2 the statistics of each of these steps are portrayed for each research concept. In this section the outcomes of the procedure will be described. The properties of the purified scales and the descriptives of the remaining items will be presented for each of the concepts.

\subsubsection{Service quality measures}

Customers' service quality perception was measured on three different levels, overall service quality, the five service quality determinants, and the 30 service quality items (see table 6.13).

\section{Overall service quality}

Customers" overall perceived service quality was measured by three different overall quality items. From the analysis (see appendix 2) it was found that the three items form a reliable, one dimensional overall quality scale with a composite reliability of .84 , which is well above the recommended 0.70 level.

6 One respondent had a relationship below 1 year (sselection criterion). We decided not to remove this client from our anallysis because they had already experienced several services from this agency ${ }^{\prime}$ and they had hined the aigency on a long-term basis. 


\section{Service quality deteminants}

Five items were formulated for each of the five service quality determinants, which clients had to rate on a 7 -point scale. Clients were also asked to give an assessment of how important they think each determinant is for the service quality of an agency, by allocating 100 points over the quality determinants. Because the determinants are all measured by one item each, no scale analysis was performed. All five items were kept for the final analysis.

\section{Senvice quality items}

Since one of the objectives of the study is to analyse whether the five quality determinants are confirmed by the tems, the analysis of the 30 quality items will be described in-depth in chapter 7. where the first research question will be explored. In table 6.13 the Cronbach's Alpha of the non-purified scales are portrayed that give a first indication of the reliability of the measures used to measure the five quality deteminants. As we can see in table 6.13 the reliability of all five quality determinant scales is above the recommended 0.70 , which gives a first indication that the proposed quality structure might be confirmed by the items used. However, Cronbachis alpha has some draw-backs as a measure of scale reliability (Steenkamp \& Van Trijp 1991. Baumgartner \& Homburg 1996) and therefore, the procedure described in section 5.2 will be used in chapter 7 to provide a deeper analysis of the structure in the 30 service quality items.

Table 6.13: Punfication and properties service quality scales:

\begin{tabular}{|c|c|c|c|c|}
\hline Concept & $\begin{array}{l}\text { Proposed measurement } \\
\text { Conceptuallisation }\end{array}$ & ltems used & $\begin{array}{l}\text { After purticic } \\
\text { ltems left }\end{array}$ & $\begin{array}{l}\text { Aton } \\
\text { Scale Properties }\end{array}$ \\
\hline Overal service quality & Unimimensional & 3 & 3 & $\begin{array}{l}\text { Composite reliability: } .84 \\
\text { Explained wariance: } 63 \%\end{array}$ \\
\hline Quality deteminiants & "ithem for each determinant & 5 & 5 & - (no scale) \\
\hline Qublity aspects & $\begin{array}{l}\text { "Potential Quality } \\
\text { " Soff Process Quality } \\
\text { Hard Process Quality } \\
\text { Immediate Outcome quality } \\
\text { Final Outcome quality }\end{array}$ & $\begin{array}{l}6 \\
7 \\
9 \\
5 \\
3\end{array}$ & $\begin{array}{l}\text { see } \\
\text { chapter } 7\end{array}$ & $\begin{array}{l}\text { Cronbach's alpha }^{B_{*}} .76 \\
\text { Cronbach's alpha: } .90 \\
\text { Cronbach's alpha: } .83 \\
\text { Cronbach's alpha: } .83 \\
\text { Cronbach's alpha: } .87\end{array}$ \\
\hline
\end{tabular}

From table 6.14 we can see that the clients are rather positive on average about the service quality delivered by their agencies. Overall service quality is perceived as good on average "and as slightly better -on average- than the quality of altemative agencies. Clients rate all five quality determinants as good on average. Especially the work of the agency (immediate outcome) and its available potential are rated most positively. The least positive are clients about the effectiveness of the work (final outcome) although the mean scores do not differ very much between the five quality determinants. Also regarding the 30 service quality item-scales the clients are rather positive on average all mean scores on the items are well above the scale-average. Clients are most positive about the soft process quality items. Compared to the overall rating of the five quality determinants, clients are less positive about the work (immediate outcome) and a little more positive about the communications with the agency (soft process). Besides this slight difference, the mean scores of the five determinants are very similar.

\footnotetext{
7 For a detailed diescription of the purification analysis see appendix 2

8 The composite reliability can only be calculated after an in-depth analysis of the measurement modell and purification of the scales. This will be done in chapter 7 , the results of which are portrayed in appendix 2 . Therefore, the Cronbach's Alpha is portrayed there, which is the reliabilty of the rough scales before purification.
} 
Table 6. 14: Descriptives service quality variables

\begin{tabular}{l|lll}
\hline Service Quality Variables & Ttems & Mean & Std. \\
\hline Overal Senvice Quality & 3 & & \\
1. Overall quality rating & 1 & 5.4 & 1.1 \\
2. Quality relative to alternatives & 1 & 5.0 & 1.2 \\
3. School-grading of quality & 1 & 7.3 & 1.2 \\
\hline Service Quality Determinants & & & \\
1. Potential Quality & 1 & 5.5 & 1.1 \\
2. Hard process Quality & 1 & 5.4 & 1.0 \\
3. Soft Process Quality & 1 & 5.4 & 1.3 \\
4. Immediate Outcome Quality & 1 & 5.6 & 1.1 \\
5. Final outcome Quality & 1 & 5.3 & 1.0 \\
\hline Service Quality Items & 30 & & \\
1. Potential Quality & 6 & 5.4 & 1.4 \\
2. Hard process Quality & 9 & 5.4 & 1.4 \\
3. Soft Process Quality & 7 & 5.7 & 1.3 \\
4. Immediate Outcome Quality & 5 & 5.3 & 1.2 \\
5. Final oulcome Quality & 3 & 5.4 & 1.2 \\
\hline
\end{tabular}

7-point Likert scales (1 disagree- 7 agree)

10 point rating scale ( $1=$ bad, $10=$ excellent)

Positive scores on service quality items are a common phenomenon in quality and satisfaction research. The responses are generally skewed with an inordinate number of responses at the very top-end of the scale (Peterson \& Wilson 1992). One explanation for this positive evaluation is that these questions are asked from existing clients. Clients who are highly dissatisfied would probably not be clients anymore, therefore the answers are more on the positive side of the scale. The standard deviation in the items shows enough differentiation in the answers by the clients, indicating that they are not all equally positive about their agency.

\subsubsection{Commitment and behavioural intentions}

\section{Relationship Commitment}

The analysis (see appendix 2) confirmed the existence of two separate relationship commitment dimensions. Reliable uni-dimensional scales were found for the affective and calculative relationship commitment, with composite reliability above the recommended .70 and explained variance above $50 \%$ (se table 6.15). The LISREL statistics (see appendix 2) indicate that the items measure independent, yet related constructs, which gives evidence for the discriminant validity of the two commitment dimensions.

\section{Behavioural intentions}

The behavioural intention measures were supposed to measure three types of relationship intentions: intentions to stay, intentions to invest in the relationship, and intentions to search for alternatives. This three dimensional structure is not confirmed by the data (see appendix 2), and the model had to be respecified into a one-dimensional concept. The intentions to stay and the intentions to search for alternatives were found to be opposite sides of the same 'coin' (i.e. construct). The items that measured the intentions to invest did not form one scale, and hence the items will be excluded from further analysis. The two items that measure the intentions to search for alternatives formed a good scale together. However, this scale is so strongly related to the items measuring the intentions to stay, that both scales cannot be regarded as separate concepts, but as sub-dimensions of one underlying construct of "stay intentions". The two sub- 
dimensions together form a reliable and valid scale of the stay intentions, with a composite reliability of .91 , as portrayed in table 6.15 .

Table 6.15. Purfication and properties of relationship commitment and intertion scales

\begin{tabular}{|c|c|c|c|c|c|}
\hline \multirow{2}{*}{$\begin{array}{l}\text { Concept } \\
\text { Relationship } \\
\text { Commitinent }\end{array}$} & $\begin{array}{l}\text { Proposed measurement } \\
\text { Conceptuallsation } \\
1 \text { Affective commitment }\end{array}$ & \multirow{2}{*}{$\begin{array}{l}\text { Hems } \\
\text { used } \\
5\end{array}$} & \multicolumn{3}{|c|}{$\begin{array}{l}\text { After punification } \\
\text { llems Scalle Properties } \\
\text { left } \quad \text { Composite reliability Explained wariance }\end{array}$} \\
\hline & $\begin{array}{l}\text { 1. Affective commitment } \\
\text { 2. Calculative commitment }\end{array}$ & & $\begin{array}{l}3 \\
3\end{array}$ & $\begin{array}{l}.90 \\
.82 \\
\end{array}$ & $\begin{array}{l}76 \% \\
60 \%\end{array}$ \\
\hline $\begin{array}{l}\text { Behavioural } \\
\text { intentions }\end{array}$ & $\begin{array}{l}\text { 1. Intentions to stay } \\
\text { 2. intentions to Invest } \\
\text { 3. Intentions to search alternatives }\end{array}$ & $\begin{array}{l}3 \\
4 \\
2\end{array}$ & 2 & $.91^{10}$ & $78 \%$ \\
\hline
\end{tabular}

Tabje 6.16: Descriptives relationship commitment and stay intentions

\begin{tabular}{l|lll}
\hline & Items & Meari & Std. \\
\hline Calculative commitment & 3 & 3.1 & 1.5 \\
Stay because too high switch costs & & 3.1 & 1.8 \\
Stay because of inuestments & & 3.4 & 1.8 \\
Stay because costsibenefits of switch & & 3.0 & 1.8 \\
\hline Affective commitment & 3 & 4.9 & 1.4 \\
Stay for positive feelings & & 4.9 & 1.6 \\
Stay for pleasant working & & 5.1 & 1.5 \\
Stay for nice relation & & 4.9 & 1.6 \\
\hline Stay intentions & 2 & 5.2 & 1.5 \\
Intentions for next assignments & 1 & 5.5 & 1.6 \\
$\quad$ Intentions to stay next two years & 2 & 2.3 & 1.8 \\
\hline Intentions to search altematives $(-)$ & & &
\end{tabular}

\#7-point Likert-scales ( $1=$ disagree, 7 :agree)

Table 6.16 shows that the clients differ considerably in the degree of affective and calculative commitment. On average, the clients indicate that their affective commitment is fairly high, committed, whereas their calculative commitment is rather low. The mean scores of the affective commitment items are all above the scale average with the highest rating for the motivation to stay because of the pleasant co-operation with the agency. The mean scores on all calculative commitment items are below the scale-average, with the highest motivation to stay because of the investmeints already made in the relationship. The expected switch costs are the least strong motivation to stay in this relationship. The clients, however, do intend to stay (see table 6.16). For future assignments as well as for the next two years they intend to keep working with the present agency. Clients do not intend to search for alternatives, on average.

It thus seems that the respondents are intending to maintain the agency relationship mainly for affective reasons, and hardly because of calculative reasons. This is an interesting finding, because from our exploratory research it seemed that clients hardly acknowledged any degree of affective commitment to their agency. They gave the impression that only the burden of looking for another agency would keep them from leaving their present one. The findings here suggest the opposite: the expected costs from a switch hardly seem to be a reason to stay, but

9 For a detalled description of the purification antalysis see appendix 2 .

10 The scalles for the stay-intentions and altemative search were found to be sub-dimensions of one underlying construct. tather than two separate constructs. The properties of this underlying construct ane described here. 
only the clients" enthusiasm about working with the agency. Since the items do not mention the word "commitment", but merely asked for clients" motivations to stay, it seems that our previous suspicion is confirmed. Clients seem to have different associations regarding the word "commitment' when asked directly, as was done in the exploratory research. Operationalising the concept by concrete items gives a different picture, which is more consistent with what the agencies indicated about their clients' commitment in the exploratory research.

The standard deviations for these variables are, however, rather high. The respondents are not unanimously strongly affectively committed or intending to stay. They are differentiated in the degree to which they intend to stay as well as regarding their motivation to do so. This means that there is enough variance in these variables to be explained by the proposed antecedents.

\subsubsection{Relational bonds and trust}

\section{Relational Bonds}

The analysis of the five proposed bond measures, suggested re-specifying the measures of the relational bonds (see appendix 2). Of the five types of bonds intended to measure (the social, planning, knowledge, economic and the additional 'stuck' bonds), only the social bonds and 'stuck bonds' were confirmed as one-dimensional reliable scales. The indicators of the planning bonds did not form a reliable scale, based on which we decided to remove this scale for further analysis. The items measuring the knowledge bonds and the economic bonds were overlapping, and even though our analysis confirmed that the items measured two different concepts, a slightly different structure was suggested. One item that was categorised as an economic bonds indicator, is more strongly related to the items measuring the knowledge bonds than to the other economic bond items. This item measured the degree to which the client invested in the relationship in terms of money, effort and time. Together with the knowledge bond items this item formed a new scale with a composite reliability of .78. Therefore, this scale is renamed as 'Investment bond', reflecting the investments made in knowledge exchange as well as the general investment in the relationship (in terms of money, time and effort).. The two remaining economic bond items reflected both the expected costs (in money, time and effort) of switching to another agency. These items formed together a reliable scale (.76) and this bond is therefore renamed as 'Switch bond', reflecting the contents of the items better.

These new four bond types are all measured by reliable scales with reliabilities around the .70 level, and with explained variances above the 50\%-level. The LISREL analysis (appendix 2) shows a good fit, indicating that the four bond types are well differentiated from each other.

\section{Trust}

The analysis of the trust items (see appendix 2) shows a one-dimensional structure. After purification, a reliable scale above the recommended .70 level resulted (see table 6.17). The items mainly reflect the behavioural dimension of trust, i.e. the degree to which clients have to control the activities by the agency. The items reflecting the clients' trust in the benevolence of the agency (e.g. having the clients best interest at heart) gave a bad fit and were therefore removed from the scale. The general trust item remained in this scale, despite its lower reliability, in order to get a theoretically more meaningful construct. The resulting scalle is reliable and valid and will be used in the subsequent analyses. The LISREL analysis (see appendix 2) shows that this trust concept is differentiated well from the service quality concept, which is the most similar concept to trust from the antecedents used in our research, providing evidence for its discriminant validity. 
Table 6.17: Punfication and properties of relational bond and trust scales

\begin{tabular}{|c|c|c|c|c|c|c|}
\hline \multirow[b]{2}{*}{ Concept } & \multicolumn{2}{|c|}{ Proposed measufement } & \multicolumn{4}{|c|}{ After purification ${ }^{31}$} \\
\hline & Conceptualisation & ltems used & hems left & New scales & | Reliabifity & Explained variance \\
\hline Relational & 1. Social & 6 & 2 & 1. Social bonds & .85 & $7 \overline{4 \%}$ \\
\hline \multirow[t]{4}{*}{ Bonds } & 2. Knowledge & 3 & $2+1^{12}$ & 2. Investment bonds & .78 & $52 \%$ \\
\hline & 3. Economic & 3 & 2 & 3. Switch bonds & .76 & $61 \%$ \\
\hline & 4. Planning & 2 & - & & & \\
\hline & 5. 'Stuck' & 2 & 2 & 4. Stuck bonds & 68 & $52 \%$ \\
\hline Trust & One-dimensional & 6 & 3 & Trust & .76 & $53 \%$ \\
\hline
\end{tabular}

In table 6.18 the descriptives of the relational bonds and trust variables are portrayed. From this table we can see that clients established social, investment and switching bonds with their agency during the relationship, although the means of these bonds are just above the scaleaverage. The clients are, on average, the least tied by contractual agreements and/or internal rules and policies to their agency, with means all below the scale-average. The strongest ties are built by the frequency of interactions, the exchanged knowledge and the invested time and effort in the present relationship and the expected investments needed for a new relationship.

Table 6.18: Descriptives relational bonds and trust

\begin{tabular}{|c|c|c|c|}
\hline & ltems & Mean & Std. \\
\hline Social bonds & 2 & 3.7 & .85 \\
\hline frequency of interactions & & 3.8 & 1.0 \\
\hline intensity of interactions & & 36 & .85 \\
\hline Investment bonds & 3 & 3.5 & .80 \\
\hline confidential information & & 3.2 & 1.1 \\
\hline intemal client knowledge & & 3.7 & .90 \\
\hline Invested timeleffort/money & & 3.7 & .92 \\
\hline Switch bonds & 2 & 3.6 & .90 \\
\hline effort finding alternative & & 3.5 & 1.1 \\
\hline effort establishment new relationship & & 3.7 & 97 \\
\hline Stuck bonds & 2 & 2.3 & 1.2 \\
\hline tied by contracts & & 2.5 & 1.3 \\
\hline tied by rules/agreements & & 2.1 & 1.4 \\
\hline Trust & 3 & 5.3 & 1.2 \\
\hline trust that agency does what is requested & & 5.4 & 1.4 \\
\hline tight control is necessary $(-)$ & & 4.5 & 1.8 \\
\hline general trust in agancy. & & 6.1 & 95 \\
\hline
\end{tabular}

W-point semantic differential (1 none - 5 very mucri)

* 7 point Likert scalle (1 disagree 7 agree)

Regarding trust, the clients indicate that they can trust their agency fairly well on average (see table 6.18). There are, however, some differences between the trust items. On a general level clients indicate unanimously that they trust their agency very much, although they are less unanimous and convinced about the degree of control necessary to make sure that the agency performs well.

11 For a detailed description of the punfication analysis see appendix 2.

12 One item of the economic bonds fomed a unidimensional scale with the two remaining items from the knowledge bonds. 


\subsubsection{Conclusion research concepts: adjusted model}

Based on the analysis of the focal research concepts, reliable and valid scales were found for almost all concepts. Also the 30 service quality items that measure the five quality determinants formed five reliable scales (using Cronbach's alpha). In chapter 7 the structure in these items will be analysed more thoroughly.

The relational bond measures and the behavioural intention measures were partly respecified based on the analyses. For both concepts several types were measured: five relational bond types and three types of behavioural intentions.

- Regarding the relational bonds, one bond type (planning bond) was not confirmed to form a separate scale, and is therefore excluded from further analysis. Furthemore, the items measuring the knowledge and economic bonds were slightly respecified: one item from the economic bond fitted better in the knowledge bond scale. The two bonds were renamed accordingly to reflect the contents of the new items better. The knowledge bond is renamed as investment bond, which reflects the degree to which the client has invested in the relationship in terms of knowledge, money, time and/or effort. The economic bond is renamed as Switch bond, which reflects the expected monetary and non-monetary costs from switching to another agency. These new bonds are easily interpreted and formed reliable and valid scales. We therefore do not expect that this change will influence the analysis of the research model negatively.

- Regarding the relationship intentions, the measures for clients' intentions to invest in the relationship performed poorly, and are excluded from further analysis. The intentions to stay and the intentions to search for alternatives turned out to be two opposite sides of the same coin, and they are respecified as two sub-scales of one underlying construct "stay intentions". This adjustment is theoretically justifiable, for clients who search for altematives do probably not intend to stay and vice versa. Specifying the two scales as sub-scales of "stay intentions" resulted in a highly reliable and valid scale for this construct, which will be used as the relationship intentions measure in further analyses.

This change in the conceptualisation of the relationship intention measure is not detrimental to the analysis of the research model. The intentions are included in the model to validate the relationship commitment measures, which can still be conducted with the adjusted intention measure. It was intended to perform an additional analysis to see whether the two commitment dimensions have differentiating effects on different kinds of behavioural intentions as Kumar et al. (1994) found in their study. Unfortunately, the different kinds of relationship intentions are not confirmed in our study, which means that this additional analysis cannot be carried out. This analysis is, however, not part of our main research objectives and will thus not influence the exploration of the research model negatively.

Graphically, the adjustments in the two concepts can be portrayed in the 'final research model' in figure 6.5 , which will be analysed in chapters 7 and 8 by the method described in de next section. 
Figure 6.5. Final Research Model

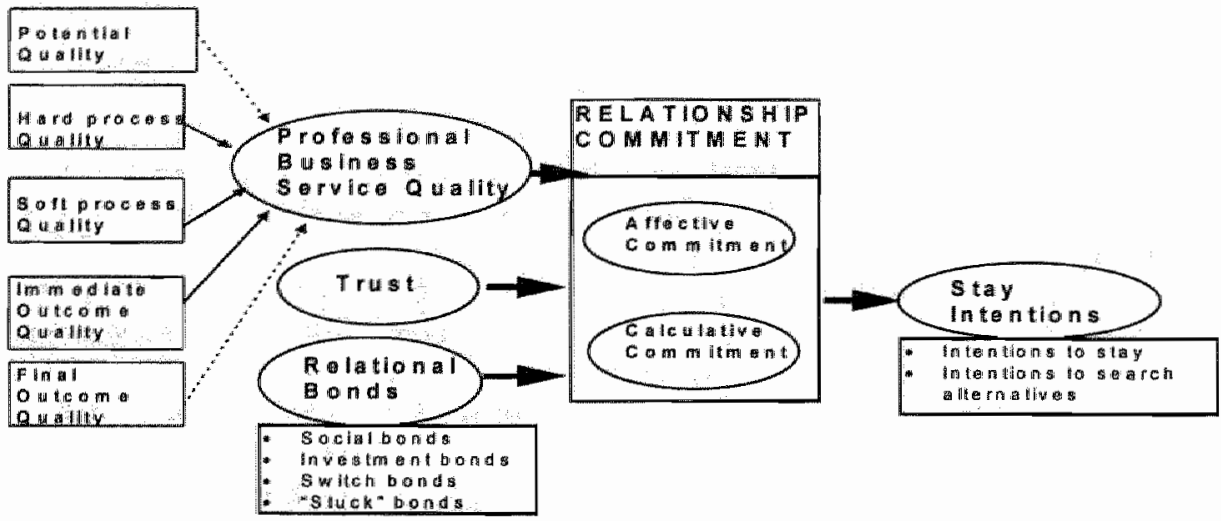

\subsection{Data analysis: methodology}

As portrayed in figure 6.5 this study investigates two research topics that are interrelated:

1. the structure of customers' quality perception, and

2. the influence of this quality concept on the maintenance of long-term relationships.

This research model is rather complex and consists of three subsequent causal paths: 1) the quality determinants are proposed to affect customers' quality perception, which 2) is proposed to affect, together with trust and relational bonds, customers' relationship commitment, which in turn, 3) is proposed to affect customers' stay-intentions. To analyse this model we will use structural equations modelling with the statistical package of LISREL8 (Jöreskog \& Sörbom 1993). Structural equations modelling is distinguished by two characteristics that are highly relevant for our research; it can estimate multiple and interrelated dependence relationships simultaneously, and has the ability to represent latent concepts in these relationships accounting for measurement error in the estimation process (Hair et al: 1995). It is therefore capable of analysing the complex causal relations between the latent constructs in our research model.

Structural equations analysis estimates a model by taking all the interrelations between the variables into account. It starts with the bivariate covariances ${ }^{13}$ between the observed variables(i.e. items) of a theoretical madel and estimates the structurall parameters that reproduce these observed bivariate covariances the best. Besides estimating the strength of proposed causal relations between (latent) concepts, structural equations modelling also provides indications about how well the estimated model can reproduce the observed covariances among the variables. It thus tests how well the theoretical model fits to the data: the model fit. Therefore, structural equations analysis is not only used to confim or reject a theoretical model, but can also (and more often so) be used to modify the theoretical model in such a way that it is statistically and theoretically more meaningful (Jöreskog \& Sörbom 1993). Because our research model is exploratory in nature, structural equations analysis will be used to explore whether our model is confirmed by the data, and if necessary, to respecify it into a model that fits the data

13 Both comelations and covariances can be used. However, because of statistical inaccuracies of correlation analysis it is advised to use the bivariate covariances (Baumgarner \& Homburg, 1996). Therefore we will speak of the covariances in the rest of the chapler. 
better and is theoretically meaningful. The model fit measures and their interpretation were already described in section 5.2. table 5.1, where the same technique is described for conducting confirmatory factor analyses for the validation and purification of our (latent) research concepts.

Any model that includes latent variables consists basically of two sub-models: the measurement model and the structural model. In the measurement model is specified which variables (scales) are proposed to measure which latent concept. In the structural model the proposed causal relationships among the latent concepts are specified, i.e., the theoretical (research) model. Although structural equations modelling is designed to estimate both models simultaneously, this should only be done if the model possesses both strong theoretical rationale and highly reliable measures (Hair et al. 1995). Because our theoretical model is still tentative and not all our measures have been validated by previous research before, we will use the two-step approach, in which the measurement and structural model are analysed in two steps (Anderson \& Gerbing 1988, cf. Frambach 1993, Hair et al. 1995). As described in section 6.4, we analysed the measures first, the results of which will be used as input in the analysis of the structural (i.e. theoretical) model. The two step approach has several advantages compared to the simultaneous estimation of both models in one single step ${ }^{14}$. The model fit that results from a one-step analysis reflects the fit of both the measurement and structural model together. A priori specified measurement models hardly ever give an acceptable fit without modification (Anderson \& Gerbing 1988), which will affect the fit of the entire (theoretical) model. The likely specification errors in the measurement model are difficult to locate in a one-step analysis, and can affect other parts of the model (Frambach 1993). This concern is particularly true in our study for not all our measures have been validated before. The two step approach maximises the interpretability of both the measurement and structural model (Hair et al. 1995), and avoids the risk of interpretational confounding with simultaneous estimation (Burt 1976). Furthermore, the simultaneous estimation of all our multiple-item latent concepts and the structural relations between them, requires a large amount of observations ${ }^{15}$. Our sample of 241 observations is not sufficient to estimate such a complex model. The model can be simplified by using composike scale scores for each latent concept, instead of the individual items, which reduces the amount of variables and parameters in the estimation of the structural model. However, items should only be aggregated if they are truly unidimensional (Baumgartner \& Homburg 1996), which can assessed by the analysis of the measurement model. With the two-step approach the measures are validated an purified in the first step, based on which rellable composite scale scores can be developed for each latent concept. Furthermore, the error variances of the scales are estimated in this first step, which can be used in the analysis of the structural model with the composite variables. As described in section 6.4 , our measures are validated and purified first by the analysis of the measurement model. These measures and their error variances will be used to analyse the research model (i.e. structural model) in the next chapters. Another advantage of the two-step approach is that the estimation of the measurement model provides an additional comparison standard to interpret the model fit of the theoretical model (Gerbing \& Anderson 1988). As described in section 5.2, structural equations modelling can only test whether a model is rejected or not rejected by the data. If a model is not rejected, the fit meas-

\footnotetext{
14 Fomell \& Yi (1992) compared the wo-step approach to the conventional one-step approach and expressed a concem for the theoretical assumptions underying the two-step approach. Anderson \& Gerbing (1992) replled by disputing these assumpfions and conclude that the advantages of the two-step approach outweigh its disadvantages.

15 As a rule-of-thumb one should have at least 5 , preferably 10 observations per estimated parmeter (Baumgartner 8 Homburg 1996).
} 
ures can not indicate how good this acceptable model is, there may be more or even better acceptable models. The fit of the measurement model can be used as a comparison standard for the fit of the theoretical (i.e. structural) model and gives indications for its improvement. In the measurement model, the latent concepts are defined by their measures, and are allowed to correlate freely amongst each other. This measurement model is also called the saturated model, for each (latent) concept is related to all other concepts. If the fit of this model is good, it means that the concepts are well differentiated from each other, and that they are measured validly and reliably. Because each concept is explained by all other concepts in the measurement model, this model can reproduce the observed bivariate covariances between the variables the best. This model will thus show the best model fit (i.e. the lowest chi-square ${ }^{16}$ ) possible between the concepts as defined. However, this model is also the least parsimonious, with the lowest degrees of freedom, for there are no theoretical constraints regarding the interrelations between the concepts. In the structurall model, theoretical constraints are specified regarding the interrelations between the concepts: each concept is proposed to be related to only certain other concepts. The fft of the measurement model can be used to analyse how well the proposed structural model performs compared to the best fit possible between the concepts as defined. A good structural model is not only accepted (i.e. "not rejected') by the data, but should ideally fit equally well to the data as the saturated model, but with the least amount of structural relations (i.e. most parsimonious, or highest degrees of freedom). We will use the fit of the measurement (saturated) model in the first step, to analyse the fit of the proposed theoretical model and to find ways for its improvement.

Because of the complexity of the research model, in which two different literature streams are integrated, structural equations modelling will be used first to analyse the theoretical proposjtions separately, before the entire research model will be assessed simultaneously. This means that the research model will be divided into sub-models, which will be tested and added subsequently. The rationale behind this is similar to the rationale for using the two-step approach. Structural equations modeling estimates the structural relation between any two (latent) concepts taking the interrelations between all other variables in the model into account. This means that if any proposed structural relation should be rejected by the data, the fit and parameter estimates of the whole model may be affected. Our research model consists of three subsequent causal paths, and a bad fit in either path will not only affect the fit of the entire model, but may also influence the parameter estimates of the other structural relations. If this is the case, it becomes difficult to locate the structural path that caused the bad fit, for several problematic relations may be identified by the program. Although it is the strength of the structural equation modelling technique that it does take all interrelations into account, we believe that the interpretability of the outcomes will increase considerably if the propositions are first analysed separately, and orily then jointly.

The simultaneous estimation of the propositions remains, however the most important analysis. The main objective of our study is to explore the integration and interrelation between the propositions on which the model is based. However, if the propositions are only estimated simultaneously, there is a chance that the integration of the propositions has to be rejected, whereas in fact only one of the propositions gives a poor fit. Because our model is built on several theoretical propositions that are nomally studied in isolation, we argue that it is theoreti-

16 Chi-square is actually a "badness of fit measure (Joreskog \& Söbom 4993). If chi-square is significant, it means that the hypothesis that the model fits badly should be accepted. See also section $5: 2$. 
cally and statistically justified to specify sub-models for each of these propositions, which are then analysed subsequently. This way, if necessary, modifications can be specified that are in line with existing theory on which the individual propositions are based. Therefore, the following sub-models will be analysed with the data from the field study:

- First, the measurement model was analysed in section 6.4 of this chapter. The measures used for each of the research concepts are validated and purified using the procedure described in section 5.2 .

- Then, the structure of customers' service quality perception will be analysed separately in chapter 7 . This is a separate research question, which is usually investigated as such in service quality literature. Our goal is to analyse the proposed structure of customers' quality perception, regardless of its effect on the maintenance of the relationship. Therefore, this part of the model will be isolated first and analysed in-depth in chapter 7.

- Then in chapter 8 , the model will be divided and estimated in three parts, starting at the right end side of the model. First, the proposed relation between customers' relationship commitment and relationship intentions will be analysed in isolation. This will be done to examine the nomological validity of the commitment dimensions that form a central part of the model. This was the main reason to include the relationship intentions in the model. Any anomalies that occur in this proposed relation will have to be taken into account when interpreting the relation between the antecedents and the commitment concept as defined. Second, after the validation and understanding of the commitment dimensions, their direct antecedents will be added to the previous sub-model. This means that the role of customers' overall quality perception, together with the trust and relational bonds, will be investigated regardless of the quality determinants on which the overall quality perception is based. This will be done to explore whether customers' quality perception plays a role at all on the maintenance of relationships (= a research objective), and to be able to interpret the outcomes of this sub-model in light of existing literature where the direct antecedents to commitment are usually studied in isolation. Finally, the quality determinants will be added to this sub-model, and the entire research model will be estimated simultaneously. In this analysis the true integration of service quality literature and business marketing literature will be examined. This analysis can also be used to assess whether the modifications suggested by the part-wise analyses are confirmed in a much more complex setting ${ }^{17}$.

\subsubsection{Using structural equation modelling}

To conduct structural equations analysis several steps and decisions have to be made. First of all, the input matrix that will be used in the analyses should be decided upon. The correlation matrix or covariance matrix of the observed variables can be used as input in LISREL8. As indicated earlier, the correlation matrix has some disadvantages. The chi-square as test-statistic is not accurate and therefore not interpretable and the standard errors of the parameters are underestimated which leads to higher t-values for the parameter estimates (cf. Baumgartner \& Homburg 1996). Therefore, the covariance matrix will be used as input matrix, and the standardised solution will be used do interpret the results.

The covariance matrix is computed with PRELIS2 (Jöreskog \& Sörbom 1993) using listwise deletion of missing values. Listwise deletion should be used to ensure that the covariances are computed over the exact same cases and thus reflect the true interrelation between variables.

17 The reader should keep in mind that the inclusion of the quality determinants not only adds five wariables to the model, but that also their bivariate covariances, with all other wariables will have to be explained. 
With pairwise deletion the bivariate covariances between the variables are computed over different cases, which may affect these covariances and therefore the estimation of parameters (Saris \& Stronkhorst 1984, Barbara \& Byme 1989). However, listwise deletion removes every respondent from the sample with a missing value on any of the variables, which reduces sample size quickly and leads to a loss of valuable information on all the variables with non-missing data: One way to deal with this problem is to impute values for the missing ones. The most common method for this is the 'mean imputation' in which a missing value is substituted with the mean of the entire sample on that item (cf. Frambach 1993). The problem with this method is that it reduces the variance in the items and may affect the significance of estimated parameters. Therefore, we used the imputation procedure provided with the PRELIS2 program. This program substitutes a missing value of a case with a (mean) value from other cases that have a similar response pattern on a set of matching variables. This way a missing values is not substituted with the general mean, but with the mean of similar cases as the one with the missing value. If no similar case is found, or if a case has too many missing values on matching variables, the program can not impute a value. With listwise deletion these cases are removed from the data-set. This procedure reduced our sample size from the original 241 to 226 cases with non-missing values. This sample size is close the 'critical sample size' of 200 which is considered to be ideal for structural equations analysis (cf. Hair et al: 1995).

The model will be estimated with the Generalised Least Squares (GLS) estimation method. This method is preferred to the more common Maximum Likelyhood (ML) method because it is based on somewhat less restrictive assumptions than ML. GLS does not require a strictly multinormal distribution in the observed variables; and can also deal with other distributions without excessive kurtosis (cf. Bollen 1989). The GLS estimators have the same desirable properties as the ML estimators (i.e. asymptotically efficient, consistent, and scale invariant, see Bollen 1989, p. 115).

These decisions apply to all the LISREL analyses conducted in chapters 7 and 8. 


\section{Chapter 7: Clients' Service Quality Perception}

The work praises the master". Dutch saying

\subsection{Introduction}

In this chapter the first research question will be addressed by exploning the structure of customers" quality perception of professional business services. The focus will be on the first part of the research imodel (see figure 7.1):

Figure 7.1: Part of research model analysed in this chapter

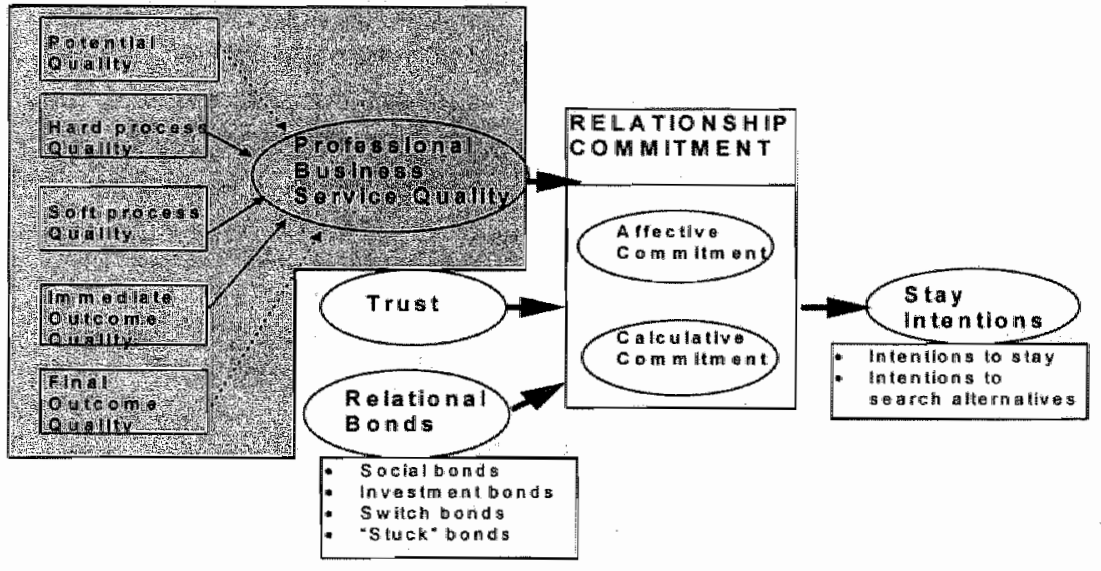

The first two research objectives will be empirically addressed by analysing the key quality determinants of customers' quality perception of advertising services, and their relative importance for customers' overall service quality perception. The propositions regarding both these objectives are graphically presented in figure 7.1 (the broken lines indicate the proposed relatively lower importance). In this chapter these propositions will be explored with the data from the field study in the advertising market. First, the structure of customers' quality perception of advertising services will be analysed in section 7.2 . Then, in section 7.3 , the relative importance of the found key quality determinants will be explored. In section 7.4 the findings from both analyses are summarised and conclusions will be drawn. 


\subsection{Customer-based service quality for advertising services}

In this section the proposed service quality model for professional business services will be explored. This model is based on the general assumption (see chapter 3) that customers base their quality perception of services not only on the services outcome, but also on the service process, and structural characteristics of the service provider, which we called the potential quality. Particularly for professional business services we proposed that customers make a distinction within the service process between the technical way in which the (core) service is produced, i.e., the hard process quality, and the interactions and communications with the customer during the process, i.e. the soft process quality. Also the service outcome of professional business services will be

Figure 7.2: Proposed determinants of professional business service quality

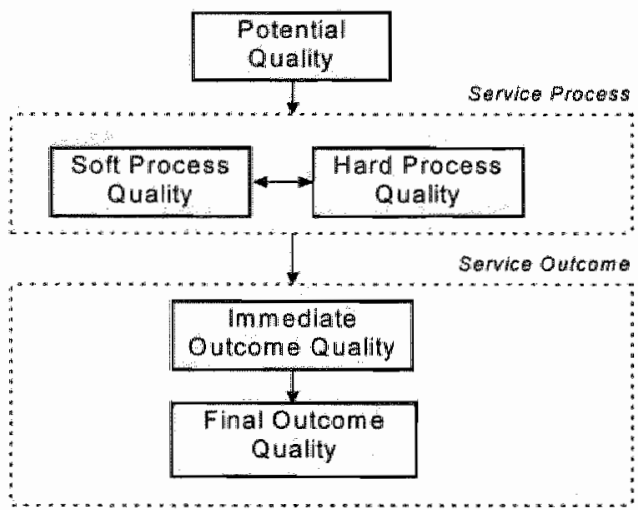
assessed by different kinds of outcomes. Customers not only evaluate what the provider actually delivers after the service production process, i.e. the immediate outcome quality, but also the results or consequences this outcome has, i.e. the final outcome quality. We thus propose that customers base their overall quality assessment of professional business services on five key quality determinants, which is portrayed in figure 7.2

This proposed structure will be explored by analyses on two different levels:

1. quality determinant level. To get a first indication whether these five quality determinants are indeed incorporated into customers' overall quality perception, the five general measures that capture each quality determinant (see chapter 5 and 6) will be analysed first. Because these measures are restricted to the five a priori proposed quality determinants, the analysis forms a first exploration of the feasibility of the proposed structure; and,

2. quality item tevel. To get a more in-depth insight into whether customers actually use these five determinants in their quality perception, the quality items will be analysed as well. 30 quality items were developed that cover the core aspects of customers' quality perception of services in general and of professional business services in particular (see chapter 5). These quality items are proposed to be indicators of the five service quality determinants. To explore whether customers' evaluation of these quality aspects is indeed guided by the five quality determinants, the underlying structure in customers' perception of the quality items will be analysed first in section 7.2.2. Then again analyses will be performed to explore how this quality structure is incorporated into customers' overall quality perception.

In section 7.2.3 the outcomes of both groups of analysis will be compared. 


\subsubsection{Analysis of quality determinant measures}

The operationalisation of the five service quality determinant items and their descriptive results are described in chapter 6 . To explore whether these quality determinant measures are incorporated into customers' overall perceived quality of advertising services two analyses will be conducted. First, the interrelations among the quality determinants will be examined. Then, the five quality determinants measures will be related to an external measure of customers' overall perceived quality.

\section{Interrelations between quality determinants: uni-dimensionality}

If the five quality determinants are all incorporated into customers' perceived service quality, they should all capture different aspects of one and the same underlying service quality construct, i.e. the determinant items should be uni-dimensional. The confirmatory analysis described in chapter 5 (section 5.2) will be used to analyse the uni-dimensionality within the quality determinants. The outcomes of this three-step analysis are portrayed in table 7.1.

Table 7. 1: Confirmatory analysis uni-dimensionality of five quality determinants

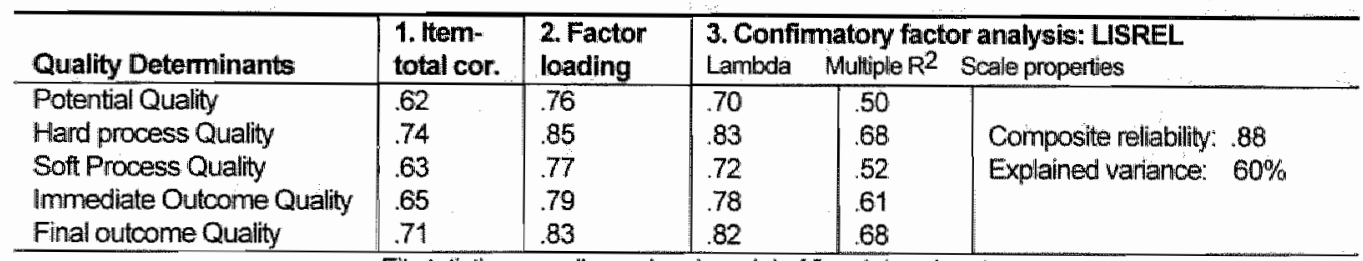

Fit statistics one-dimensional model of five determinants

$$
X^{2}=28, d f=5, p<.00 \text {, }
$$

RMSEA $.14, \mathrm{GF}=.95, \mathrm{AGFI}=.85, \mathrm{CFI}=.98$

The first step in the analysis (see section 5.2) are the item-total correlations between the five quality determinant items. All item-total correlations (see table 7.1) of the measures exceed the recommended 60 level. This is a first indication that the items share one underlying construct. The subsequent exploratory (principal axis) factor analysis indicates that the items share only one factor together, which explains $64 \%$ of the variance in the items, which also supports the notion of uni-dimensionality in the items. In the last step, the five measures are subjected to a confimatory factor-analysis with L.ISREL8 to explore whether the (bivariate) covariances between the five determinants are sufficiently explained by one underlying construct. The analysis shows that all five determinant measures are reliable indicators of one underlying construct, with squared multiple correlations exceeding .50 (see table 7.1). The determinants together form a reliable scale with a composite reliability of .88 and $60 \%$ explained variance (for an explanation of these measures see section 5.2).

However, the model as a whole shows a poor fit (see table 7.1), indicating that the covariances between the quality determinants are not sufficiently explained by their relation to one underlying construct. Analysis of the residuals is needed to find the cause of this. The residuals suggests that the immediate outcome quality and final outcome quality determinants share more variance together than their relation to the latent construct allows. Adding an error covariance 
between the two outcome determinants decreased the chi-square value significantly' and resulted in a good overall model fit. This could mean that respondents hardly differentiate between the two kinds of outcome quality, and that both quality determinants could form together one sub-dimension of overall service quality: "outcome quality", rather than two separate determinants.

To explore this idea, a composite scale was made of the immediate and final outcome quality items together into one 'outcome quality' deteminant. This scale replaces the immediate and final outcome measures, reducing the model to four quality determinants instead of five. This adjusted model was then analysed again with a confirmatory factor analysis. As indicated in table 7.2 , this model of four quality determinants shows a good overall model fit. The multiple squared correlations of the four determinants are above .50 , and together they form a scale with a composite reliability of .85 , with $58 \%$ variance extracted. These properties are comparable to the ones found from the five quality determinant model, indicating that that no significant information is lost by combining the immediate outcome and final outcome together.

Table 7.2: Confimatory factor analysis four quality determinants

\begin{tabular}{|c|c|c|c|}
\hline Four Quality Determimants & \multicolumn{2}{|c|}{ LISREL parameters } & Scale properties \\
\hline Potential Quality & .72 & .52 & \\
\hline Hard Process Quality & .86 & .73 & Composite reliability: 85 \\
\hline Soft Process Quality & .72 & .52 & Explained wariance $\quad 58 \%$ \\
\hline "Outcome Quality" & .74 & .55 & \\
\hline
\end{tabular}

Fit statistics one-dimensional model of four deteminants

$$
X^{2}=3,7, d f=2, p=16 \text {, }
$$

RMSEA.06, $\mathrm{GFI}=99, \mathrm{AGFI}=96, \mathrm{CF}=1.0$

\# Composite measure of immediate and final outcome quality deteminant thems.

So, although the analysis supports that the five determinants do share one underlying construct, it also indicates that customers hardly distinguish between the immediate outcome quality and final outcome quality of advertising services. It seems that customers' quality perception is based on only one 'outcome quality' determinant, in which both service outcomes are somehow combined.

\section{Relation to overall service quality}

The previous analysis showed that the quality determinants are reliable and valid indicators of one underlying construct. This underlying construct is supposed to be customers' overall perceived service quality. To establish the convergent validity of this quality construct, it will be related to another measure of customers' overall perceived service quality. Respondents" overall perceived service quality was measured by three items, which were found to be reliablle and valid indicators of the overall service quality construct (see chapter 6).

The underlying construct of the four quality determinants is correlated to the underlying construct of the overall service quality items, which are bath supposed to measure customers' overall perceived service quality (see figure 7.3). The underlying factor of the quality determi-

1 Decrease in chi-square value $=20.4$ with 1 extra degree of freedom. 
nants has a disattenuated correlation ${ }^{2}$ of .95 with the overall quality construct, with a standard error of 0.02 . To analyse whether this correlation could be regarded as a unity-relation (correlation $=1$ ), a chi-square difference test in LISREL8 was performed. In the null-madel the correlation between the two constructs is set free, and in the alternative model the correlation between the two quality constructs is constrained to unity.

The chi-square of this alternative model is slightly higher than that of the null-model. The increase is, however, insignificant (increase $=2.7$, df =1), which means that the hy-

Figure 7.3: Correlation two scales of overall service quality

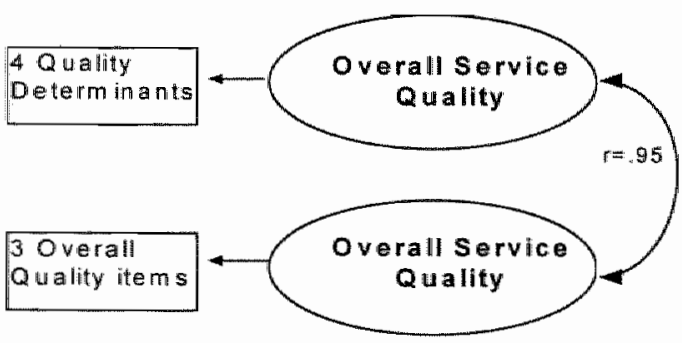
pothesis that the constructs have a correlation of 1 , cannot be rejected. The four quality deteminants are thus indeed indicators of customers' overall perceived service quality.

These results show that the four service quality determinants are reliable and valid indicators of clients' overall perceived service quality. It thus seems that clients base their quality assessment on four quality determinants instead of five: the potential quality, the hard process quality, the soft process quality and the outcome quality, which consists of an evaluation of the immediate and final service outcome together.

\subsubsection{Analysis of quality items}

In the previous section analyses were performed with the five a priori proposed quality determinants. The (four) quality determinants are found to be strongly related to customers' quality perception, which provides a first support for the proposed quality model. However, since the clients were 'forced' to evaluate the five proposed quality deteminants only "the analysis does not indicate whether customers actually use these quality deteminants in their overall quality perception $^{3}$. This will be explored by an analysis of the 30 quality items that were found to be used by clients in their quality perception of professional business services. First, the structure by which customers evaluate these 30 quality items will be examined. A confirmatory analysis will be conducted to explore whether customers' evaluation of the quality items can be captured by the proposed five quality determinants. Then the found structure will be analysed further to see whether it is part of customers" overall perceived service quality.

\section{Structure of quality item evaluation}

The 30 quality items used in the study were taken from other service quality studies as crucial service quality indicators, and were categorised into the five quality determinants of professional business services. The Cronbach's. Alpha analysis in chapter 6 indicated that the items form good operationalisations of the five quality determinants. This suggests that customers' evaluation of the quality items is indeed guided by the five quality determinants. This structure (see

\footnotetext{
2 This is the "pure" comelation between two latent constructs, i.e comected for the measurement error in the indicators (see Joreskog \& Sïrbom 1993)

3. The analysis already showed that customers probably do not make as sharp a distinction between the immediate and finel outcome quality of the service as we proposed.
} 
figure 7.4 ) will be analysed here more in-depth by using the more rigid confirmatory analysis that was also used for the other concepts in our study (see section 5.2).

This analysis will be used to explore whether the items are accurate indicators of the proposed five quality determinants, and if so, to re-

Figure 7.4: Proposed stucture in quality items

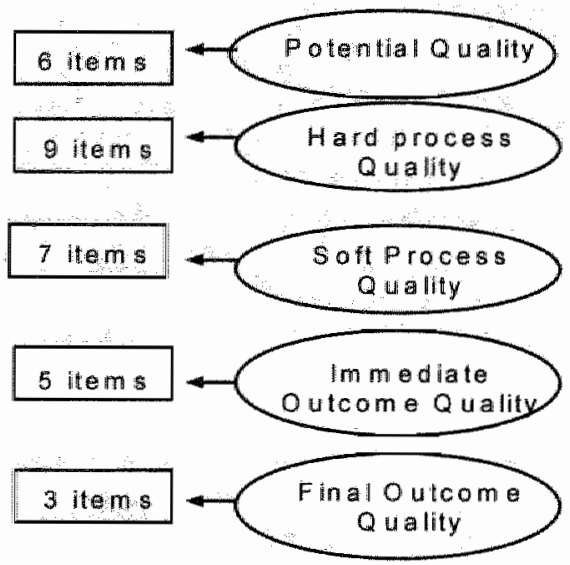
duce the elaborate amount of items into a concise set for each determinant. The first two steps of the analysis (see section 5.2) are taken for each proposed quality determinant separately. The final structure that lies within all the items will then be analysed in step 3: the confirmatory factor analysis. In appendix 2 the statistics of each of the three steps are described in detail. Below the main outcomes of each step will be presented.

\section{Item-total comelations per determinant}

The item-total correlations were calculated separately for the items of each proposed deteminant (see appendix 2). The items of the soft process, immediate outcome and final outcome quality showed high item-total correlations above the .60 level. Of the potential quality items, only three of the six items had item-total correlations close to the recommended .60 level (see section 5.2 for the criteria), indicating that these three items share one underlying construct. The hard process quality items had very low item-total correlations amongst each other. Too many items had to be removed before an agreeable set would remain. This could indicate that the items cover different scales instead of one. An exploratory factor analysis on the hard process quality items revealed that the nine items could be classified into two factors (see appendix 2 ). There is a clear distinction between items loading high on one factor and low on the othert:

- items reflecting the FUNCTIONAL RELIABILITY and Accuracy in the agency's way of working, i.e. meeting deadlines, budgets and the agreed upon strategy, and the accuracy and flexibility in the execution; and,

- items reflecting the exhibited COMPETENCE of the agency during the service production process, l.e. the degree to which the agency shows understanding of the clients' problems and strategies and their capability to translate that into communication.

This distinction within the items is logical and interpretable. Both factors were initially included as hard process quality elements. Apparently clients make a clear distinction between their evaluation of the way an assignment is produced, and the competence by which it is produced. This may be an important finding, particularly for professional business services, in which the competence (or expertise) of the professionals plays a central role (cf. LaPierre \& Filiatrault 1995). Both factors could thus form separate quality determinants. Therefore, item-total correlation analysis were conducted on each of the two "hard process quality' scales separately. Three items of each scale had item-total correlations close to or above the recommended .60 (see

4 Only wo items loaded moderately high on both factors 
appendix 2). This first step thus resulted in the identification of six quality deteminants instead of the proposed five. The next steps will be conducted on these six quality determinants.

2. Exploratory factor analysis (PAF)

The six determinants were then subjected to an exploratory principal axis factoring factor analysis, to assess the uni-dimensionality of each quality determinant separately. This analysis is used to confirm the proposed one-factorial structure of each determinant and to select the items with the highest factor loading. The six factor analyses indicate that each quality determinant is indeed uni-dimensional. Based on this analysis the three highest laading items of the Soft process quality scale are selected, and the other two are removed to get a concise set of items. One item of the Functional reliability and of the Competence scale is removed, because of their relatively low factor loading (see appendix 2).

These two steps in the analysis thus indicate that all five proposed quality determinants are confirmed except for the hard process quality determinant, which is represented by two dimensions instead of one: FUNCTIONAL RELIABILITY and COMPETENCE. This six-dimensional structure will be analysed further in the next step.

\section{Confirmatory factor analysis}

The six-dimensional structure of the quality items was then subjected to a confirmatory factor analysis in LISREL8, to explore whether the interrelations (covariances) between all the remaining quality items can indeed be explained by six underlying constructs.

The first analysis showed a poor fit, because two items from different determinants were strongly related (see appendix 2). The immediate outcome quality item 'Agency's work relates well to the incurred costs' showed a high error covariance with the Functional Reliability item 'Agency stays within budget'. The items apparently share a cost aspect beside the relation to their respective quality determinant. Since we defined our quality concept as referring to the "get" elements and not the 'give' elements (see chapter 5), this shared cost aspect is not relevant for the quality concept. Therefore, the item belonging to the immediate outcome quality determinant is removed (see appendix 2). After the removal of this item, the fit of the six-dimensional model is fairly good (see table 7.3). Although the chi-square value is significant, it is lower than two times the degrees of freedom, and the RMSEA indicates that the approximate fit is good (see section 5.2 for the criteria). The items form relliable scales for the six quality determinants with composite reliabilities ranging from 72 to 89 . All scales have an explained variance percentage above the recommended $50 \%$. This analysis thus confirms that a six-dimensional structure underlies customers' evaluation of the quality items, and that the dimensions are well differentiated from each other.

It thus seems that the five dimensional structure proposed in the items, is for the mast part confirmed. However, the analyses suggest adding a separate dimension within the hard process quality items. The Functional Reliability in the service delivery process is assessed differently from the exhibited Competence by the agency. This is portrayed in figure 7.5 . 
Table 7.3. Descriptives final sib quality dimensions

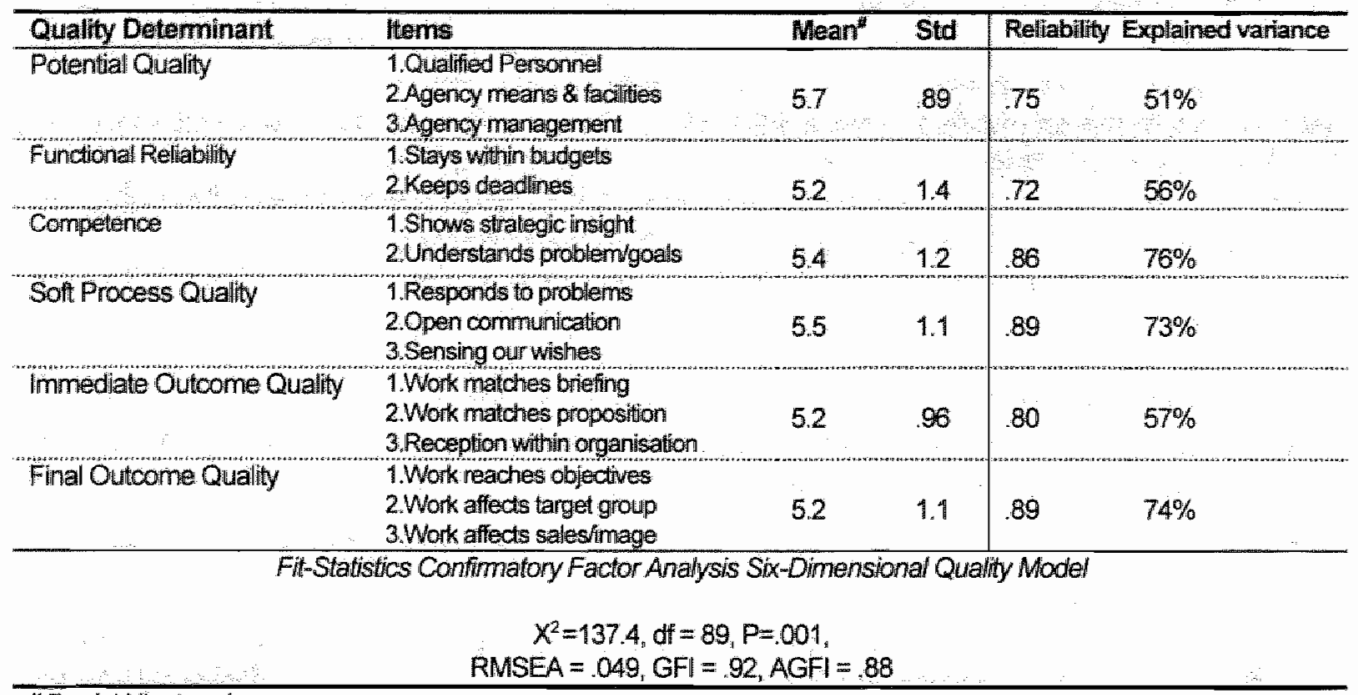

\#7-point Likert-scales

Figure 7.5: Proposed versus found structure in service quality items

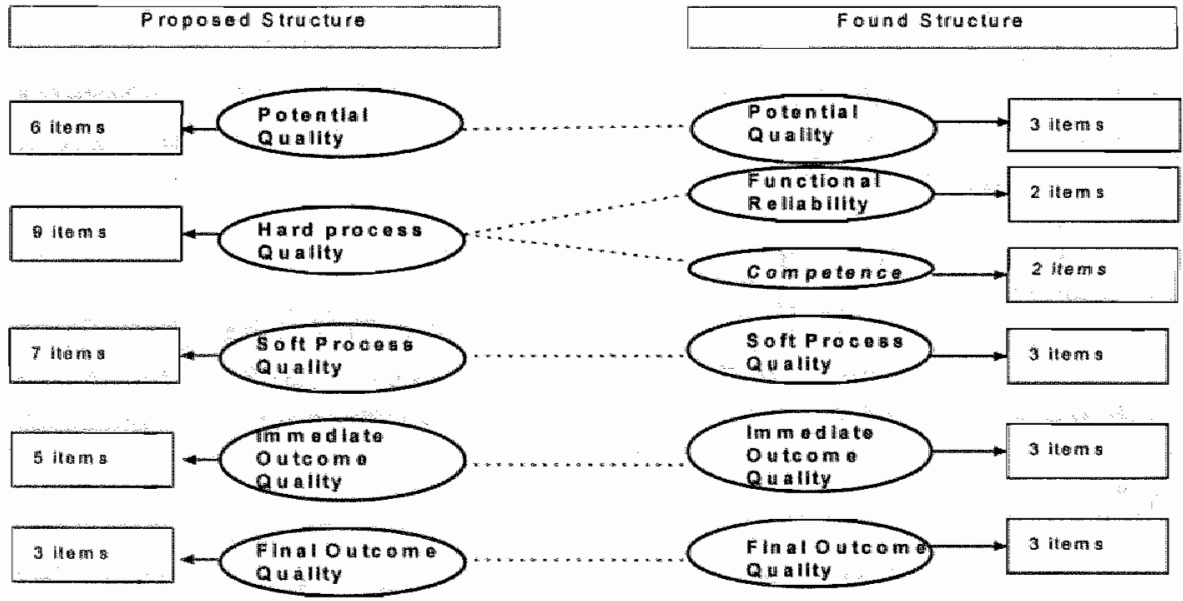

The careful reader will have noticed that our terminology has changed. To distinguish
between the five quality determinants that were proposed and the six determinants found
by the analysis from the quality items, we will call the found determinants quality dimen-
sions, instead of deteminants. This distinction is merely to prevent confusion in the dis-
cussion that follows and has no theoretical consequences.

2. Inter-nelations among the six quality dimensions: uni-dimensionality 
So, six quality dimensions underlie customers' evaluation of the service quality items. This finding, however, does not necessarily mean that all six dimensions are part of customers' overall quality assessment of advertising services. Like the analyses done with the five quality determinant items in 7.2 .1 , the interrelations between the six quality dimensions will be analysed to explore whether they are all part of one undertying construct: overall perceived service quality. By this analysis we can explore whether the new two hard process quality dimensions are a rele vant addition to the proposed quality model ${ }_{i}$ and whether the finding (in section 7.2.1) that customers do not make a sharp distinction in their evaluation of the two outcome quality determinants is supported by the quality-item data.

A hierarchical confirmatory factor analysis will be conducted to assess whether the six quality dimensions can be regarded as indicators of one underlying construct. The factor analysis is a hierarchical one, because the quality items are indicators of the six quality dimensions, and it will now be assessed whether the six dimensions, in tum, share one underlying construct. These six dimensions are thus first order factors that are proposed to be indicators of a second order factor: overall perceived senvice quality. This structure is portrayed in figure 7.6.

Because of the many quality items, and their strong interrelations, composite scale scores will be used for each of the six quality dimensions ${ }^{5}$ and the error terms of the scales will be fixed using the composite scale reliability ${ }^{k}$. In table 7.4 the outcomes of this analysis are presented.

Figure 7.6: Hieranchical confimatory factor analysis of quality items: LISREL notation

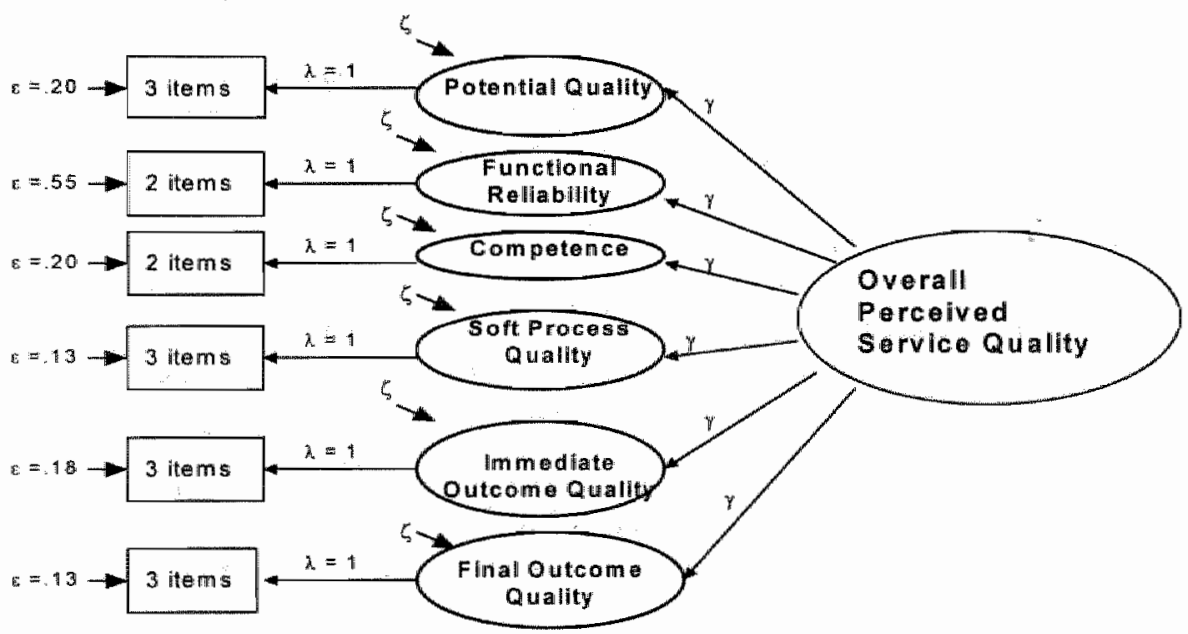

The analysis shows that all six quality dimensions are significant and reliable indicators of one underlying construct, with coefficients all above .75 and squared multiple correlations above the recommended .50 . However, the fit of this model is not very good, with a significant chi-square that is higher than two times the degrees of freedom, and a RMSEA indicating that also an approximate fit is highly unlikely. This means that the interrelations(covariances) between the six

5 The mean of the scale items are used.

6 Error variance $=(1$-composite reliabillty) * scale variance (ct. Baumgartner \& Homburg 1996). 
dimensions are not sufficiently explained by their joint relation to one underlying construct. Again the residuals will be analysed to trace the cause of this problem.

Table 7. 4: Results hierarchical factor analysis six quality dimensions

\begin{tabular}{|c|c|c|}
\hline Quality dimension scales & Standardised coefficient $(y)$ & Mulliple $\mathrm{R}^{2}$ \\
\hline Potential Quality & .76 & .57 \\
\hline Functional Reliabillty & .79 & .62 \\
\hline Competence & .78 & .61 \\
\hline Soft Process Quality & .93 & .86 \\
\hline Immediate Outcome Quality & .97 & .93 \\
\hline Final outcome Quality & .77 & .58 \\
\hline \multicolumn{3}{|c|}{ Fit statistics hie rarchical factor analysis' } \\
\hline \multicolumn{3}{|c|}{$\begin{array}{c}X^{2}=36,3, d^{f}=10, p<00 \\
\text { RMSEA }=\|1, G F I=95, A G F\|=89, C F \mid=99\end{array}$} \\
\hline
\end{tabular}

The analysis of the residuals indicates that the immediate outcome quality dimension and the final outcome quality dimension have a high error covariance. They thus share more variance with each other than their relation to the latent construct justifies. Adding the error-covariance to the model would decrease the chi-square value significantly ${ }^{8}$. Again it seems that customers hardly differentiate between the two outcome quality dimensions and that they are evaluated in a similar manner. This finding thus confirms the finding found from the five quality determinant items in section 7.2.1. Before the two dimensions will be combined for statistical reasons, as was done in the analysis in section 7.2 .1 , the quality items provide additional information by which the interrelation between the two outcome quality dimensions can be analysed more indepth. This analysis will be conducted to explore how the two outcome quality dimensions should be included in the quality model.

\section{- Analysis of outcome quality dimensions}

The previous analyses on both levels of quality measures, indicate that clients' evaluations of the immediate outcome quality and final outcome quality are strongly related to each other, stronger than the other quality determinants. On the other hand, the analysis of the quality items indicated that the immediate outcome quality and final outcame quality are two different dimensions that underlie customers" evaluation of the quality items (see table 7.3). Therefore, it will be analysed here whether the two outcome quality dimensions measure different aspects of clients" quality perception, as was proposed, or whether they both measure only one underlying quality determinant: Outcome quality, as was suggested by the analysis in section 7.2.1. This question will be analysed in two ways:

1. First, the comelation between the two outcome quality dimensions will be examined. If the correlation between two latent constructs is 1 (i.e. unity relation), then the items of each construct measure one and the same concept (Béland and Maheux 1989). If the two outcome quality dimensions are likely to have a correlation of 1 , they thus measure the same concept, and cannot be regarded as separate service quality dimensions.

\footnotetext{
7 Because of offending estimates, the emror variance of the lmmediate outcome deteminant is fixed at a low level $(05)$.

8 Decreese in chi-square value $=9.7$ with 1 extra degree of freedom.
} 
The disattenuated correlation ${ }^{9}$ between the two outcome quality dimensions is 81 with a standard error of .09. They are thus indeed highly correlated. To analyse whether this high correlation should be regarded as a unity relation, a chi-square difference test is conducted with LISREL8. Two alternative models are compared in this analysis: in the null-model the two outcome dimensions are freely correlated, in the altemative model the correlation is constrained to 1. The restriction of the correlation to unity, resulted in an increase in the chi-square value of 5.5 , with one extra degree of freedom. This increase is significant at the $5 \%$ level, which means that the altemative model gives a significantly worse fit to the data than the null model. The two outcome quality dimensions thus measure different, yet related, concepts. And customers do differentiate between the two outcome quality concepts. They are, however, found to be too strongly interrelated to be regarded as independent dimensions of customers" service quality assessment. This could mean that they form two distinct sub-dimensions of one Outcome quality determinant.

2. to explore this new proposition, another hierarchical factor analysis is conducted with the six quality dimensions, but this time the two outcome quality dimensions are specified as two subdimensions (indicators) of one underlying "Outcome Quality" dimension. The other four quality dimensions are specified as before, with fixed error variances based on the reliability of the item-scales. These five quality dimensions are then related to the higher-order factor "Overall Perceived Service Quality" (see figure 7.7).

This model is subjected to a hierarchical confirmatory factor analysis in LISREL8 and will be compared to the original six-dimensional model in which the two outcome quality dimensions are separate quality determinants. The new model shows a significant decrease in chi-square compared to the original model ${ }^{\text {to }}$ (see table 7.5). This indicates that the alternative fivedimensional structure gives a significantly better representation of the covariances between the quality dimensions than the original six-dimensional model.

Table 7.5: LISREL estimates of altemative quality model

\begin{tabular}{|c|c|c|c|}
\hline Quality dimensions & Lambda $(\lambda)$ & Gamma $(\gamma)$ & Multiple $\mathbf{R}^{2}$ \\
\hline $\begin{array}{l}\text { 1. Potential Quality } \\
\text { 2. Functional Relliability } \\
\text { 3. Competence } \\
\text { 4. Soft Process Quallity } \\
\text { 5. Outcome Quafity } \\
\qquad \text { Immediate outcome } \\
\text { - final outcome }\end{array}$ & $\begin{array}{l}.74 \\
.93\end{array}$ & $\begin{array}{l}.76 \\
.79 \\
.79 \\
.94 \\
.87\end{array}$ & $\begin{array}{l}.58 \\
.62 \\
.62 \\
.88 \\
.76\end{array}$ \\
\hline \multicolumn{4}{|c|}{$\begin{array}{l}\text { Fit statistics hierarchical five-dimensional quality model } \\
\text { with immediate and final outcome as sub-dimensions of "Outcome Quality" }\end{array}$} \\
\hline \multicolumn{4}{|c|}{$\begin{array}{l}\text { Chi-square }=20.4, \mathrm{df}=9, \mathrm{p}=.02 \\
\text { RMSEA }=.07, \mathrm{p} \text {-value dose fit }=15 \\
\mathrm{GFI}=.97, \mathrm{AGFI}=.93, \mathrm{CF}=.99\end{array}$} \\
\hline
\end{tabular}

9 This is the 'pure' correlation between the two latent constructs, taking the measurement error into alccount.

10 Decrease in chi square value $=15.9$, with one extra degree of freedom. 
Figure 7.7: Altemative quality model: LSREL notation

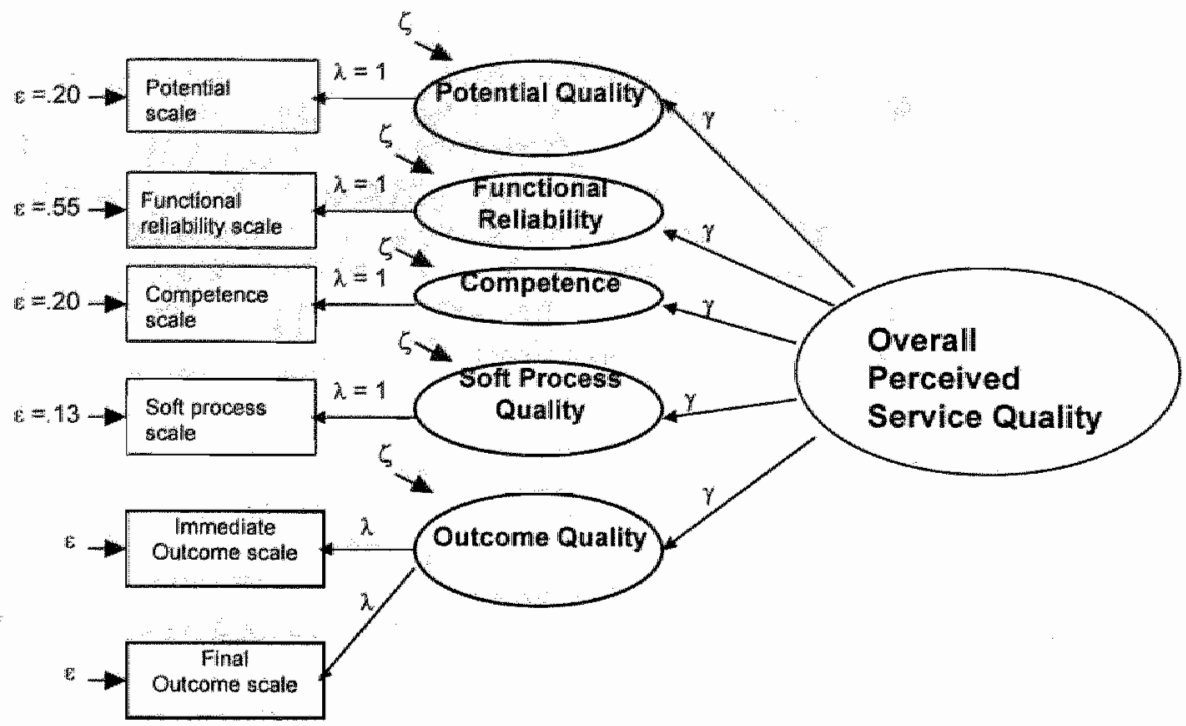

These altemative five quality dimensions are good and reliable indicators of customers' overall perceived service quality, and the two outcome quality dimensions are good indicators of the new "Outcome quality" dimension (see table 7.5). The fit of this model is highly acceptable and much better than the six-dimensional structure.

This analysis thus provided a confimation and important addition to the finding from the previous analysis regarding the two outcome quality determinants. It can be concluded that customers do distinguish between the quality of the immediate outcome and the quality of the finall outcome of advertising services. However, in assessing the overall quality of advertising services, customers use only one outcome quality dimension, which is based on the evaluation of the immediate and finall outcome quality.

Furthermore, the interrelation between the newly found hard process quality dimensions will be examined: the Functional Reliability and the Competence. Both dimensions were found to be separate dimensions underlying customers' evaluation of the quality items, which does not necessarily mean that they are independently incorporated into customers' overall quality assessment (as we saw regarding the two outcome quality dimensions). In accordance with our propositions, these dimensions could be categorised as separate sub-dimensions of the hard process quality determinant. This will be examined next. 


\section{- Analysis of the Functional Reliability and Competence quality dimensions}

To examine whether the two newly found hard process quality dimensions should be regarded as separate quality determinants or as part of one hard process quality determinant, their correlation will be analysed first. The two quality dimensions have a correlation of .54 , with a standard error of .07 . This correlation is thus far from unity, and the items clearly measure two distinct quality dimensions.

It is, however, theoretically possible that the two quality dimensions share a "hard process quality' variance that is not present in the other quality dimensions. Therefore, an alternative quality model was specified, in which the Functional reliability dimension and the Competence dimension are defined as sub-dimensions of one Hard Process quality determinant. This altemative quality model was then subjected to a hierarchical confirmatory factor analysis, with the other four quality dimensions as defined above (i.e. including the new "outcome quality" dimension). This alternative model shows a worse fit" to the data than the model in which the Functional reliability and Competence are defined as separate quality dimensions. This alternative model should thus be rejected.

The Functional Reliability and Competence dimensions thus do not share a 'hard process quality' determinant together. Their interrelation (covariance) is explained better by the overall service quality concept they share together with the other quality dimensions. The dimensions should thus both be treated as separate quality determinants. This is an important finding, for it calls for an adjustment of the initially proposed quality model. It seems that customers do not base they quality assessment on the hard process quality as such, but that the Competence and Functional Reliability are taken separately into account in their overall quality perception of advertising services.

\section{Relation to overall service quality}

The analyses thus suggest that the initial quality model can be modified in two ways.

The proposed Hard Process quality determinant is respecified into two separate quality determinants: Functional Reliability and Competence; and, the proposed Immediate Outcome quality and Final Outcome dimensions should be regarded as sub-

Figure 7.8: Correlation between two measures of perceived service quality

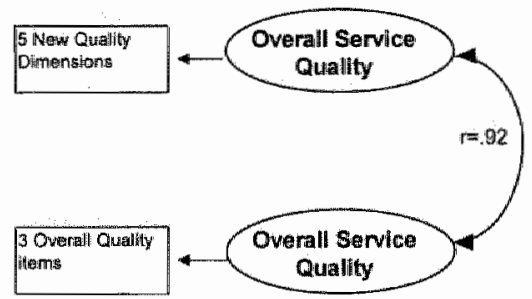
dimensions of one Outcome quality dimension. The analyses showed that this adjusted quality model represents the underlying quality construct fairly well. To validate whether these adjusted five quality dimensions are indeed dimensions of overall service quality, its correlation to the overall service quality measure will be analysed (see figure 7.8 ).

11 Chi-square $=31.6, \mathrm{df}=9, \mathrm{p}=000 . \mathrm{GF}=95, \mathrm{AGF}=89$ and $\mathrm{RMSEA}=11$. We can see that all measures are worse than the model in figure 7.7and chi-square, AGFI and RMSEA are all below their recommended levels (see table 5.1).. The chi-square difference test cannot be performed because additional values were set fixed. But even if the model fit is not significantly worse: it is definitely not a better madel. Therefore the modification will be rejected. 
The underlying construct of the five quality dimensions has a disattenuated correlation of .92 with the overall quality measure; with a standard error of .07. It thus seems highly likely that the two concepts have a unity relationship. To explore this hypothesis statistically, a chi-square difference test is performed with LISREL8, by fixing the correlation to unity between the two concepts. This restriction resulted in an insignificant increase of the chi-square value ${ }^{12}$ compared to the model without this restriction. The hypothesis that the correlation is 1 can thus not be rejected. This means that the new quality model is indeed a reliable and valid representation of customers overall service quality perception. This new quality model will be summarised in the next paragraph.

\subsubsection{Synthesis structure of customers' quality perception}

The findings of both groups of analyses, in section 7.2.1 and 7.2.2, thus both largely support the proposed quality model. Two important modifications were suggested:

1. both analyses indicate that the proposed immediate and final outcome quality determinants are not well differentiated in customers' overall quality perception. It seems that customers base their quality assessment on one "Outcome quality" determinant, which is based on both the immediate outcome and final outcome quality. Customers thus do differentiate between the two service outcomes, but not enough to define them as separate quality determinants; and,

2. analysis of the quality items resulted in a second modification to the proposed quality model. The Hard process quality determinant seems to consist of two quality dimensions that form separate quality determinants in customers' service quality perception. Customers' quality perception is based on both the Functional Reliability and the Competence exhibited during the service production process.

These two adjustments are graphically presented by the shaded areas in figure 7.9.

The finding that customers include the exhibited Competence as a separate determinant in their quality perception is a well-interpretable finding, particularly for professional business senvices. The competence and expertise of the professionals lie at the basis of any professional service. Customers apparently distinguish well between the professionalism of the service providers in their field of expertise (Competence) and the professionalism in their way of working (Functional Reliability).

The finding that the immediate outcome and final outcome quality are not separate quality determinants is also interesting. It was proposed that specifically in professional business services customers would base their quality perception on both types of outcomes. Although we found that customers indeed distinguish between the two, their evaluations are strongly related, and customers' quality perception is based on only one outcome quality determinant in which both are comprised. One rationale for this is that the effectiveness and final results of advertising services are difficult to measure and difficult to account for by the service only (Szmigin 1993, Halinen 1994). Apparently their evaluation of the work itself and its effectiveness become 'blurred' into one outcome evaluation.

12 Increase in chi-square $=.03$, with one extra degree of freedom. 
Figure 7.9: Comparison of proposed and modified quality structure

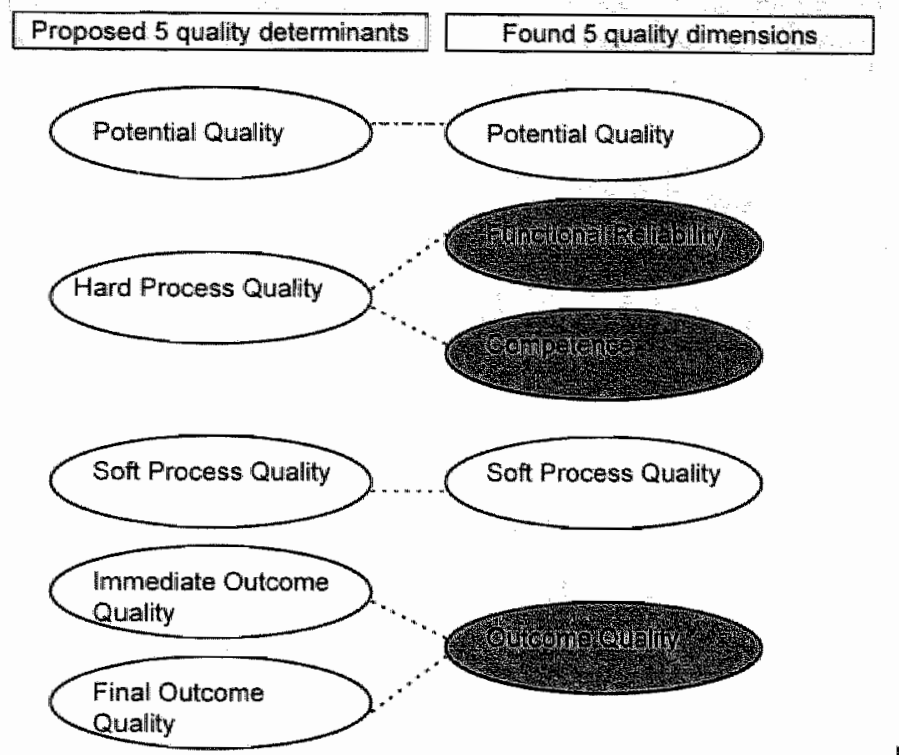

In the next section the relation between these quality dimensions and customers' overall quality perception will be analysed.

\subsection{Relative importance quality determinants}

So far the structure of customers" service quality perception was analysed. Customers' overall quality perception of advertising services was found to be based on five slightly different quality dimensions than initially proposed. This means that these five quality dimensions somehow play a role in customers' quality perception. In this section the second objective of the study will be addressed by an exploration of the relative importance of each of the quality dimensions/determinants ${ }^{13}$ for customers' overall service quality perception. From the exploratory research it was suggested that the potential quality and final outcome quality might not be as important for customers" quality perception as the other quality deteminants.

The relative importance will be analysed in two ways:

1. directly. Customers were asked to rate the relative importance of the initially proposed five service quality determinants; and,

2. indirectly. The quality determinants/dimensions will be related to the external measure of overall perceived quality, to determine their absolute (correlation) and relative (regression) contribution to customers' overall perceived service quality. Quality determinants that contribute stronger to customers' overall perceived quality can be regarded as relatively more important.

Because the direct importance scores were only asked for the initially proposed five quality determinants, the evidence gathered from these five quality determinant measures will be examined first. Then the relative importance of the five 'new' quality dimensions will be explored by the indirect analysis only.

13 The reader should be reminded that "quality determinants" refersi to the initially proposed five quality determinants, and "quality dimensions' refers to the found fiwe quality dimensions in the previous analyses. 


\subsubsection{Evidence from the initial five quality determinant measures}

In the original quality model the potential quality as well as the final outcome quality were proposed to be less important for customers' quality perception of advertising services. This proposition will be analysed here with the initial five quality determinant measures.

\section{Direct importance}

Respondents were asked to rate the relative importance of the five original quality deteminants by allocating 100 importance points among the five determinants. If all determinants are regarded as equally important, respondents would assign to each 20 importance points. Every point a quality determinant gets above that, will be at the cost of the importance of another quality deteminant. In table 7.6 the average importance points assigned to each determinant and their standard deviations are given.

Table 7.6. Direct importance scores fuve onginal quality deteminants

\begin{tabular}{|c|c|c|c|}
\hline Service Quality Determinant & Average importance & Sitd. & $\begin{array}{l}\text { Friedman test }{ }^{1 / 4} \\
\text { Meam rank }\end{array}$ \\
\hline Potential Quality & 14.7 & 8,1 & $2, \overline{32}$ \\
\hline Hard Process Quallity & 18.8 & 9,2 & 2,95 \\
\hline Soft Process Quality & 14.5 & 7.5 & 2,35 \\
\hline Immediate Outcome Quality & 24.6 & 10,1 & 3,67 \\
\hline Final Outcome Qualiy & 27.4 & 142 & 3,71 \\
\hline Total (sum) & 100 points & & $\begin{array}{c}\text { Chi-square }=193,3, \text { of }=4, p=.000 \\
\text { Kendalls } W=23\end{array}$ \\
\hline
\end{tabular}

The importance scores in table 7.6 show that clients rate the immediate and final outcome quality as the most important quality determinants. Together they get a little more than half of the 100 importance points. The potential quality and the soft process quality are rated as the least important quality determinants. The hard process quality is rated exactly in between these two extremes. The Friedman test is significant (see table 7.6) indicating that the distribution of importance scores differs significantly between the determinants which means that the determinants are not equally important. Kendall's $W$ is very low, indicating that there considerable disagreement in the ranking of the determinants between the respondents (see footnote) and there is no clear ranking among the determinants. The mean ranking scores show that the potential and soft process quality determinants hardy differ in ranking and that they are both significantly less important than the two outcome quality determinants, with the hard process quality somewhere in between ${ }^{15}$. Clients apparently want foremost effective work that clients appreciate and that is produced in a professional way. How the clients are treated during the production process, or the potential of the agency seems to be considerably less important. The proposed lower importance of the potential quality is thus confirmed by these data. However, regarding the importance of the final outcome quality the data suggest the opposite. Clients rate the final outcome as the most important quality determinant.

14 Friedman test is a non-parametric test for multiple related samples. It calculates the ranking of the determinants per rater, and tests the equality of the importance score distribution among the 5 variables. Kendall's $W$ indicates the concordlance re garding the ratings of the deteminants. 0 means complete disagreement 1 complete agreement among the raters.

15 Wilcoxon signed rank tests show that potential and soft process quality do not differ significantly in importance, and neither do the two outcome qualities $(p>10)$. The importance of the thard process quality differs significantly from both groups of quality determinants, and lies thus indeed in between. 


\section{Indirect analysis of onginal five quality determinants}

Next to the direct importance measure, a regression analysis is conducted with LISREL 8 to analyse the relative contribution of each of the five original quality determinant measures to clients' overall service quality assessment. This analysis results in indirect importance measures, by inferring the importance of a determinant from its relative contribution to overall quality. The standardised regression coefficients make it possible to make direct comparisons between the contributions of each determinant to the overall quality assessment.

The five quality determinant measures are specified as antecedents to the overall service quality measure. Because the five quality determinants are measured by one item each, the measurement error cannot be assessed and is therefore fixed at zero. The overall quality construct is defined by the three overall quality items. The results of this regression are found in table 7.7 .

Table 7.7: Regression of proposed quality cleterminants on overall service quality

\begin{tabular}{l|l|ll}
\hline & \multicolumn{3}{|l|}{ Relation to overall service quality: } \\
Service Quality Determinants & Comelation & Regression coefficients (t-values) \\
\hline Potential Quality & .62 & 11 & $(1.9)$ \\
Hard process Quality & .74 & .26 & $(3.9)$ \\
Soft Process Quality & .70 & .26 & $(4.4)$ \\
Immediate Outcome Quality & .71 & .27 & $(4.2)$ \\
Final outcome Quallity & .72 & .19 & $(2.8)$ \\
\hline
\end{tabular}

The five original quality determinants together explain $76 \%$ of the variance in customers' overall perceived service quality. The hard process, soft process and immediate outcome quality determinants have the highest and equal effects on clients' overall quality assessment. The correlations show that the final outcome quality has an equal absolute contribution to overall service quality as the three above. However, its regression coefficient next to the other quality determinants is relatively lower. Its contribution is significant and the final outcome quality explains a unique part of customers' service quality perception next to the contribution of the immediate outcome quality. The effect of the potential quality determinant is not significant ( $\alpha=05$ ) next to the other determinants on the explanation of the overall quality assessment. This finding thus supports the proposition that the potential quality and final outcome are relatively less important for customers' quality assessment.

Comparing these findings to the direct importance rating clients made themselves, several differences occur. The indirect analysis indicates that clients' evaluation of the work itself is more important than their evaluation of its effectiveness, which is contrary to what clients indicate themselves. This is probably explained by the fact that both outcome determinants are strongly interrelated. The direct allocation of the importance scores forces the clients to differentiate between each determinant separately, whereas in reality clients' perception of the two outcome qualities are less differentiated. A large part of the contribution of the final outcome quality is already explained by the contribution of the immediate outcome quality determinant. Or stated differently, if clients perceive the immediate outcome as good (or bad), this will have a positive effect on the perceived quality, the actual effectiveness of this work will then not influence the perceived quality as much anymore. However, the final outcome quality does contribute significantly, and thus could either enhance or off-set the effects of the immediate outcome quality. Furthermore, the soft process quality seems to be far more important on clients' overall quality assessment than they indicate themselves. It even has an equally strong effect as the immedi- 
ate outcome quality determinant. It seems that clients are unaware of, or unwilling to admit directly, that the way they are being treated during the service production process has an important influence on their quality assessment of advertising services. If could be that when clients are asked directly they use different criteria than they actually (unconsciously?) use in their quality assessment. Direct assessments probably provoke a more rational deliberation of what should be important to them, rather than what actually is important.

\subsubsection{Evidence from the adjusted quality dimensions}

For the modified quality structure there are no direct importance measures. Therefore, the relative importance of these dimensions will be explored only indirectly, by the regression of the quality dimensions on the overall quality measure. In LISREL8 a regression model is specified (see figure 7.10) between the five new quality dimensions and customers" overall perceived quality. The quality dimensions are defined by their indicators (=items) and the new 'Outcome Quality 'dimension is defined by the scales of the immediate outcome and final outcome dimension. The results of this regression are presented in table 7.8 .

Figure 7.10: Regression of quality dimensions on overall service quality

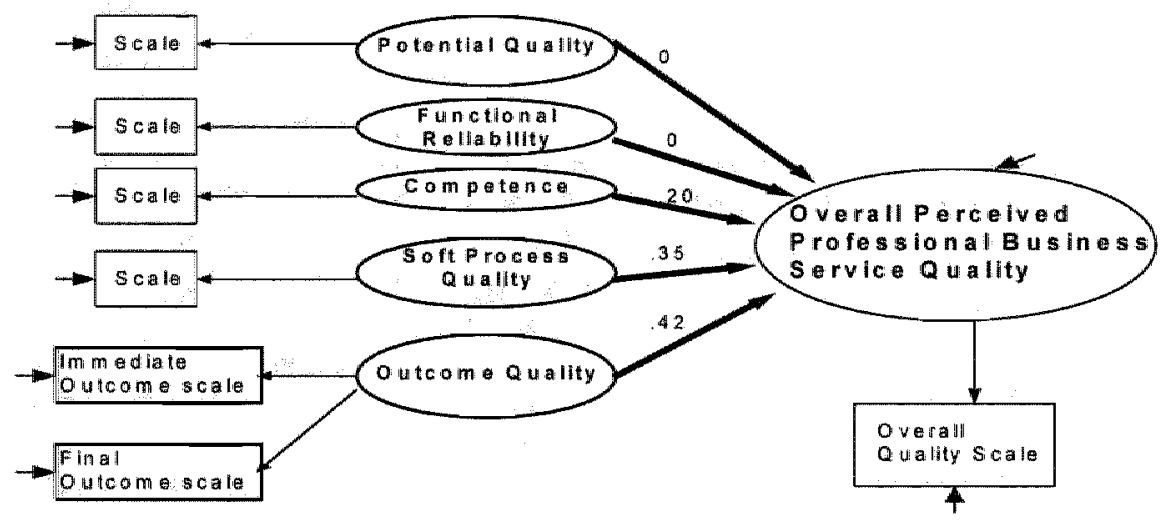

Table 7.8: Regnession of adjusted quality dimensions on overall senvice quality

\begin{tabular}{|c|c|c|c|}
\hline \multirow[b]{2}{*}{ Service Quality Dimensions } & \multicolumn{3}{|c|}{ Relation to overall service quality } \\
\hline & Comelation & Regr & ts (t-values) \\
\hline Potential Quality & 67 & $0^{3}$ & \\
\hline Functional Reliability & .52 & $0^{s}$ & \\
\hline Competence & 69 & .20 & $(2.41)$ \\
\hline Soft Process Qually & .81 & .35 & $(2.74)$ \\
\hline Outcome quality & 84 & .42 & $(3.56)$ \\
\hline $\begin{array}{l}\text { - Immediate outcome } \\
\text { - Final outcome }\end{array}$ & $\begin{array}{l}.83 \\
.72\end{array}$ & \multicolumn{2}{|c|}{ Coefficient of determination: 78} \\
\hline \multicolumn{4}{|c|}{$\begin{array}{l}\text { Fit statistics regression model } \\
\qquad \begin{array}{l}X^{2}=13.8, d f=6, p=03 \\
\text { MSEA } .076, G F I=.98, A G F \mid=.92\end{array}\end{array}$} \\
\hline
\end{tabular}

$\$$ The initial analysis showed insignificant coefficients for both quality dimensions. Fixing each coefficient to 0 resulted in insignificant increases of the chi-squane value (both restrictions increased chi-square by 3 points, with 2 degrees of freedom, $p=48$ ). This means that the coefficients are not significantly different from 0 , and should thus be regarded as 0 . 
The five quality determinants explain $78 \%$ of variance in the overall service quality construct. The regression model shows a fairly good fit to the data (see table 7.8). The Outcome Quality contributes the strongest to customers' quality perception, closely followed by the Soft Process quality, and then the Competence dimension. Again, the potential quality does not contribute significantly to the explanation of customers' service quality assessment. Also the added Functional Reliability dimension does not seem to contribute significantly to the overall quality, relative to the other quality dimensions.

Compared to the analysis with the original five quality determinants this analysis shows very similar findings. Again the Outcome quality is the most important quality dimension for customers' overall perceived service quality. From the correlations (in table 7.8) we can see that both outcome quality dimensions are strongly related to customers' overall service quality assessment, especially the immediate outcome quality dimension. Since the outcome quality dimensions are strongly interrelated, this might again suggest that the immediate autcome quality explains most of their joint effect on overall perceived service quality, with a smaller unique contribution of the final outcome dimension.

Also the soft process quality is found again to be very important for customers' overall service quality assessment, which contributes almost as much as the outcome quality dimension. The communication and treatment of the clients during the service production process seem to have an important influence on their quality assessment.

Aglain, the potential quality is found to be relatively unimportant for customers' quality perception of advertising services. This was also suggested in the exploratory research in the advertising market. So although the potential quality is a reliable indicator of customers' service quality perception, i.e. one of the dimensions/determinants customers base their quality assessment on, its relative contribution is very low. This could be easily explained by the fact that the respondents already have a relationship with their agency and thus have already experienced its services. It is highly likely that the agency was selected for the potential it cocild offer the client, and thus forms a sort of pre-condition before a relationship will start. Once the relation is established, the actual service experiences (i.e. the process and outcome dimensions) become more important for their service quality assessments.

The significant contribution of the hard process quality determinant, found in the previous analysis $s_{x}$ is here confimed regarding the Competence dimension. The competence exhibited by the professionals during the service production process contributes significantly to customers' quality perception, although not as strong as the outcome quality or the soft process quality. This underscores the relevance of this 'new' quality dimension for professional business services. Customers not only evaluate the Competence separately "it also has a unique, significant contribution to their quality assessment.

The Functional Reliability, however, is not important relative to the other quality dimensions, even though the exploratory research and other studies considered it an important quality aspect for professional business services. The correlation (in table 7.8) shows that also its absolute relation to overall quality is not as high as any of the other dimensions, even compared to the potential quality. Apparently this quality dimension is not as important for customers' quality perception as the others, even though the trade press shows frequently that it may cause friction between client and agency when deadlines are not kept or budgets are surpassed. 


\subsection{Conclusions clients" service quality perception}

In this chapter the structure of customers' quality perception of advertising services was anallysed. Several analyses were performed to explore the key determinants of customers' quality perception, and the relative importance of these determinants for customers' overall quality assessment of advertising services.

\section{Key quality determinants}

The proposed quality model for professional business services (see chapter 2 or section 7.1 ) was analysed to explore the general quality determinants that customers use to assess the quality of advertising services. The findings confirm the basic structure of the proposed quality model: customers base their overall service quality perception on the potential of the service provider, on the service production process, and on the outcomes of the service production process. However, two modifications are suggested to the proposed model, which are indicated by the shaded areas in figure 7.11 .

Firstly, clients seem to differentiate less strongly between the immediate outcome quality and the final outcome quality than initially proposed. Customers' evaluation of the agency's work itself (immediate outcome) is closely related to their evaluation of its effectiveness (final outcome), is combined into one outcome quality determinant, which is as such incorporated into their overall quality assessment. On the one hand, this finding

Figure 7.11. Quality determinants of adventising senvices

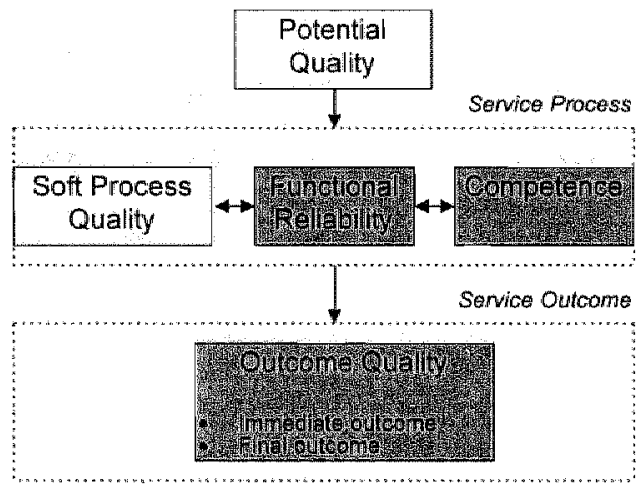
confirms the proposition that customers do distinguish between the immediate outcome and final outcome of advertising services. This is one of the specific characteristics of professional business services that was included in the quality model for professional business senices. On the other hand, the findings also show that customers' evaluation of both outcome qualities is strongly interrelated. and they are not independently

related to the overall quality assessment. This means that work that is assessed as good (bad) is likely to be also perceived as (in)effective, and that (in)effective work is more likely to be perceived as good (bad) work. This is an interesting finding. For if we can reasonably assume that the advertisements that clients rate as good are not necessarily also effective advertisements (and vice versa), this means that customers' perception of the two outcome qualities are strongly related. Advertising services are one of the few professional business services where customers have tangible evidence of the immediate service outcome, which can be clearly distinguished from its final outcome. So, if customers have difficulties to differentiate clearly between the two outcomes of advertising services, it is likely that this finding also holds for other professional business services. 
The second modification suggested by the analyses regards the Hard Process Quality deteminant in the proposed quality model. The results show that this quality deteminant consists of wo dimensions that were found to be separate determinants of customers' quality perception of advertising services. The Functional Reliability of the agency, i.e the degree to which the agency keeps to deadlines and budgets during the service production process, is evaluated differently from the Competence the professionals exhibit during the service production process. Clients thus clearly distinguish between the professionalism of the process by which the service is produced and the professionalism of the contents of the service performance, regardless of how it is produced. This is an important finding, for the competence (or expertise) of the service professionals lies at the core of professional business services. As hard as it may be for clients to assess the competence of the professionals, they apparently do so and incorporate this in their quality perception of the service provider. Because the competence is cnucial for any professional business services, it is highly likely that this modification to the quality model is also relevant for other professional business services.

As interesting as unanticipated findings may be, the confirmation of propositions is equally important. The analyses confirmed our proposition that the Soft Process quality is a key service quality determinant. Quality is not only based on the technical aspects and the results of the services but also on the interactions and treatment of the customer during the (long) service production processes. Furthermore, it is confimed that not only the actual service experiences play a role in customers' quality perception, but also the structural characteristics of the agency: the potential quality. From a customers' perspective service quality is thus determined by what has been produced, how it was produced, and by whom.

\section{Relative importance of quality deteminants}

This list of "what, how and who" also indicates the order of importance of the quality determinants for customers" quality perception of advertising services. The indirect analyses of the relative importance of both the original and adjusted quality determinants largely support the proposition that the potential quality and final outcome quality are relatively less important for customers' quality assessment of advertising services than the other quality determinants. As proposed from the exploratory research, the potential quality is the least important quality determinant, relative to the other determinants. So, although it was found to be a reliable indicator of customers' quality assessment, it hardly contributes to their quality perception once quality can be assessed from actual service experiences, i.e. the other quality determinants. Since the respondents in this study all had at least a year's experience with the agency, this is a logical explanation.

The final outcome quality was also proposed to be relatively less important, because it is difficult to assess and account for by clients (Halinen 1994) and because clients are also partly responsible for the results (Szmigin 1993). According to the clients themselves, this proposition stiould be rejected. They rate the effectiveness of the campaigns as the most important quality determinant, closely followed by the quality of the delivered work. The two indirect importance analyses also indicate that the outcome quality influences customers' overall quality perception the most. However, this finding does not necessarily reject the proposition, because the effect of the final outcome quality determinant cannot be clearly differentiated from the effect of the immediate outcome quality determinant on customers' overall service quality assessment. The strong interrelation between the two outcome qualities is interesting in this respect, for it implies that the unique contribution of each outcome deteminant will be small, compared to their shared contri- 
bution to overall perceived quality. One indirect analysis indicated that the final outcome has a relatively low unique contribution to customers' overall quality assessment once the effect of immediate outcome quality is taken into account, which would support the proposition. Considering the intangibility and difficulty of the accountability of advertising effectiveness, it seems. likely that customers will partly infer the final outcome quality from the more tangible cues they have, i.e., that their evaluation of the agency's work will influence their perception of its effectiveness. However, regardless of how the strong interrelation between the two service outcomes should be explained, the outcome quality is the most important quality determinant.

The next most important quality determinant found from the indirect analyses is the soft process quality, which contributes almost as much to customers" quality perception as the outcome quality. This is an interesting finding because clients themselves, when asked directly, rate the soft quality as the least important quality determinant. Customers themselves indicate that all that counts to them is good work, the other determinants are much less important, and the soft process quality even the least important. Both indirect analyses, however, showed that the soft process quality is the second most important quality determinant. Also in the exploratory research clients indicated that the soft process quality is very important to them, which was expressed by one client as: "all agencies are alike, except for their people". It therefore seems likely that when clients are asked directly, they are inclined to analyse the quality determinants more rationally than they actually do in "real life". Apparently, when asked to make a rational comparison between the (initial) five quality determinants, clients find that the soft aspects should not be important for the quality of advertising services. Research has shown that the personal interactions and communications are not just social or peripheral quality cues, but really add value to professional services (Crosby \& Stephens 1987 ), which could also be concluded from our (indirect) findings. Because both indirect importance analyses are highly consistent with each other and with our propositions, and both regression analyses explained customers" overall quality assessment for more than $75 \%$, we think that these results are more valid than customers' direct importance ratings. Other studies have also shown that indirect importance ratings of service quality dimensions give better results than direct one (Taylor 1995). It seems that clients are unaware, or unwilling to admit, that the interactions with the agency and the way they are treated play an important role in their quality perception.

Also the newly found Competence determinant contributes significantly to customers" overall perceived quality, although not as much as the outcome quality and soft process quality. This is an important finding for it implies that customers not only evaluate the Competence separately (as found in the quality structure analysis), but it also uniquely contributes to their quality perception, next to the other quality determinants. This provides further support for the inclusion of this quality determinant in the quality model for professional business services.

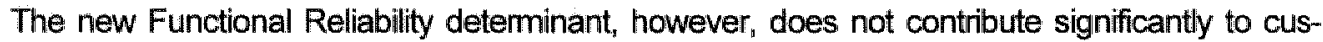
tomers' quality perception, next to the other deteminants. This is a surprising finding, for LaPierre \& Filiatrault (1995) found it to be one of the most important quality determinants for professional business services (i.c. engineering services). Keeping to deadlines, budgets and agreed-upon strategies not only increases efficiency, but also gives clients concrete guidelines to evaluate the usually long and intransparant service production processes. Also the frequently reported complaints in the trade press about agencies that surpass deadlines, or worse, the budgets, would suggest that this aspect is important to clients. Our findings, however, indicate that these frictions do not influence customers" quality perception significantly as long as they 


\section{Chapter 8: Service Quality and Relationships}

"Love is like butter,

it needs bread undemeath",

riddish saying

\subsection{Introduction}

In this chapter the second research question will be addressed by exploning the importance of customers" service quality perception for the maintenance of long-term business relationships. As specified in the research model, this question will be approached by analysing its importance relative to other identified antecedents to relationship maintenance; relational bonds and trust. As described in section 6.5 , each proposition will be analysed subsequently before the whole model will be explored simultaneously. The research model will be analysed in three steps (see figure 8.1).

Figure 8.1: Parts of research model analysed in this chapter

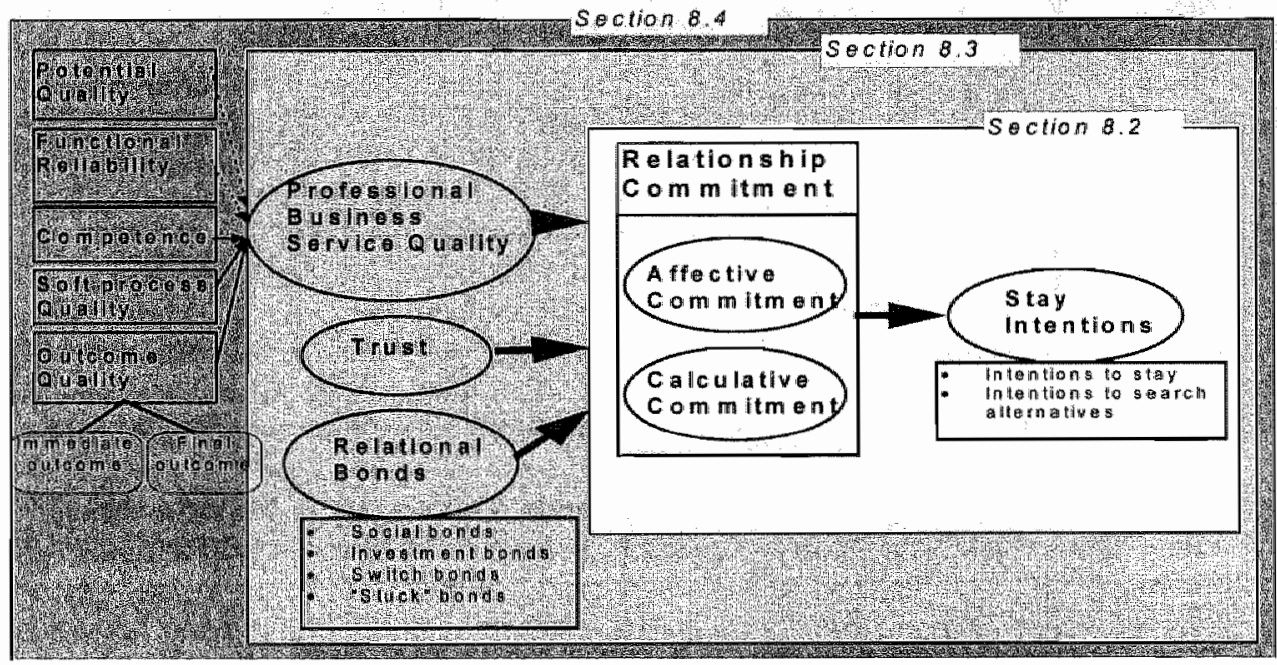

In section 8.2 the concept of relationship maintenance will be examined and the validity of its proposed structure will be analysed for agency-client relationships. In section 8.3 the third research objective will be addressed by analysing the relation between the proposed antecedents and relationship maintenance for agency-client relationships. From this analysis the contribution of customers' overall perceived quality to the maintenance of the relationship, relative to the other antecedents will be assessed. Finally, in section 8.4 . the entire model will be analysed by including the five service quality dimensions found from the analysis in the previous chapter. The fourth objective will be addressed by assessing the relative importance of service quality and its determinants for the maintenance of long-term agency-client relationships. 


\subsection{Structure of relationship maintenance}

In the business relationship literature (reviewed in chapter 3 ) relationship commitment is regarded as the most important indicator for the long-term retention of business relationships. The stronger the commitment of the parties to the relationship, the more likely it is that the relationship will be maintained on a long-term basis. Relationship commitment is defined as the customers' intentionality to continue a business relationship. It is the attitude or motivation on which customers' relationship intentions are based. Two different motivations can underlie customers" intentions to maintain a relationship; the percerved need and the desire to continue a relationship. These motivations are defined as two dimensions of relationship commitment: calculative commitment and affective commitment. The stronger either of these motivations are, the more likely it is that customers' relationship intentions are 'really' long-term.

This structure of relationship commitment has so far been studied in the channel relationship literature. Only Young \& Denize (1994) proposed a similar structure of relationship commitment for professional business service relationships. Since service relationships can be quite different from channel relationships, this concept of relationship commitment is analysed first, before its antecedents will be explored in the next section (see figure 8.1).

First, the proposed two-dimensional structure of relationship commitment will be examined, followed by an analysis of the interrelation of the commitment dimensions with customers' relationship intentions. Finally, the structure will be analysed by relating it to the time dimension, i.e. the length of the relationship to gain a deeper understanding of the commitment concept.

\subsubsection{Structure of commitment dimensions}

From the analysis in chapter 6 , the existence of two relationship commitment dimensions was confirmed. Reliable and valid measures were found for customers' calculative commitment and their affective commitment to the relationship with their agency. Also a valid and reliable measure for customers' relationship intentions was found, which consists of both their intentions to stay and their intentions to search for alternatives (see chapter 6). Because many authors include behavioural intentions in their definition of relationship commitment (see chapter 3), we will first analyse whether our measures of relationship commitment are differentiated well enough from customers' stay-intientions.

A three-factorial model was specified in which the calculative commitment, affective commit-

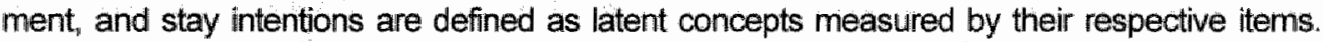
This model was subjected to a confirmatory factor analysis with LISREL 8 , to confirm whether the items represent three conceptually different constructs. The fit of this model is very good (see table 8.1 ). This means that the covariances between the items are explained well by three different undertying concepts. In table 8.1 the disattenuated correlations between the three concepts are presented. Calculative commitment is significantly, but moderately correlated to both affective commitment and stay-intentions. Affective commitment and stay-intentions are strongly positively correlated, but this correlation is well below unity. There is thus a clear distinction between customers' calculative motivations, affective motivations and their actual intentions to stay. 
Table 8.1: Fit-statistics \& comelations of commitment dimensions and intentions

\begin{tabular}{l|lll}
\hline & \multicolumn{3}{|l}{ Disattenuated comelations (t-values) } \\
& Calculative Commitment & Affective Commitment \\
\hline Calculative Commitment & - & & - \\
Affective Commitment & 24 & $(3.2)$ & - \\
Stay intentions & 20 & $(26)$ & $74(19.4)$ \\
\hline
\end{tabular}

Fif statistics three-factor confirmatony factor analysis

$X^{2}=27.5, \mathrm{df}=24, \mathrm{p}=28$

$\mathrm{RMSEA}=026, \mathrm{GFI}=97, \mathrm{ASF}=.95, \mathrm{CF}=1.0$

From the low correlation between the calculative and affective commitment dimensions (see table 8.1) it seems that they are truly different dimensions of relationship commitment. A chisquare difference test showed that the dimensions are not related strong enough to assume that they share one underlying commitment dimension ${ }^{1}$. Calculative and affective commitment should thus be regarded as separate commitment concepts. This finding is consistent with the assumption that the two motivations to keep a relationship are not inextricably linked (cf. Young \& Denise 1994). Clients who perceive a need to keep the relationship, do not necessarily also desire to continue it, and vice versa. The descriptives of the commitment dimensions in chapter 6, indicate that the respondents show a low calculative commitment on average, whereas their affective commitment is much stronger on average. Apparently many respondents desire to continue the relation with their agency, but do not perceive a need to do so: The dimensions thus capture different kinds of commitment that are related, yet separate, concepts.

\subsubsection{Commitment and behavioural intentions}

From the analysis above it was found that the commitment dimensions are conceptually differentiated from the stay-intentions. Since the commitment dimensions reflect customers' motivations to continue the relationship, they are proposed to underlie customers' relationship intentions. The stronger a party is committed, the more s/he is willing to stay in the relationship. The previous analysis showed that the commitment dimensions should be regarded as independent, though related, concepts. Each commitment dimension could thus influence customers' relationship intentions. To understand the role of commitment in agency-client relationships the relation between the commitment dimensions and the stay-intentions will be analysed.

The correlations in table 8.1 show that affective commitment is related stronger to clients' stay intentions than the calculative

Figure 8.2: Regression (t-values) of commitment an stay-intentions

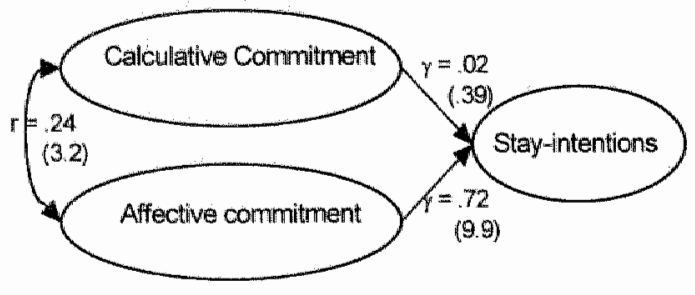
commitment. To see how the commitment dimensions contribute to the explanation of customers' stay intentions a regression analysis is performed (see figure 8.2). Calculative commitment alone explains only $4 \%$ of variance in the stay intentions, and together with the affective com-

\footnotetext{
1 Specifying a model in which the commitment dimensions are specified as two sub-dimensions of one underlying construct
} resulted in a significant increase in chi square of $71.3_{i}$ with 2 extra degrees of freedom. 
mitment it has no significant contribution to the stay intentions at all. The affective commitment explains $53 \%$ of variance in the stay intentions alone. Kumar et al. (1994) also found that affective commitment had the strongest positve effects on different kinds of relationship inten. tions. Calculative commitment was less strongly related to a party's stay intentions, but stil significantly. Apparently, in agency-client relationships calculative commitment plays a less important role to keep the relationship. From this analysis it seems that clients stay mainly because of affective motivations.

\subsubsection{The time dimension}

The last analysis conducted to understand the measures of relationship maintenance is theit correlation to the length of the relationship. The goal of this analysis is two-fold. Firsty, relationships are dynamic phenomena that are studied here in a cross-sectional setting. We therefore have to check how the time-dimension is related to the concepts. Although the interrelations between the commitment and stay-intentions variables do not give rise to this concem, is possible that the three variables all share an underlying time-dimension, which might interfere with the focal relations that are under study. Secondly, relating the concepts to time gives a deeper understanding of the "behaviour' of these concepts during an agency-client relationship.

Table 8.2: Correlation between relationship variables andrelationship length

\begin{tabular}{l|l}
\hline Relationship variables & $\begin{array}{l}\text { Corretation to } \\
\text { Relationship length (vears) }\end{array}$ \\
\hline Calculative Commitment & -.10 \\
Affective Commitment & $-.24^{* *}$ \\
Stay-intentions & $-12^{*}$ \\
$*$ Intention to stay & $.14^{*}$ \\
\hline
\end{tabular}

$=$ significant at $5 \%$ level

= significant al $10 \%$ level

Table 8.2 shows that calculative commitment has no significant correlation with relationship length and is thus not dependent on it. Apparently, in agency-client relationships the (perceived) costs of leaving do not increase automatically over time in their cost-benefit calculations of the relationship. The amount of investments and costs that motivate the client to keep the relationship are thus relationship-specific, and not time related. Affective commitment has a moderate, though significant, negative correlation with the length of the relation. This means that the duration of the relationship decreases the desire to continue the relationship slightly. The correlation of the stay intentions with relationship length, shows a negative correlation with customers' stay-intentions and a positive correlation to customers' intentions to search for alternatives. This indicates that the longer the relationship lasts, customers are less inclined to stay in the relationship and start looking around a little bit more. Agency-cilent relationships thus do not automatically strengthen over time, and in fact may become slightly less strong. These correlations are, however, very low. This means that other factors are more important for the strength of customers' relationship commitment and stay intentions. The analysis thus shows that time is not a factor that interferes with our measures of relationship maintenance. The degree of relationship maintenance is relationship specific, and not automatically related to time. Analysis of the antecedents that do contribute to the maintenance of agency-client relationships is thus an interesting next step. 


\subsubsection{Summary commitment structure}

The analyses above indicate that also in agency client-relationships two dimensions of relationship commitment can be distinguished. These commitment dimensions are only moderately interrelated. Chents who are committed for calculative reasons are not necessarily also affecthely committed and vice versa. Customers' affective commitment is strongly related to customers" stay intentions. The calculative commiment, however, is only moderately related to customers" stay intentions and does not contribute significantly to the intentions next to the affective commitment. $\mathrm{SO}_{\text {, in }}$ agency-client relationships calculative motivations hardly play a role in the maintenance of the relationship. This may be due to the few and different investments that are made in these relationships. The finding that calculative commitment is not related to time supports this notion. In the next section it will be analysed which antecedents do contribute to customers' relationship commitment:

\subsection{Antecedents to relationship maintenance}

In this section the proposed antecedents to customers' relationship commitment will be analysed (see figure 8.1). From the literature review and exploratory research three antecedents to customers' commitment in profiessional business service relationships were identified: the

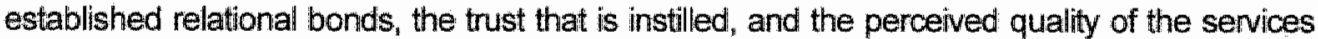
rendered. As relational bonds for professional business service relationships in general, and advertising services in particular, four types were identified; the social bonds, investment bonds, switch bonds, and stuck bonds.

As indicated in figure 8.1 , in this section the influence of the three main antecedents, will be analysed without the quality determinants. With this sub-model we will explore whether and how the customer-based service quality concept as such contributes to the maintenance of the agency-client relationships. In section 8.4 the quality determinants will be added to the model. First, a correlation analysis will be performed between the concepts of the research sub-model to see how the proposed antecedents are related to customers' relationship commitment. Then structural equations analysis with LISREL 8 will be used to examine the proposed causal relations between the concepts (see section 6.5). From this analysis conclusions will be drawn regarding the antecedents of customers' relationship commitment in agency-client relationships, and the relative importance of customers ${ }^{\prime}$ overall perceived service quality.

\section{1 Correlation analysis}

In table 8.3 the bivariate disattenuated correlations between the proposed antecedents with the Wo dimensions of relationship commitment are portrayed.

Table 8.3: Comblations between antecedents and commitment dimensions

\begin{tabular}{|c|c|c|}
\hline Antecedents & Afrective Commitment & Calculative Commitment \\
\hline Social bonds & $.30^{\text {tht }}$ & .15 \\
\hline Investment Bonds & $.19^{\text {*t }}$ & 12 \\
\hline Switch Bonds & $.35^{* * *}$ & $33^{*}$ \\
\hline SSuck Bonds & $-.20^{*-\pi}$ & .04 \\
\hline Trust & $.74 * *$ & .08 \\
\hline Sentce Quality & $78^{m+w}$ & 15 \\
\hline Calculatuve commitment & $.24^{\prime \prime}$ & \\
\hline
\end{tabular}

\footnotetext{
* significant at the $5 \%$ level
} 
Table 8.3 shows that all proposed antecedents are significantly comelated to affective commitment. The 'stuck bonds' are negatively comelated to affective commitment as could be ex pected. The more clients are tied by contracts or regulations(i.e. "stuck" ) to their agency, the less they desire to stay because of affective motivations. The investment and switch bonds are positively related to affective commitment, indicating that the more a client has invested in the relation and the more difficult s/he perceives a switch to be, the more they desire to continue the relationship. Also the social bonds are positively related to the desire to continue the relationship. Trust is indeed very strongly related to customers' affective commitment, as was found in many other studies (cf. Morgan \& Hunt 1994, Halinen 1994). Also customers' overall perceived service quality is positively and very strongly related to the affective commitment, like the trust variable. This give a first indication that service quality does contribute to the maintenance of long-term customer relationships.

The correlations of the antecedents with calculative commitment, show a different pattern. The switch bonds is the only antecedent variable that is significantly (positively) related to the calculative commitment. As expected, the more a client perceives difficulties in switching to another agency, the more s/he is motivated by calculative reasons to continue the current relationship. The investments made into the relationship and the social network that is created, do not seem to be significantly related to the calculative motivation to continue the relationship. Apparently, the investments made into the relation are not related to customers" perceived need to continue the relationship but only to their desire to continue it. Also the trust in the relationship and the perceived service quality are not seen as assets that make it necessary to continue the relationship, but are only related to the desire to keep on working with the agency. These findings underscore the special position of calculative commitment in agency-client relationship, as indicated from the analysis in the previous section.

However, bivariate correlations do not necessarily indicate causal relations between the variables. Correlations can be the result of a complex set of undertying structural equations, hence multivariate analysis is needed to analyse the unique contributions of each of the variables, taking their interrelations into account.

\subsubsection{Structural equations analysis}

As described in section 6.5 , structural equations modelling will be used to analyse the research model. Because our research model is exploratory in nature, structural equations modelling will be used to explore whether our model is confirmed by the data, and if necessary to respecify it into a model that fits the data better and is theoretically meaningful.

As indicated in section 6.5, the two-step approach (Anderson \& Gerbing 1988, Hair et al. 1995) will be used. In the two-step approach the measurement model and the structural model are analysed in two steps. Apart from the statistical and interpretation advantages of this approach, it also provides a comparison standard for the fit measures of the theoretical model. In section 5.2 the fit-measures and their criteria are described and discussed. In section 6.5 the use of the measurement model fit as comparison standard is explained. In the next paragraphs, the twostep analysis will be performed on the research sub-model (see figure 8.1). First, the measurement model will be analysed, and then the proposed structural model. Based on a comparison of these madels, improvements to the model will be explored. 


\section{- Analysis of the measurement model}

The validation and purification of the measures is described in chapter 6 . Based on this analysis, reliable, valid and concise scales were developed for each of the concepts of the research model. In the sub-model analysed here, nine different research concepts are defined, which are each measured by multiple tems (see chapter 6 and figure 8.1). To reduce the (statistical) complexity of this modell, the individual items are aggregated ${ }^{2}$ into composite scale scores ${ }^{3}$ and their error variance is fixed by the composite reliability of each scale, which were calculated in chapter 6 . These composite measures will be used as input into the structural model. The fit of the measurement model of these nine latent concepts is portrayed in table 8.4.

Table 8.4: Fit-statistics of saturated(sub-limodel

\begin{tabular}{l|l}
\hline Fit-index & Fit-statistics saturated (Emeasurement) model \\
\hline Absolute fit - indices: & $X^{2}=23.8$, df $=16, p=.094$ \\
& $G F I=.98$, \\
Approximate fit & AGFI $=.92$ \\
Relative fit & RMSEA $=.047$ \\
\hline
\end{tabular}

The saturated sub-model shows a good fit to the data. The chi-square value is not significant at the $5 \%$ level and in between two times the degrees of freedom. The fit indices independent of sample size (GFI) and adjusted for parsimony (AGFI) are above the recommended .90 level. The approximate fit (RMSEA) indicates that the model shows a close fit to the estimated population covariances (Browne \& Cudeck 1993), and the relative fit (CFI) shows that the concepts are not independent from each other. These statistics will be used as a comparison standard for the assessment of the structural model in the next paragraph.

\section{- Analysis of the proposed structural (sub-)model}

In the research model, customers' perceived quality, their trust in the agency and four relational bonds are proposed to influence customers' relationship commitment, which, in tum, influences their stay intentions. In the previous analysis was found that the two commitment dimensions should be treated as related, but separate constructs. Therefore, the proposed antecedents are related to each of the commitment dimensions separately. All concepts are defined by their composite scale scores and the stay-intentions by its two sub-dimensions (see chapter 6 ). The proposed structural relations between the nine concepts are portrayed in figure 8.3. This model is subjected to a structural equations analysis in LISREL8. In table 8.5 the estimated (standardised) parameters of the structural relations and the fit-statistics of the sub-model are portrayed.

\footnotetext{
2 see Baumgartner \& Homburg (1996).

3 i.e. average of the scale-items.

4 For a description of the criteria for the model fit-indices see chapler 5 , table 5.1.
} 
Figure 8.3: Proposed structural (sub-)model

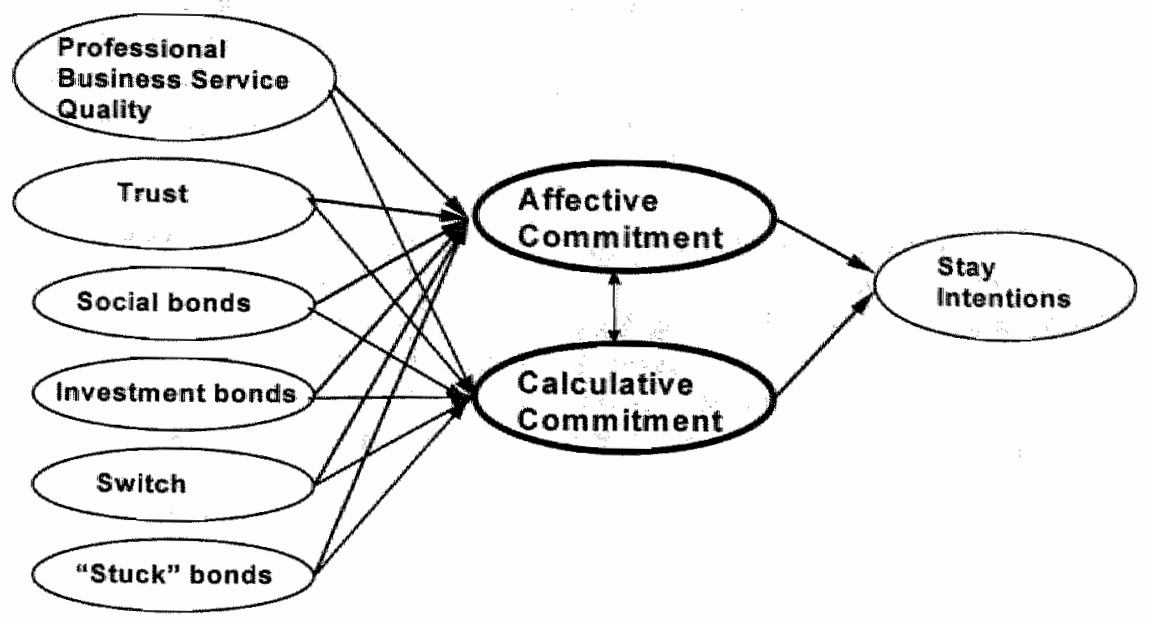

Table 8.5: Estimated parameters and fit-statistics of proposed(sub-)model

\begin{tabular}{|c|c|c|c|}
\hline Antecedents & $\begin{array}{l}\text { Estimated standardised c } \\
\text { Affective Commiltment }\end{array}$ & $\begin{array}{l}\text { oefficients ( } t \text {-values) } \\
\text { Calcullative commitment }\end{array}$ & Stay Intentions \\
\hline Service Quality & $.58^{* * *} \quad(5.16)$ & $-.01 \quad(-0.06)$ & \\
\hline Trust & $.34^{+k+1} \quad(3.12)$ & $(0.08)$ & \\
\hline Social bonds & $(1.18)$ & $(0.57)$ & \\
\hline Investment Bonds & $(1.32)$ & $(-1.0)$ & $\therefore$ \\
\hline Switch Bonds & $(0,38)$ & $(2.79)$ & \\
\hline 'Stuck' Bonds & $.04 \quad(0.50)$ & $.05 \quad(0.41)$ & \\
\hline Affective commitment & - & $.12^{* * *} \quad(2.15)$ & (8.89) \\
\hline Calculative Commitment & $.12^{*+*}(2.15)$ & - & $(0.17)$ \\
\hline Multiple $\mathbf{R}^{2}$ & .74 & .12 & .65 \\
\hline
\end{tabular}

Fit statistics proposed sub-model

$$
X^{2}=45.5, d f=22, P=002
$$

RMSEA $=069, \mathrm{GFI}=96, \mathrm{AGFI}=89, \mathrm{CFI}=1.0$

$=$ Significant at $5 \%$ level

this is an enror contelation (Psi), not a causal path.

The table shows that $74 \%$ of the variance of affective commitment is explained by customers' perceived service quality, the established trust, and its correlation to calculative commitment. The structural parameters of all other antecedents were insignificant at the $5 \%$ level, despite the significant bivariate correlations with affective commitment that were found in the correlation analysis. 
Calculative commitment is explained for $12 \%$ by the switch bonds and its correlation with affective commitment. All other antecedents do not contribute significantly to the explanation of calculative commitment, as was also found from the bivariate comelations.

The variance of the stay intentions is explained for $65 \%$ by the affective commitment alone. Calculative commitment does not contribute significantly to the stay intentions, as was already found in the previous section.

The fit of the proposed structural model as a whole is moderate (see table 8.5). The chi-square value is too high to indicate a good absolute fit (significant and above two times the degrees of freedom). However, the RMSEA indicates that the approximate fit is reasonable (below the maximum of .08), and the GFI is good, although adjusted for parsimony (AGFI), it just falls below the recommended .90 level: Based on this, the model does not necessarily have to be rejected. As described in section 8.3 .1 , the fit of this model can be compared to the fit of the saturated model to get additional information. A chi-square difference test is performed between the fit-statistics of the proposed structural model versus the saturated model. As shown in table 8.6, the chi-square value of the structural model is 21.7 higher than the saturated model, with six extra degrees of freedom. This increase is significant $(p=.001)$, indicating that the structural model shows a significantly worse fit to the observed covariances than the saturated model.

Table 8.6: Fit-statistics and difference test of proposed and saturated(sub-ymodel

\begin{tabular}{l|lll}
\hline & $\mathrm{X}^{2}$ & df & p-value \\
\hline Saturated sub-model (Ms) & 23.8 & 16 & .094 \\
Proposed sub-model (Mt) & 45.5 & 22 & .002 \\
& & & \\
X'difference test $_{\text {Mit-Ms }}$ & $\Delta \mathbf{X}^{2}$ & $\Delta d f$ & p-value \\
\hline
\end{tabular}

These findings indicate that modifications may be necessary to the proposed model to improve its fit to the observed interrelations between the concepts. In the next paragraph the modification procedure is described.

\section{- Developing an alternative (sub-) model}

The initially proposed model does not explain the observed covariances between the variables sufficiently. This means that paths may have to be added between the concepts that represent the observed covariances better. An altemative less constrained (sub-)model (Gerbing \& Anderson, 1988) will be specified in which more paths are defined (i.e. less parameters are constrained to zero). To identify the concepts among which the interrellations are not explained sufficiently by the proposed structural sub-model, the residuals of the estimated model are analysed. This analysis indicates that the interrelation between the stay intentions with service quality as well as with the stuck bonds are insufficiently explained by the structural model. The modification indices suggest that the model fit would be improved significantly, if a direct path from service quality to clients' stay-intentions would be added, next to its path to affective commitment, and if a direct path from the stuck-bonds to the stay-intentions would be included. Before these paths are added for statistical reasons, their theoretical meaning has to be assessed first. 
1. "Stuck' bonds $\rightarrow$ stay intentions

A direct effect of the stuck-bonds to the stay intentions, means that the contracts and regulations that tie a customer to its agency will influence their stay intentions directly, regardless of their degree of commitment. This seems a plausible relation. Contracts more or less fonce a client to stay, regardless of their desire or perceived need to do so. Therefore, this path will be added to the model.

\section{Quality perception $\rightarrow>$ stay intentions}

Adding a direct path from service quality to stay intentions, means that service quality can influence clients' stay intentions directly, regardless of customers' relationship commitment. Many service quality studies found that customers' quality perception has a direct effect on their behavioural intentions (cf. Zeithaml et al. 1996). This direct path to the stay-intentions is thus well interpretable. In our study we specifically wanted to differentiate between customers' stay intentions and the attitudes from which they stem (commitment). Since the influence of service quality on long-term relationship maintenance is the core issue in this study we decided to add this direct path to the stay-intentions in the alternative (sub-)model as well.

Figure 8.4. Altemative sub-model; wo paths added

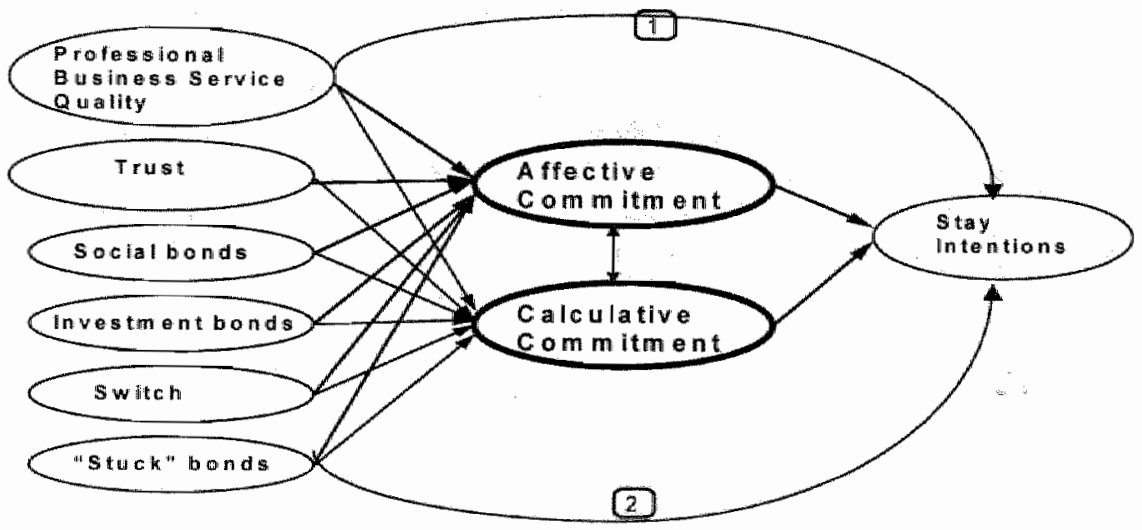

This alternative model is portrayed in figure 8.4 , and is estimated again in LISREL8. The fitstatistics of this altemative model are presented in table 8.7. The addition of each path to the proposed structural model resulted in a significant decrease in the chi-square value. The alternative model with both added paths shows a good fit to the data (see table 8.7). The fit of this model is significantly better than the proposed structural model. A chi-square difference test of this alternative less constrained model against the saturated model shows that the increase in the chi-square value is not significant (see table 8.7). This means that this less constrained model fits equally good to the data as the saturated model.

This alternative model is, however, not very parsimonious. It has only four additional degrees of freedom than the saturated model. To increase parsimony, a constrained (sub-)model (Gerbing \& Anderson 1988) will be developed based on the alternative less constrained sub-model. The less constrained altemative model shows many insignificant paths, which are the same as in the proposed structural model (see table 8.5). The relational bonds, for instance, do not all contribute significantly to customers" relationship commitment as initially proposed (see table 
8.5). By chi-square difference tests it can be examined whether these paths should be considered as zero relationships between the proposed concepts. Each insignificant parameter will be constrained to zero, and the chi-square value of the resulting model is compared to the chisquare value of the model with the path set free. Paths that are found to be zero can be removed from the model, increasing its parsimony.

Table 6.7: Fil-statistics and difference tests of nested altemative (sub-)models

\begin{tabular}{|c|c|c|c|c|c|c|}
\hline \multirow[b]{2}{*}{ Modals } & \multicolumn{2}{|c|}{ Albsolute fit statistics } & \multicolumn{4}{|c|}{ Chilsquare difference tests } \\
\hline & $x^{2} \quad d f$ & p-value & Models & $\Delta x^{2}$ & $\Delta d f$ & p-value \\
\hline Saturated sub-model (Ms) & 23.8 & .094 & & & & \\
\hline Proposed sub-model & 455 & .002 & Mt -Ms & 21.7 & 6 & .001 \\
\hline $\begin{array}{l}\text { Unconstrained sub-model (Mu) } \\
\text { (2 suggested paths added) }\end{array}$ & 25.7 & .17 & $\begin{array}{l}M u-M t \\
M u-M S\end{array}$ & $\begin{array}{l}19.6 \\
1.93\end{array}$ & $\begin{array}{l}2 \\
4\end{array}$ & $\begin{array}{l}<.00 \\
75\end{array}$ \\
\hline $\begin{array}{l}\text { Constrained sub-model (Mc) } \\
\text { (in.s relations from Mu set to } 0 \text { ) }\end{array}$ & 30.6 & 49 & $\begin{array}{l}\text { Mc-Mu } \\
\text { Mc-Ms }\end{array}$ & $\begin{array}{l}4.84 \\
6.77\end{array}$ & $\begin{array}{l}11 \\
15\end{array}$ & .94 \\
\hline
\end{tabular}

Eleven (insignificant) parameters were subsequentiy constrained to zero ${ }^{5}$. Each constrained parameter resulted in an insignificant increase in the chi-square value, indicating that the hypothesis that each path is zero cannot be rejected. The resulting model with eleven additionally constrained parameters, shows a good fit. The model fit does not differ significantly from the fit of the saturated model nor the of less constrained alternative model (see table 8.7). This means that the insignificant parameters found in the less constrained alternative model are indeed zero, and that this new structural model fits maximally to the observed covariances between the variables, within the constraints of our theoretical assumptions. In figure 8.5 this new (sub-) model is portrayed with the estimated parameters. The parameters and t-values are presented in table 8.8 .

Figure 8.5: Final sub-model' with parameters

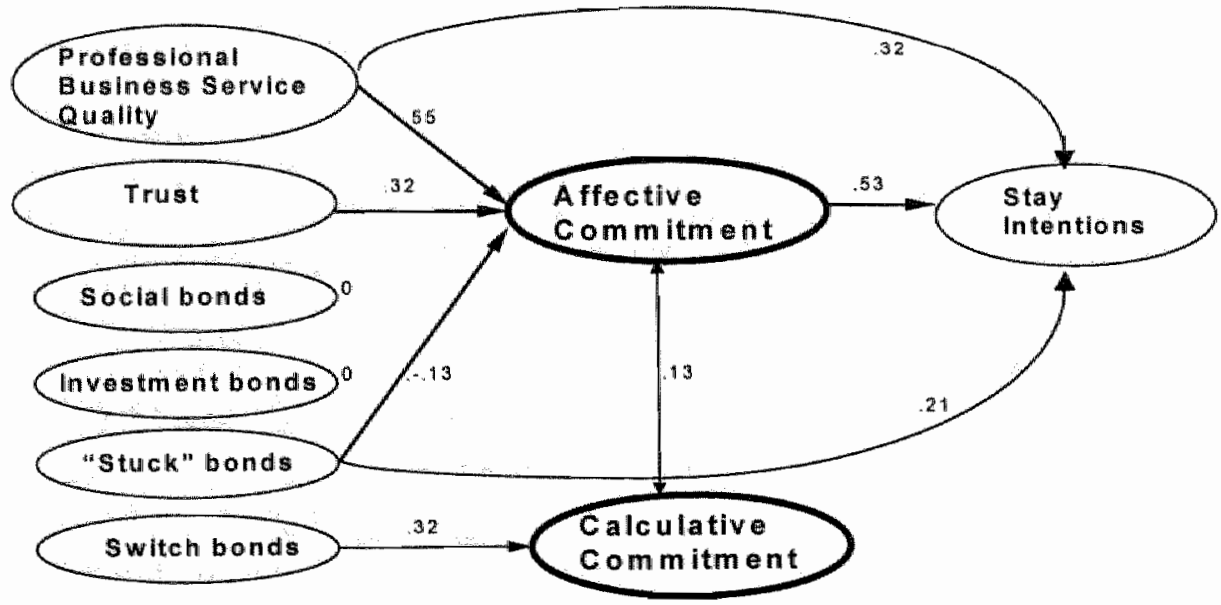

5 In table 8.5 the insignificant structural parameters are portrayed. Apart from the 'stuck bonds" all these paths are confimed to be zero. Also wo correllations between the antecedents themselves were found to be insignificant: the comelation between stuck bonds and switch bonds, and between the stuck bonds and service quality are set to zero. 
Table 8.8: Estimated parameters and fit-statistics of final sub-model

\begin{tabular}{|c|c|c|c|}
\hline & Standardised significant & effictents (t-values) & \\
\hline Antecedents & Affective Commitment & Calculative commitment & Stay Intentions \\
\hline Service Quality & $(5.75)$ & $-5-1,-10$ & $32^{*}(3.01)$ \\
\hline Trust & $.32^{4 *} \quad(3.15)$ & 0 & \\
\hline Stuck" Bonds & $-13^{*} \quad(-2.06)$ & 0 & $.21^{* *}(3.01)$ \\
\hline Swittch Bonds & 0 & $.32 \quad(3.91)$ & \\
\hline $\begin{array}{l}\text { Social bonds } \\
\text { Investinent Bonds }\end{array}$ & $\begin{array}{l}0 \\
0\end{array}$ & $\begin{array}{l}0 \\
0\end{array}$ & \\
\hline $\begin{array}{l}\text { Affective commitment } \\
\text { Calculative Commitment }\end{array}$ & $13^{\text {tate }}$ & $.13^{+1}(2.55)$ & $\begin{array}{ll}53^{*} & (4.69) \\
0 & \end{array}$ \\
\hline Multiple $R^{2}$ & .68 & .10 & 64 \\
\hline
\end{tabular}

Fit statistics final sub-model

$X^{2}=30.6, \mathrm{df}=31, P=49$

RMSEA $=0.0, \mathrm{GFI}=.98, \mathrm{AGFI}=95, \mathrm{CFI}=1.0$

\footnotetext{
All significant at $5 \%$ level.

Whis is an error correlation (Psil), not a causal path.
}

Table 8.8 shows that a considerable amount of variance of affective commitment and stayintentions is explained by the antecedents in the model, $68 \%$ and $64 \%$ respectively. Affective commitment is significantly influenced by the client's perceived service quality and their trust in the agency. Also the 'stuck bonds' influence the affective commitment significantly, yet negafively. The stay-intentions are influenced by customers' affective commitment, and directly by the perceived service quality and the 'stuck bonds'. Calculative commitment does influence the stay-intentions significantly, and is itself explained for only $10 \%$ by the switch bonds, and its correlation with affective commitment.

The table (8.8) shows that customers' perceived overall service quality is indeed positively related to customers' affective commitment, and very strongly so. The standardised parameters indicate that service quality has the strongest causal relation to customers' affective commitment compared to any of the other antecedents. Service quality does not contribute significantly to customers' calculative commitment. It thus seems that service quality does not contribute to customers' perceived need to keep on working with the agency. However, service quality not only influences customers" desire to continue, but also clients' stay intentions directly, regardless of their desire or perceived need to do so. This could mean that the delivered service quality is a motivation in itself to continue a relationship, apart from the perceived need or desire to continue the relationship. In the next paragraph the role of service quality will be discussed further.

As proposed, trust is positively and strongly related to clients' affective commitment to the relationship. Although it was tentatively proposed that trust could be regarded as an important relationship asset that would influence customers' perceived need to continue the relationship, the analysis shows that trust is not significantly related to customers' calculative commitment. It apparently only contributes to customers' desire to continue the relationship.

Regarding the relational bonds, only the 'stuck bonds' were found to have a significant contribution to customers' affective commitment. This relation is a negative one indicating that the more a client is stuck to their agency, the less they desire to continue working with them. This 
was also suggested in the exploratory research: the more clients feel forced to keep a relationship by reasons outside their control, the less they voluntarily desire to continue it. On the other hand, being stuck influences customers' stay-intentions positively. This means that although it diminishes clients" desire to stay, if does increase the likelihood that they will stay, exactly because they are stuck to the relationship. The 'stuck bonds' are not significantly related to calculative commitment, indicating that rules and contracts do not contribute to the perceived need to continue the relationship. Apparently the contracts as such will not add anything to the relation that make it necessary to work with this particular agency other than the contract itself. Being stuck could thus be regarded as a motivation in itself to continue a relationship. The switch bonds are positively related to the calculative commitment, as expected. The more a client experiences difficulties to switch, the more s/he feels the need to continue working with the agency. The switch costs do not contribute to the affective commitment. The expected costs of switching thus only contribute to the calculative motivations to maintain the relationship, and not to the affective desire to continue. This is a logical finding. Counter to our expectations, the social and investment bonds do not contribute at all to customers' relationship commitment. Despite their significant bivariate correlations to affective commitment and the stay-intentions (see table 8.9), their causal relations could not be differentiated from zero. The fit of the final sub-model is good, which indicates that the covariances between these bonds and the other variables are sufficiently reproduced by their interrelations with the other antecedents only ${ }^{6}$. To pursue this thought, the bivariate correlations of these two relational bonds with the other variables are presented in table 8.9 .

Table 8.9: Comelations of soclal and investment bonds with all other vaniables

\begin{tabular}{|c|c|c|c|c|c|c|c|c|}
\hline & $\begin{array}{l}\text { Disialter } \\
\text { Sociall }\end{array}$ & $\begin{array}{l}\text { ated bin } \\
\text { Stuck }\end{array}$ & $\begin{array}{l}\text { fate corre } \\
\text { Switch }\end{array}$ & $\begin{array}{l}\text { Tions } \\
\text { Trust }\end{array}$ & Quallity & Affect & Calcul & Stay \\
\hline $\begin{array}{l}\text { Social Bonds } \\
\text { Invest Bonds }\end{array}$ & $.72^{-1 *}$ & $\begin{array}{l}.27^{\text {* }} \\
.42^{\text {t* }}\end{array}$ & $\begin{array}{l}.49^{\text {tiv }} \\
.59^{\text {nt* }}\end{array}$ & $\begin{array}{l}.29^{\star \star \hbar} \\
.27^{\text {t* }}\end{array}$ & $\begin{array}{l}.41^{\star *} \\
.35^{* *}\end{array}$ & $\begin{array}{l}.30^{\text {nt }} \\
.19^{* * *}\end{array}$ & $\begin{array}{l}.15 \\
.12\end{array}$ & 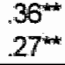 \\
\hline
\end{tabular}

* Significant at $5 \%$ level

The table shows that the social and investment bonds are highly correlated with each other and that they are each strongly related to the switch bonds. A possible explanation for their insignificant parameters to the dependent variables could be that the investment bonds and the social bonds are antecedents to the switch bonds. Because the switch costs influence calculative commitment, the two bonds would contribute to calculative commitment through their relationship with the switch costs. This implies that the switch bonds could be a more general bonding factor, influenced by several relational bonds. This is a very likely suggestion, for the more that is invested in the current relationship, the more costly a switch will be perceived. This thought will not be pursued further, because the structure of relational bonds is not at stake here. It suffices to conclude that although social bonds and investment bonds are related to affective commitment and customers' stay-initentions, they do not contribute significantly to the maintenance of the relationship relative to the other antecedents included in the model.

The findings are thus well interpretable and the adjustments to the initially proposed sub-model are not only a statistical improvement, but are also theoretically meaningful.

\footnotetext{
6 In LISREL analysis, all indiependent variables are conrellated freely.
} 


\subsubsection{Relative importance of antecedents for relationship maintenance}

In table 8.8 the estimated standardised parameters of the new structural sub-model were presented. These parameters represent the direct contribution of each variable to the dependent variable. The analysis showed that customers" stay intentions are not only deternined by their relationship commitment. The stuck bonds and service quality also influence the stayintentions directly. Because affective commitment has a strong influence on the stay intentions as well, all variables that contribute to the affective commitment will also contribute to the stay intentions indirectly.

In table 8.10 the direct and indirect effects of each antecedent on customers' affective commitment and their stay intentions are portrayed. The total effect of each antecedent on customers' stay-intention is the sum of their direct effect and indirect effect through the affective commitment variable. In table 8.10 the standardised effects are portrayed, from which the relative importance of each of the antecedents can be assessed.

Table 8.10: Total effects of antecedents on affective commitment and stay intentions

\begin{tabular}{|c|c|c|c|c|}
\hline Antecedents & $\begin{array}{l}\text { Total effects ( } t \text {-values) on } \\
\text { Affective commitment }\end{array}$ & Stay Intentions & $\begin{array}{l}\text { Effects on ste } \\
\text { Direct }\end{array}$ & $\begin{array}{l}\text { nitentions } \\
\text { Indilinect }\end{array}$ \\
\hline Senvice Quality & $.55^{\text {k* }}(5.75)$ & $.60^{* x}(6.71)$ & $.32^{* *}(3.01)$ & $.29^{\text {tid }} \quad(3.72)$ \\
\hline Stuck Bonds & $-.13^{2+4} \quad(-2.06)$ & $14 *(2.08)$ & $.21^{\text {the }}(3.01)$ & $(-1.82)$ \\
\hline Trust & $32 *(3,15)$ & $.17^{* *}(258)$ & & $.17^{*+k} \quad(2.58)$ \\
\hline Affective commisment & & $53^{* * *} \cdot(4.69)$ & $.53^{* *} \cdot(4.69)$ & \\
\hline
\end{tabular}

$=$ significant at $5 \%$ level

Because all antecedents are only directly related to affective commitment, the total effects on affective commitment are the same as the standardised parameters in the final sub-model. As described above, service quality contributes the most to clients" affective commitment, more than 1.5 times as much as trust does. Moreover, trust is not related directly to customers' stayintentions, but only indirectly (and significantly) through its effect on customers' affective commitment. Customers' perceived service quality, on the other hand, does also directly influence their stay intentions. It contributes stronger to customers' stay intentions than contracts or regulations do which give the customer little choice other than to stay. The total effect of service quality (direct + through affective commitment) on customers' stay-intentions is slightly stronger than customers' affective commitment. So, customers' overall quality perception contributes significantly to the maintenance of agency-client relationships, to clients' relationship commitment as well as to their stay intentions. From this analysis it seems that customers' service quality perception is the most important variable for the maintenance of long-term customer relationships in the advertising market.

From table 8.10 it can be seen that the indirect effect of the stuck bonds on stay-intentions is insignificant. This means that the negative effect of the 'stuck bonds' on the affective commitment does not off-set it's positive direct effect on customers' intentions to stay. Being stuck thus definitely increases the chances that customers will stay, even though it significantly decreases their desire to do so. Clients are thus indeed stuck to the relationship. 


\subsubsection{Summary antecedents to relationship maintenance}

In the research model customers' perceived service quality, the trust, and the relational bonds were proposed to contribute to the maintenance of agency-client relationships. The analyses in this section largely confirm these propositions and suggest a few important modifications.

In general, the analyses confirm that overall perceived service quality, and the established trust are important antecedents to relationship maintenance in agency-client relationships. The contribution of the relational bonds is only confirmed for the switch bonds and the stuck bonds. The investment bonds and social bonds do not contribute at all to the maintenance of the relationship, next to the other antecedents. They share so much variance with the other antecedents (especially the switch bonds) that they have no unique contribution to the explanation of either of the relationship variables.

Overall perceived service quality and the established trust influence customers' affective commitment positively. The stuck bonds influence customers' affective commitment negatively. Only the switch bonds are (positively) related to customers' calculative commitment. Apparently, customers service quality and the established trust, strongly enhance only customers' desire to maintain the relationship. The stuck bonds, on the other hand, decrease customers' desire to maintain the relationship, as could be expected from clients who are stuck to their agency. The perceived costs of switching enhance customers' calculative motivations to keep the relationship, and do not contribute to their affective desire to maintain it. However, the analysis also shows that customers" calculative commitment does not contribute to their stay intentions. So even though customers do perceive switching costs "which do enhance their calculative motivations to stay, these motivations do not seem to be strong enough to make customers actually intend to stay in agency-client relationships. Of the commitment dimensions, only customers' affective motivations enhance their stay intentions considerably.

Two important other variables were found to influence customers' stay intentions. The stuck bonds as well as the perceived service quality also influence the stay intentions directly, regardless of customers' commitment to the relationship. Regarding the stuck bonds this is a very logical finding, for if a client is stuck to its agency, they have to stay, whether they like it or not (the negative relation to affective commitment suggests that they do no like it). This stuck bond could thus be regarded as a third motivation to keep the relationship, which is not inextricably linked to the desire nor the perceived need to continue a relationship: the obligation to continue the relationship. The implications of this finding will be discussed in the next chapter.

The direct contribution of service quality to the stay-intentions is an additional finding, which is highly relevant for our research goals. Service quality thus influences customers" stay intentions both directly and through its influence on customers' affective commitment. This confirms the finding of many studies that customers' quality perception influences their behavioural intentions (viz. Zeithaml et al. 1996). However, the total effect on customers' stay intentions is only partly explained by its influence on customers' commitment to the relationship. A unique part of customers' service quality perception does not contribute to the desire to stay, nor to the perceived need to stay, but somehow forms a reason in itself to stay in the relationship. We will elaborate on this more deeply at the end of this chapter and in the next chapter.

Customers' (overall) quality perception thus not only contributes to the maintenance of agencyclient relationships, but it is the most important antecedent relative to the other antecedents. 


\subsection{Service quality determinants and relationship maintenance}

The previous analyses indicate that customers' perceived quality contributes strongly to the long-term maintenance of agency-client relationships, also relative to the other antecedents. In this section the analysis will be extended by adding the quality determinants ${ }^{7}$ found from chapter 7 to the model. The goal of this analysis is to explore whether the findings are also confirned in a more complex model, and to examine whether the strong influence of customers' overall perceived quality can be explained by the key quality determinants. In this section the entire research model will be assessed (see figure 8.1).

The analyses in chapter 7 showed that customers' overall perceived service quality is based on their evaluation of the potential quality, the functional reliability and competence, the soft process quality " and finally the outcome quality, which is comprised of both the immediate and final outcome quality. It was found that customers' overall quality perception is influenced the most by the outcome quality, the soft process quality and the exhibited competence. The potential quality and functional reliability did not contribute significantly to the explanation of customers' overall perceived quality next to these three determinants.

Including the quality determinants extends the research model with five additional variables. The measurement model thus consists of 14 concepts instead of 9 , and should therefore be assessed again before the new structural model will be analysed. The fit of this measurement (saturated) model is good, indicating that all concepts are measured by valid indicators that are well differentiated from each other (see table 8.11).

Because one of the goals is to explore whether the previous findings are also valid in this more complex model, the structural model is specified as the initially proposed research model, including the paths that were found insignificant in the previous analyses, and excluding the additional paths that were suggested by the previous analyses. This original research model shows a fairly good fit to the data (see table 8.11) indicating that the propositions are largely supported and that specifying the quality determinants as antecedents to customers' overall quality perception is a good addition. However, comparing the model fit with the saturated model suggests that improvements could be made to this original model (see table 8.11).

\section{Modifications}

An analysis of the residuals indicates again that the 'stuck bonds' are also directly related to customers' stay intentions. Adding this path from the stuck bonds directly to the stay intentions significantly increases the fit of the model. The analysis also indicates again that service quality is stronger related to customers' stay-intentions than the original model allows for. However, it seems that this additional path is entirely explained by the outcome quality determinant. Adding the path from the outcome quality determinant directly to the stay intentions increases the model fit significantily ${ }^{8}$. Therefore both paths are added in the modified less constrained model (see table 8.11).

\footnotetext{
7 The modified five quality dimensions will be used that were found as key-quality deteminants of advertising services firom the analyses in chapter 7. Therefore these quality dimensions will be called quality determinants.

8 Ading the path from outcome quality directly to the stay intentions decreases chi-square 8.6 , with one extra degree of freedom. This decrease is significant $(p=.001)$
} 
Table 8.11: Fit-statistics and difference tests of nested altemative models.

\begin{tabular}{|c|c|c|c|c|c|c|}
\hline \multirow[b]{2}{*}{ Modells } & \multicolumn{2}{|c|}{ Absolute fit statistics } & \multicolumn{4}{|c|}{ Chi-square difference tests } \\
\hline & $x^{2}$ & p-value & Models compared & $\Delta x^{2}$ & $\Delta d f f$ & p-value \\
\hline Saturated model & 52,3 & .09 & & & & \\
\hline Proposed Model & 928 & .02 & $\mathrm{Mt}-\mathrm{Ms}$ & 40.5 & 26 & .03 \\
\hline $\begin{array}{l}\text { Modfied model } \\
\text { (2 suggested paths added) }\end{array}$ & 76,3 & .14 & $\begin{array}{l}M m-M t \\
M m-M S\end{array}$ & $\begin{array}{l}16.7 \\
24\end{array}$ & $\begin{array}{l}2 \\
24\end{array}$ & $\begin{array}{l}<.00 \\
.46\end{array}$ \\
\hline $\begin{array}{l}\text { Final model } \\
\text { (n.s. paths in Mm set to o) }\end{array}$ & $\begin{array}{rr}83.9 & 75 \\
\end{array}$ & 22 & $\begin{array}{l}\text { Mf }-M m \\
M f-M s\end{array}$ & \begin{tabular}{|l}
7.7 \\
31.7 \\
\end{tabular} & $\begin{array}{l}11 \\
35\end{array}$ & $\begin{array}{l}.74 \\
.63\end{array}$ \\
\hline
\end{tabular}

Again $x$ this estimated modified less constrained model shows many insignificant paths. These are the same paths as were found from the analysis of service quality in section.7.3 and of the simplified research model in section 8.3. Restricting these paths to zero resulted in nonsignificant changes in the model fit (see table 8.11) and enhanced the parsimony of the model. This final constrained model is thus the most parsimonious model with maximum model fit (i.e. equally good as the saturated model), within the constraints of our theoretical assumptions. The final model is graphically presented in figure 8.6.

The final model is thus entirely consistent with the part-wise analyses, even though the compllexity of the model increased considerably. The findings of this model provide additionall information to the earlier findings. In table 8.12 the findings are presented.

Table 8.12. Estimated parameters and fit-statistics of final model

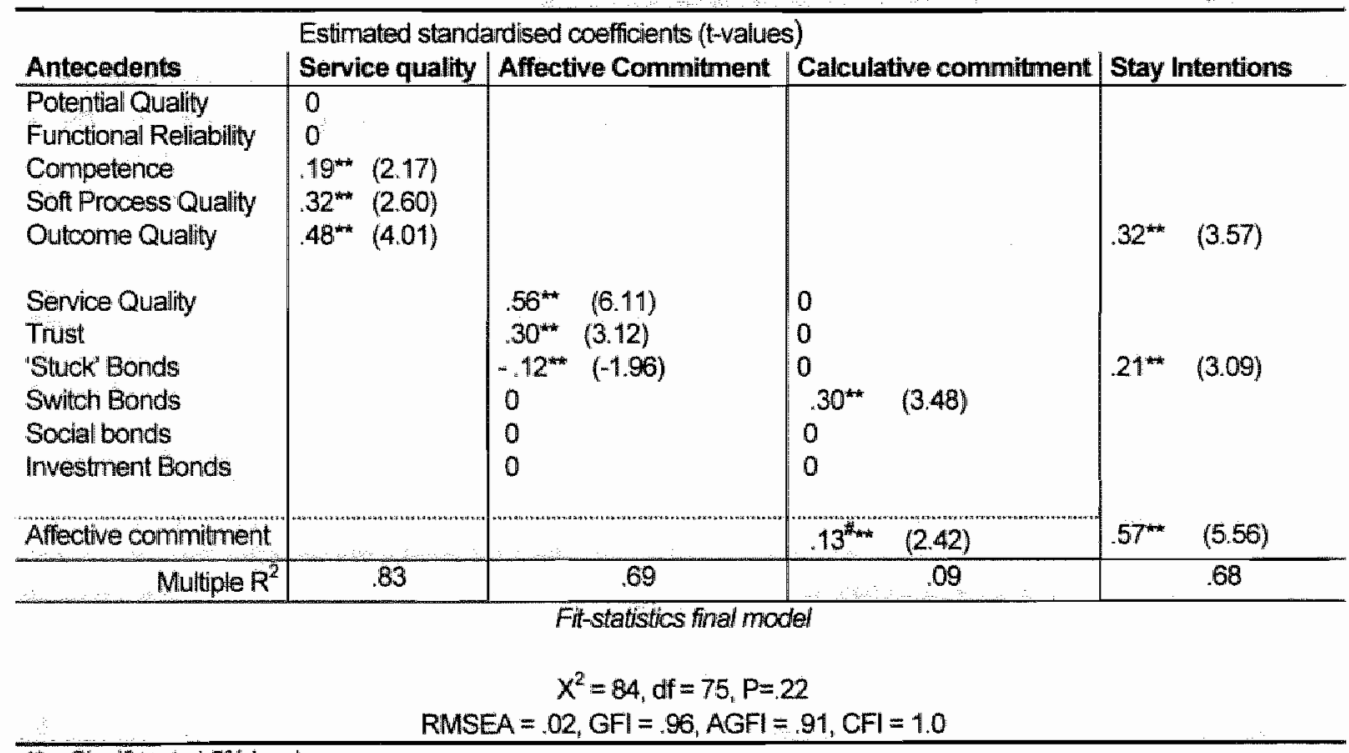

* Significant at $5 \%$ level

\# this is an error comelation (Psi), not a causal path. 


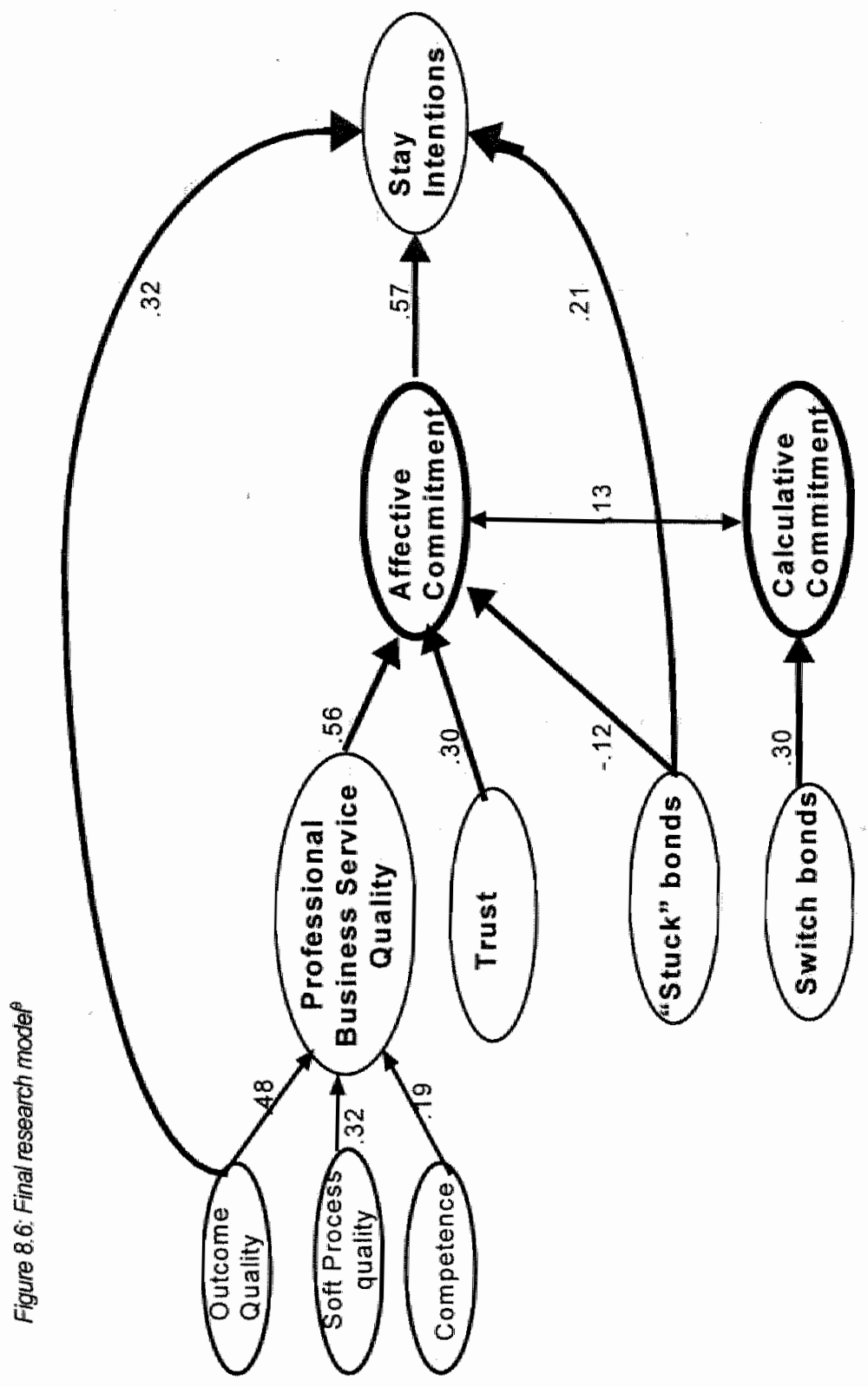

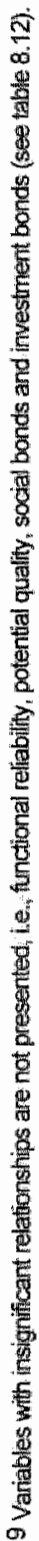


These findings confirm those from the previous sub-model analyses. Customers' overall perceived quality is explained for $83 \%$ by the three quality determinants, outcome quality, soft process quality, and competence. Affective commitment is explained for $69 \%$ by the overail service quality, the established trust, and by the 'stuck bonds', which contribute negatively. Customers' calculative commitment is only explained for $9 \%$ by the switch bonds, and does not contribute significantly to customers' stay intentions. The stay-intentions are explained for $68 \%$ by customers' affective commitment, the stuck bonds, and customers' perceived outcome quality. This outcome quality is a composite measure of customers' perception of the immediate and final outcome quality, as described in chapter 7 .

This analysis provides additional insights into the role of the quality determinants for the maintenance of agency-client relationships. The outcome quality determinant is related to customers" stay intentions directly, and is entirely responsible for the observed covariance between overall perceived quality with the stay-intentions that was found in the previous analysis. Customers" affective commitment is thus only influenced by customers' overall perceived quality, which in turn is based on the three quality determinants together, whereas the stay intentions are also directly influenced by the outcome quality(see figure 8.6).

The competence and soft process quality thus only contribute to the maintenance of the relationship indirectly, through their effect on customers' overall perceived service quality. The outcome quality determinant not only contributes indirectly, but also directly on customers' stay intentions. The total effects of the quality determinants, i.e. their direct effects and indirect effects, on the relationship variables are presented in table 8.13 .

Tabie 8.13: Total effects of quality determinants on relationship variables

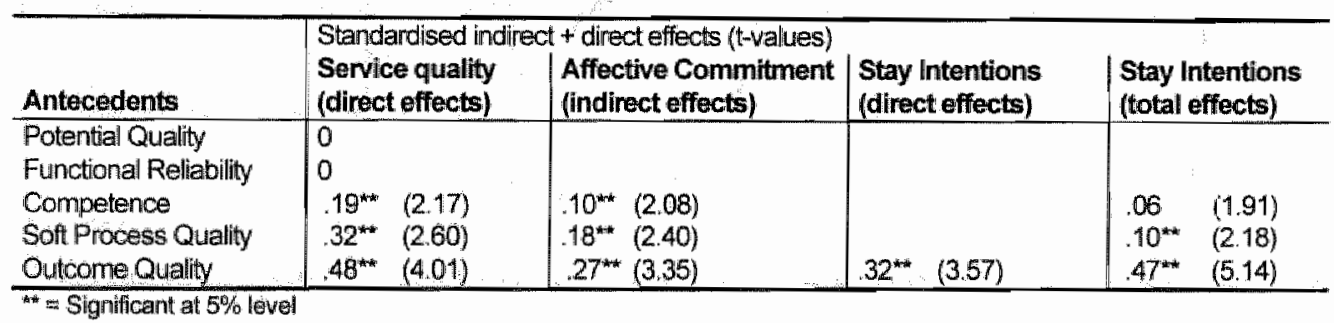

As was found in chapter 7, the outcome quality determinant (consisting of both the immediate and final outcome quality) contributes the strongest to customers' quality perception, closely followed by the soft process quality and the competence. Since all three quality determinants are only indirectly related to the affective commitment, this relative importance order remains the same for their (indirect) effects on customers' affective commitment. All three determinants have a significant effect on customers affective commitment via their contribution to customers' service quality perception. The competence and soft process quality affect customers' stayintentions very indirectly, via their effects on overall service quality, its subsequent effect on affective commitment, which in turn influences customers' stay intentions (see figure 8.6). The table shows that only the soft process quality influences customers' stay-intentions significantly via this indirect way, whereas the effect of competence is not significant anymore. Because the outcome quality also influences the stay-intentions directly, it has a high significant total effect on the stay-intentions. The soft process quality and outcome quality thus both contribute to customers' stay intentions. 
So, the three quality determinants influence customers' desire to continue the relationship (affective commitment). However, the quality and effectiveness of the work can also be a motivation in itself to keep the relationship, regardless whether the customers really desire or perceive a need to continue. This means that even if clients do not desire to continue the relationship (affective commitment), either because of low soft process quality, bad competence, or low trust, they would still be inclined to stay if the outcome is perceived as good or effective. On the other hand, if the outcome quality is perceived as low it can off-set part of the effect of customers' affective motivations to stay. It seems that the outcome quality could be regarded as the core-service, which has immediate effects if it is good or bad, whereas the other quality determinants are more peripheral (laccobucci et al. 1994). It can form a motivation in itself to continue a relationship.

On the other hand, customers' affective commitment is stronger related to their stay-intentions than the outcome quality. Their desire to continue is thus the most important motivation to maintain a relationship. It is questionable for how long a relationship can be maintained by excellent outcome quality if the customers are not also affectively committed.

\subsection{Summary \& Conclusions}

In this chapter the core question of the study was addressed: the importance of customers' perceived service quality on the maintenance of long-term business relationships. Before the answer to this question will be discussed, the findings regarding the underlying assumptions will be summarised by which the relation between service quality and relationship maintenance is studied in this thesis. The research objective was to explore the contribution of a customerbased quality concept to the maintenance of relationships, relative to other antecedents that have been found in the business relationship literature. From a literature review and exploratory research propositions were made regarding the structure of relationship maintenance in professional business service relationships and its antecedents. These propositions will be addressed first.

\section{Relationship maintenance}

Customers' relationship commitment is proposed to be the most important variable that determines the maintenance of long-term customer relationships. Customers' relationship commitment consists of two dimensions, reflecting the need to continue and the desire to continue the relationship, which are both related to customers' actual stay intentions.

The study confirms the existence of the two commitment dimensions in agency-client relationships. However, only customers' affective commitment contributes significantly and strongly to their actual stay-intentions. So even though clients can be motivated to continue the relationship because of the expected costs and losses at a switch, this motivation is not strong enough to influence their actual stay-intentions. Only if the clients are affectively motivated to, they actually intend to stay.

This finding may be specific to professional service relationships, because investments in these relations are highly intangible. This study indicates that clients do invest in time, effort and knowledge, and that they do perceive switching costs. These switching costs also do contribute to their calculative motivations to stay, but -again- these are not strong enough to actually keep a relationship only because of them. Apparently the investments are interpreted differently in 
these relationships than in relationships where the investments are more tangible, like e.g. in channel relationships (of. Kumar et al. 1994, Geyskens \& Steenkamp 1995). Customers will only maintain the relation if they really desire to.

\section{Antecedents}

Relational bonds, trust and customers" quality perception were proposed to influence customers relationship commitment.

This proposition is confirmed regarding trust and customers' service quality perception, which both contribute significantly to customers' affective commitment. This finding is consistent with many other studies that studied the effect of mainly trust on a party's affective commitment (Cf: Anderson \& Weitz 1992, Morgan \& Hunt 1994). Both variables do not contribute to customers" calculative commitment. In the two studies reported by Geyskens \& Steenkamp (1995) "trust was found to be slightly negatively related to calculative commitment in one study, and also non-significant in the other. Our findings are thus consistent with the literature and it seems that customers ${ }^{t}$ trust, as well as their quality perception strongly influence customers' desire to keep on working with their agency.

Relational bonds were also found to contribute to customers' commitment, although not as much as proposed. Only the switch bonds and the 'stuck bonds' contribute significantly to customers' commitment. The investment bonds and social bonds do not contribute to relationship maintenance, next to the other antecedents. This implies again, that the investments as such, nor the created social network as such, will motivate customers to maintain the relationship. These bonds were found to be strongly related to the switch bonds, which is significantly related to customers' calculative commitment. However, even if these bonds contribute indirectly to customers calculative commitment, the relation is not very strong, and moreover, calculative commitment is not a strong motivation to keep the relation. So, again, it seems that the investments play a different role in these relationships, and that there are hardly any structural bonds between clients and their agency that in themselves can maintain the relationship.

The structural bond that does contribute to relationship maintenance is a very physical one: the 'stuck bonds'. This tie is, however, negatively related to customers' commitment: the more clients feel 'stuck' to their agency by forces outside the focal relationship (contract and regulations), the less they voluntarily desire to continue it. The stuck bonds were also faund to be positively related to customers' stay intentions directly. So regardless of customers' desire or perceived need, customers intend to stay if they are stuck, which is inherent to being 'stuck".

\section{The importance of service quality for relationship maintenance}

The study thus indicates that service quality does contribute to customers' relationship commitment, also next to the other antecedents. Compared to the antecedents used in this study, it was found to be the strongest contributor to customers" affective commitment, even stronger than the established trust in the relationship. Trust makes a good second.

Interestingly, customers' quality perception is not only strongly related to their affective commitment, but also contributes significantly to customers' stay intentions directly, regardless of their relationship commitment. This effect is explained by one quallity determinant only: the outcome quality, which consists of both the immediate outcome quality and the final outcome quality dimensions. So even though the outcome quality, the soft process quality, and the competence 
exhibited by the agency together explain customers" overall quality perception the most, the outcome quality also independently infiuences customers stay intentions directly. This is an important contribution to existing research on service quality. One of the goals of the research was to analyse the assumed relationship between service quality perception and customer retention. The study confirms the frequently found relationship between service quality perception and behavioural intentions, but gives more in-depth insight into how this relationship is explained. The effect of service quality on the stay intentions is partly explained by an effect on customers' affective commitment and partly by a direct effect. All three quality determinants contribute (indirectly) to customers' affective commitment, whereas only the outcome quality contributes also to the stay-intention directly. The implications of this finding will be discussed in the mext chapter.

Therefore, the importance of the produced service outcomes can not be overlooked ${ }_{\mathrm{p}}$ and even though customers' affective commitment is the most important variable to maintain a long-term relationship, the chances for its continuation will be considerably decreased if the produced work is not satisfactory or effective. As stated in our motto: "Love is like butter, it needs bread underneath"; the love between an agency and a client is a cruciai ingredient, but only if it is backed-up by tangible results it will become really tasteful. 


\section{Chapter 9: Conclusions and Discussion}

"Mit dem Wissen wächst der Zweifel"

(The more you know, the more you doubt)

Goethe

\subsection{Introduction}

This chapter concludes our study into a customer-based service quality concept for professional business services, and its importance for the maintenance of long-term customer relationships. This study aimed to contribute to existing research in two ways.

- First to gain a better understanding of customers' assessment of the quality of professional business services. Although the customer-based quality concept is used since the early 1980 's in the services marketing literature, research on customers' quality perception of professional business services has received very little attention so far. "The theoretical and empirical literature dealing with professional services is far less developed than that of more traditional services. More precisely, there has been very little efforts to investigate business to business professional services quality" (LaPierre \& Filitrault 1995, p.3). Recent empirical studies in the professional business services field adopted and adapted validated quality models that were developed for the more traditional (consumer) services. In this study a general service quality model is developed that is based on the specific characteristics of professional business services. The feasibility of this model is empirically explored in the advertising market.

- Second, an empirical analysis of the importance of customers' perceived service quality for the maintenance of long-term customer relationships is provided. The impact of service quality on a service firm's profitability is to a great extent ascribed to its assumed positive effect on customer loyalty. Loyalty is traditionally approached from a transactional perspective, and several studies found that service quality is positively related to customers' repurchase intentions. The current notion of loyalty is, however, approached from a relationship perspective. The establishment of long-term customer relationships has become a new marketing paradigm. In the services marketing literature the relation between service quality and this notion of loyalty has hardly been addressed. Therefore, insights from the business marketing literature were used to understand the development of business relationships and to identify the variables that are crucial for their long-term maintenance. The role of customers' perceived service quality is examined next to the other factors that contribute to the maintenance of long-term relationships.

These two themes were captured in the following two research questions:

1. How do customers assess the quality of professional business senvices? What are the key quality determinants in their quality assessment?

2. Does service quality contribute to the maintenance of long-term customer relationships? What is its importance next to other factors that enhance long-term customer relationships?

These questions were explored by a literature review and two empirical studies in the advertising market. 
In section 9.2 the findings regarding each research question will be summarised and discussed, and the main conclusions will be drawn in section 9.3. The managerial implications of the study will be discussed in section 9.4 . Then, in section 9.5 the limitations of the study will be addressed, after which avenues for further research will be indicated in section 9.6.

\subsection{Findings and discussion}

\subsubsection{Service quality perception of professional business services}

The goal was to develop and explore a customer-based quality concept for professional business services. In this quality concept the quality criteria of customers are central to the delivery of quality, rather than industry or professional-based quality standards. Professional service providers have long been reluctant to adopt this customer-based view, due to market characteristics (see chapters 1 and 2), and the professional nature of the services. More than any other service, professionals do have professional standards they have to live up to, which is basically their core competence. However, if customers do not recognise the (profiessional) quality that is delivered, it becomes questionable what this quality really is. It is the customer who has to pay for the service and who decides with which provider to deal. Therefore, customers' quality standards are a crucial addition, rather than replacement, to the professional standards of the practitioners. Practitioners will have to deliver quality that is not only excellent in their own eyes, but also in the customers' eyes. This customer-based quality concept is defined as the customers' overall assessment of the excellence or superiority of a service provider, based on an accumulated perception of all previous experiences with the service provider. Customers will base their quality perception on the whole senvice experience which is multidimensional in nature. Understanding the key quality determinants of customers' quality perception of professional business services, is paramount for the management and control of the service quality.

On the most general level three quality dimensions can be identified that customers use in their quality perception. Customers' not only evaluate the service outcome, but also the process by which it is produced, and characteristics of the service provider who produces it. Customers thus base their quality assessment on what has been produced, how it was produced, and by whom. Based on the specific characteristics of professional business services five key quality determinants were proposed to play a central role in customers' quality perception (see chapter 3). This quality structure was analysed in the exploratory research in the advertising market in chapter 4 . In the subsequent field study, these quality determinants were operationalised in several ways (see chapter 5) and used in the survey among clients of advertising agencies (see chapter 6 ). In chapter 7 these measures were analysed, and five key quality determinants (slightly different from the originally proposed ones) were found for customers' quality perception of advertising services, as portrayed in figure 9.1.

These findings support our proposition that customers base their quality perception on the potential of the agency, the hard process and soft process quality of the service production process, and on the immediate and final outcome of the produced services. However, the analysis also revealed that customers do not evaluate the hard process quality as such, but distinguish between two separate dimensions within the hard process quality. The competence and the functional reliability displayed during the service production process were found to be separate quality determinants in customers' quality perception. Secondly, the interrelations 
between the quality deteminants showed that the immediate and final outcome quality determinants are related stronger to each other than we had proposed. It seems that customers hardly distinguish between the immediate outcome quality and the final outcome quality of the services in their overall quality perception. Although customers do differentiate between the two concepts, their evaluation of these service outcome determinants is so strongly related that they should be regarded as sub-dimensions of one outcome quality determinant (see figure 9.1).

Figure 9.1: Structure of clients" quality perception of advertising services

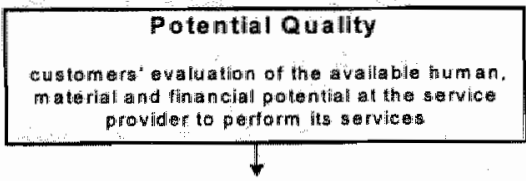

Service Proces

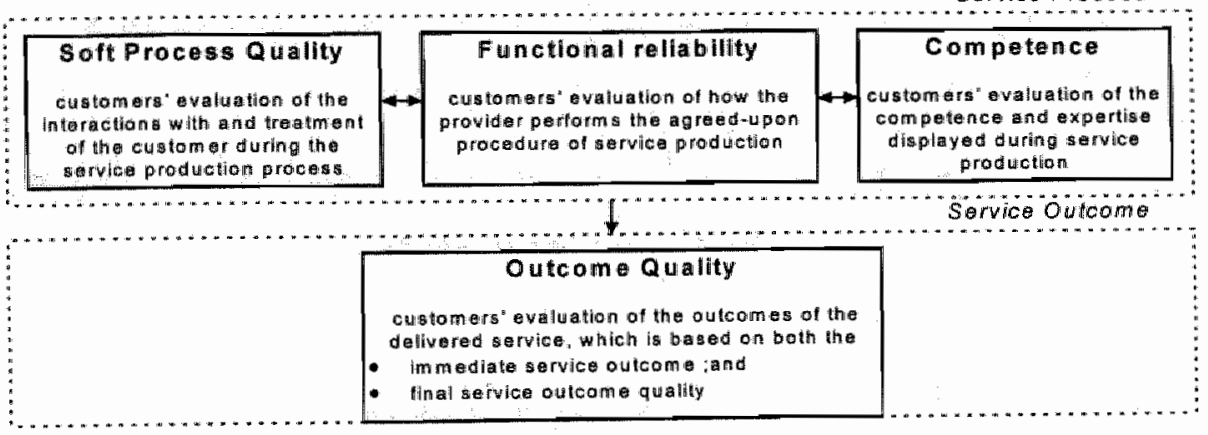

These five quality deteminants were found to be independent, reliable and valid indicators of customers" overall quality perception. The five quality determinants are all taken into account in customers' overall perceived service quality. However, they do not contribute equally to customers' overall perceived service quality. Regression of customers' evaluation of the five quality determinants on their overall perceived quality shows that the outcome quality and the soft process quality contribute the most to customers' overall quality assessment. Also the perceived competence contributes significantly. The potential quality and functional reliability do not contribute significantly anymore, after the inclusion of the other dimensions. The analysis thus indicates that clients' quality assessment is determined mostly by their evaluation of the agency's work and its perceived effectiveness, by the way the clients are treated during the service production process, and by the competence the agency shows during the service production process. The way the assignment is handled (functional reliability) and the available potential at the agency hardly play any role next to these three quality determinants.

Do these findings indicate that customers' perception of professional business senvices is indeed different from other (traditional) services?

Firstly, the findings confirm the general distinction into the potential quality, process quality and outcome quality dimensions. Or stated differently, also for professional business services, customers' quality perception is based on what is produced, how it is produced and by whom it is produced. The findings indicate that also the potential quality as such plays a role in customers' quality perception. This means that quality is not only based on customers" service experi- 
ence, but also on the structural characteristics of the service provider. However, the regression analyses in chapter 7 show that when all other quality determinants are taken into account, the potential quality does not contribute uniquely to customers" quality perception. This means that once customers have experience with the services of the provider, the experience becomes more important than the potential quality. As Haller (1995) proposed, the potential quality is probably a determinant that signals the quality of a provider, which will be most important when the customer has no, or little, experience with the provider. It may thus play an important role when an agency is selected to start a relationships with. Since the clients in our research had all at least a year experience with their agency, the potential quality will not play a decisive role anymore in their quality assessment, compared to the experiences they have already gained.

Second, the findings suggest an important addition to the traditional quality models by the new break-down of the service process quality dimensions customers use in their quality perception. The service process quality is evaluated on three different service quality determinants: the soft process quality, the functional reliability and the competence, which are separate quality determinants of customers 'overall quality perception. The soft process quality is the most important one, followed by the competence determinant. The functional reliability did not add significantly to customers' quality perception, next to all other quality determinants.

- The separate role of the competence deteminant seems to be particularly relevant for professional business services. Customers do not only evaluate it differently from the other quality determinants included in the study, it also uniquely contributes to customers' overall quality perception. This finding is well interpretable particularly for professional business services, because the competence and expertise of the professionals are the core of these services. Although competence was initially proposed to be part of customers hard process quality evaluation, like the SERVQUAL model defines it as part of the 'assurance' dimension together with other quality aspects (see table 2. 2), it seems that customers make a clear distinction between the professionalism of the process by which the services are produced (functional reliability) and the professionalism of the contents of the service performance (competence). Customers do evaluate the competence of the provider separately, and incorporate it in their quality perception. Therefore, the competence dimension should be included as a separate quality determinant in the quality model for professional business services.

- Regarding the functional reliability determinant, the finding is rather surprising. Freeman \& Dart (1993) and LaPierre \& Filitrault (1995) found that customers are particularly concemed about the degree to which the provider sticks to the budgets and timetables in their quality perception of professional business services. Especially because this is about all that customers can control during the long, intransparant service production processes. Also the trade press in the advertising market often reports about hassles regarding budgets and deadlines. However, although this dimension is incorporated in customers' quality perception, it does not contribute significantly next to the other quality determinants. Apparently, the outcomes of the service, the soft process quality, and the competence can make up for these hassles during the process.

- The found importance of the soft process quality confirms the findings of many other service quality studies. Five of the original ten SERVQUAL dimensions can be categorised as soft process quality aspects (see table 2.3). Also the studies regarding professional business senices found it as an important quality dimension. Interestingly, though, we found that customers themselves do not think it to be an important quality determinant. When asked directly, customers' assign it the lowest importance rating of all quality determinants (see 7.3.1). All that clients seem to care about is the outcome of the service (final and immediate) and the professional way in which it is produced. Apparently, clients are not aware, or unwilling to admit how strongly 
the soft process quality influences their actual overall quality perception (see chapter 7). Interestingly, the clients in the exploratory research did indicate that the soft process quality is very important to them (see chapter 4). Research has shown that the personal and social interactions are not just social or peripheral quality cues, but really add value to professional services (Crosby \& Stephens 1987). It seems that clients do not acknowledge this rationally, when they are asked to allocate importance points among the quality deteminants.

Third, regarding the senvice outcome quality determinants, it appears that customers do not make as sharp a distinction between the immediate outcome and final outcome quality of professional business services, as was proposed. This is an interesting finding, because particularly for professional (business) services these two kinds of service outcomes can be identified. It is even more interesting because advertising services are one of the few professional business services in which a clear physical distinction can be made between these two outcomes. Unlike other business services, customers get tangible evidence of the immediate outcome (the advertisements), which can be evaluated separately from its effects (image or sales results). Although we found that customers do distinguish between the two service outcomes as such, and do evaluate them separately, it seems that their evaluation is strongly related. This means that advertisements (immediate outcome) that are rated as good by the client, are also likely to be evaluated as effective (final outcome), and vice versa. If we can reasonably assume that this linear relation is not always true in reality, it means that mainly customers' perceptions of these outcome qualities are strongly related. The question is then which of the two is more important for customers" quality perception, i.e., is effective work in hindsight also rated as "good", or is 'good" work perceived as more effective? Although our data do not allow us to give a conclusive answer, we will argue for this latter view. As with many professional business services, the final outcome of advertising services is difficult to measure by objective standards, the effects are long-term and easily influenced by other factors (Szmigin 1993, Halinen 1994). In advertising services, the immediate outcome is more easy to evaluate. Halinen (1994) found from a qualitative study in the advertising industry that the final outcome is not as important as the immediate outcome, exactly because customers have difficulties in evaluating it, and the effects cannot always be attributed to the work by the agency. The regression analysis of the proposed five quality determinants (see section 7.3.1) showed that although both outcome quality determinants are strongly related to customers" quality perception, the effect of the final outcome quality was considerably less than the immediate outcome quality. This means that the influence of the final outcome is largely explained by the evaluation of the immediate outcome. It is thus highly likely that custamers transfer their evaluation of the immediate outcome to their perception of the effectiveness.

- Regardless of the cause for the strong interrelation, the finding implies that also for advertising services, customers' quality perception is based on one outcome quality determinant. Since there is a clear physical distinction between the two service outcomes in advertising services, it is highly likely that this finding is also transferable to other professional business services. Customers apparently do not make a sharp distinction between the immediate and final outcome quality in their overall service quality assessment. However the outcome quality determinant is based on customers' evaluation of both the immediate and final outcome quality. It should be noted that both service outcomes thus do play a role in customers' quality perception, and should be incorporated in the outcome quality determinant. 


\subsubsection{Service quality perception and long-term relationship maintenance}

The second research question regards the importance of the customer-based service quality concept for the maintenance of long-term customer relationships. This question was approached by integrating the service quality literature with the business relationship literature. Based on this literature review (see chapter 3), the question was operationalised by exploring the effects of customers' quality perception on their relationship commitment. Three important antecedents to customers" relationship commitment were proposed for professional business senvice relationships. Firstly, customers' service quality perception. Secondly, the trust that is established in the service provider. And, thirdly, the relational bonds that are developed during the course of a relationship. These bonds can be either social (interpersonal) or structural (interorganisational) in nature and are formed by different kinds of investments and adaptations to each other. The exploratory study in the advertising industry confirmed the existence and importance of these antecedents in long-term agency relationships, and four relational bonds were identified for agency-client relationships. Social bonds are the bonds created by the relational network between the two parties; investment bonds are the bonds created by the investments in knowledge exchange, time, and money during the relationship; switch bonds are the bonds created by the expected costs of switching the current agency and starting-up with a new agency, and "stuck" bonds are the ties created by contractual and regulatory agreements. In the field study these antecedents were included in the research model (see figure 8.1), to explore the importance of customers service quality perception next to these antecedents.

These propositions were analysed in chapter 8 , the findings of which are presented in figure 8.6. In sum, the findings confirm the existence of two different kinds of relationship commitment in agency-client relationships: affective commitment and calculative commitment. Also the proposed antecedents are for a large part confirmed: customers' quality perception, their trust in the agency and the relational bonds created during the relation contribute to customers' relationship commitment, although only part of the relational bonds were confirmed. Customers' actual stay-infentions are influenced strongly by their affective commitment, as proposed. Customers calculative commitment, however, did not contribute significanily to their stayintentions. Instead, the 'stuck bonds' and customers perceived outcome quality were found to influence the stay-intentions also directly. These findings will be discussed below.

First, the two relationship commitment dimensions are confirmed for agency-client relationships. These dimensions were found to be independent, though related, concepts. This means that two different motivations can underlie customers' intentions to continue the relationship that are not inextricably linked, which confirms the findings of Young \& Denize (1994). Customers who stay for calculative reasons are not necessarily also affectively committed and vice versa. However, clients' calculative commitment was not very strong and only weakly related to customers' actual stay-intentions. It seems that in these relationships only customers affective commitment is a strong enough motivation for customers to actually continue the relationship.

Second, none of the antecedents contributes to clients' calculative commitment, except for the perceived switch costs. The findings thus suggest that the expected costs of switching do motivate the clients to keep the relationship, but that these motivations are not strong enough to actually maintain it. Apparently, customers' investments and calculative motivations do not play an important role in agency-client relationships. This finding might be transferable to other professional business service relationships, for the investments in business service relationships are highly intangible. We found that customers do invest, especially in knowledge, time 
and effort during the relationship. These investments are, however, probably evaluated differently from the tangible investments customers make in other business relationships, like channel relationships (Morgan \& Hunt 1994, Geyskens et al. 1996) or even distribution services (Wilson et al. 1995). Like Freeman \& Dart (1993) argued, it seems that in business service relationships there are no structural bonds, and customers will only stay if they desire to.

The affective commitment is thus a strong indicator for the maintenance of long-term relationships. Only if customers desire to continue the relationship, they also actually intend to continue it, regardless of what they have already invested in the relation, or of the perceived costs of switching. Both trust and service quality are strongly related to customers' affective commitment and thus both enhance the maintenance of a long-term relationship. The bonds, neither social nor structural in nature, contribute to the affective commitment of customers. So again, there are no inter-organisational ties that will keep the parties together. The affective commitment will only result from the activities within the relationship itself, regardless of what has been built around it. Except for the 'stuck bonds'.

Fourth, the only inter-organisational bond that can keep the parties together are the "stuck" bonds, i.e., the contractual and regulatory ties between the parties. These bonds are directly related to customers' stay-intentions, which means that the contracts and regulations can be a motivation in itself to continue the relation, regardless of the desire or perceived need to continue. However, being stuck to the relation influences customers' affective commitment negatively. This means that although contracts and regulations can maintain the relation, it decreases customers' desire to continue it. This in line with what Young \& Wilkinson (1989) found in channel relationships. They found that written agreements produced more conflict between the parties than urwritten agreements, and that the conflict, in tum, is related to a less relational orientation by the partners. Contracts are thus not just another motivation to continue the relation, they actually decrease other motivations to maintain it. It is thus highly unlikely that the contracts and regulations will maintain a long-term relationship beyond the terms of the contract. In fact, one of the clients in our exploratory research (see chapter 4) who felt stuck to his agency, decided to hire other agencies on the side. This underscores the importance of the underlying motivation from which the intentions stem for long-term relationships.

Fifth, trust is an important antecedent to customers' affective commitment. This is consistent with what is found in many other studies on business (service) relationships (Morgan \& Hunt 1994. Halinen 1994). However, customers' perceived service quality contributes stronger to their affective commitment. Moreover, service quality not only contributes to customers" desire to continue the relationship, but also directly to their stay intentions. This direct effect is entirely caused by the outcome quality determinant. This means that regardless of customers' desire or perceived need to continue the relationship, if excellent service outcomes are produced, customers intend to stay with the provider. The outcome quality can thus be a motivation in itself to keep the relationship.

What does this mean for the importance of customers' perceived quality on the maintenance of long-term relationships?

Our study indicates that service quality contributes the strongest to customers" affective commitment to the relationship. And affective commitment is the strongest motivation to maintain the relationship. So, from the variables included in our study, service quality is the most important antecedent to the maintenance of the relationship, closely followed by the established trust. 
This is consistent with what LaBahn \& Kohli (1995) found for agency-client relationships. Studles in other business relationships, however, found that a party's satisfiaction (comparable to the service quality concept) did either not contribute at all (Morgan \& Hunt, 1994) or not as much as the structural bonds (Ganesan 1994, Wilson et al. 1995) to a party's relationship commitment. 1t thus seems that the absence of strong structural bonds in agency-client relationships makes customers' quality perception all the more important for the retention of customers. From our study it seems that a customer-based quality concept is one of the most impontant contributors to the long-term maintenance of customer relationships. If we can assume (like Freeman \& Dart, 1993) that there are no structural bonds in any business service relationship, then this important role of customers' quality perception might also be applicable to other professional business service relationships.

On top of that, customers' assessment of the outcome quality also influences customers stayintentions directly. Although this only underscores the importance of customers' quality perceptions for relationship maintenance, it has some interesting implications.

- Firstly, the finding confirms the positive effect that has been found between service quality and customers" stay intentions (cf. Zeithaml et al. 1996). However, the core of our research is to explore the contribution of service quality to the long-tem maintenance of a relationship. We argued that the stay-intentions might be transaction-oriented and that it is the attitude (i.e. commitment) from which the intentions stem that determines the long-term character of the relationship. The findings suggest that even if customers do not desire to maintain the relation (affective commitment) they would still be inclined to stay if their agency produces excellent and effective work. It is, however, questionable whether the perceived outcome quality as such is a sufficient motivation to maintain a relation on the long-fem. It is highly likely that if customers are not also affectively committed, the outcome quality alone can only maintain the relationship as long as the work is perceived as good, but will more easily dissolve once problems occur. Real customer loyalty originates from the part of service quality that contributes to customers' affective commitment. The strong relation between service quality and stay-intentions, thus only partly reflects the true loyalty of customers. As indicated above, service quality does influence customers' affective commitment strongly.

- Secondly, it has implications for the interreiation between the different quality deteminants. The outcome quality determinant influences customers' quality perception the strongest and influences the stay-intentions directly, regardless of the other quality determinants. The work as such can thus be a reason to stay or leave, regardless of how it was brought about (i.e. process quality determinants). So even if the interactions are superb (soft process quality) and an excellent understanding of customers ${ }^{\prime}$ problems is displayed (competence), if the work is not rated as good, clients will be less inclined to stay hereby off-setting part of the effect of customers" affective commitment. This puts the service outcome quality in a special position relative to the service process quality determinants. The outcome quality could be regarded as the 'core service', and the process determinants as service 'peripherals" (laccobucci et al. 1994, LaPlerre 1996). If the core service is not good, the peripherals cannot make-up for it. However "if the core service is good, the peripherals can strongly enhance its positive effect. Although it seerns that outcome quality is all that counts, the findings also showed that the soft process quality and competence together have an equally strong effect on customers' affective commitment as the outcome quality (see table 8.13). Assuming that the affective commitment is more indicative for the long-term retention of customers than their stay-intentions alone, this means that the 'peripherals' add significant value to the relationship and cannot be ignored by professional business service providers if a long-term relationship is aimed for. 


\subsection{Conclusion}

The study indicates that customers' perceived service quality is indeed related to the enhancement of long-ferm customer relationships in professional business services, like advertising. We found empirical evidence that service quality not only influences customers' relationship intentions, but also contributes to the maintenance of long-term relationships. This finding thus supports a generally held assumption, which so far, has hardly been addressed empirically. A customer-based quality concept for professional business services will induce customer loyalty, which has been found to contribute to the profitability of a company.

The customer-based quality concept is thus crucial also for professional business services. The findings show that the general distinction into three super-ordinate service quality dimensions is also applicable to customers' quality assessment of professional business services. Thus, universally, customers base their service quality perception on the following super-ordinate service dimensions, which each consist of different service-specific elements:

1. stable characteristics of the provider;

2. the service process; and,

3. the service outcome.

As was found in studies in other service industries, the outcome of the service seems to be most important for customers' quality perception, closely followed by the process of service production. Even though we argued that the service outcome of professional business services is different from other kinds of services because the results of professional (business) services are usually delayed, it seems that customers still use one outcome dimension to evaluate the service performance. Furthermore, competence is a crucial and separate factor in the evaluation of the quality of professional business services, more so than in other services.

Furthermore, our study adds to the understanding of customer loyalty. Service quality is generally assumed to induce customer loyalty because of its positive effect on customers' behavioural intentions. The rationale of our study is based on the assumption that behavioural intentions alone, are not a good indicator for customers' true loyalty to a service provider. Therefore, we used the relationship commitment concept from the business marketing literature, that reflects the attitude (or motivations) on which customers' intentions are based. The commitment underlying the intentions determines customers' true loyalty and the maintenance of long-term relationships. Our study confirms that service quality contributes to customer loyalty, but also indicates that customers' behavioural intentions cannot be linearly translated into customer loyalty. The strong positive relation between service quality and behavioural intentions is only partly explained by customers' true loyalty (i.e. relationship commitment). The underlying attitude is thus a better indicator for customers' loyalty. The attitude that is most important for the long-term maintenance of professional business service relationships is customers' affective commitment. The (non)imanetary investments and expected switch costs do not contribute to customers' loyalty. It seems that as long as customers' are not stuck by contracts or regulations to their agency, they will only maintain the relation if they are affectively committed to the relationship or when good outcome quality is delivered. This important finding implies that agencies should not take any client for granted but should invest in keeping the customer deliberately willing to continue the relation. From the variables included in our study this willingness is influenced most by the delivered service quality and the trust in the agency. 
Another conclusion that emerges from our research, regards the measurement of the importance of service quality dimensions. As described in chapter 7 , we measured the relative importance of the service quality dimensions in two ways: directly, by asking clients to allocate 100 importance points among the quality determinants, and indirecty by a regression analysis. Bath methods resulted in different outcomes. Customers rated the soff process quality as much less important than the importance rating that resulted from two different regression analyses. The fact that two different indirect analyses showed the same results, and that these results are consistent with the findings of the exploratory study and other studies in the service quality area (see chapter 7), are strong indications that the indirect importance analysis is superior to the direct one. It seems that when customers are asked directly they make a more rational comparison between the service quality dimensions that do not reflect their actual perceptions and preferences accurately. Since the used direct importance measurement is common practise in service quality studies, this finding has implications for future service quality studies. Also Taylor (1995) concludes from a review of different importance score methods in service quality measurement that the explicit (i.e. direct) importance measures are inadequate. He argues that only implicit (i.e. indirect) importance weights are a good way to analyse the relative importance of service quality dimensions. Our study indicates that the regression of quality dimensions on an overall quality measures is a good alternative, like Parasuraman et al. (1994b) and Taylor (1995) suggest. Other methods by which implicit impoitance weights can be assessed are conjoint analysis and multidimensional scaling (cf. Taylor 1995). 


\subsection{Managerial implications}

This study indicates that a customer-based quality concept is very valuable also for professional business service providers. The quality management and control of these services should be guided by customers' quality criteria and perceptions in addition to the professional standards.

The study shows that not only the effectiveness of the service counts. Customers want foremost that the produced work itself is excellent. Therefore, it is important to find out what criteria customers use to assess the service outcome. Our operationalisation of the immediate outcome quality of advertising services indicates that it is not so much the creativity of the work that is evaluated. Clients judge the work mainly on the outcomes that are promised by the agency, during the briefing as well as during the production process. This finding implies that service providers should foremost communicate clearly what outcomes customers can expect and then make sure that they perform accordingly.

Second, service providers will have to pay attention to the soft process quality, i.e., open communication to the customers, keeping them informed, and showing a proactive attitude. This means that a customer orientation does not only consist of reacting accurately to customers' wishes, but also to actively anticipate to future events and co-operate with the client. Although clients themselves do not rate this as an important aspect, it seems to have a major influence on their service quality perception.

Third, competence plays an important role in customers' quality perception. In light of the increasing expertise at the clients' side, this finding implies that a customer-based approach to service quality does not jeopardise the professional standards of professional business services. In fact, this finding means that the professionals should be even more aware of the developments in their field of expertise, for clients will evaluate them on it. The qualifications of the professional and the availability of professional equipment and facilities are part of the potential quality, and will therefore not suffice to ensure the perceived competence once customers have experience with the service provider. Customers evaluate the competence displayed in each service performance. This means that clients should be enabled to evaluate the competence, i.e., proof of the providers' competence is needed. Ideas and performances that are developed behind closed doors, are difficult to evaluate. Yet, clients do evaluate the competence, and the criteria used will be uncontrollable for the service provider. The professionals should thus involve the client in the whole service production process, to enable the client to evaluate the competence better, and to gain more control over the aspects that customers will include in their competence assessment.

Fourth, although we found that the functional reliability is not as important as the above mentioned quality determinants, it is still one of the determinants of customers' quality perception. This finding has two implications. First of all, its relative lesser importance implies that service providers should not allocate too much energy to the highly visible and vivid hassles regarding budget deficits and deadline failures, at the expense of the other quality determinants. Proactive communications with the client (soft process quality) might even prevent it from becoming a problem. On the other hand, enough energy should be devoted to this aspect to prevent it from influencing the perception of the other quality determinants. Again, it seems most important that service providers communicate clearly what customers can expect during the service process 
and when, and then act accordingly. This implies that a good planning system is needed, by Which reasonable budgets and deadlines can be estimated. Overpromising may be effective in the short term (i.e. attraction of new customers) but can become detrimental on the long run: Research on tolerance zones (cf. Strandvik 1994) shows that customers do tolerate some deviance from their expectations, but not too much. However; exceeding customers' expectations remains the most beneficial strategy.

In sum, the delivery of excellent service quality requires first of all that service providers should carefully listen to the customers. The quality standards used by customers should be analysed thoroughly and continuously to detect possible changes. These analyses should regard the whole service performance and not just its outcomes. Quality programs can then be developed that are based on these standards, which should also be evaluated on a continuous basis. Secondly, the delivery of excellent quality implies that service providers also communicate clearly and openly with their customers. As indicated above, the service process as well as the service outcome are evaluated by the degree to which promises have been met. The more visible and understandable the service performance becomes, the more customers will be able to form realistic expectations, which can be adjusted in time if deviances occur during the process. By communicating clearly, service providers can also partly control the information and experiences that customers will use in their quality assessment. These two basic requirements: listening and communicating, put rigorous demands on the skills of professionals. Not only their expertise is important, but also their communication skills to translate this expertise into understandable language, and to translate customers' needs into service standards. These requirements will not only secure excellent quality, but will also enhance customer relationships.

Only customers' affective commitment will maintain a long-term business relationship. Customers should thus have affective motivations, and a desire to continue the relationship. No structural ties are built that are strong enough to keep a relationship when the desire has diminished. This means that no client should ever be taken for granted. Established clients should be nurtured as much as new ones. The data even suggest that established clients should be nurtured more than is currently done, for customers' affective commitment dirninishes slightly over the length of the relation.

Also contracts cannot ensure a long-term relationship. Although contracts seem to secure a steady flow of income on the short run, they may jeopardise the relationship in the long-run. Contracts are detrimental to customers" desire to continue. Service providers should thus continuously work to ensure that customers remain enthusiastic about the relation and are affectively committed. Apart from the service quality delivered, we found that trust is an important way to achieve this. Trust can replace written contracts and contributes to the positive willingness to keep a relationship. Lusch \& Brown (1996) found that normative contracts are more reinforcing for strong relationships than written contracts. Normative contracts refer to a mutual agreement about each other's roles and adaptations. These agreements should thus be communicated clearly, but can only be executed based on trust. A recent publication summarised the main factors that create trust in service relationships (Geyskens \& Steenkamp 1997). Fair treatment, open bi-lateral communication, a co-operative orientation and economic results will all contribute to the trust in the service provider. 
It thus seems that clear bi-lateral communications and expectations are not only crucial for the quality of the service assignments, but also for the strength and endurance of the whole relationship. Interestingly, agencies themselves describe "clients from hell" as clients who ".give unsatisfactory briefings, are unclear in what they want, cannot make decisions and do not want to lister" (p.8). If agencies would be as perceptive regarding their own 'devilish' behaviours in this respect, they would already be half-way to a "heavenly" relationship.

\subsection{Limitations}

As indicated in chapter 4 , the study should be regarded as exploratory in nature and the findings provide important indications for the propositions rather than hard conclusions. in this light a few limitations of the study will be addressed.

First, the study is conducted in the advertising service industry, which may limit the generalisation of the findings to other professional business services. However, the theoretical model was derived from professional business service studies in general, and many of our findings are supported by existing literature. As indicated in the discussion above, advertising services have specific features that make the findings transferable to other professional business services. Still, some of the findings may be industry-specific and replications of this study in other professional business service industries will make the findings more conclusive.

Second, our measures for the relationship variables are relatively new in quantitative research in professional business service relationships. Although we found reliable and valid measures for all the focal research concepts, some of the measures may be improved in subsequent research. The method of validation we used, by the assessment of uni-dimensionality of measures, is much more rigorous than the traditional Cronbach's alpha analysis (Steenkamp \& Van Trijp 1991). Our trust measure and the different relationship intentions measures were taken from conventionally validated scales in other studies. These scales contained reverse poled items ${ }^{2}$. Research has now shown that the polarity of items can impact the dimensionality of the scale (Herche \& Engelland 1996). We therefore had to remove the "intentions to invest' scale, the inclusion of which would have enriched our understanding of the differentiating effects of affective and calculative commitment. Also some of the trust items had to be removed because of this. Although we found a reliable and valid scale for the remaining trust items, and its nomological validity is confirmed in the research model, the trust measure could be enhanced in subsequent research taking the advise of Herche \& Engelland (1996) into account.

Third, understanding the causes of the maintenance of long-term relationships fully, should ideally be studied in a longitudinal setting, like Halinen (1994) did. These studies are, however, almost impossible to execute because of the time needed for their execution, and the participation that is needed from the respondents. Using cross-sectional data -like we did- necessarily simplifies the actual dynamic processes that underlie the studied concepts. This is a general limitation of this kind of research. In our study we tried to capture the general antecedents to the maintenance of relationships, and we think that the findings provide interesting indications of this in business service relationships. These results can be used in subsequent longitudinal studies.

1 Adformatie nr. 18, may 2nd 1997

2 This is usually done to correct for response acquiescence bias 
Fourth, it should be noted that our respondents were rather positive about the quality of their agency. This seems to be a general problem in satisfaction and service quality research. Peterson \& Wilson (1992) found that customen' ratings of their satisfaction or quality perceptions is generally more concentrated on the positive end of the scales. Although the positive quality rating might be an indication of selection bias, we found that clients selected by the agencies were not more positive than the BVA-members who selected themselves. Since we studied clients with existing agency relationships, this might indicate that only customers who are positive stay within the relationship. This supports the importance of service quality and affective commitment for the establishment and maintenance of relationships.

\subsection{Further research}

The discussion of the results of our study and its limitations suggest many avenues for further research.

First, the structure of customers' quality perception of professional business services should be studied also in other professional business service industries to confirm its generalisability. Particularly interesting would be to investigate how the outcome quality is evaluated for professional business services in which the immediate outcome is not as tangible as in advertising services (e.g. management consultancy), or in which the final outcome is more objectively measurable than in advertising services (e.g. legal services, financial investment services).

Second, the service quality concept should be explored further. If the outcome quality of professional business services is so impontant for customens' quality perception, more insights should be gathered as to how customers evaluate this outcome. Particularly, the strong interrelation between customers' perception of the immediate and final outcome quality could be analysed further. We argued that customers" final outcome quality perception might be biased by the more tangible immediate outcome quality of advertising services. So how then is this immediate outcome evaluated? What criteria do customers use to assess whether the produced work is good? How subjective is this evaluation? It could be that emotions play an important role in assessing the outcome of a professional service, like Alford \& Sherell (1996) found for customers" evaluation of dental services. Michell (1988) argued that the creativity of an agency is evaluated very subjectively, defining it as "doing the unexpected within the rigid parameters of the brief'. Also the competence dimension needs further exploration. How do customers assess the competence of a professional service provider? What activities and performances signal competence to a customer?

Third, we found that the potential quality does not play a significant role once clients have a relationship with the service provider. It is, however, one of the five quality determinants customers base their quality perception on. Therefore, we argued that the potential might be more important in the beginning of the relationship, when clients have little or no experience with the service provider. This implies that the relative importance of the service quality determinants might change during a relationship. In fact, several authors have suggested this (cf. Venetis 1997) but very little empirical research has been conducted so far. It would be interesting to investigate whether the outcome quality is as important in the beginning of the relationship as we found for already established relationships. 
Fourth, an important question that is raised by our study is the role of relational bonds and calculative commitment in professional business service relationships. The findings suggest that relationships in the advertising market are different from other business relationships. Clients hardly have to invest in equipment, technology, training or other tangible factors. On the other hand, we found that investments in knowledge, and time and energy can be rather high. Also the perceived switch costs can be considerable; it is difficult and time consuming to compare altemative agencies, and other studies have shown that it can take up to two years for a client to recuperate from a switch (Newsome 1980). Further research should be conducted to understand the role of the monetary and especially the non-monetary investments and costs in professional business relationships. Furthemore, we found that clients do exhibit some degree of calculative commitment. The question is then how these calculative motivations are brought about. The switch bonds explained this variable for only $9 \%$. This means that other variables are important for customers' calculative motivations. Interestingly, also in channel relationships it was found that a party's calculative commitment is for a very small part explained by the interdependence (viz. structural bonds) between the parties (Geyskens et al. 1996). Further research should be conducted into this calculative commitment concept and the factors that contribute to customers" calculative motivations to keep a relationship.

Fifth, customers' affective commitment is explained for almost $70 \%$ by the antecedents used in our study. This means that customers affective commitment is for the most part influenced by the studied antecedents. However, there still remains a part in customers' affective commitment that may be influenced by other variables. Since we only studied the customers' side of the relationship, it might be interesting to involve the relationship commitment of the service provider into the model. Relationship commitment should be mutual, i.e. the relationship will be the strongest if both partners are committed: Commitment is also regarded as reciprocal, i.e. the commitment of one partner will increase the commitment of the other party (Anderson \& Weitz 1992). The commitment by the service provider could thus be an important additional antecedent to customers affective commitment. Also our exploratory research in the advertising market suggested that customers are very concerned about the commitment of the agency to them. Further research could be conducted to investigate which behaviours by the service provider signall commitment to the client and how this affects customers' relationship commitment in return.

Finally, our study started from the assumption that service quality influences customer loyalty, which in turn contributes to the profitability of the service provider (see figure 1.1). In this study the first assumption is confirmed: service quality contributes to customer loyalty. Subsequent research should now be conducted to further investigate the second assumption: loyalty influences profitability. This link is explained by several causes, which can be summarised by stating that loyal customers will decrease operation and search costs and will increase revenues (see section 2.3). Further research could thus concentrate on finding how customers' affective commitment is related to less costs and more revenues. Are affectively committed clients indeed less price sensitive (Garvin 1988) or do they buy more services (Rose 1990) or do other factors play a role as well? 


\section{Appendix 1: The Questionnaire}

(translated from Dutch) 


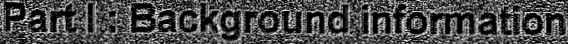

1. To which industry does your company belong? (8 categories)

2. How would you characterise your company in tems of customer markets?(national intemational)

3. What is the size of your company? Sales ( 6 categories) \& Employees (5 categories)

4. With which advertising agency has your organisation been in contact for over one year, and you are personally involved with? (in case of more than one agency: name the agency that is most important to your company or the agency with which you have the most experience).

Agency in

Please answer all the following questions that refer to "your agency" about this agency.

5. Which communication means are used by your organisation? Who is primanily engaged in this communication: your agency, another (specialised) agency or your own organisation?

\section{Communication mean}

1. Product/brand advertising

2. Corporate advertising

3. Public Relations

4. Direct Marketing activities

5. Sponsoring

6. Sales promotions

7. Internal communication

8. Labour market communication yes/no

9. Different, viz::

1. Co-ordination of the communication activities
Primarily taken care of by agency/other agency/organisation agency/other agency/organisation agency/other agency/organisation agency/other" agency/organisation agency/other agency/organisation agency/other agency/organisation agencylother agency/organisation agency/other agency/organisation agency/other agency/organisation agency/other agency/organisation

6. In which of the following activities do you involve your agency? (tick all that apply).

1. Development marketing strategy

2. Development communication strategy

3. Development creative concept

4. Production/execution of communication
5. Media planning and handling

6. Research

7. Other,

7. How important is the communication taken care of by this agency, for the success of your products and/ororganisation? (1.not at all important -5 . crucial)

8. What is the average yearly communication budget spent through this agency ?(8 categories)

9. For what assignments do you use this agency? (tick the most applicable altemative)

- Ad Hoc assignments (short term activities)

- For specific projects (development and execution of well-defined projects)

- For the long term fulfilment of communication needs 
10. What is the importance of your account to this agency?(1 not important-5.very important)

11. For how long does your organisation work with this agency. year

12. For how long do you personally have contacts with (persons of) this agency. ........year

13. How is the relation with this agency at this moment? (1. Problematic-5.Very close)

14. What is your function? Job description:

15. By which activities are you actively involved regarding this agency?

- Big picture (overall relationship or performance of agency)

- Development of marketing and communication strategy

- Evaluation of concepts and end products of agency

- Creation and discussion of briefings with agency

- Handling of ongoing activities and execution

16. What is your influence in important agency decisions? (1.none - 5. final decision maker)

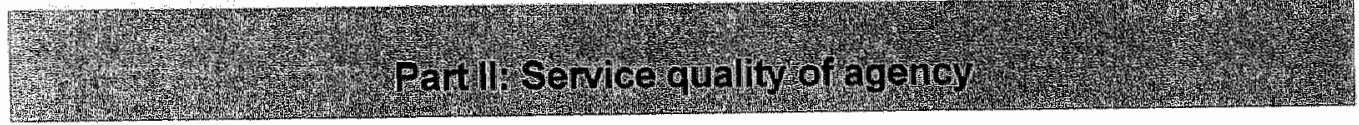

- Five service quality determinants

16. What do you think of the quality of your agency on the following aspects? Please encircle your opinion about the five statements. Rate the importance of each of the satements mentioned in the five statements for a good agency, by dividing 100 importance points among the five.

4. The potential avallable at our agency (avaitable means, expertise people, services 8 management), is:

2. The professionalism and approach by which our agency takes on, works out and executes an assignment, is:

3. The way our agenoy deals and communicates with us, is:

4. The creative and communicative work(concepts, advertisements and campaigns) that the agency made for us, is:

5. The effectiveness of the work made by the agency, is:

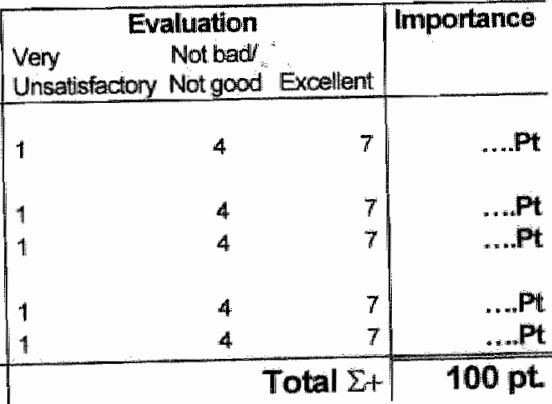

\section{- Overall perceived service quality}

17. With what school grade would you evaluate the quality of your agency (1-10):

18. How would you evaluate the service quality of your agency in general? (1 very poor - 7 excellient)

19. How would you evaluate the service quality of your agency compared to other agencies:

(1 much worse - 7 much better) 


\section{- Service quality items}

20. Please encircle your opinion about each of the following statements.

\section{OUR AGENCY}

1. has a good reputation

2. has much experience with comparable accounts

3. has experienced and qualified personnel

4. has availability of professional facilites and equipment

5. has all required communication services and expertise in-house

6. has an efficient and stable agency management

7. stays strictly within the agreed-upon strategy

8. stays within the budgets and quotations

9. keeps well to deadlines

10. pays attention to the little details in the execution of the communication

11. exhibits good strategic insight into our business

12. shows that they understand our communication issues and goals well

13. is competent in translating our needs\&goals into communication

14. is flexible in adapting plans to circumstances and/or our wishes

\section{THE DELINERED WORK}

15. reaches the intended objectives

16. has a notable effect in the target market

17. influences our sales and/or image positively

18. is usually very creative

19. is consistent with our briefing

20. is consistent with what they promised

21. is recerved well in our organisation

22. is well related to the costs (money, time, effort) we made

\section{THE CONTACT PERSONNEL}

23. are always open to our ideas and wishes

24. respond adequately to problems we raise

25. communicate very openly with us: they are direct and keep us informed

26. have a proactive attitude towards us: they anticipate on problems and/or come with suggestions and ideas

27. are pleasant to associate with

28. sense well what we want

29. are always reachable

30. dare to argue if they don't agree with us

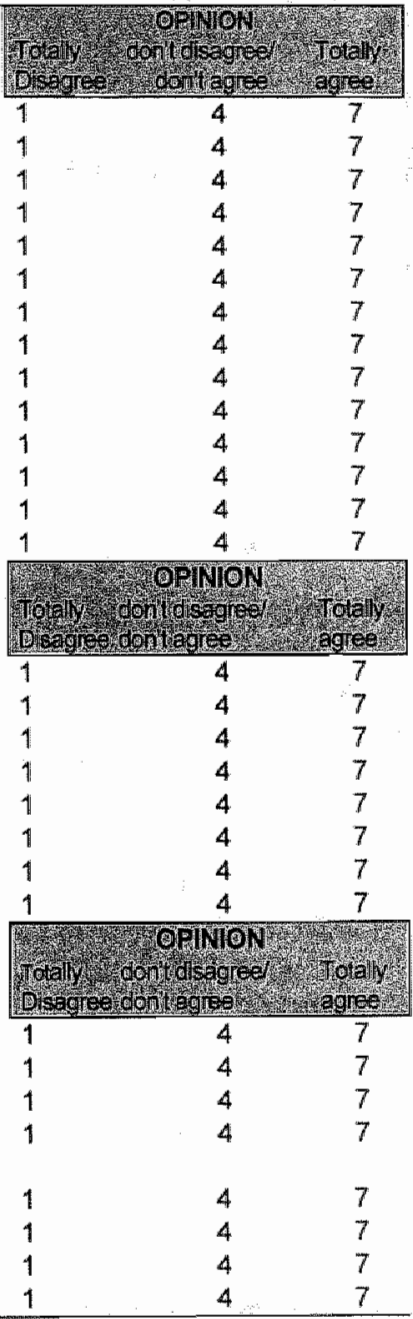




\section{- Relational bonds}

21. To what extent are the following characteristics present in the relationship between your organisation and your agency? (Look at the two extremes of each scale and tick the box. that represents the degree to which the characteristic is present the best)

1. Amount of people of your organisation in direct contact with your agency.......PERSONS

2. Amount of hierarchical levels in direct contact with your agency LEVELS

3. Relationship between the contact persons: (of own organisation and agency)

4. Usual contact frequency: (between your onganisation and your agency)

5. Usual contact intensity: (between your organisation and your agency)

6. The contact persons: (of your organisation and your agency)

7. Our agency is:

8. The work procedures and interaction patterns, arre: (between your organisation and the agency)

9. Contractual agreements: (between your organisation and your agency)

10. Agreements and policy within your own organisation(international rules, shares, culture):

11. The amount of specific knowledge gained at the agency regarding the organisation's business and market:

12. The amount of confidential (strategic) information you provided to the agency:

13. The amount of understanding gained by the agency about your intemall organisation culture:

14. The amount of time, money and/or effort invested in the establishment of the relation with the agency:

15. Amount of effort needed to find an agency comparable or better than your current agency:

16. Amount of time, money and effort needed to build a new relationship:

\begin{tabular}{|c|c|}
\hline \multicolumn{2}{|c|}{ scalle } \\
\hline 1 & 5 \\
\hline $\begin{array}{l}\text { Strictly business } \\
\text { and formal }\end{array}$ & $\begin{array}{l}\text { Personal } \\
\text { friendiship }\end{array}$ \\
\hline $\begin{array}{l}\text { Incidental } \\
\text { contact }\end{array}$ & $\begin{array}{l}\text { Frequent } \\
\text { contact }\end{array}$ \\
\hline $\begin{array}{l}\text { Superficial } \\
\text { contact }\end{array}$ & $\begin{array}{l}\text { Intensine } \\
\text { comtad }\end{array}$ \\
\hline $\begin{array}{l}\text { Can not get } \\
\text { allong }\end{array}$ & $\begin{array}{l}\text { Can get: } \\
\text { along }\end{array}$ \\
\hline $\begin{array}{l}\text { Poonly adjusted } \\
\text { to us }\end{array}$ & $\begin{array}{l}\text { Very much } \\
\text { adjusted to us }\end{array}$ \\
\hline $\begin{array}{l}\text { Established anew } \\
\text { every tüme }\end{array}$ & $\begin{array}{r}\text { Fully } \\
\text { institutionalised }\end{array}$ \\
\hline $\begin{array}{l}\text { Do not the } \\
\text { you to this agenoy }\end{array}$ & $\begin{array}{l}\text { The you strongly } \\
\text { 10. this agency }\end{array}$ \\
\hline $\begin{array}{l}\text { Do not tie } \\
\text { you to this agency }\end{array}$ & $\begin{array}{l}\text { The you strongly } \\
\text { to this agency }\end{array}$ \\
\hline None & Very mudh \\
\hline None & Very much \\
\hline None & Very much \\
\hline None & Very muchi \\
\hline None & Wery muth \\
\hline None & Very muich \\
\hline
\end{tabular}

\section{- Trust}

22. Encircle the number that best represents your opinion for each of the following statements.

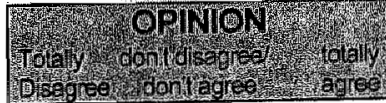

\begin{tabular}{|c|c|c|c|c|c|c|c|}
\hline 1. We trust our agency to get the job done right, even if we do not review their work & & $\angle$ & 3 & 4 & $\mathbf{5}$ & 6 & \\
\hline $\begin{array}{l}\text { 2. If I or my associates can not be reached, we are willing to let our agency make } \\
\text { important decisions without our involvement }\end{array}$ & 1 & 2 & $\mathbf{3}$ & 4 & 5 & 6 & 7 \\
\hline 3. We accept our agency's advice without questioning their motives & 1 & 2 & 3 & 4 & 5 & 6 & 7 \\
\hline $\begin{array}{l}\text { 4. We trust that our agency has our best interest at heart and will not undertake } \\
\text { actions that will harm us }\end{array}$ & 1 & 2 & 3 & 4. & 5 & 6 & 7 \\
\hline $\begin{array}{l}\text { 5. We have to check our agency's work to make sure that the work is done } \\
\text { correctly }\end{array}$ & 1 & 2 & 3 & 4 & 5 & 6 & 7 \\
\hline 6. In general, we can trust our agency & 1 & 2 & 3 & 4 & 5 & 6 & \\
\hline
\end{tabular}




\section{- Relationship Commitment}

23. How do you evaluate the relation with your agency? Encircle your opinion on each of the following statements.

1. We fel strong sense of loyalty fowards our agency.

2. It fis questionable what another agency has to offer, therefore we stay with this agenoy.

3. If it would be very easy we would llike to replace this agency

4. Right now it is a matter of necessity for us to keep working with this agency

5. We do not want to leave this agency because we benefit a lot from them

6. We desire to keep on working with this agency because we truly believe in and sympathise with their philosophy and goals

7. It will cost us too much time, money and effort to switch to another agency, that is why we stay at this agency

8. Our positive feelings towards this agency are a major reason to continue working with them

9. We continue to work with this agenoy because otherwise we would lose all the investments we made into this relationship

10. We stay with this agency because the costs of breaking with them would not outweigh the uncertain benefits another agency can provide

11. We stay with this agency because it is pleasant to work with them

12. We remain client of this agency because we genuinely enjoy the relationship with them

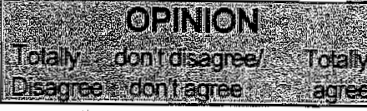

$\begin{array}{lllllll}1 & 2 & 3 & 4 & 5 & 6 & 7 \\ 1 & 2 & 3 & 4 & 5 & 6 & 7 \\ 1 & 2 & 3 & 4 & 5 & 6 & 7 \\ 1 & 2 & 3 & 4 & 5 & 6 & 7 \\ 1 & 2 & 3 & 4 & 5 & 6 & 7 \\ 1 & 2 & 3 & 4 & 5 & 6 & 7 \\ 1 & 2 & 3 & 4 & 5 & 6 & 7 \\ 1 & 2 & 3 & 4 & 5 & 6 & 7 \\ 1 & 2 & 3 & 4 & 5 & 6 & 7 \\ 1 & 2 & 3 & 4 & 5 & 6 & 7 \\ 1 & 2 & 3 & 4 & 5 & 6 & 7 \\ 1 & 2 & 3 & 4 & 5 & 6 & 7\end{array}$

\section{- Behavioural intentions}

24. The following statements concem the intentions you have with your agency. Encircle the number that best represents your opinion for each statement.

1. Comparable communication assignments in the future, we will certainly assign to this agency

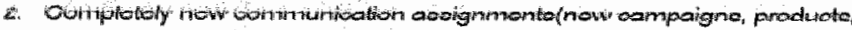
target markets, etc.) we will certainly assign to this agency

3. It is highly likely that we will continue the relationship within the next two years

4. We are looking for other agencies and altematives, to reduce the activities by this agency

5. We want to involve our agency more into our marketing and communication policy

6. We are willing to put effort in maintaining the relationship with this agency

7. If this agency makes emors; we will start to negotiate with another agency

8. We intend to assign more assignments, activities or product lines to this agency

9. We want to replace this agency in the near future

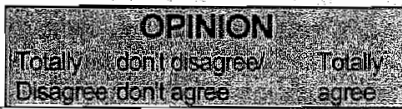

$12+5,7$

25. Do you have any objections if your answers would be used anonymously in a summary report for your agency? (Yes/No).

26. Do you want to receive an overview of the results of this research? (yes/no)

27. Do you have any question or remarks considening this questionnaire or research? 


\section{Appendix 2: Measure Validation and Purification}




\section{Introduction}

In this appendix the statistics and steps taken in the validation and purification of the measurement scales is portrayed. The procedure described by Steenkamp and van Trip (1991) is used. This is a confirmatory analysis by which a priori defined scales can be validated and reduced to a set of items that reliably and validly measure the concept at hand. For multivariate analysis, the ideal amount of items measuring one latent construct should be around three (Gerbing \& Anderson 1988, Baumgartner \& Homburg 1996).

The procedure is described in section 5.2 and consists of three steps. Each step examines the a priori defined measurement scales and gives indications about how well each item measures its proposed concept In each step poor performing items can be detected and will be deleted from the analysis in the following steps. After step 3 the scale is reduced to a concise set of items that reliably and validly measure their proposed concepts. For concepts that are proposed to be multi-dimensional, the analysis should be done for each dimension separately, to develop valid and concise scales for each dimension (Steenkamp \& Van Trijp 1991). The steps are the following (see also section 5.2 ):

1. Item-total correlation between the items measuring one construct (criterion: $>=.60$ )

2. Principal axis factoring factor analysis (criterion: select items with highest factor loading)

3. Confirmatory Factor analysis using LISREL. (criterion: good model fit, and for each item: Lambda $>=.60$, multiple $\mathrm{R}^{2}>.50$ )

\section{Overall perceived service quality}

Overall perceived service quality is measured by three items. From table A.1 below can be seen that the three items form a uni-dimensional reliable scale together (reliability $=.84$ ). The item-total correlations are all above 60 , the factor scores are all high. The confimatory factor analysis shows lambda's and multiple $R^{2}$ for each item that indicate that each item is a reliable and valid indicator for the underlying quality construct.

Table A. 1: Confimatory analysis overall service quality items

\begin{tabular}{|c|c|c|c|c|c|}
\hline Overall quality Items & $\begin{array}{l}\text { 1. Itemm } \\
\text { total com }\end{array}$ & $\begin{array}{l}\text { 2. Factor } \\
\text { scores }\end{array}$ & $\begin{array}{l}\text { 3. Confil } \\
\text { Lambda }\end{array}$ & $\begin{array}{l}\text { atory factor } \\
\text { Multiple } \mathrm{R}^{2}\end{array}$ & $\begin{array}{l}\text { analysis } \\
\text { Scale properties }\end{array}$ \\
\hline $\begin{array}{l}\text { Overall sevice qually rating } \\
\text { Qually relative to altematives } \\
\text { School grading of acjency }\end{array}$ & $\begin{array}{l}62 \\
69 \\
72\end{array}$ & $\begin{array}{l}68 \\
.79 \\
.86\end{array}$ & $\begin{array}{l}72 \\
78 \\
87\end{array}$ & $\begin{array}{l}.52 \\
.62 \\
.76\end{array}$ & $\begin{array}{l}\text { Composite neliability: } 84 \\
\text { Variance explained: } 63 \%\end{array}$ \\
\hline
\end{tabular}

\section{Service quality determinants}

In chapter 7 the validation and purification of the 30 quality items is described in-depth. As portrayed in table A.2, the 30 quality items were defined to measure 5 quality determinants. The item-total comelation analysis and the exploratory factor analysis were conducted per quality determinant scale separately (see table 3.2A). These two steps resulted in the delletion of several items per quality deteminant scale. 
Table A. 2 Scale analysis senvice quality items

\begin{tabular}{|c|c|c|c|c|}
\hline Quality determinant & Items & 1a. Item-total & 1b. Item-total & 2. Factor loading \\
\hline Potential Quality & $\begin{array}{l}\text { 1. Reputation } \\
\text { 2. Experience } \\
\text { 3. qualfied Personnel } \\
\text { 4. means \& facilities } \\
\text { 5. full service } \\
\text { 6. agency management }\end{array}$ & $\begin{array}{l}.49 \\
.39 \\
.60 \\
.49 \\
.45 \\
47\end{array}$ & $\begin{array}{l}\text { removed } \\
\text { removed } \\
59 \\
54 \\
\text { remowed } \\
56 \\
\end{array}$ & $\begin{array}{l}75 \\
67 \\
68 \\
\end{array}$ \\
\hline \multirow[t]{2}{*}{ Hard Process Quality } & $\begin{array}{l}\text { 7. Keeps strategy } \\
\text { 8. keeps budgets } \\
9 . \text { keeps deadlines } \\
\text { 10. accuracy execution } \\
\text { 11. flexible } \\
\text { 12. reachable }\end{array}$ & $\begin{array}{l}.58 \\
.52 \\
.64 \\
.60 \\
.51 \\
.27\end{array}$ & $\begin{array}{l}\text { remowed } \\
58 \\
66 \\
\text { removed } \\
54 \\
\text { remmoned }\end{array}$ & $\begin{array}{l}.78 \\
.80 \\
.60^{*}\end{array}$ \\
\hline & $\begin{array}{l}\text { 13. strategic insight } \\
\text { 14. understands problem } \\
\text { 15. translation }\end{array}$ & $\begin{array}{l}.48 \\
.64 \\
.57\end{array}$ & $\begin{array}{l}.65 \\
.79 \\
.56 \\
\end{array}$ & $\begin{array}{l}-.79 \\
-.96 \\
-.55^{*}\end{array}$ \\
\hline Soft Process Quality & $\begin{array}{l}\text { 16. Open to ideas } \\
\text { 17. response to problems } \\
\text { 18. open communication } \\
\text { 19. proactive } \\
\text { 20. pleasant dealing } \\
\text { 21. sensing wishes } \\
\text { 22. argues }\end{array}$ & $\begin{array}{l}.58 \\
.81 \\
.79 \\
72 \\
71 \\
.80 \\
48\end{array}$ & $\begin{array}{l}\text { removied } \\
.77 \\
.79 \\
.72 \\
.70 \\
.78 \\
\text { Remowed }\end{array}$ & $\begin{array}{l}.82 \\
.82 \\
.76 \\
.75^{*} \\
.84 \\
.\end{array}$ \\
\hline $\begin{array}{l}\text { Immediate Outcome } \\
\text { Quality }\end{array}$ & $\begin{array}{l}\text { 23. creativity } \\
\text { 24. match briefing } \\
\text { 25. match proposition } \\
\text { 26. reception organisation } \\
\text { 27. cost relation }\end{array}$ & $\begin{array}{l}.52 \\
.68 \\
.61 \\
.67 \\
.61\end{array}$ & $\begin{array}{l}.63 \\
.63 \\
63 \\
.65\end{array}$ & $\begin{array}{l}.72 \\
.72 \\
72 \\
71 \\
.74^{*}\end{array}$ \\
\hline Final outcome Quality & $\begin{array}{l}\text { 28. reaches objectives } \\
\text { 29. affects target group } \\
\text { 30. affects sales'image }\end{array}$ & $\begin{array}{l}.76 \\
.78 \\
.72\end{array}$ & $\begin{array}{l}.76 \\
.78 \\
.72\end{array}$ & $\begin{array}{l}.84 \\
.88 \\
.78\end{array}$ \\
\hline
\end{tabular}

"Removed after purification (see chapter 6 )

Table A.3. Confimatory factor analysis senvice quality determinants

\begin{tabular}{|c|c|c|c|c|c|}
\hline Quality Deferminant & Items & Lambeda & Multiple $R^{2}$ & Reliability & Explained variance \\
\hline \multirow{3}{*}{ Potential Quality } & Qualified Personnel & .80 & .65 & & \\
\hline & Agency means \& facilties & .59 & 34 & .75 & $51 \%$ \\
\hline & Agency management & .73 & .53 & & \\
\hline \multirow[t]{2}{*}{ Functional Reliability } & Stays within budgets & .61 & .38 & & \\
\hline & Keeps cleadlines & .87 & .75 & .72 & $56 \%$ \\
\hline \multirow[t]{2}{*}{ Competence } & Shows strategic insight & .82 & .67 & & \\
\hline & Understands problemigoals & .92 & .85 & 86 & $76 \%$ \\
\hline \multirow[t]{2}{*}{ Soft Process Quality } & Responds to problems & .83 & .68 & & \\
\hline & $\begin{array}{l}\text { Open cormmunication } \\
\text { Sensing Our wishes }\end{array}$ & .86 & .73 & .89 & $73 \%$ \\
\hline Immediate Outcome & Work matches briefing & $\begin{array}{l}01 \\
79\end{array}$ & 62 & & \\
\hline Quality & Work matches proposition & .70 & .49 & 80 & $57 \%$ \\
\hline & Reception within organisation & .78 & .61 & & \\
\hline Final Outcome & Work reaches abjectives & .86 & 74 & & \\
\hline Quality & $\begin{array}{l}\text { Work affects target group } \\
\text { Wonk affects sales/inage }\end{array}$ & 89 & $\begin{array}{l}80 \\
66\end{array}$ & .89 & $74 \%$ \\
\hline
\end{tabular}

Confimatory factor analysis six-dimensional quality model after removal of immediate outcome ftem 5

$$
X^{2}=137.4, \mathrm{df}=89, p=.004^{\prime}
$$

RMSEA $=.049, \mathrm{GFI}=92, \mathrm{AGFI}=.88$ 
As described in chapter 7, the hard process quality items were found to measure two different concepts rather than one, which we called functional reliability (items 7-12) and competence (items $13-15$ ). These two steps resulted in six quality dimensions instead of five, which were then jointly subjected to a confimatory factor analysis in step 3 (see table A.3).

The initial confimatory factor andysis showed a poor fit because outcome quality item no. 5 had a high error covariance with functional reliability item no. 1. Both tems share a cost aspect that is not intended to measure in the quality items. Therefore, outcome quality item 5 is removed and the resulting modell is portrayed in table A.3. From table A.3 we can see that the six quality dimensions show a good model fit, and that each dimension is measured reliably and validly by the purfifed scales.

\section{Relationship commitment}

Two dimensions of relationship commitment are measured: calculative and affective commitment. Following the procedure, the scales developed for each dimension will be analysed first separately and then jointly. In tables A.4 and 5 the outcomes of the three steps are portrayed.

First, the item-total comelations for the items of each dimension are calculated. All affective commitment items had item-total correlations higher than 60 , indicating that they measure one underlying construct. The calculative commitment items showed much less consistency. Four items had to be removed subsequently before the remaining items had item-total correlations above .60 . The three remaining items all referred to the motivation to stay because of the expected switch costs (lost investments, costs of switch, uncertain benefits of switch). These costs are central to the definition of customers' perceived need to stay, and therefore these three remaining items can be used as the operationalisation of calculative commitment.

Table A.4. Scale analysis commitment scales

\begin{tabular}{|c|c|c|c|}
\hline Initial commitment scales & $\begin{array}{l}\text { 1a. Item-total } \\
\text { correllations }\end{array}$ & $\begin{array}{l}\text { 1b. Item-total } \\
\text { comelations }\end{array}$ & $\begin{array}{l}\text { 2. Factor loading } 2 \text { - } \\
\text { factor solution }\end{array}$ \\
\hline $\begin{array}{l}\text { Calculative commitment } \\
\text { 1. Stay bectause uncertain what others offer } \\
\text { 2. Stay because too difficult to switch } \\
\text { 3. Stay because of necessity } \\
\text { 4. Stay because of benefits } \\
\text { 5. Stay because too high switch cosis } \\
\text { 6. Stay because of lost investments } \\
\text { 7. Stay because costs don't outweigh benefits of switch }\end{array}$ & $\begin{array}{l}.51 \\
.13 \\
.06 \\
.34 \\
.51 \\
.56 \\
.56\end{array}$ & $\begin{array}{l}\text { removed } \\
\text { removed } \\
\text { removed } \\
\text { removed } \\
65 \\
.66 \\
.64\end{array}$ & $\begin{array}{l}\text { remowed } \\
\text { remowed } \\
\text { removed } \\
\text { removed } \\
.78 \\
.77 \\
.74\end{array}$ \\
\hline $\begin{array}{l}\text { Affective commitment } \\
\text { 1. Strong sense of loyalt } \\
\text { 2. Stay because sympathise with goals" } \\
\text { 3. Stay because of positive feelings } \\
\text { 4. Stay because of pleasent working } \\
\text { 5. Stay because of nice relation }\end{array}$ & $\begin{array}{l}.60 \\
.64 \\
.77 \\
.82 \\
.78\end{array}$ & $\begin{array}{l}.60 \\
.64 \\
.77 \\
.82 \\
.78\end{array}$ & $\begin{array}{l}.63^{4} \\
.66^{4} \\
.83 \\
.87 \\
.91\end{array}$ \\
\hline
\end{tabular}

= removed after analysis

The remaining items of both dimensions were jointly subjected to a principal axis factoring factor analysis with oblique rotation. The analysis gave a two factor solution with all calculative items loading high on one factor and all affective commitment items loading high on the other factor. From table A.4 can be seen that the three caiculative items loaded equally high on their factor, whereas there was some differentiation among the affective commitment items. The three 
items with the highest factor loading $(>.8)$ were selected. The three remaining affective commitment items refer to the motivation to stay because of the pleasantness of dealing and working with the agency, which cover the definition of affective commitment.

The initial commitment scales are thus reduced to three items per commitment dimension. These scales were then jointily analysed by a confirmatory factor analysis. A measurement model is specified with two latent constructs (affective commitment and calculative commitment) measured by three indicators each. This model is subjected to a confinnatory factor analysis with LISREL 8. As shown in table A.5 this two-dimensional model gave a very good fit (Chisquare $12,95, d f=8, p=11$ ) on all absolute and relative fit-indices. The respective items formed reliable scales with composite reliabilities well above the recommended .70 and explained variances above the recommended $50 \%$. The items all had squared multiple correlations above .5 , which indicates that they are reliable and valid measures for the commitment dimensions.

Table A.5: Confinatory factor analysis two commitment dimensions

\begin{tabular}{l|l|l|lc}
\hline Commitment dimensions & Lambda & Multiple R & Scale Properties \\
\hline Calculative commitment & & & & \\
1. Stay because too high switch costs & .74 & .54 & Composite reliability: & .82 \\
2. Stay because of lost investments. & .79 & .63 & & \\
3. Stay because casts don't outweigh benefits of switch & .79 & .62 & & \\
\hline Affective commitment & & & & \\
1. Stay because of positive feellings & .78 & .61 & Composite reliablity: & .90 \\
2. Stay because of pleasant working & .93 & .87 & explained variance: & $76 \%$ \\
3. Stay because of nice relation & .90 & .81 & & \\
\hline
\end{tabular}

Fit-statistics two-dinensional commitment moded

$X^{2}=12.95, d f=8, p=11$,

RMSEA $=.052, \mathrm{GFI}=.98, \mathrm{AGFI}=.95, \mathrm{CFI}=1.0$

The analysis thus confimed the existence of two relationship commitment dimensions, which are each measured reliably and validly, and are well differentiated from each other (divergent validity). The purified item-scales will be used in the analysis of the research model in chapter 8 .

\section{Relationship intentions}

For the relationship intention measures, the same procedure is followed (see tables A.6, A.7). Three kinds of relationship intentions were measured: 1) stay-intentions, 2) investment intentions, and 3 ) intentions to search for alternatives.

Each intention type was operationalised by multiple items, which are analysed separately with the item-total comelation analysis (see table A.6). The items measuring the 'stay intentions' and 'search for altematives' have all item-total correlation above .60. However, none of the investment items had item-total correlation above .60. Apparently, the items do not capture one single underlying concept together. The bivariate correlations among the four investment items ranges from .15 to .40 , indicating that the items are indeed not strongly related to each other. To see if the items capture different concepts, a principal axis factoring factor analysis was conducted on only the four investment items. This analysis showed that the items have one underlying factor in common, but the items have very low factor loadings. So no other dimensions are captured by the items, they just seem poor indicators of one dimension. Therefore the entire scale of 'investment intentions' is removed from further analysis. 
Table A.6: Scale analysis of retalionship intention scales

\begin{tabular}{|c|c|c|}
\hline llems puer dimension & $\begin{array}{l}\text { 1tem-totall } \\
\text { correlatouns }\end{array}$ & 2. Factor loading per scale \\
\hline $\begin{array}{l}\text { Stay intentions } \\
\text { 1. Intend to give comparable assignments } \\
2 \text {. Intend to give new assignmenls to agenoy } \\
3 \text {. Intend to sitay for next two years }\end{array}$ & $\begin{array}{l}76 \\
79 \\
79\end{array}$ & $\begin{array}{l}.88 \\
76 \\
.90\end{array}$ \\
\hline $\begin{array}{l}\text { Irvestment intentions: } \\
\text { 1. Intend to involve agancy more } \\
\text { 2. Intend to make effort to kepp relation } \\
\text { 3. Wilting to accept falures to keep relation } \\
\text { 4. Intend to out-source more to agency }\end{array}$ & $\begin{array}{l}40 \\
50 \\
29 \\
35\end{array}$ & $\begin{array}{l}\text { removed } \\
\text { removed } \\
\text { removed } \\
\text { removed }\end{array}$ \\
\hline $\begin{array}{l}\text { Intentions to search for altematives } \\
\text { 1. Intend to took for altematives } \\
\text { 2. Intend to replace agency }\end{array}$ & $\begin{array}{l}63 \\
.63\end{array}$ & $\begin{array}{l}-.79 \\
-.88\end{array}$ \\
\hline
\end{tabular}

After this first step the items belonging to the stay intentions and the intentions to search for alternatives were thus retained. These items were then subjected to a principal axis factoring factor analysis with oblique rotation. This analysis did not confim the expected two factors within the items, but grouped all items into one factor. The items belonging to the stay intentions had high factor loading on this factor and the alternative search items had also high, but negative loading on this factor. Apparently, the alternative search items reflect the exact opposite of clients" intentions to stay. They thus measure the opposite sides of one underlying factor: customers" stay intentions. Because of the high factor loadings of all the items (see table A.6) all items could be retained as indicators of this underlying 'stay intentions' factor.

These items were then subjected to a confirmatory factor analysis in LISREL 8, to see whether this one-dimensional structure in the intentions items is confirmed. The five items were specified as indicators of one latent construct in the measurement model. From table A.7 can be see that all five items are reliable and valid indicators of the latent construct "stay intentions" forming a scalle with a composite reliability of .95 , explaining $80 \%$ of variance. However, the fit statistics show a poor fit of this one-dimensional model to the data (Chi-square $=47.1$, df 5 ) on most of the absolute and relative fit-statistics. The RMSEA is. 19(far above the maximum level of .08), indicating that also an approximate fit is not likely. Analysis of the residuals indicates that the two ittems measuring the 'search for alternatives' share more covariation than is explained by their relation to the construct of 'stay intentions', and also two items of the 'intentions to stay' scale share a high error covariance. These error covariances are well interpretable: the alternative search items do share the search for alternative, although not enough to form a separate factor, and they share a method covariance because both items are stated reversal from the other items (Baumgartner \& Homburg 1996). The two related 'stay intention' items both reflect clients' intentions to give next assignments to their current agency: one asks for the intentions to give comparable assignments and one for new assignments. In the qualitative pre-test it seemed that these two kinds of future assignments indicate different degrees of the intentions to stay. Staying for comparable assignments is less strong than when clients' would also assign different assignments to the agency (see chapter 5 ). Apparently the kind of assignment does not matter that much, and they are strongly related.

It thus seems that the 'intentions to search for alternatives' is not a separate construct as was proposed, but a sub-dimension of the latent construct "stay intentions". Also the two items 
asking for the intentions regarding future assignments could fom together a sub-dimenslon of this construct. To analyse this idea the items of both sub-dimensions were averaged into one indicator each, reflecting the communality of the items belonging to the sub-dimension. The one remaining item of the initial stay intentions scale that measures clients" intentions to stay with the agency for the next two years, is kept as a separate indicator of the "stay intentions" construct, We thus created a one-dimensional scale of "stay intentions" consisting of three indicators, 1. Intentions for future assignments (=composite of 2 items), 2 . Intentions to stay next two years (= 1 item), and 3 . Intention to search for altematives (= composite of 2 items). This procedure resembles a hierarchical factor-structure" with three sub-dimensions for the "stay-intentions" construct. This revised structure was subjected to a confirmatory factor analysis using LISREL8. The analysis showed that the three indicators fomed a reliable and valid scale of the latent construct "stay intentions". The fit of this model is good, on absolute as well as relative fit measures, as can been seen in table A.7

The initial model of three separate relational intentions measures is thus respecified into one "stay intentions" construct that consists of 3 sub-dimensions, which are specified as indicators. This construct is measured reliably and validly by the three indicators.

Table A.7: Confimatory factor analysis initial and adjusted "stay intentions"

\begin{tabular}{|c|c|c|c|c|}
\hline & Lambda & Multiple $\mathrm{R}^{2}$ & Scale properties & \\
\hline $\begin{array}{l}\text { Stay intentions } \\
\text { 1. Intend to give comparable assignments } \\
\text { 2. Intend to give new assignments to agency } \\
\text { 3. Intend to stay for next two years } \\
\text { 4. intend to look for altematives } \\
\text { 5. Intend to replace agency }\end{array}$ & $\begin{array}{r}.93 \\
.80 \\
.90 \\
-.86 \\
-.92\end{array}$ & $\begin{array}{l}.86 \\
.65 \\
.82 \\
.74 \\
.84\end{array}$ & $\begin{array}{l}\text { Composite reliability: } \\
\text { explained wariance: }\end{array}$ & $\begin{array}{r}.95 \\
80 \%\end{array}$ \\
\hline
\end{tabular}

Fit-statistics one dimensional intentions model

$$
X^{2}=47,1, d f=5,(p=00),
$$

RMSEA $=.19, \mathrm{GF}=.92, \mathrm{AGFI}=.75, \mathrm{CF}=.99$

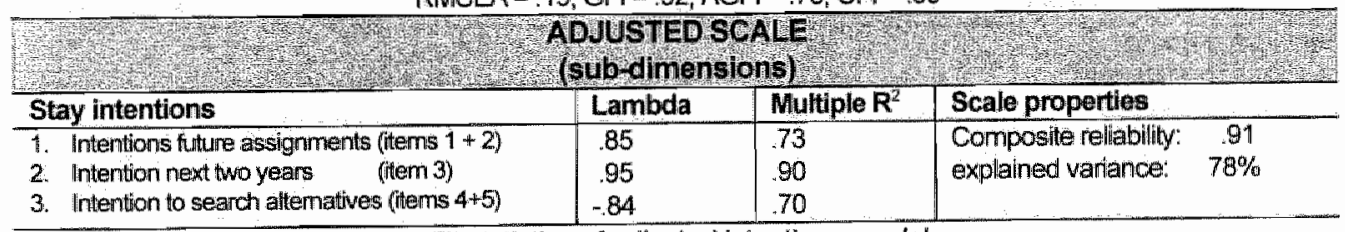

Fit statistics of adjusted intentions model,

together with the two dimensions of commitiment?

$$
X^{2}=27,5, d f=24(p=.28),
$$

RMSEA $=.026, \mathrm{GFI}=97, \mathrm{AGFI}=95, \mathrm{CFI}=1.0$

\footnotetext{
HHerarchical confinmatory factor analysis can only be conducted if at least 4 first order factors are defined, olherwise the model is not identified (Bollen 1989\%. Therefore, the ttems of each sub-dimension are averaged and specified as indicators ( $\mathrm{A}$ (n)derson \& Gerbing 1988, Baumgarther \& Homburg $1996 \%$.

2 A construct with 3 indicators is saturated and fit can not be calculated. Therefore, the fit is estimated together with the confimed commitment dimensionsi. A good model fit is a good fit of all the constructs.
} 


\section{Relational bonds}

For the relational bonds four different bond types were measured: 1) social bonds, 2) planning bonds, 3) knowledge bonds, 4) economic bonds, and 4) the 'stuck' bonds.

Each of these bond types were first subjected to an item-total comelation analysis. As can be seen in table A.8, several tems had to be removed in order to reduce the item-set to items with item-total correlation exceeding 60 . Of the six social bond items four items were removed based on this analysis. The remaining two tems reflect the frequency and intensity of the interactions with the agency, which are the only two items that share an underlying construct. The items referting to the relationship itself and the chemistry between the contact persons did not share enough variance with these items, nor among themselves to warrant a separate dimension. The remaining items thus only represent a specific part of the social bonds that can be created during a relationship. The planning bonds were measured by two items. These items are, however, not inter-related enough to support the assumption that they measure one underlying construct. Therefore this entire bond type is removed from further analysis. The knowledge bond items showed item-total correlations close to .60 and were kept as indicators of the knowledge bonds. The economic bonds items were all kept for the next steps in the analysis. The 'stuck' bond items also have item-total correlations close to 60 , and were kept as indicators of the 'stuck bonds'.

Table A.8: Analysis of bonds scales

\begin{tabular}{|c|c|c|}
\hline Items per dimansion & 1a. ltem-total correlation & 1b. Itom-total after deletion \\
\hline $\begin{array}{l}\text { Social bonds } \\
\text { 1. No. persons in direct contact" } \\
\text { 2. no. Level in direct contact" } \\
\text { 3. degree fiendiship" } \\
\text { 4. frequency of interactions } \\
\text { 5. intensity of interactions } \\
\text { 6. interpersonal chemistry }\end{array}$ & $\begin{array}{l}.24 \\
.45 \\
.13 \\
.31 \\
.35 \\
.27\end{array}$ & $\begin{array}{l}\text { removed } \\
\text { removed } \\
\text { removed } \\
71 \\
.71 \\
\text { nerroved }\end{array}$ \\
\hline $\begin{array}{l}\text { Planning bonds } \\
\text { 1. Adjustment of agency } \\
\text { 2. Inktitulionalised procedures }\end{array}$ & $\begin{array}{r}33 \\
.33 \\
\end{array}$ & $\begin{array}{l}\text { removed } \\
\text { nemoved }\end{array}$ \\
\hline $\begin{array}{l}\text { Knowledge bonds } \\
\text { 1. exchanged knowtecige } \\
\text { 2. confidentlal information } \\
\text { 3. nntemal client knowledge }\end{array}$ & $\begin{array}{r}54 \\
.52 \\
.61 \\
\end{array}$ & $\begin{array}{l}54 \\
52 \\
61\end{array}$ \\
\hline $\begin{array}{l}\text { Economic bonds } \\
\text { 1. Inwested time/efiontmoney } \\
\text { 2. Expected seardi costs } \\
\text { 3. Expected stant } 4 \text { ip costs }\end{array}$ & $\begin{array}{l}.42 \\
.57 \\
.64 \\
\end{array}$ & $\begin{array}{l}.42 \\
60 \\
.60 \\
\end{array}$ \\
\hline $\begin{array}{l}\text { Stuck bonds } \\
\text { 1. lied by contracts } \\
\text { 2. tied by nules/agnements }\end{array}$ & $\begin{array}{r}.54 \\
.54\end{array}$ & $\begin{array}{r}.54 \\
.54\end{array}$ \\
\hline
\end{tabular}

Temoved after analysis

The remaining items were subjected to an exploratory factor analysis(PAF), which revealed a 4factorial solution in the items. Some items showed high loading on more than one factor. Therefore, the structure will be analysed by a confimatory factor analysis which provides more information as to how the scalles could be adjusted, to reflect the bonds better. 
A measurement model is specified with the four bond types as latent constructs measured by the indicators that remained from the item-total conelations (see table A.8). This model was subjected to a confimatory factor analysis using LISREL 8. The four dimensions show a moderate fit, see table A.9: Chi square is significant $(70$, df $30, \mathrm{P}<00)$ and the AGFl just below the recommended level of .90 . However, the RMSEA is just acceptable $(.077)$, indicating that there might be an approximate fit, and also GFI is above its recommended level (.94). The reliability of the bond scales are acceptable, and the items have acceptable lambda's (above.60). The analysis thus confirms the existence of these four different bonds, and indicates that the items are moderate to good indicators of these bonds. Analysis of the residuals, indicates that the fit of this model could be improved by some adjustments in the item structure.

The analysis of the residuals indicates that the economic bond item "degree of investment in current relationship" is stronger related to the knowledge bonds than to the economic bond items. This is theoretically interpretable, the knowledge exchange with the agency can be regarded as an investment into the current relationship. Furthermore, the other two economical bond items both reflect switching costs, which are apparently evaluated differently different from the investments in the current relationship. Based on this, the 'investment' item is added to the knowledge bond items, forming a new scale that will be called "inwestment bonds" (rather than knowledge bonds only). The remaining economic bond items are renamed into "switch bond" indicators, reflecting the content of the items more accurately.

This new structure was then again analysed with a confimatory factor analysis, with the four new bonds as latent constructs and the respecified items as indicators. The outcomes of this analysis revealed problems with one particular item within the new "investment bond" scale. This item, measuring the "exchanged knowledge and expertise" was therefore removed, which resulted in a significant decrease of the chi-square measure (chi-square decrease $=36$ units, df $=8$ ). This new structure, with the item removed, shows a significantly better fit than the initially proposed structure (see table A.9). Chi-square is insignificant at the $1 \%$ level , and is within two times the degrees of freedom. The RMSEA is at an acceptable level (.057) and the AGFI is above the recommended .9 level (.92). The reliabilities of the scales have slightly improved. All scales are reliable and are explained for more than $50 \%$ by the latent construct.

Table A. 9: Confimatory factor analysis initial and acjusted bond scales

\begin{tabular}{|c|c|c|c|c|c|}
\hline Bonds & Ltems & Lambda & Multople $R^{2}$ & Scale propertios & \\
\hline Sociall bonds & $\begin{array}{l}\text { ii. Frequency of interactions } \\
\text { 2. Intensity of interactions }\end{array}$ & $\begin{array}{l}.85 \\
.85\end{array}$ & $\begin{array}{l}.71 \\
.72\end{array}$ & $\begin{array}{l}\text { Composite rellability } \\
\text { Explained variance }\end{array}$ & $\begin{array}{l}83 \\
74 \%\end{array}$ \\
\hline $\begin{array}{l}\text { Knowledige } \\
\text { bonds }\end{array}$ & $\begin{array}{l}\text { 3. Exchanged krowedge } \\
\text { 4. Confidential information } \\
\text { 5. Internal client knowledge }\end{array}$ & $\begin{array}{l}66 \\
71 \\
77\end{array}$ & $\begin{array}{l}.44 \\
.5 \\
6\end{array}$ & $\begin{array}{l}\text { Composite reliability } \\
\text { Explained variances: }\end{array}$ & $51 \%$ \\
\hline $\begin{array}{l}\text { Economic } \\
\text { bonds }\end{array}$ & $\begin{array}{l}\text { 6. Invested timelefforthoney } \\
\text { 7. Search costs allemalive agency } \\
\text { 8. Start-up costs new relationship }\end{array}$ & $\begin{array}{l}74 \\
.68 \\
78\end{array}$ & $\begin{array}{l}.54 \\
.48 \\
.61\end{array}$ & $\begin{array}{l}\text { Composite roliability } \\
\text { Explained variance: }\end{array}$ & $\begin{array}{l}78 \\
53,6 \%\end{array}$ \\
\hline Stuck bonds & $\begin{array}{l}\text { 9. Tied by contracts } \\
\text { 10. Tied by nules/agneements. }\end{array}$ & $\begin{array}{l}83 \\
60\end{array}$ & $\begin{array}{r}.68 \\
.35 \\
\end{array}$ & $\begin{array}{l}\text { Composite reflability } \\
\text { Explaned variance: }\end{array}$ & $\begin{array}{r}.60 \\
52 \% \\
\end{array}$ \\
\hline
\end{tabular}




\begin{tabular}{|c|c|c|c|c|c|}
\hline (1) & 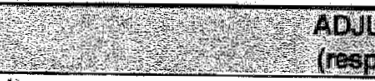 & 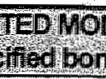 & Why & & 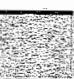 \\
\hline Bonds & Hems & Lambda & Multiple $\mathbb{R}^{2}$ & Scale propperties & \\
\hline Social bonds & $\begin{array}{l}\text { 1. Frequency of interactions } \\
\text { 2. Intensity of interactions }\end{array}$ & 88 & 77 & $\begin{array}{l}\text { Composite reliablity } \\
\text { Explained vaniance: }\end{array}$ & $\begin{array}{r}85 \\
74 \%\end{array}$ \\
\hline $\begin{array}{l}\text { linvostrinemt } \\
\text { bonds }\end{array}$ & 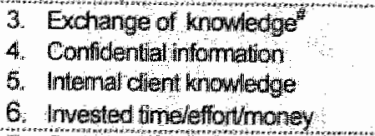 & $\begin{array}{l}\text { removed } \\
74 \\
67 \\
75\end{array}$ & $\begin{array}{l}\text { remowed } \\
55 \\
44 \\
57\end{array}$ & $\begin{array}{l}\text { Composite reliability } \\
\text { Explained wariance: }\end{array}$ & $\begin{array}{l}.78 \\
52 \%\end{array}$ \\
\hline Switch bonds & $\begin{array}{l}\text { 7. Searith costh allemative agency } \\
\text { 8. Start-up costs new relationshp }\end{array}$ & .88 & 46 & $\begin{array}{l}\text { Camposite reliability } \\
\text { Explained variance: }\end{array}$ & $61 \%$ \\
\hline Stuck bonds & $\begin{array}{l}\text { 9. Tied by combacts } \\
\text { 10. Tied by inlesilagreements }\end{array}$ & 62 & $\begin{array}{l}67 \\
.37\end{array}$ & $\begin{array}{l}\text { Composite reliability } \\
\text { Explained wariance: }\end{array}$ & $52 \%$ \\
\hline \multicolumn{6}{|c|}{ Fit-statistics adjusted four dimensional bonds model } \\
\hline
\end{tabular}

The proposed five bond types are thus respecified into four bonds types, which are theoretically interpretable and measured reliably and validly. These four bonds types will be used in the analysis of the research model in chapter 8.

\section{Trust}

Trust was proposed to be a uni-dimensional concept, and operationalised by six items based on previous research. The same procedure is used to purify the trust scale. The analysis of the item-total comelations resulted in the removal of two items from the scale. The remaining items had item-total correlations above or close to 60 (see table A.10).

Table A. 10: ltem analysis of trust scale

\begin{tabular}{|c|c|c|c|}
\hline Trust Items & 1.a. Item-total cort. & $\begin{array}{l}\text { 1b. Item-total } \\
\text { after deletion }\end{array}$ & 2. Factor lloading \\
\hline T. Agency pertomm well without control & .62 & .62 & .70 \\
\hline 2. Truist agency in ŝmportant decisions & .39 & removed & remowed \\
\hline 3. Trust in agenoy's motives & 48 & removed & removed \\
\hline 4. Trust that clients interest at heart & .51 & .46 & $.58^{k}$ \\
\hline 5. Trust that no oontrol is necessseny & .57 & 60 & .70 \\
\hline 6. General trust agency & .55 & .59 & .71 \\
\hline
\end{tabular}

= removed hom analysis

The exploratory factor analysis (PAF) confirmed the one-dimensionality of these items. One item had a low factor loading and was subsequently removed from the scale (table A.10).

The remaining three items were specified as indicators of the latent trust construct and subjected to a confirmatory factor analysis. The model shows a very good fit to the data, with Chisquare non significant $(p=72)$ and all other relative and absolute fit measures well above their recommended levels. From table A.11 can be seen that the general trust measure is not as reliable as the other two items. The scale as a whole, however, is reliable and the explained variance is above the recommended $50 \%$. The general trust item is therefore kept to enhance the theoretical relevance of the trust construct. 
Table A.11: Confimatoyy factor analysis trust items

\begin{tabular}{|c|c|c|c|c|}
\hline Trust items & Lambida & Multiple $\mathrm{R}^{2}$ & Scale properties & \\
\hline 1. Agency performs well without control & 83 & 69 & Composite reliability: & .76 \\
\hline 2. Trust that no control necessary & .75 & .57 & Explained varianoe: & $53 \%$ \\
\hline 3. General trust in agency & .58 & .34 & & \\
\hline \multicolumn{5}{|c|}{$\begin{array}{l}\text { Fit-statistics ons-dimensional trust model } \\
\text { together with the overall quality dimension? }\end{array}$} \\
\hline \multicolumn{5}{|c|}{$\begin{aligned} & X^{2}=5.3, \text { of }=8,(p=72), \\
\text { RMSEA } & 0, G F I=.99, A G F I=.98, C F I=1.0\end{aligned}$} \\
\hline
\end{tabular}

$\sqrt{\text { see footnote } 2}$ 


\section{References}

Aaker, D.A \& Day, G.S. (1990), Marketing Research, 4th ed, Wiley, New York.

Alford; B. L. \& Sherell, D. L. (1996), The Role of Affect in Consumer Satisfaction Judgements of Credence-Based Services", Joumal of Business Research, Vol 28, no.1, pp. 71-85.

Allen, N.J. \& Meyer, J.P. (1990), The Measurement and Antecedents of Affective, Continuance and Normative Commitment to the Organization", Joumal of Occupational Psychology, Vol.63, p.1-18.

Andaleeb, S.S. (1996), "An Experimental Investigation of Satisfaction and Commitment in Marketing Channels: The Role of Trust \& Dependence", Joumal of Retailing. Vol.72, no. 1 , pp. 77-93.

Anderson, EW. (1992), "Customer Satisfaction and Business Performance", Paper presented at Supporting Service Quality, Marketing Science institute conference, Boston, MA.

Anderson, J.C. (1995). "Relationships in Business markets: Exchange Episodes, Value Creation, and their Empirical Assessment", Joumal of the Academy of Marketing Science, Vol.23, no.4, pp. 346350.

Anderson, E. W. \& Fomell, C. (1992),"Customer Satisfaction and Business Performance", paper presented at Frontiers in Services conference, Vanderbilt university 1992.

Anderson, E. W. \& Fomell, C. (1994), "A Customer Satisfaction Research Prospectus", in: Serwice Quatity: New Directions in Theory and Practice, Rust, R.T. and Oliver, R.L. (eds.), Sage, Beverty Hills, pp. 241-268.

Anderson, E. W., Fornell, C. \& Lehmann, D. R. (1994), "Customer satisfaction, Market Share, and profitability: Findings From Sweden", Joumal of Marketing, Vol.58, no.3, pp. 53-66.

Anderson, J.C. \& Gerbing, D.W. (1988), "Structural Equation Modelling in Practice: A Review and Recommended Two-step Approach", Psychological Bulletin, Vol.103, no.3, pp. 411-423.

Anderson, J.C. \& Gerbing, D.W. (1992), "Assumptions and Comparative Strengths of the Two-Step Approach", Sociological Methods \& Research, Vol.20, no.3, pp. 321-333.

Anderson, J. C. \& Narus, J. A. (1990), "A Model of Distributor Firm and Manufacturer Firm Working Partnerships", Joumal of Marketing, Voll.54, no. 1, pp. 42-58.

Anderson, E.W. \& Sullivan, M.W. (1993), "The Antecedents and Consequences of Customer Satisfaction for Firms", Marketing Science, Vol.12, no.2, pp. 125-143.

Anderson, E. W. \& Weitz, B. (1989), "Determinants of Continuity in Conventional Industrial Channel Dyads" "Marketing Science, Vol.8, no.4, pp. 310-323.

Anderson, E. W. \& Weitz, B. (1992), "The Use of Pledges to Build and Sustain Commitment in Distribution Channels", Joumal of Marketing Reseanch, Vol.29, no.1, pp. 18-34.

Assael, H. (1987), Consumer Behavior and Marketing Action, Kent Publishing Company, Boston.

Babakus, E. \& Boller, G.W. (1992). "An Empirical Assessment of the SERVQUAL Scale", Joumal of Business Research, Vol.24, pp. 253-268.

Babakus, E. \& Mangold, W.G. (1992),"Adapting the SERVQUAL Scale to Hospital Services: An Empirical Investigation", Heath Services Research, Vol.26, no.6, pp. 767-786.

Bagozzi, R.P. \& Yi, Y. (1988), "On The Evaluation of Structural Equation Models", Joumal of the Academy of Marketing Science, Vol.16, no. 1, pp. 74-94.

Barbara \& Byme (1989), A Primer of LISREL: Basic Applications \& Programmes for Confirmatory Factor Analytic Models.

Baumgartner, H. \& Honburg, C. (1996), "Applications of Structural Equation Modelling in Marketing and Consumer Research: A Review", intemational Joumal of Research in Markoting, Vol. 13 " no.2, pp. 121-139.

Becker, H. S. (1960), "Notes on the Concept of Commitment", American Joumal of Sociology, Vol.66, pp. $32-42$.

Beland, F.\& MaheLx, B. (1989),"Construct Validity and Second-onder Factorial Model, the second order Factor Model", Quality and Quantity, Vol.23, pp. 143-159. 
Berry, L.L. (1983), "Relationship Marketing". in: Emenging Perspectives on Services Marketing, Berry. Shostack \& Upah (eds.), Chicago, AMA proceedings series, Illinois.

Berry, L.L. (1995), "Relationship Marketing of Services; Growing Interest, Emerging Perspectives", Journal of the Academy of Marketing Science, Vol.23, no. 4 , pp. 236-245.

Berry, L.L. \& Parasuraman, A. (1991), Marketing Services: Competing through quality, Free Press, New York.

Bitner, M.J. (1990), "Evaluating Service Encounters: The Effects of Physical Surroundings and Employee Responses", Joumal of Marketing, Vol.54, no.2, pp. 69-82.

Blau, P. M. (1964), Exchange and Power in Social Life; Wiley, New York.

Bloemer "J.M.M. (1993), Loyaliteit en Tevredenheid; een studie naar de relatie tussen merktrouw en consumententevredenheid, Dissertation Research, University of Maastricht, Universitaire Pers, Maastricht, The Netherlands.

Bloemer, J.M.M., de Ruyter, K. \& Venetis (1994), "Kwaliteit en Tevredenheid in de Dienstvertening: Kop, Munt of een Dubbeltje op zijn Kant?", In: Recente ontwikkelingen in het marktonderzoek NMM Jaarboek'94-95, pp. 205-219.

Bochove, J. van (1994), "Bureaus scoren slecht op de belangrijkste succesfactoren", Nieuwstribune, week 21, pp. 32-36.

Bojanic, D.C. (1991), "Quality Measurement in Professional Service Firms", Joumal of Professional Senvices Marketing, Vol.17, no.2, pp. 27-36.

Bolton, R.N. \& Drew" J.H. (1991)" "A Multistage Model of Customers' Assessments of Service Quality and Value", Joumal of Consumer Reseanch, Vol.17, pp. 375-384.

Bolton, R.N. \& Drew, J.H. (1994), "Linking Customer Satisfaction to Service Operations andi Outcomes", in: Service Quality: New Directions in Theory and Practice, Rust, R.T. and Oliver, R.L. (eds.), Sage, Beverty Hills, pp, 173-200.

Bollen . K. A. (1989), Structural Equations with Latent Vaniables, Wiley, New York.

Boulding, W., Kalra, A., Staelin, R. \& Zeithaml, A. (1993), "A Dynamic Process Model of Service Quality: From Expectations to Behavioral Intentions", Jourmal of Marketing Research, Vol.30, no. 1, pp.7-27. Bovee, C.L. \& Arens, W.F. (1992), Contemporary Advertising, Irwin, Homewood, Illinois:

Browne, M.W. \& Cudeck, R., (1993), "Alternative ways of assessing model fit", in: Testing Structural Equation Madels, K.A. Bollen \& J.S.Long(eds.) "Sage, Newbury Park "CA pp.136-162.

Buchanan, B. (1974),"Building Organisational Cormmitment: The Socialisation of Managers in Work Organisations", Administrative Science Quarterly, Vol 19, pp. 533-546.

Buchanan, R.W.J. (1990), Customer Retention: The key Link Between Customer Satisfaction and Profitability, Unpublished Paper, Bain and Company.

Buchanam, B. \& Michell, P.C. (1991),"Using Structural Factors to Assess the Risk of Failure in AgencyClient Relationships", Joumal of Advertising Research, Vol. 30, no. 5, pp. 68-75.

Buzzell, R. D. \& Gale, B.T. (1987), The PIMS Principles, Free Press, New York.

Capon, N., Farley, J.U. \& Hoenig, S. (1990), "Determinants of Financial Performance: A Meta-Analysis", Management Science, Vol.36, no.4, pp. 1143-1159.

Carman, J.M. (1990), "Consumer Perceptions of Service Quaity: An Assessment of the SERVQUAL Dimensions", Joumal of Retailing "Vol.66, no. 1, pp. 33-55.

Churchill, G.A.. Jr. (1979), "A Paradigm for Developing Better Measures of Marketing Constructs", Journal of Marketing Research, Voll 16, no.1, pp. 64-73.

Churchill, G.A.. Jr. (1995), Marketing Research. Methodological Foundations, Dryden Press, Hinsdale.

Clemens, B. (1994), "Etatvergabe, Mehr Bauch als Kopf", M\&V Background, Vol.35, na.9, pp. 83-84.

Cook, K.S. \& Emerson. R.M. (1978), "Power, Equity and Commitment in Exchange Networks", American Sociological Review, Vol.43, no.4, pp. 721-739.

Corsten, H. (1990), Betriebswitschaftlehre der Dienstleistungsuntemehmungen: Einführung, 2 nd ed." MünchenWien, Germany.

Cronin J.J., \& Taylor, S.A. (1992), "Measuring service quality. A re-examination and extension", Joumal of Marketing, Vol.56, no. 3 , pp. $55-68$. 
Cronin J.d. \& Taylor, S.A. (1994), "SERVPERF Versus SERVQUAL: Reconciling Performance Based and Perceptions-Minus-Expectations Measurement of Service Quality", Soumal of Marketing. Vol.58, no.1, pp. 125-131

Crosby, P.B. (1979), Quality is Free, MoGraw-Hill, New York.

Crosby, P.B. (1984), Quality without Tears, New Amenican Library, New York.

Crosby, LA. (1991), "Building and Maintaining Quality in the Service Rellationship", in: Service Quality: Muttidisciplinary and Multinational Perspectives, Brown, Gummesson, Edvardsson \& Gustavsson (eds.), Lexington Books, Mass.

Crosby, LA. Evans, KR. \& Cowles, D. (1990), Relationship Quality in Services Selling: An Interpersonal Influerice Perspective", Joumal of Marketing, Vol.54, no.2, pp. 68-81.

Crosby, LA \& Stephens, N. (1987), "Effects of Relationship Marketing on Satisfaction, Retention, and Prices in the Life Insurance Industry", Joumal of Marketing Research, Vol.27, no.6, pp. 404-411.

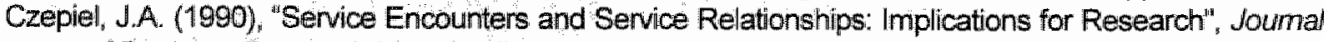
of Business Research, Vol.20, pp. 1321.

Czepiel, JA. \& Gilmore, R. (1987),"Exploning the Concept of Loyalty in Services", in:The Services Chatlenge: Integrating for Competitive Advantage, American Marketing Association, Chicago, pp.91-94.

Dassen, R.d.M. (1995), Audit Quality: An Empinical Study of the Attributes and Deteminants of Audit Quality Perceptions, Dissertation research, University of Maastricht, Drukkerij Groenvelt B.V., Landgraaf, The Netherlands.

Day, G.S. (1969), "A two-dimensional concept of brand loyalty", Joumal of Advertising Research, Vol.9, pp. $29-35$.

Day, G.S. (1970), Buyer Attitudes and Brand Choice Behavior, Free Press, New York.

Day, E. \& Barksdale, H.C. (1992), "How Firms Select Professional Services.", Industial Marketing Management, Vol.21, pp. 85-91.

Day, E., Denton, L.L. \& Hickner, J.A. (1988), "Clients' Selection and Retention Criteria: Some Marketing Implications for the Small CPA Firms", Joumal of Professional Services Marketing, Vol.3, no.4, pp. 283-295.

Donabedian, A. (1980), The Definition of Quality and Approaches to its Assessment and Monitoring. Vol.l, UMI Dissertation Services, Ann Arbor.

Doyle, P., Corstjens, M. \& Michell, P.C.N. (1980), "Signals of Vulnerability in Agency-Client Relations", Joumal of Marketing, Vol.44, no.4, pp. 18-23.

Dwyer, F.R., Schurr, P.H. \& Oh,S. (1987), "Developing Buyer-Seller Relationships", Joumal of Marketing, Vol.51, no.2, pp. 11-27.

Edvardsson, B., Thomasson, B. \& Ovretveit, J. (1994), Quality of Services, Making it Really Work. McGraw-Hill, New York.

Elfring. T. (1993), "Structure and Growth of Business Services in Europe", in Buckley, P.J. and Casson, M. (eds), The Structure of European Industry, Kluwer Academic publishers.

Engel, J.F. \& Blackwell, R.D. (1982), Consumer Behavior, 4th edition, The Dryden Press, Chicago.

Finn, D.W. \& Lamb, Ch.W. (1991), "An Evaluation of the SERVQUAL Scales in a Retail Setting", Advances in Consumer Research, Voll 18.

Fisk, R.P. Brown, S.W. \& Bitner, M.J. (1995),"Services Management Literature Overview: A Rationale for Interdisciplinary Study", in: Understanding Services Management "Glynn \& Bames (eds.), Wiley, Chichester, pp. 1-33.

Ford, D. (1980), "The development of buyer-seller relationships in industrial markets." European Jouma! of Marketing, Vol.14, no.5, pp. 339-354.

Ford, D. (1990), Interaction, Relationships, Networks, Sage Publications, Inc., London.

Ford, D. \& Rosson, P.J. ("1982), "The Relationships Between Export Manufacturers and Their Overseas Distributors", Export Management: An Intemational Context, Czinkota, M.R. \& Tesar, G. (eds.). Praeger, New York, pp. 257-275.

Fornell, C. (1991) "National and Comporate Customer Satisfaction Indices", Paper presented at the Word Quality Day, World Trade Centre, Amsterdam, The Netherlands.

Fornell, C. (1992), "A National customer barometer: the Swedish experience.", Joumal of Marketing, Vol.56, no. 1, pp. 6-22. 
Fomell, C. \& Yi, Y. (1992), "Assumptions of the Two-Step Approach to Latent Variable Modeling"; Sociological Methods \& Reseanch, Vol. 20, no.3, pp. 291-320.

Frambach, R.T. (1993), De adoptie en diffusie van innovaties in de industriele markt, Dissertation report Katholieke Universiteit Brabant, Tilburg, the Netherlands.

Freeman, K.D. \& Dart, J. (1993), "Measuring the Perceived Quality of Professional Business Services" Joumal of Professional Senvices Marketing. Vol:9, no. 1, pp. $27-48$

Ganesan, Sh. (1994), "Determinants of Long-Term Orientation in Buyer-Seller Relationships", Joumal of Marketing, Vol.58, no.2, pp. 1-19.

Gardner, C.A. (1986), Dissertation Proposal, George Washington University, Washington D.C.

Garvin, D.A. (1984),"What Does Product Quality Really Mean?", Sloan Management Review, Vol.25. no. 3 , pp. $25-43$.

Garvin, D.A. (1987), "Competing on the Eight Dimensions of Quality", Harvard Business Review, Vol.65, no.6. pp. 101-109.

Garvin, D.A. (1988), Managing Quality, The Strategic and Competitive Edge, Free Press, New York.

Gerbing, D.W. \& Anderson, J.C. (1988), "An Updated Paradigm for Scale Development Incorporating Unidimensionality and Its Assessment", Joumal of Marketing Research, Vol.25, no.3, pp. 186-192.

Geyskens, I. \& Steenkamp, J-B.E.M. (1994), An Investigation into the Joint Effects of Trust and Dependence on Relationship Commitment: A Cross national Study "Onderzoeksrapport Nr.9432, Katholieke Universiteit Leuven, Belgium.

Geyskens, I. \& Steenkamp J-B.E.M. (1995), "An Investigation into the Joint Effects of Trust and Interdependence on Relationship Commitment", Proceedings of the 24th EMAC Conference, Bergadaa (eds) "Paris 1995, pp. 351-371.

Geyskens, I. \& Steenkamp, J-B.E.M. (1997), "De rol van vertrouwen bij het opbouwen lange termijn relaties in de diensten sectar", Maandblad voor Accountancy en Bednjfseconomie, Vol.71, no.4, pp. 164-171.

Geyskens, 1., Steenkamp, J-B.E.M, Scheer, L.K. \& Kumar, N. (1996),"The Effects of Trust and Interdependency on Relationship Commitment", Intemational Joumal of Research in Markeling, Vol.13, no.4, pp. 303-319.Grönroos, C. (1982),"Strategic Management and Marketing in the Service Sector", Research report no.8, Publication of Swedish School of Economics and Business Administration, Helsingfors, Finland.

Grönroos, C. (1984), "A Service Quality Model and Its Marketing Implications", European Joumal of Marketing, Vol. 18, no.4, pp. 36-44.

Grönroos, C. (1987),"Developing the Service Offering:A Source of Competitive Advantage", in: Add Value to Your Service, C. Surprenant (ed.), American Marketing Association, Chicago, pp. 81-85.

Grönroos, C. (1988), "Service Quality: Six Criteria of Good Perceived Service Quality", Review of Business, Vol.9, no.3, pp. 10-13.

Grönroos, C. (1990), "Relationship Approach to Marketing in Service Contexts: The Marketing and Organizational Behavior interface:", Joumal of Business Research, Vol.20, pp. 3-11.

Grönroos, C. (1993), "Toward a Third Phase in Service Quality Research: Challenges and future directions", in: Advances in Services Marketing and Management: Research and Practice, Vol.2,

Swart, Bowen \& Brown (eds), JAl Press, Greenwich, pp. 49-64.

Gummesson, E. (1978), "Towards a Theory of Professional Services Marketing" "Industnal Marketing Management, Vol.7, no.2, pp. 89-95.

Gummesson, E. (1979), Models of professional serwice Marketing "Working Paper, no: 11, The Marketing Techniques Center, Sweden.

Gummesson, E. (1983), On marketing and Management of Professional Services.

Gummesson, E. (1991), "Service Quality: A Holistic View", in: Service Quality: Multidisciplinary and Multinational Perspectives, Brown, Gummesson, Edvardsson \& Gustavsson (eds.), Lexington Books, Mass. pp. 3-23.

Gummesson, E. \& Grönoos, C. (1987), "Quality of Services-Lessons from the Product Sector", in: Add Value to Your Service, C. Surprenant (ed.) "American Marketing Association, Chicago.

Hair, J.F., Anderson, R.E., Tatham, R.L. \& Black, W.C. (1995), Multivariate Data Analysis, with readings, fourth edition, Prentice Hall Intemational, UK 
Hakkansson, H. (eds.) (1982), Intemational marketing and purchasing of industrial goods: An interaction approach, Wiley, Chichester.

Halinen. A. (1994), Exchange Relationships in Professional Services; A Study of Relationship Development in the Advertising Sector, Published Dissertation Project, SarjalSenies A-6. Turku School of Economics and Business Administration, Finland.

Halinen, A (1996), "Service Quality in Professional Business Services:Arelationship Approach", in: $A d-$ vances in Services Marketing and Management Research and Practice, Vol.5, Swartz, Bowen \& Brown (eds), JAl Press, Greenwich,pp. 315-341

Häller, S: (1995), Beurteilung won Dienstleistungsqualität; Dynamische Betrachtung des Qualiatsurteils in Weiterbllingsbereich, Dissertation research, Gabler Detischer Universitätsverlag, Wiesbaden, Germany.

Han, S.L. (1992), Antecedents of Buyer-Seller Long-Term Relationships: An Exploratory Model of Structural Bonding and Social Bonding, working paper, Institute for the Study of Business Markets, The Pennsylvania State University, University Park, PA.

Han, S.L. Wison, D.T. \& Dant, S.P. (1993), "Buyer-Supplier Relationships Today", Industrial Marketing Management, Vol.22, pp. 331-338.

Heekin, JR. (1983), "Why Advertising Agencies Lose Accounts" "Unpublished manuscript. On reference from Wackman et al. 1987.

Helde, J:B. \& John, G. (1988), "The Role of Dependence Balancing in Safeguarding Transaction-Specific Assets in Conventional Channels", Joumal of Marketing, Vol.52, no.1, pp. $20-35$.

Heide, J.B. \& John, G. (1992), "Do Norms Matter in Marketing Relationships?", Joumal of Marketing,

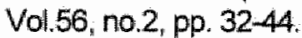

Herche, J. \& Engelland; B. (1996),"Reversed-Polanty ltems and Scale Unidimensionality", Joumal of the Academy of Marketing Science, Vol.24, no.4, pp. 366-375.

Hogerzeil-Hulsebos, $\mathbb{N}$. (1994) "Bureau Client Satisfaction Onderzoek, SKIM/Indis, The Netherlands.

lacobucci, D., Grayson K.A. \& Ostrom, A.L. (1994), "The Calculus of Service Quality and Customer Satisfaction", in: Advances in Services Marketing and Management: Research and Practice, Vol.3, Swartz, Bowen \& Brown (eds), JAl Press, Greenwich, pp. 1-68.

Jackson. B.B. (1985), Winning and keeping industrial customers: The dynamics of customer relationships, Lexington Books, Mass.

Jacoby, J. \& Chesnut, R.W. (1978), Brand Loyalty Measurement and Management, Wiley, New York.

Jöreskog, K.G. \& Sörbom, D. (1993), LISREL 8. Structural Equation Modelling with the Simplis Commana Language, Lawrence Erbaum Associates, Hillsdale, NJ.

Juran, J.M. (1982), Upper Management and Quality, Juran Institute, New York.

Juran, J.M. Gryna, F.M. \& Bingham R.S. (eds) (1974), Quality Control Handbook, 3rd ed., MoGraw-Hill, New York.

Kasper, J.D.P. (1988), "On Problem Perception, Satisfaction and Brand Loyalty", Joumal of Economic Psychology, Vol.9, no.5, pp. 387-397.

Kasper, U.D.P., de Vries jr., W. \& van Helsdingen, P.J.C. (1997), Services Marketing Management, an Intemational Perspective, forthcoming.

Kaynak, E. Kucukemiroglu, O. \& Odabasi, Y. (1994), "Advertising Agency/Client Relationships in an Advanced Developing Country", European Joumal of Marketing. Vol:28, no.1, pp. 35-55.

Kerlinger, F.N. (1986), Foundations of Behavioural Research", $3^{\text {rid }}$ edition, Holt, Rinehart \& Winston, New York.

Kumar, N., Scheer, L.K. \& Steenkamp, J-B.E.M. (1995), "The Effects of Perceived Interdependence on Dealer Attitudes", Joumal of Marketing Research, Voll.32, no.4, pp. 348-356.

Kumar, N., Hibbard, J.D. \& Stem, L.W. (1994), The Nature and Consequences of Marketing Channel intermediary Commitment, Working Paper, Nr.94-115, Marketing Science institute.

LaBahn, D.W. \& Kohli, C. (1995), "The Commitment-Trust Theory of Relationship Marketing: An Extension and Application to Advertising Agency - Client Relationships", Paper presented at the AMA Educator's conference, summer 1995. 
LaPierre, J. (1996), "Service Quality:The Construct, lts Dimensionality and Its Measurement": in: Advances in Services Marketing and Management: Research and Practice, Vol.5, Swartz, Bowen \& Brown (eds), JAl Press, Greenwich, pp. 45-71.

LaPierre, J. \& Filiatrault, P. (1995), "The Foundations of Research on the Quality of Professional Services: to Organizations", in: Managing Senvice Quality, Vollll, Lemmink \& Kunst (eds) "Paul Chapman publishing, London, pp. 97-108.

LaPierre, J., Filiatrault, P. \& Koelemeijer, K. (1994), "Industrial Professional Services Quality Evaluation Criteria: A Comparative Analysis Between Consulting Engineers of North America (Quebec) and Europe (France).", in: Proceedings of the 23rd EMAC Conference, Bloemer, Lemmink \& Kasper (eds.), Maastricht, The Netherlands.

Lehtinen, U. \& Lehtinen, J.R. (1991). "Two Approaches to Service Quality Dimensions"; Service Industries doumal, Vol.3.

Lehtinen, U, Ojasalo, J. \& Ojasalo, K. (1996), "On Service Quality Dimensions and Customers' Perceptions", in: Managing Service Quality, Vol.ll, Lemmink \& Kunst (eds). Paul Chapman publishing, London, pp. 109-115.

Levinthal, D.A. \& Fichman, M. (1988), "Dynamics of Interorganizational Attachments: Auditor-Client Relationships", Administrative Science Quarterly, Vol.33, no.3, pp. 345-369.

Liljander, V. \& Strandvik, T. (1994) "The Relation between Service Quality, Satisfaction and Intentions". in: Managing Senvice Quality, Voll.I, Lemmink \& Kunst (eds), Paul Chapman publishing, London, pp. $45-63$.

Liljander, V. \& Strandvik, T. (1995), "The Nature of Customer Relationships in Services", in: Advances in Services Marketing and Management: Research and Practice, Vol.4, Swartz, Bowen \& Brown (eds), JAll Press, Greenwich, pp. 141-167.

Lusch, R.F. \& Brown, J.R. (1996),"Interdependency, Contracting, and Relational Behavior in Marketing Channels" , Joumal of Marketing, Vol.60, no.4, pp. $19-39$.

McGee, G.W. \& Ford, R.C. (1987), "Two (or More) Dimensions of Organizational Commitment: Reexamination of the Affective and Continuance Commitment Scales", Joumal of Applied Psychology, Vol. 72 , no. 4, pp. 638-642.

Meyer, J.P. \& Allen, N.J. (1984), "Testing the 'Side-bet Theory" of Organizational Commitment:Some Methodological Considerations", Joumal of Applied Psychology, Vol.69, no.3, pp. 372-378.

Meyer, A. \& Mattmüller, R. (1987),"Qualität von Dienstleistungen. Entwurf eines praxisorientierten Qualitätsmodells", Marketing Zeitschrift für Forschung und Praxis, Vol.9, no.3, pp. 187-195.

Michell, P.C.N. (1987), "Auditing of Agency-Client Relations", Joumal of Advertising Research" Vol.26, no.6. ${ }_{n}$ pp. $29-41$

Michell, P.C.N. (1988), Advertising Agency-Client Relations: A Strategic Perspective, Croom Helm, London.

Michell, P.C.N. (1988a), "The Influence of Organizational Compatibility an Account Switching", Joumal of Advertising Research, Vol.27, no.3, pp. 33-38.

Michell, P.C.N. (1988b) "Point of View: Advertising Account Loyalty - A Segmentation Approach", Journal of Advertising Research, Vol.27, no.6, pp. 61-67.

Michell, P.C.N., Cataquet, H. \& Hague, S. (1992), "Establishing the Causes of Disaffection in AgencyClient Relationships", Joumal of Advertising Research, Vol 30, no. 2, pp. 41-48.

Mietillä, A. \& Möller, K.E. (1990), "Interaction Perspective into Professional Business Services: A Conceptual Analysis", in: proceedings of sixth IMP conference, R. Fiocca \& I. Snehota (eds.), University of Bocconi, Milan.

Möller, K.E. (1986), "Buying Behavior of Industrial Components: Inductive Approach for Descriptive Model Building", in: Research in Intemational Marketing. P.W. Tumbull \& S.J. Palliwoda (eds.), Croom Helm, London, pp. 79-133.

Möller, K.E. \& Wilson, D.T. (eds.) (1995), Business Marketing: An Interaction and Network Perspeactive, KJuwer Academic Publishers, Boston.

Moore, S.A. (1994), Perception of Service Quality: An Empincal Analysis in the Freight Sector, Dissertation research, European Business Management School, University of Wales, UK. 
Moorman, C.M., Deshpandé, R. \& Zaltman, G. (1993a), "Factors Affecting Trust in Market Research Relationships", Joumal of Marketing, Vol.57, no. 1, pp. 81-101.

Moorman, C.M., Deshpandé, R. \& Zaltman, G. (1993b), Relationships Between Providers and Users of Market Research: The Role of Personal Trust, Working Paper, No 93-111, Marketing Science Institute.

Morgan "N.A. (1991), "Corporate Legal Advice and Client Quality Perceptions"; Marketing Intelligence and Planning, Vol 8 , no.6, pp. 33-39.

Morgan; RM. \& Hunt, S.D. (1994), "The Commitment-Trust Theory of Relationship Marketing", Joumal of Marketing, Vol 58, no. 3 , pp. 20-38:

Mowday, R.T., Porter, LW. \& Steers, R.M. (1982), Employee-Organizational Linkages: the Psychology of Commitment; Absenteeism, and Tumover, Academic Press, New York.

Neijzen, J.A. \& Trompetter, M. (1989). Kwaliteitszorg in Dienstvertenende Organisaties, Kluwer Bednifswetenschappen, Deventer; The Netherlands.

Newsome, JE. (1980); "A Basis for Partnership: Choosing an Advertising Agency"", Advertising Age, Vol.66, pp. 26-28.

Niflesen, J.P.H. (1993), "Marketing wan diensten: Besluitvormingsprocessen bij het kiezen van diensten.", Tijdschriff woor Marketing, Maart 1993, pp. 14-22.

Paliwoda, S.J. \& Thomson, P. (1986), "Industrial Product Class and Market Behavior, A Study in the French Packaging Market", in: Research in Intemational Marketing. P.W. Tumbull \& S.J. Paliwoda (eds.), Croom Helm, London, pp. $299-326$.

Parasuraman, A. (1995), "Measuring and Monitoring Services Quality" , in: Understanding Services Management, Glynn \& Bames (eds.), Wiley, Chichester, pp. 143-177.

Parasuraman, A. Berry, L.L. \& Zeithaml, V.A. (1991),"Refinement and Reassessment of the SERVQUAL Scale", Joumal of Retailing, Vol.67, no.4, pp. $420-450$.

Parasuraman, A., Zeithaml, V.A., \& Bery, L.L. (1985), "A Conceptual model of service quality and its implications for future research", Joumal of Marketing, Vol.49, no.4, pp. 41-50.

Parasuraman, A, Zeithaml, V.A., \& Berry, L.L. (1990), "An Empinical Examination of Relationships in an Extended Service Quality Model", Working Paper 90-122, Marketing Science Institute.

Parasuraman, A., Zeithaml, V.A., \& Bery, L.L. (1993), "More on Measuring Service Quality: The Critical Role of Expectations", Joumal of retailing, Vol.69, no.1, pp. 140-147.

Parasuraman, A. Zeithaml, V.A., \& Berry, L.L. (1994), "Altemative Scales for Measuring Service Quality" A Comparative assessment Based on Psychometric and Diagnostic Crtteria", Joumal of Retaling, Vol.70, no. 3 , pp. 201-230.

Parasuraman, A., Zeithaml, V.A., \& Berry, L.L. (1994b), "Reassessment of Expectations as a Comparison Standard in Measuring Service Quality: Implications for Future Research", Joumal of Marketing, Vol.58, no.1, pp. 111-124.

Patterson, P.G. (1995), "A Conceptual Model of Customer Satisfaction for Business-to-Business, Professional Services" "in: Advances in Services Marketing and Management: Research and Practice, Vol.4, Swartz, Bowen \& Brown (eds); JAI Press, Greenwich, pp. 169-193.

Peters, T.d. (1988), Thrwing on Chaos, Alfred A. Knopf, New York.

Peterson, R.A. \& Wilson, W.R. (1992), "Measuning Customer satisfaction: Fact and Artefact", Joumal of the Academy of manketing Science, Vol.20, no.4, pp. 61-71

Poiesz, T.B.C. \& Bloemer, JMM. (1991)," Customer (Dis)Satisfaction with the Performance of Complex Products and Services", in: Proceedings of EMAC 1991 conference, Vol.2, pp. 446-462.

Porter, L.W., Steers, R.M., Mowday, R. T. \& Boulian, P.V. (1974), "Organisational Commitment, Job Satisfaction and Turnover Among Psychiatric Technicians", Joumal of Applied Psychology, Vol 59 , pp. $603-609$.

Raphael, G.M. (1981), "Job Hazard: Cold ear in the Agency Business", Advertising Age, June 1".

Reichers, A.E. (1985), "A Review and Reconceptualization of Organizational Commitment", Academy of Management Joumal, Vol. 10, pp. 465-476.

Reichheld, F.F. (1993); "Loyalty-Based Management", Harvard Business Review, Vol.71, no.2, pp. 64-73. 
Reichheld, F.F. \& Sasser W.E. Jr. (1990), "Zero defections: Quality comes to Services" "Hanvard Bus:ness Review, Vol.68, no.5, pp. 105-111.

Rose, S. (1990),"The Coming Revolution in Credit Cards", Joumal of Retall Banking, Vol.12, no.3, pp. $17-19$.

Rust, R.T. \& Oliver, R.L. (1994), "Service Quality: Insights and Managenal Implications From the Frontier", in: Service Qualify: New Directions in Theory and Practice, Rust, R.T. and Oliver, R.L. (eds.) "Sage, Beverly Hills; pp. 1-20.

Rust, R.T. \& Zahorik, A.J. (1993), "Customer Satisfaction, Customer retention, and Market Share", Journal of Retailing, Vol.69, no.2, pp. 193-215.

Rust, R.T., Zahorik, A.J., \& Keiningham, T.L. (1995), "Retum on Quality (ROQ): Making Service Quality Financially Accountable", Joumal of Marketing, Vol.59, no.2, pp. 58-70.

Saris, W.E. \& Stronkhorst, L.H. (1984), Causal Modelling in Nonexperimental Research: An lntroduction to the LISREL Approach, Sociometric Research Foundation, Amsterdam, the Netherlands.

Scheer, L.K. \& Stern, L.W. (1992), "The effects of Influence type and Performance Outcomes on Attitude toward the Influencer.", Joumal of marketing Research, Vol.29, no.2, pp. 182-241.

Schijns, J.M.C. (1993), "Relationship Marketing.", in: Proceedings of 22nd Emac conference, Barcelona.

Seabright, M.A., Levinthal, D.A. \& Fichman, M. (1992), "Role of individual attachments in the dissolution of interorganizational relationships.", Academy of Management Joumal, Vol.35, no.1, pp. 122-161.

Sharma, D.D. (1994), "Classifying Buyers to Gain Marketing Insight: A Relationships Approach to Professional Services", Intemational Business Review, Vol.3, no. 1, pp. 15-30.

Sheth, JN. \& Parvatiyar, A. (1995), "The Evolution of Relationship Marketing", Intemational Business Review, Vol.4, no 4 , pp. $397-418$.

Shostack, G.L. (1984), "Designing Services that Deliver", Harvard Business Review, Vol.62, no.1, pp. $133-139$.

Shostack, G.L. (1987), "Service Positioning Through Structural Change", Joumal of Markeling; Vol.51, no.1, pp. $34-43$.

Spekman, R.E. (1988), "Strategic Supplier Selection: Understanding Long-Term Buyer Relationships", Business Horizons, July/Aug, pp. 75-81.

Sriram, V. \& Mummalaneni, V. (1990),"Determinants of Source Loyalty in Buyer-Seller Relationships", Joumal of Purchasing and Materials Management, Vol.26, no.3, pp. 21-26.

Steenkamp, J-B.E.M. \& van Trijp, H.C.M. (1991), "The Use of Lisrel in Validating Marketing Constructs", Intemational Joumal of Research in Marketing, Vol.8, pp. 283-299.

Stiff, R. \& Gleason, S.E. (1981), "The Effects of Marketing Activities on the Quality of Professional Services", in: Marketing Services, Donelly, J.H. \& George, W.R. (eds.), American Marketing Association Proceedingls, Chicago, pp. 78-81.

Storbacka, K. \& Strandvik, T.(1994), "A Relationship Marketing Perspective on the Link Between Service Quality and Customer Profitability in Retail Banking", in: Proceedings of intemational Quality in Services Conference, QUIS, July 5-B 1994, Norwalk, Connecticut, pp. 1-24.

Strandvik, T. (1994), Tolerance Zones in Perceived Service Quality, Dissertation Research Nr.58, Helsingfors, Publication of Swedish School of Economics and Business Administration.

Strandvik, T. \& Liljander, V. (1994), "A Comparison of Episode Performance and Relationship Performance for a Discrete Service", in: Proceedings of the 3rd Service Marketing Workshop, Februari 1994, Berlin, Germany.

Swartz, T.A. and Brown, S.W. (1989), "Consumer and Provider Expectations and Experiences in Evaluating Professional Services Quality", Joumal of the Academy of Marketing Science, Vol.17, pp. 189-195.

Szmigin, I.T.D. (1993), "Managing Quality in Business-to-Business Services", European Joumal of Marketing, Vol.27, no.1, pp. 5-21.

Taylor, S.A. (1995), "Service Quality and Consumer Attitudes: Reconciling Theory and Measurement", in: Advances in Services Marketing and Management: Research and Practice, Vol.4, Swartz, Bowen \& Brown (eds), JAl Press, Greerwich, pp. 1-36. 
Teas, R.K (1988), "An Analysis of the Deteminants of Industrial Consumers' Perceptions of the Quality of Financial Services Marketing Relationships" "Joumal of Professional Services Marketing, Vol. 14 no. $3, \mathrm{pp} .71-88$.

Thibaut, JW. \& Kelley, H.H. (1959), The Social Psychology of Groups, Wiley, New York.

Tumbull, P. W. \& Wilson, D.T. (1989), "Developing and Protecting Profitable Customer Relationships.". Inclustrial Marketing Management, Vol.18, pp. 233-238.

Tzokas, N., Chryssochoidis, G. \& Blundell, B. (1994), "Provision of Services to Professional CustomersAssessing Service Quality in a European Setting", in: Proceedings of the 23rd EMAC Conference, Bloemer, Lemmink \& Kasper (eds.), Maastricht, The Netherlands, pp. 1061-1075.

Ulrich, D. (1989), "Tie the Corporate Knot: Gaining Complete Customer Commitment", Slaan Management Review, Vol 30, pp. 19-27.

Valla, J.P. (1986), "The French Approach to Europe', In: Strategies for Intemational Industial Marketing: The Management of Customer Relationships in European Industrial Markets, Tumbull \& Valla (eds.), Croom Helm, New York, Chapter 2.

Venetis, K.A. (1997), "Service Quality Dimensions of Professional Business Services: Structure and Dynamics within Long-Tem Relationships", in: Managing Service Quality, Vol.lll, Lemmink \& Kunst (eds), Paul Chapman publishing, London, pp 71-87.

Verbeke, W. (1988), "Developing an Advertising Agency-Client Relationship in the Netherlands", Joumal of Advertising Research, Vol.28, no.6, pp. 19-26.

Wackman, D.B., Salmon, C.T. \& Salmon, C.C. (1987), "Developing an Advertising Agency-Client Relationship", Joumal of Advertising Research, Vol.26, no.6.

Weilbacher, W.M. (1983), Choosing an Advertising Agency, Crain Communications, Chicago.

Williamson, O.E. (1985), "Credible Commitment: Using Hostages to Support Exchange", Amenican Economic Rewiew, Vol.73, no.4, pp. 519-540.

Wills, J.R., Jr. (1992), "Winning New Business: An Analysis of Advertising Agency Activities", Joumal of Advertising Research, Vol.31, no.5, pp. 10-16.

Wilson "D.T. (1990), Creating and Managing Buyer-Seller Relationships, Institute for the Study of Business markets, Research Report no.5, Pennsylvania.

Wilson, D.T. (1995), "An Integrated Model of Buyer-Seller Relationships", Joumal of the Academy of Marketing Science, Vol.23, no 4, pp. 335-345.

Wilson, T.L. \& Smith, F.E. (1996), "Business services 1982-1992; Growth, Industry characteristics, Financial performance", Industrial Marketing Management, Vol. 25, no.2, pp. 163-171.

Wilson, D.T. \& Mummalaneni, V. (1986) "Bonding and Commitment in Buyer-Seller Relationships: A preliminary Conceptualisation", Industral Marketing and Purchasing, Vol.1, no.3, pp. 44-58.

Wilson, D.T. \& Mummalaneni, V. (1988), Modelling and Measuring Buyer-Seller Relationships, Institute for the Study of Business markets, Research Report no.3, Pennsylvania.

Wilson, D.T. \& Mummalaneni, V. (1990), Buyer-Seller Relationships as a Eonding Process: A Preliminary Conceptualisation, Working Draft, The Pennsylvania State University.

Wilson "D.T., Soni, P.K. \& OKeeffe, M. (1995), Modelling Customer Retention as a Relationship Problem, Institute for the Study of Business markets, Research Report no. 13, Pennsylvania.

Woodside, A.G., Wilson, E.J. \& Milrer, P. (1992), "Buying and Marketing CPA Services.", Industral Marketing Management, Vol 21 , pp. 265-272.

Yin, R.K. (1989), Case Study Research: Design and Methods, Applied Social Research Methods Series, vol. 5, Sage Publications, London.

Yorke, D.A. (1990), "Developing an interactive approach to the marketing of professional services.", in: Interaction, Relationships, Networks, Ford, D. (ed), Sage Publications Inc., London, pp. 346-358.

Young, L. \& Denize, S. (1994), "Super-Glued Relationships", Paper presented at the 10th IMP Annual Conference, Groningen, The Netherlands.

Young. L. \& Wilkinson, I.F. (1989) "The Role of Trust and Co-Operation in Marketing Channels: A Preliminary Study", European Joumal of Marketing, Vol.7, pp. 22-34.

Zahorik, A.J. \& Rust, R.T. (1992), "Modeling the Impact of Service Quality on Profitability", in: Advances in Services Marketing and Management: Research and Practice, Vol.1, Swart, Bowen \& Brown (eds), JAl Press, Greenwich, pp. 247-276. 
Zeithaml, V.A. (1988), "Consumer Perceptions of Price, Quality, and Value: A Means-End Model and Synthesis of Evidence", Joumal of Marketing, Vol. 52, no. $3, \mathrm{pp} .2-22$.

Zeithaml, V.A. "Berry, L.L. \& Parasuraman, A. (1988), "Communication and control processes in the delivery of service quality", Journal of Marketing, Vol.52, no.2, pp 35-48.

Zeithaml, V.A., Berry, LL. \& Parasuraman, A. (1990), Delivening quality service: Balancing customer perceptions \& expectations, Free Press, New York.

Zeithaml, V.A., Berry, L.L. \& Parasuraman, A. (1996), "The Behavioral Consequences of Service Quality", Joumal of Marketing, Vol.60, no.2, pp. 31-46.

Zeithaml V.A. \& Bitner, M.J. (1996), Services Marketing, McGraw-Hill, New York. 


\section{Samenvatting}

\section{DIENSTKWALITEIT EN KLANTLOYALITEIT IN PROFESSIONELE ZAKELIJKE DIENSTRELATIES:}

Een empirische studie naar het klant-georiênteerde kwaliteitsbegrip in de reclamemarkt.

De kwaliteit van dienstverlening wordt beschouwd als de kritische succesfactor voor dienstverlenende ondernemingen. Dienstkwaliteit draagt bij tot de winstgevendheid van dienstverleners door haar positieve invloed op enerzijds het aantrekken van klanten en anderzijds op de loyaliteit van bestaande klanten. Aangezien diensten ontastbare processen of ervaringen zijn, is het moeilijk objectieve maatstaven voor haar kwaliteit vast te stellen. Daarom wordt de kwaliteit van diensten gedefineerd vanuit de klant: wat de klant als kwaliteit ervaart is de kwaliteit die geleverd is. Men spreekt dan ook wel van gepercipieerde kwaliteit. Vanuit dit klantgeoriënteerd perspectief worden kwaliteitsmaatstaven bepaald door de kwaliteitscriteria van klanten. Het belang van dit klantgeoriënteerde kwaliteitsconcept wordt onderschreven door zowel de praktijk als de wetenschap "alwaar het sinds de jaren ' 80 is uitgegroeid tot één van de meest onderzochte onderwerpen binnen de dienstenmarketing. Toch zijn er een aantal zaken onderbelicht gebleven.

Zo is er nog maar weinig onderzoek gedaan naar dit kwaliteitsconcept in de professionele zakelijke dienstverlening. In deze dienstsector is de kwaliteit traditioneel benaderd vanuit de richtlijnen van de beroepsgroep en de instanties die deze markten bewaakten. Door de huidige ingrijpende markt veranderingen, zoals de toenemende expertise van klanten, dereguleringsmaatregelen en de toenemende (internationale) concurrentie, pleiten auteurs nu voor de overstap naar het klant-georiënteerde kwaliteitsconcept en schrijven er dezelfde positieve consequenties aan toe als voor de meer conventionele (consumenten) diensten is gevonden. Er is echter weinig bekend over hoe klanten de kwaliteit van deze diensten evalueren. Professionele zakellike diensten onderscheiden zich door een aantal specifieke kenmerken die een invloed kunnen hebben op de kwaliteitsbeleving van klanten. In deze studie zal hier op in worden gegaan door een kwaliteitsmodel te ontwikkelen specifiek voor deze diensten.

Voorts zal in deze studie nader in worden gegaan op de invloed van dit kwaliteitsconcept op de loyaliteit van klanten. Verschillende studies hebben aangetoond dat dienstkwaliteit de heraankoopintenties van klanten bevordert. Koopintenties kunnen echter transactie-gericht zijn en geven weinig inzicht in de werkelijke loyaliteit van klanten. In deze studie zal klantloyaliteit dan ook vanuit een relatie perspectief benaderd worden, en wordt onderzocht in hoeverre dienstkwaliteit bijdraagt tot de bestendiging van lange termijn klantrelaties. Relaties zijn dynamische processen, waarin meerdere factoren van invloed zijn op haar ontwikkeling en behoud. In de business marketing literatuur 
wordt de laatste jaren veel aandacht besteed aan de dynamiek van inter-organisationele relaties. In dit proefschrift zal worden onderzocht welke factoren bepalend zijn voor het ontstaan en behoud van lange termijn klantrelaties in de zakelijke dienstverlening en welke rol dienstkwaliteit hierin speelt. Hiertoe zal de liferatuur uit twee marketingdisciplines worden geïntegreerd: de dienstkwaliteit literatuur vanuit de diensten marketing en de relatie literatuur vanuit de business marketing.

De volgende twee onderzoeksvragen staan centraal in deze studie:

1. Hoe evalueren klanten de kwaliteit van professionele zakelike diensten, en wat zijn de kerndeterminanten van dit kwaliteitsoordeel?

2. Draagt dienstkwaliteit bij tot de bestendiging van lange termijn klantrelaties? Wat is het belang van dienstkwaliteit naast andere factoren die lange termijn relaties bevorderen?

Deze vragen worden eerst theoretisch benaderd in hoofdstukken 2 en 3, op basis waarvan een onderzoeksmodel wordt opgesteld. Dit onderzoeksmodel wordt empirisch onderzocht in de Nederlandse reclame markt zoals beschreven in hoofdstukken 4-6. In hoofdstukken 7 en 8 worden de twee onderzoeksvragen apart geanalyseerd en beantwoord. Hoofdstuk 9 sluit dit proefschrift af met de conclusies en discussie, en volgt een bespreking van de management implicaties en richtingen voor vervolgonderzoek.

In hoofdstuk 2 wordt een literatuuroverzicht gegeven over het klant-georiënteerde kwaliteitsconcept vanuit de diensten marketing. Op basis van verschillende conventionele dienstkwaliteitsmodellen, de specifieke eigenschappen van professionele zakelijke diensten, en de aanpassingen die voor deze diensten zijn voorgesteld wordt een kwaliteitsmodel ontwikkeld voor professionele zakelijke diensten. Dit model wordt vervolgens vergeleken met de uitkomsten van de recente empirische studies naar de kwaliteitsbeoordeling van klanten over deze diensten. In dit model worden vijf kerndeterminanten voorgesteld die bepalend zijn voor het kwaliteitsoordeel van klanten. Net als in de conventionele kwaliteitsmodellen gaat dit model ervan wit dat het kwaliteitsoordeel niet alleen wordt gevormd door de uitkomst van het dienstverleningsproces, maar ook door het proces zelf, en door het aanwezige potentieel waarmee de dienst geproduceerd is. Specifiek voor professionele diensten wordt een extra onderscheid gemaakt in twee aparte kwaliteitsdeterminanten binnen de proces kwaliteil en binnen de uitkomst kwaliteit; 1) de harde proces kwaliteit en 2) de softe proces kwaliteit, en; 3) de directe uitkomst kwaliteit en 4) de uiteindelijke uitkomst kwaliteit. De harde proces kwaliteit is het oordeel over de (technische) wijze waarop de gevraagde dienst wordt geproduceerd, terwijl de softe proces kwaliteit wordt beoordeeld op basis van de interacties en communicaties met de dienstverlener gedurende dit productieproces. De directe uitkomst kwaliteit is het klantoordeel over de directe uitkomsten van het productieproces, terwijl de uiteindelijke uitkomst kwaliteit wordt beoordeeld op basis van de gevolgen die de directe uitkomst heeft voor de klant. Dit onderscheid in verschillende uitkomsten is specifiek voor professionele diensten waarvan de uiteindelijke resultaten van de dienst vaak pas merkbaar lang nadat de dienst geleverd is. Tezamen met de potentiële kwaliteit vormen dit de vijf kern kwaliteitsdeterminanten in het kwaliteitsmodel, welke worden ondersteund door de empirische studies. 
In hoofdstuk 3 wordt een literatuuroverzicht gegeven over inter-organisationele relaties vanuit de business marketing. Allereerst wordt een beschrijving gegeven van de ontwikkeling van zakelijke relaties en wat een lange termijn relatie kenmerkt. Auteurs zijn het er over eens dat het relatiecommitment van de partners bepalend is voor de ontwikkeling en bestendiging van lange termijn relaties. Relatiecommitment is een partner 's bewuste continuatie van een zakelijke relatie, en vormt de motivatie of attitude op basis waarvan een partner van plan is de relatie te continueren. Twee soorten motivaties worden onderscheiden voor lange termijn relaties: affectieve motivaties die de wil weergeven om de relatie te behouden vanwege positieve gevoelens, en calculatieve motivaties die de noodzaak weergeven om de relatie te behouden vanwege een calculerende kosten/baten afweging. Voorts wordt een overzicht gegeven van theoretische en empirische studies aangaande de factoren die het relatiecommitment van zakenpartners beïnvloeden. Drie antecedenten van relatiecommitment komen uit verschillende studies naar voren en die ook relevant zijn voor zakelijke dienstrelaties: 1) het vertrouwen in de partner, 2) de opgebouwde relationele banden, zowel sociale banden op interpersoonlijk niveau als structurele banden op inter-organisatieniveau (investeringen, aanpassingen e.d.), en 3) de tevredenheid van de partner waarvan de definitie sterk overeenkomt met het klant-georiënteerde dienstkwaliteit concept in de diensten marketing. Op basis hiervan veronderstellen we dan ook dat dienstkwaliteit zal bijdragen tot het relatiecommitment van de klant, hoewel haar relatieve contributie ten opzichte van de andere twee antecedenten nog onduidelijk is. Dit zal worden onderzocht in het empirisch onderzoek.

In hoofdstuk 4 worden de veronderstellingen uit hoofdstuk 2 en 3 geïntegreerd tot één onderzoeksmodel en wordt de onderzoeksopzet beschreven waarmee dit model empirisch wordt onderzocht in de reclame markt. Het empirisch onderzoek bestaat uit drie stappen. Allereerst wordt een kwalitatief onderzoek gehouden in de reclame markt om een eerste indicatie te krijgen van de houdbaarheid van het model binnen deze professionele dienstenmarkt. Vervolgens wordt een kwalitatief vooronderzoek uitgevoerd om de concepten van het model te operationaliseren en te vertalen naar het jargon van de reclamemarkt. Deze operationalisaties worden vervolgens gebruikt in de vragenlijst voor de derde stap, welke bestaat uit een grootschalig veldonderzoek onder klanten van reclamebureaus. Voorts wordt de eerste empirisch stap in dit hoofdstuk uitgewerkt: het kwalitatief onderzoek. Informatie werd verkregen door een deskresearch van studies in de reclame markt, diepte-interviews met experts op de markt (6 reclamebureaus, 2 branche organisaties en een bureau dat adverteerders adviseert in de selectie van reclamebureaus) en diepte-interviews met 6 klanten van reclamebureaus. De verkregen informatie ondersteund de toepasbaarheid van het ontwikkelde kwaliteitsmodel voor reclamediensten, en het belang van de voorgestelde relatieconcepten. De sociale en structurele relationele banden worden aangescherpt voor reclamebureauklant relaties en het onderzoeksmodel wordt daaraan aangepast.

In hoofdstuk 5 wordt de ontwikkeling van het meetinstrument voor de onderzoeksconcepten beschreven. Om tot betrouwbare meting van de concepten te komen worden zij elk door meerdere items (schalen) gemeten. De methode wordt uiteengezet die wordt gevolgd om tot betrouwbare en valide maten voor de concepten te komen. De eerste 
stappen van dit proces worden in de rest van het hoofdstuk uitgewerkt, wat uitmondt in de vragenlijst. De items zijn gegenereerd op basis van het kwalitatieve onderzoek en van bestaande meetschalen en zijn vervolgens aangescherpt en aangepast op basis van verschillende pre-tests. Deze vragenlijst zal in het veldonderzoek gebruikt worden.

In hoofdstuk 6 wordt de opzet en eerste resultaten van het veldonderzoek beschreven. Aangezien het gaat om de invloed van dienstiwaliteit op het behoud van bestaande relaties wordt de vragenlijst verstuurd naar adverteerders die minimaal 1 jaar een relatie hebben met hun reclamebureau, waar de respondent zelf bij betrokken is, en waarvan minimaal gebruik wordt gemaakt van de kerndiensten van reclamebureaus: strategie en creatief concept. Middels de medewerking van 33 reclamebureaus en de BVA (associatie van Nederlandse adverteerders) worden 1.112 vragenlijsten persoonlijk geadresseerd verstuurd naar adverteerders in Nederland. Hiervan komen uiteindelijk 241 ingevuld en bruikbaar terug van adverteerders die aan de onderzoekscriteria voldoen. Vervolgens worden de meetschalen gevalideerd en opgeschoond met behulp van de data, wat resulteert in valide en betrouwbare schalen voor elk onderzoeksconcept. Op basis van deze analyses worden de gemeten relationele banden iets aangepast. Deze blijken uit vier soorten banden te bestaan in bureau-klantrelaties: de sociale banden op basis van de interpersoonlijke interacties, de investeringsbanden op basis van de investeringen in kennis, tijd en geld, de overstapbanden op basis van de verwachte kosten en moeite van de overstap naar een ander bureau, en de vaste banden op basis van contracten of andere overeenkomsten waardoor de klant 'vastzit' aan het bureau. Het onderzoeksmodel wordt hieraan aangepast.

In hoofdstuk 7 wordt het eerste deel van het onderzoeksmodel geanalyseerd: het klant-georiënteerde kwaliteitsmodel. Op basis van verschillende analyses blijkt dat het voorgestelde kwaliteitsmodel grotendeels wordt bevestigd. Het kwaliteitsoordeel van adverteerders is gebaseerd op de volgende vijf kwaliteitsdeterminanten die iets afwijken van de voorgestelde vijf: 1) het potentieel van het bureau, 2) de functionele betrouwbaarheid gedurende het proces (nakomen van afspraken e.d.), 3) de competentie van het bureau, 4) de softe proces kwaliteit, en 5) de uitkomst kwaliteit, welke is gebaseerd op zowel de onmiddellijke als de uiteindelijke uitkomst kwaliteit. Hieruit blijkt dat klanten binnen het technische dienstverleningsproces (harde proces kwaliteit) een onderscheid maken tussen werkwijze in het proces en de competentie waarmee het gebeurd. Bovendien blijkt dat klanten weliswaar onderscheid maken tussen de onmiddellijke en uiteindelijke uitkomst van reclamediensten, maar dat de perceptie van beide uitkomsten sterk samenhangen en in het kwaliteitsoordeel worden samengevoegd tot één uitkomst kwaliteitdeterminant. Vervolgens wordt het relatieve belang van deze determinanten geanalyseerd waaruit blijkt dat de uitkomst kwaliteit de meest belangrijke determinant is, gevolgd door de softe proces kwaliteit en de competentie. De potentiële kwaliteit en de functionele betrouwbaarheid blijken naast deze drie determinanten niet meer significant bij te dragen aan het totale kwaliteitsoordeel van klanten. 
In hoofdstuk 8 wordt het gehele onderzoeksmodel geanalyseerd in drie stappen om de invloed van dienstkwaliteit op de klantloyaliteit te bepalen. Allereerst wordt de relatie tussen de relatiecommitment dimensies en de relatie intenties geanalyseerd. Hieruit bijikt dat vooral het affectief commitment van kllanten bijdraagt tot hun intenties om de relatie te behouden, de calculatieve motivaties spelen hierop nauwelijks een rol. In de tweede stap worden de antecedenten van dit relatiecommitment geanalyseerd. Hieruit blijkt dat de dienstkwaliteit, het vertrouwen en slechts enkele van de relationele banden bijdragen tot het relatiecommitment van klanten. Opmerkelijk is dat de sociale banden en investeringsbanden niet bijdragen tot het behoud van de relatie. Van deze antecedenten blijkt dienstkwaliteit het sterkst gerelateerd te zijn aan het relatiecommitment van klanten, gevolgd door het vertrouwen "de overstapbanden en vervolgens de vaste banden, die een negatief verband hebben met het relatilecommitment. Bovendien heeft de gepercipieerde dienstkwaliteit ook een directe invloed op de relatie intenties van klanten, naast haar invloed via relatiecommitment. In de derde stap worden ook de kwaliteitsdeterminanten aan het model toegevoegd en wordt het gehele onderzoeksmodel in één keer geschat. De uitkomsten bevestigen de bovengenoemde deelresultaten en voegen daar nog een interessante bevinding aan toe. De directe relatie tussen dienstkwalteit en relatie intenties blijkt volledig verklaard te worden door de uitkomst kwaliteit.

In hoofdstuk 9 worden de conclusies getrokken en bediscussieerd. De belangrijkste conclusie is dat het klant-georiënteerde kwaliteitsconcept een belangrijke bijdrage levert aan de bestendiging van lange termijn klantrelaties in de professionele zakelijke dienstverlening. Dienstkwaliteit heeft de sterkste invloed op het relatiecommitment van klanten. De klantrelaties in deze dienstensector lijken fragiel van aard, waarin nauwelijks sociale en/of structurele banden worden opgebouwd die de relatie op lange termijn in stand houden. De fragiliteit versterkt het belang van de dienstkwaliteit wat uit deze studie als enige bindende factor naar voren kwam naast het opgebouwde vertrouwen. Het klant-georiënteerd kwaliteitsconcept is dus ook zeer belangrijk voor professionele zakelijke dienstverleners. Deze studie laat zien dat dit kwaliteitsconcept ook voor professionele zakelijke diensten uit meerdere determinanten bestaat en waarvan de basisstructuur universeel lijkt te zijn. Ook voor professionele zakelijke diensten baseren klanten hun kwaliteitsoordeel op structurele kenmerken van de dienstverlener, het dienstverleningsproces, en op de uitkomsten van dit proces. Specilfiek voor deze diensten lijkt vooral de beoordeling van de proces kwaliteit af te wijken van de conventionele kwaliteitsmodellen. De competentie waarmee het dienstverleningsproces wordt uitgevoerd wordt apart beoordeeld van de werkwijze in het proces en de softe proces kwaliteit. Aangezien de expertise van de professionals tot de kern van professionele diensten behoort, lijkt het dat deze bevinding te generaliseren is naar andere professionele (zakelijke) diensten. Naast deze competentie, zijn de softe proces kwaliteit en de uitkomst kwaliteit de belangrijkste kwaliteitsdeterminanten.

Naast deze hoofdconclusies worden andere bevindingen besproken en de management implicaties gegeven. Na een bespreking van de beperkingen in het onderzoek wordt het hoofdstuk afgesloten met aanbevelingen voor vervolgonderzoek. 


\section{Curriculum Vitae}

Karin Venetis was born in 1968 in Marlow (U.K.). She studied Social \& Organisational Psychology at the University of Groningen, and received her Masters degree in 1992. During her studies she worked for two years as teaching assistant at the University of Groningen, Faculty of Psychology. In 1990 she started working for the Maastricht University, faculty of Economics and Business Administration as lecturer in Marketing. In 1992 she became Assistant Professor of Marketing at the same faculty. She participates in several post-doctoral and management training programmes as marketing lecturer and is involved in research projects concerning services marketing and relationship marketing.

Karin Venetis, geboren in 1968 in Marlow (U.K.), studeerde na haar eindexamen Gymnasium$\beta$, sociale en organisatie psychologie aan de faculteit der Psychologische, Pedagogische en Saciale Wetenschappen aan de Rijksuniversiteilt in Groningen. Tijdens haar studie werkte zij twee jaar als onderwijsassistent Psychologie. Vanaf 1990 werkte zij als toegevoegd docent marketing aan de Universiteit Maastricht, faculteit der Economische Wetenschappen en Internationale Bedriffskunde. In 1992 werd zij universitair docent marketing aan dezelfde faculteit. $\mathrm{Ze}$ is betrokken bij verschillende post-doctorale en management opleidingen als marketingdocent en verricht onderzoek op het gebied van diensten-en relatiemarketing. 